Distribution Category:

LMFBR Physic: (UC-79d)

NLL-76-21

ARCONE :IATIONAL IABORATORY

9700 South Cass Avenue

Argonne, lllinols 60439

SHI3D: A SINGLE-CHAMEL, iPATIAL FLUX SMTHESIS CODE POR DLFFUSION THEORY CALCULATIOAS

by

C. H. Adars:

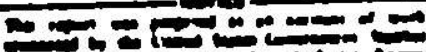

ctor $2-2=0$

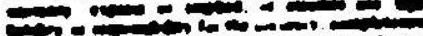

Can-

rom

Applied Phyelce Division

July 1976 

TABIE CP CONTENTS

Pore

Asstract. . . . . . . . . . ............. 1

I. ImTRODUCTION. . . . . . . . . . . . . . . . 1

II. SMTtESIS THEORY ND EGUATLOHS. . . . . . . . . . . . 2

A. Diffusion Theory Difference Equections........... 2

B. The SIngle-Channel Syntheels Approximation. . . . . . . S

C. Derivation of the syathesis Equations . . . . . . . 7

Walcheed Realduals. . . . . . . . . . . . 7

A Vartaclonal Derivation. . . . . . . . . . . . 11

D. The Solution of the Synchesis Elesavalue Equations. . . . 13

Fiesion Source Iteration with Wielandt Acceleration. . If

Solution by Forverd Elialnation, Beclererd substitution. is

Scallns and Dlfferenclns. . . . . . . . . . . . Is

E. Ocher Calculatlons. . . . . . . . . . . . . 17

Mulcleheanel Synthesle. ................ 17

Perturbaclon theory ................. 18

III. usen constocutions . . . . . . . . . . . . . . 18

A. Ccoc strandards and the anc syeten . . . . . . . . . . 18

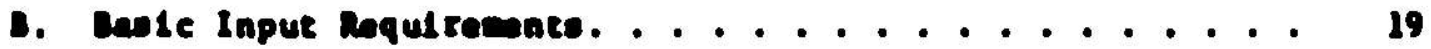

Expenesion Functions . . . . . . . . . . . . 19

Croes Sections. . . . . . . . . . . . . . . 19

Gountry. . . . . . . . . . . . . . . . . 21

Code Depandont Input - sMmPLL . . . . . . . . . . . 22

C. Runntens the AaC Syeten sm30 - ARcrole. . . . . . . . . 22

Input and Outgut Date Sete. . . . . . . . . . . . 22

Job Coactol and sycolle Parmetere . . . . . . . . 22

Saple Input. . . . . . . . . . . . . . . . 22

D. Mulelple Problew and raserers. . . . . . . . . . . 26

Mulclpie Probles ................. 26

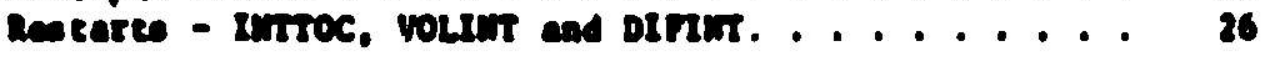

C. Edice and Output cpelora. . . . . . . . . . . . . 27

secadard outpus .................. 27

Opeleasl output .................. 27

costalns coolltelent ploce . . . . . . . . . . 28

T. Etror nascoges. . . . . . . . . . . . . . . . 28

G. Storage hequlremate and hualag rlen. . . . . . . . 28 
TABLE OF CONTENTS

Pase

H. Applications of Synthes 1. . . . . . . . . . . . 29

Choosing Expanaton Functions. . . . . . . . . . . . 29

Blanket Function - STP016, גJCO10 and ARCSPO16 . . . . . 31

IV. CODE STRUCTURE AND PROGRATITNG CONSIDERATIONS . . . . . . . 31

A. The ARC Syocen SYN3D. . . . . . . . . . . . . 31

STP018. . .................. 33

F1le Defintelons. ............. 33

B. Overlay sturcture . . . . . . . . . . . . . 33

Maln Driver ................... 33

TRANSL. .................... 33

C'LRD ...................... 38

HusC . . . . . . . . . . . . . . . . 38

INTEG . . . . . . . . . . . . . . . . 39

SOLVE ...................... 40

EDITS ..................... 40

C. BPoImTER, A Dynanic Storage Allocation Subprogran Packege . 40

IBM Adlocation. ................444 44

CDC Allocation. ................. 44

v. THE ARCONAE CODE CENTER VERSIONS OF SYN3D . . . . . . . . 44

A. The sw30 Package .................. 44

SYN3D ....................... 46 46

APOIMTER. ................... 46

CDFIL. . . . . . . . . . . . . . . . 46

B. Cods structure. . . . . . . . . . . . . . . . 46

C. F1le Nuber Aasignanate . . . . . . . . . . . . . 47

D. Runniag the Coda Canter 8Ti30 a a stand-Alone Prosran. . . 47

CDTIL. . . . . . . . . . . . . . . . 4 47

SEeK Table Inttiallsation ............. 50

The SYN3D BCD Control Dete. . . . . . . . . . . . 50

Exarples of Input Decke usth Control Card.. . . . . . . 52

Bporimta................... 52

E. Saple Problem . . . . . . . . . . . . . . 52

Modal Descrlpetons. ................ 52

F1le of the Cods cunter Tape. . . . . . . . . . 52

serple Problen 1. . . . . . . . . . . . . . 60

sarple Problen 2. . . . . . . . . . . . . . . 60

Saple Problea 3. . . . . . . . . . . . . . . 62

saple Problen 4. . . . . . . . . . . . . . 62 
TABLE OF CONTENTS

Pare

F. Suggested Modifications to the Code . . . . . . . . 65

TIMER . . . . . . . . . . . . . . . 65

SEEK In1tializazion.............. 65

Eliminat1ng BCD input Data. . . . . . . . . . . 65

Matrix Inversion and Multiplication Subroutines . . . 66

Restrictions on Problem Size in SOLVE........ 66

APPENDICES. . . . . . . . . . . . . . . . . . . 67

A. Code Abstract . . . . . . . . . . . . . 67

B. STP018 - The ARC System Standard Path for SYN3D . . . . . 69

C. ARCSP018 - The ARC System Catalogued Procedure for SYN3D. . 72

D. Input Data Set SYNFIL . . . . . . . . . . . . . 80

E. Code-Dapendent Binary filea . . . . . . . . . . 101

COHPXS. . . . . . . . . . . . . . . 101

DCCOEF. . . . . . . . ......... 105

DIFINT. . . . . . . . . . . . . . . . 109

INTTOC. . . . . ................ 111

REQRLX. . . ................... 119

REQXST. . . .................. 121

SYNCON. .................... 123

VOLINT. .................... 125

F. SYN3D Errur Hasageg. . . . . . . . . . . . . . . 127

G. Fortran Vardable Gloseary . . . . . . . . . . . . 132

H. Sample Problea Output . . . . . . . . . . . . . . . 141

Probles 1 - Cosplete Oisput, with Crose Section Edits - 141

Problen 2 - Complete Output ............. 157

Problear 3 - Partial Output. . . . . . . . . . . . 163

Problen 4 - Partial Output. . . . . . . . . . . . 173

I. CCCC Vereion III Standard . . . . . . . . . . . . 182

GzODST. . . . . . . . . . . . . . . . 183

Isorxs. . . . . . . . . . . . . . . . 188

NdxsR. . . . . . . . . . . . . . . 194

zNATDN. . . . . . . . . . . . . ... 196

RTflux. . . . . . . . . . . . . . . . 198

Atruux. . . . . . . . . . . . . . . . 200

PWDLIT. . . . ................. 202

RzRux. . . . . . . . . . . . . . . . 203

J. ARCsP016 - The ARC Syatee Catalosund Procedure for Ganerating a flad source for an Inhosogeneoun calculetion of a law-reactivity-plane eyathesis expansion function..... 


\section{TABLE OF CONTENTS}

Pare

K. STP016 - The ARC Syetem Standard Path for Generating a fixed source for an Inhosogeneou calculation of a lowreactivity-plane synthesis expansion function ....... 208

ACKionledgents . . . . . . . . . . . . . . . . . 210

refergnces ............................ 211 


\section{LIST OF FIGURES}

No.

Title

Pase

III-1. ARC System SYN3D Input Deck. The Three-Dimensional Mode! Is Bullt up $f$ rom Two-Dimensionul A.NIP Data Setg. . . . . .

11I-2. Input for a Blanket Expansion Function Calculation Using ARCSPO16 and ARCSPO3 (DIF2D) . . . . . . . . . . . .

IV-1. SYN3D Program Structure Show Ing Subroutine Calling Sequences. TRANSL is used only in the ARC SYN3D, HMG4C is used only in the code center version. Routines called by several subroutines in a branch are 118 ted under the branch nam. For example, SEEK 18 used throughout the code, QUIT 1s called by several subroutines in HMG4C, etc ............. 34

iV-2. Example of BPOINTER Use . . . . . . . . . . . . 42

V-1. Input Deck with control cards for the IBM 370/195. Execute CDFILE to generate Interface f1les, LInk edit SYN3D and execute sapple problem 4. The source code for CDFILE is in the f1le 6CDFILE and the CDFILE Input is In the f1le dDATA. Interface files not needed in thie job are copled to the

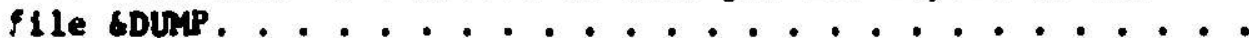

V-2. Input deck with control cerds for the CDC 7600. Execute CDFILE to generate Interface f1les, load SYN3D and execute sample problem 4. The relocatable object code for CDFILE 1s in the t1le "CDFILE" and the CDFILE Input is in the tile "DATA". The I1le "PROG" contains the relocatable object code for SYW 3D. Interface t1les not needed in this job are copled to the flle "TAPEg". . . . . . . . . . . . . 36

v-3. The geonetry of the 3D teet sodel ............. S7

V-4. SYN3D BCD Input and Input interface f1les for the firet sarple problen. Each Input file is Identifled by a sequence nuber fron Table $V-7$ and 1s aselgned a logicel unit nuber conseletent witis Table V-3. The BCD data conelets of the SEEK Initlalization card, " "DARDS-PER-CARD-TYPE" card and a set of type-nubbered carde. . . . . . . . . . . . .

V-5. SYN3D BCD Input and Iaput Interface 1110 for the second -ere le problen. Each Input t1le 1s Identilled by a eequence number from Table V-7 and is aseigaed a loglcal unit nuber consistent with Toble V-3. The BCD date conelets of the SEEX InItialieution card, "CARDS-PER-CARD-TYPE" card and a set of typa-numbered carda. . . . . . . . . . . . . 


\section{LIST OF FIGURES}

No.

V-6. SYN3D BCD Input and input interface files for the third sample problem. Each input file is 1 dentified by a scquence number from Table $V-7$ and is assigned a logical unit number consistent with Table V-3. The BCD data consists of the SEFK Initiallzation card, "CARDS-PER-CARD-TYPE" card and a set of type-numbered cards. . . . . . . . . . . . . . .

V-7. SYN3D E.CD input and infut interface flles for the fourth sample problew. Each Input file is Identifled by a sequence number: from Table $V-7$ and 1 assigned a logical unit number conslotent with Table V-3. The BCD data consists of the SEEK Inttiallzation card, "CARDS-PER-CARD-TYPE" cerd and a set of type-nubered cards. . . . . . . . . . . . . . 


\section{LIST OP TABLES}

No. Title

III-1. ARC Syater and CCCC Input F1lec for SYN3D. These are not - 11 requ11 $\therefore$ ine are generated by SYN3D or 1 te ARC Syeter Standard Pt: a.t other any never be nweded at all . . . . 20

III-2. ARC SYN3D I I, '... ...d Output Date Set Names and Job Control Subst1tution Symbollc Paraneters. . . . . . . . . . 23

III-3. ARC Systen SYW 3D Running TInes and Storage Requiresente for Two Fast Critical Assedbly Models on the IBH 370/195. The GCFR Model was Run at Two Different Contalner S1zes . . . . . 30

IV-1. SYN3D Subrout Ines and Coman Blocks . . . . . . . . . 35

IV-2. BPOINTER Subprogran Descriptions. . . . . . . . . . 42

V-1. Dascrifition of SYN3D Tapes and the BCD Files they Contaln.. 45

v-2. SYN3D segents. . . . . . . . . . . . . . . 45

V-3. Files Requited by the Code Center Verelon of SYN 3D (GEODST through ZNATDN are CCCC f1les. The rest my be treated as scrttch flles.) ..................... 48

V-4. CDFILE Input Data..................... 51

V-5. Examples of CDFILE Hodes of Operation. These Exanples Aasum File 5 la Card Input, File 6 is Printer Output and P1le 7 is Punch Output....................... 51

V-6. Compositions Ueed in Tast Problen. . . . . . . . . . 58

V-7. Description of the CDPILE BCD Data Blocks In F11. 4 of the Code Center Tape. . . . . . . . . . . . . . . . . . 
8MN3D: A SIMGLE-CHANE, SPATIAL FWX SHTTHESIS CODE FOR

DIFPUSION THEORY CALCULATIONS

by

C. H. Adare

\begin{abstract}
Th. report is a wer's manul lor 5YW30, a computer code whlch wes ingle-chanael, epatial flux eynthesis to calculate approxdente olut lone to two and three-dimaslonal, IInltedifference, Eultigroup neutron diffulon theory equetlons. SYN3D is dostened to ren la conjunction vith any one of ecveral oneand two-dicanalonel, linite-diflerence codea (required to genarate the eynthes ls uxpansion funcelons) curruntly belns used in the tast resctor comunlty. The report descrlbes the theory and equeclons. the we of the code, and the Iepleanatation on the Ian $370 / 195$ and CDC 7600 of the verston of 5 ris 30 avallable through the Argonne code canter.
\end{abstract}

\title{
1. Intropuction
}

Thls report is a wer's eavul for stm3, a computer code whlch wes

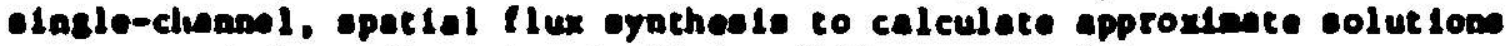

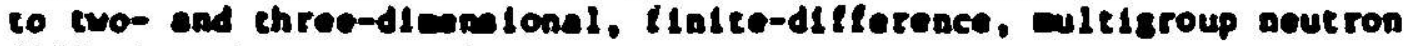
diflusion theory equetions.

srw 30 is designed to run in conjunction vith any one of eeveral oneand two-dimenional flatto-diflerence codes (requl red to panerete the eyacheats expanston (uncticas) curreatly belas uned in the last resctor cenanty. Mose of the date for a calculation ant be supplited in the formete of the stenderd Iatertece Filee daflaed by the contetee on Computer code Coordination (cocc). Appeadln A of thle report is the coputer code ebetract for smis.

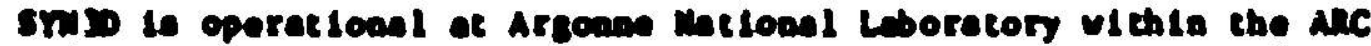

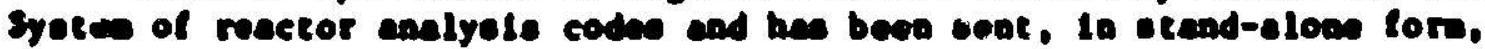
to the Arresan Code Cencer lor distribut lea to other laboretortes. cectlon II. III and IV of chis report cover enterlal of Interese to were of both the NC syoten and code Conter vervion of the codet

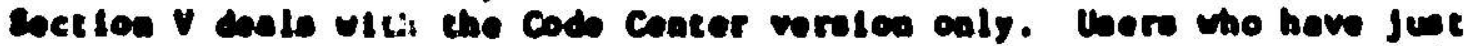

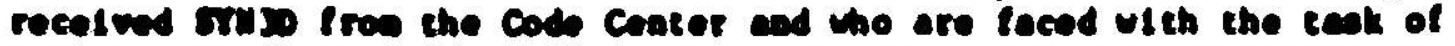

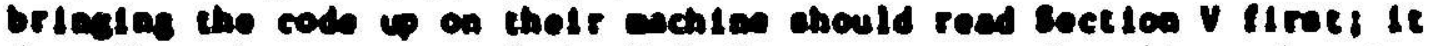

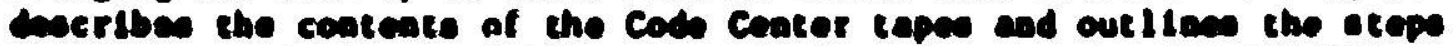

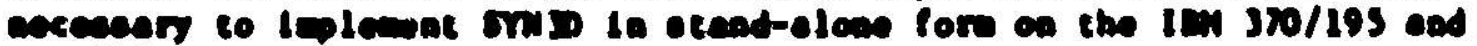
ac rop. 



\section{SYNTHESIS THEORY AND EQUATIONS}

In this section we develop the synthes1s approximation used in SYN30 from the mesh-box-centered, diffusion theory, fintre-difference equations and describe the solution of the resulting synthesis equations.

\section{A. Diffusion Theory Difference Equations}

There are two finite-difference forms of the neutron diffusion equations currently used in reactor analysis. In the derivation of the first, the fluxes in the differential equations are expanded in Taylor series about the mesh points (1.c. the intersections of the mesh 1 ines in two dimenstons and mesh planes in three). The PDQ code contains this formulation. 1,2 The other difference equations are derived by expanding the fluxes about a point at the center of a mesh block. The codes 2DB, 3DB, DIF2D, CITATION and VENTURE use this approach. ${ }^{3-6}$ SYN3D 18 designed to calculate an approximate solution for the second type of difference equation, which is the form most frequently used in fast reactor analysis.

In $x-y-z$ geometry the three-dimensional, finite-difference equations associated with the mesh block defined by $x$ mesh Interval 1 , $y$ mesh Interval $\mathrm{j}$, and $z$ mesh Interval $k$ in energy group 8 can be written:

$$
\begin{aligned}
& -d_{i+1 j k}^{x g}\left[\phi_{i+1 j k}^{g}-\phi_{i j k}^{g}\right] \Delta y_{j} \Delta z_{k}+d_{i j k}^{x g}\left[\phi_{i j k}^{g}-\phi_{i-1 j k}^{g}\right] \Delta y_{j} \Delta z_{k} \\
& -d_{i j+1 k}^{g}\left[\phi_{i j+1 k}^{g}-\phi_{i j k}^{g}\right] \Delta x_{i} \Delta z_{k}+d_{i j k}^{g g}\left[\phi_{i j k}^{g}-\phi_{i j-1 k}^{g}\right] \Delta x_{i} \Delta z_{k} \\
& -d_{i j k+1}^{z g}\left[\phi_{i j k+1}^{g}-\phi_{i j k}^{g}\right] \Delta x_{i} \Delta y_{j}+d_{i j k}^{z g}\left[\phi_{i j k}^{g}-\phi_{i j k-1}^{g}\right] \Delta x_{i} \Delta y_{j} \\
& +\sum_{8}^{g} v_{i j k} r_{i j k}^{g g} \phi_{i j k}^{g}-v_{i j k} s_{i j k}^{g}=0, \\
& i=1 \ldots I, j=1 \ldots J, \quad k=1 \ldots k, \quad g=1 \ldots G .
\end{aligned}
$$

I 16 the number of $x$ mesh intervals, $J$ is the number of $y$ mesh Intervals, and $K$ 1s the numer of axial wesh intervals. $G$ is the number of energy groups. No equations are written fin those mesh blocks which contain a blecknese theory material.

Ijk 10 the diacrete group flux asociated with mech block $(1, j, k)$. 1jk 1s Ident1cally zero if mah block $(1, j, k)$ is in a bleckness thgory ration. If $1-0$ or $I+1, J=0$ or $J+1$, or $k=0$ or $K+1$ the $1, k$ are excerior fluxes and their definition depends on the boundary conditions at the correeponding boundery of the model. For homogeneous boundery conditlone of the form 


$$
c_{1}^{g} \nu^{g} \hat{n} \cdot \nabla \phi^{g}+c_{2}^{g} g=0
$$

where $\mathrm{t}$ is the outward normal unit vector, the exterior fluxes for the boundary are Identically zero; the boundary condition is specified by the definition of the d's (see below). Equation (2) includes the cases of zero flux $\left[C_{\}}^{8}-0\right]$, zero current $\left[C_{\}}^{8}=0\right]$ and logarithmic (or extrapolated) conditions. The exterior fluxes at a boundary with periodic conditions are identically equal to the first interior fluxes on one of the other boundary surfaces of the model.

The three types of d's [ $d_{1 j k}^{x g}, d_{1 j k}^{y g}, d_{1 j k}^{z 8}$ ] are defined simllarly, and so it is necessary to discuss only one of them [ $d_{i j k}^{x /}$ ]. If the mesh blocks $(1, j, k)$ and $(1-1, j, k)$ are within the boundarles of the model, and neither contalas a blackness theory material,

$$
\begin{aligned}
& d_{i j k}^{x g}=\frac{2 D_{i-i j k}^{g} D_{i j k}^{g}}{\Delta x_{i} D_{i-1 j k}^{g}+\Delta x_{i-1} D_{i j k}^{g}}, \\
& i=1 \ldots I, \quad j=1 \ldots J, \quad k=1 \ldots k, \quad g=1 \ldots . G .
\end{aligned}
$$

$D_{1 j k}^{8}$ is the group 8 diffusion coefficient for mesh block $(1, j, k)$ and $\Delta x_{1}$, $\Delta y_{1}$, and $\Delta z_{k}$ define 1 ts size. If one of the mesh blocks is outside the boundary of the model (the cases $1-1$ and $1-I+1$ ), but that boundary surface has a perfodic boundary condition, then Eq. (3) still holds $1 f$ It 18 understood that the exterfor mesh block is 1dentical to a corresponding interlor mesh block on some other boundary.

SYN3D permits anisotroplc diffusign coefficients. The value of $D_{1 j k}^{8}$ appearing in the expression for $d_{1 j k}^{x / k}$ may be different from the value of $D_{1 j k}^{g}$ appearing in $d_{1 j k}^{y}$.

For the homogeneous boundary condition given by Eq. (2) at $1=1$ as well as when there is an internal interface between a blackness theory material in mesh block $(1-1, j, k)$ and an ordinary material in $(1, j, k)$,

$$
d_{i j k}^{x g}=\frac{D_{i j k}^{g} c_{2}^{g}}{L_{i j k}^{g} c_{i}^{g}+\frac{1}{\Delta} \Delta x_{i} c_{2}^{g}} \text {. }
$$

In the case of a blackness theory boundary, $h$ In Eq. (2) 18 the unit normal Into the blackness region at the interface. When $\mathrm{Eq}$. (2) is the boundary condition at 1 - I, and for an internal interface between a blackness theory material in mesh block $(1, j, k)$ and an ordinary materlal in $(1-1, j, k)$,

$$
d_{i j k}^{x g}-\frac{D_{i-1 j k}^{g} c_{2}^{8}}{D_{i-1 j k}^{8} C_{1}^{g}+1 \Delta x_{i-1} c_{2}^{g}}
$$


If both $(1-1, j, k)$ and $(1, j, k)$ contain blackness theory material $d_{1}^{x 8}$ is not defined, because the only two equations in which it could appear are never written.

The remaining notation in Eq. (1) 18 simpler to define. $v_{i f k}$ is the volume of mesh block $(1, j, k)$. r $88^{\circ}$ is basically the combination of macroscopic cross sections representing absorption, scattering, and fission. $8_{1 j \mathrm{k}}^{8}$ is an inhomogeneous source. With the proper definitions of rifk and $\mathrm{g}_{\mathrm{j}}$. Eq. (1) becomes the statement of an elgenvalue probler, an outer 1teration of an elgenvalue problem, a distributed source problem, or even one time step of an Implicit space-time calculation. To cast Eq. (1) in the form of the elgenvalue problem, for example,

$$
\begin{aligned}
& s_{i j k}^{g}=0, \\
& r_{i j k}^{g g^{\prime}}=\sum_{R^{g}}^{g} g g^{-}+\sum_{s}^{g^{+} g^{\prime}}-\lambda \chi^{g} u \Sigma_{f}^{g^{\prime}},
\end{aligned}
$$

where $\Sigma_{R}^{8}$ is the total macroscopic cross section for removal from group 8 , $\Sigma_{8^{+}} 8^{-} 18$ the cross sectign for scittering into group 8 from $8^{\circ}, x^{8}$ is the flssion spectrum and $v \Sigma^{8}$ is the cross section for neutron production by fission. $\lambda$ is the elgenvalue, and $\delta_{8 g^{-}}$is the Kronecker delta.

In $r-2$ and triangular geometries the finite-difference equations are similar to Eq. (1) if one alters some definitions. In $r-2$ geometry the " $x$ " dimension 18 the radial dimension, and the leakage finite-difference coefficient away from external boundaries and blackness reglons becones

$$
d_{i j k}^{x g}=\frac{2 D_{i-2 j k}^{g} D_{i j k}^{g}}{\Delta x_{i} D_{i-1 j k}^{g}+\Delta x_{i-1} I \nu_{i j k}^{g}}\left(2 \pi x_{i}\right)
$$

where $x_{1}$ is the radial position of the interface between mesh interval 1-1 and 1. The leakage coefficlents at boundarles (Eqs. (4) and (5)) are also multiplied by 2Il $x_{1}$. Now $v_{1}$ is the volume of an annulue.

For geometries which have triangular mesh in the plane, each woh cell couples to 3 other cells in the plane rather than to 4. The couplins between internal mesh triangles $(1-1, j, k)$ and $(1, j, k)$ is

$$
J_{i j k}^{x g}=\frac{2 \sqrt{3} v_{i-1 j k}^{g} v_{i j k}^{g}}{v_{i-1 j k}^{g}+v_{i j k}^{g}}
$$

and no $\Delta y_{1}$ appears aultiplying the cern (as in Eq. (1)). Whan one olde of - triangle io an exterior (or blackness reglon) boundery the coefflelent 1. given by 


$$
d_{i j k}^{x g}=\frac{D_{i j k}^{g} c_{2}^{g}}{2 \sqrt{3} D_{i j k}^{g} c_{1}^{g}+\Delta x c_{2}^{8}}(2 \sqrt{3} \Delta x)
$$

$\Delta x$ is not subscripted since in regular triangular mesh there is only one characteristic length, the side of a triangle. When the triangular ash is blsected by boundary, and the flux, therefore, 1s defined for a point on the boundary,

$$
d_{i j k}^{x g}=\frac{c_{2}^{g}}{4 c_{i}^{8} D_{i j k}}(2 \sqrt{3} \Delta x)
$$

\section{B. The Single-Channel Synthesis Approximation}

The equations and capabilities of srijo are besed on Kaplen's bleadins mothod. 7 Kaplan sugeested that the three-dimasional neutron flux can often be approximated by the triel functedon

$$
\phi_{i j k}^{8}-\sum_{n=1}^{N} q_{h k}^{8} H_{n i j}^{S} .
$$

The planer expansion functions, Hig. are knora functloes, precalculated by the wer. They should be the bet practenl estinses of the planar llux dietributicas encountered at varlou axdel peattloas. The combining coefficients, 4h, are the uakocurs of the ayachesis calculation.

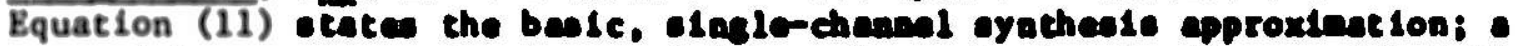

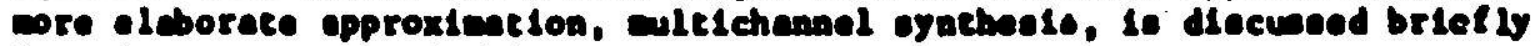
In a later ecetion of this report.

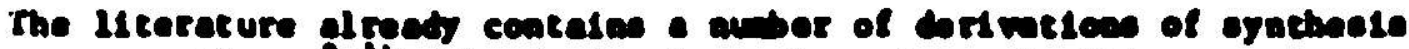

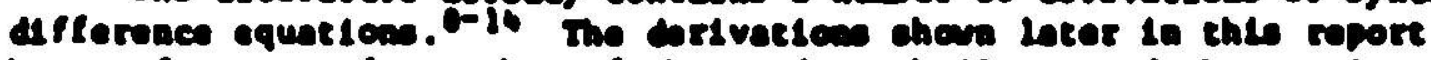

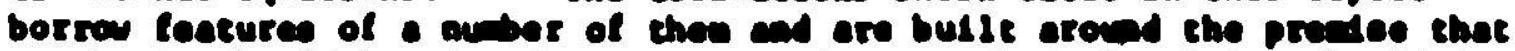

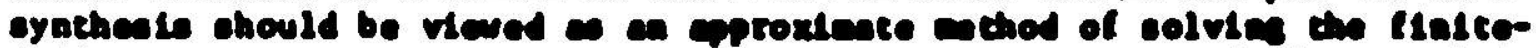

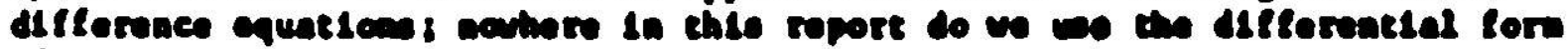

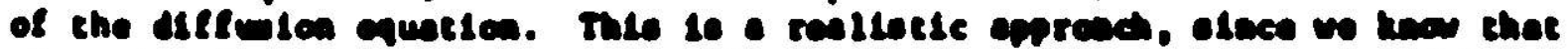

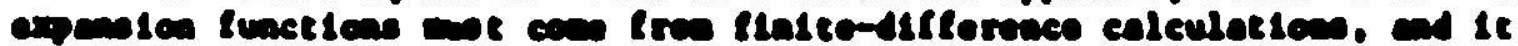

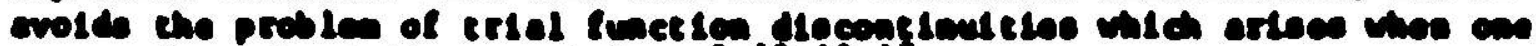

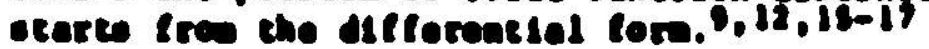

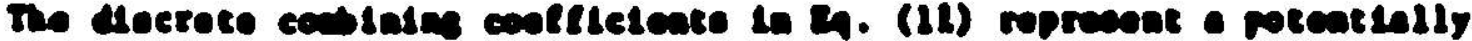

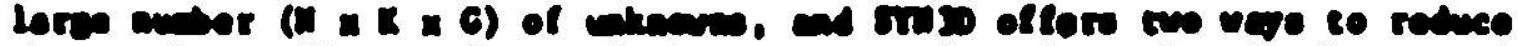

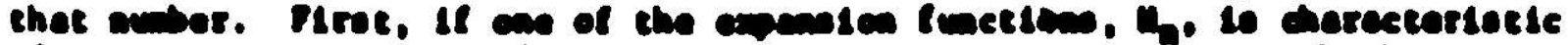

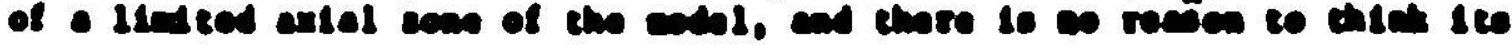


presence any help the solution aray from that zone, one can siaply set the corresponding coubining coefficlents, hk equal to zero for ranges of values of $k$. This is the discrete analog to the treatment of the continuous equations suggested in Ref. 18 and has the effect of excluding particular expansion functions from the trial function in particular axial zones. Carried to the extreme that only one corbining coefficlent in each group reanine unknown for each mesh interval, Eq. (11) reduces to the onefunction-per-sone eynthesis form proposed by Meyez. 19 In a variac1on of this procedure, setting to zero all those combining coefficients associeted with a particular $n$ and $s$ offer achanis for apecifying different numbers of expansion function for each enercy group.

The second way to reduce the nuber of unknowns 1o by group collapsing. 20 Group-collapeed syntheels to not to be confused with sroup collepsed cross ection; 1t eleply mane that the user epeciflee some prescription for expreselns the $G$ combining coefficlente for the $G$ group fluxes of one expansion function in teres of a ealler number, $G^{\%}$, of unknowns. In this work we vill allow llnear transforations of the form

$$
a_{n k}^{g}-\sum_{b=1}^{c^{-}} u^{b} a_{n k}^{b} .
$$

Note that we have lint ted ourselves to one collapsing schene for all expansion function and reglone of the nodel. To see hor group collapsing at the be applied, consider the exeple of a four-group oodel collapsed to two groups. If the matrix u vas given by

$$
u=\left(\begin{array}{ll}
1 & 0 \\
1 & 0 \\
0 & 1 \\
0 & 1
\end{array}\right) \text {. }
$$

chen the eynchesis erial function [Eq. (11)] for each group flux becone

$$
\begin{aligned}
& \varphi_{j k}=\sum_{n=1}^{N} u_{n k}^{1}\left\|_{n i j}^{l}, \Delta_{i j k}^{2}=\sum_{n=1}^{N} a_{n k}^{1}\right\|_{n i j}^{2} \\
& \varphi_{j j k}^{3}=\sum_{n=1}^{N} 4_{n k}^{2}\left\|_{n j j}^{3}, v_{j k}^{4}=\sum_{n=1}^{N} a_{n k}^{2}\right\|_{n i j}^{4}
\end{aligned}
$$

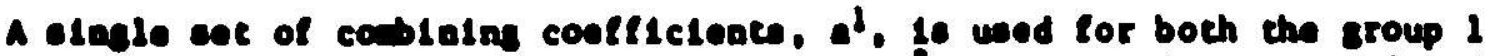
and erow 2 eriel function. Another eot, $a^{2}$. Is uned with eroups 3 and

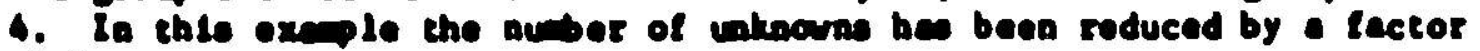
of 2.

One conetralat ahould be applind to the doflatition of the entrix

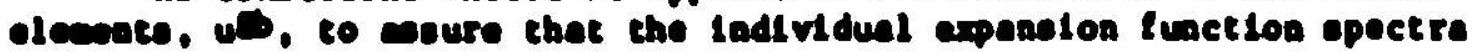


are recoverable frow the group-collapsed synthesis trial function [Eq. (11)], and that is

$$
\sum_{b=1}^{G} u^{g b}=\text { the same value for all } \mathrm{g} \text {. }
$$

This constraint 1s desirable since the user has supplied expansion functions which should have spectra characteristic of the varlous reglons of the model. becomes

With the group-collapsing option added, the synthesis trial function

$$
\phi_{i j k}^{g}=\sum_{b=1}^{G} u^{g b} \sum_{n=1}^{N} a_{n k}^{b} H_{n i j}^{g} .
$$

Note that Eq. (16) reduces to the tatement of group-dependent synthesis (Eq. (11)) when $u^{b b}$ 1o the unit matrix.

So far we have discussed only the trial function for the direct flux. For a variational derivation of the synthesis equations and for perturbation theory, an adjoint flux is required.

$$
\phi_{i j k}^{* k}=\sum_{b=1}^{l i} u^{*} g b \sum_{n=1}^{N} a_{n k}^{* b} \|_{n i j}^{*}
$$

$u$ is the adjoint Broup-collapsing schene, which does not have to be the sane as the dirget group-collapsing metrix, u. * is the adjoint combining coefficlent. $H_{n}$ is wer-supplied expaneion function for the adjoint trial function and ts wually called a weighting function. In order to keep the eynthesie equation in a forn conventent to solve, there wut be the cans number of nonzero adjolnt cosbining coefflclents, ab, a there ere direct, $a_{n k}^{b}$, at each extal weeh interval, $k$.

c. Derivation of the Synthesis Equations

There are two mthode comonly used to derive syatheale equations. We flret outline the wes etralchtforward of then, the velghted realduals (or weleht-and-1ategrate) approach, and naxt ahou a dorivation fron a varlational principle.

\section{Weighted Residuals}

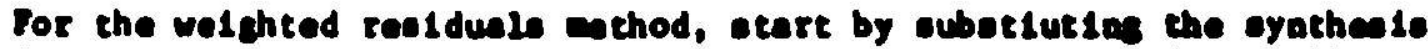
trial function (Eq. (16)) lato the flatcedlflerence cquetion (Eq. (1)). Then mitiply eech equetion for a particular axlal esch laterval (1.e. each comblation of l,J.8 lor one k) by the lacter 


$$
u^{*} b^{\prime} \| l_{n}^{*} g
$$

and sum the weighted equations over the Indices $1, \mathrm{~J}$ and 8 . Repeat this procedure for a total number of multiplfers (Eq. (18)) equal to the number of combining coefficients for a single value of $k$, making sure that each time the combination of collapsed group ( $\left.b^{\prime}\right)$ and expansion function ( $n^{\prime}$ ) for the multiplier is unique. We shall account later for the fact that some of the combining coefficients may be zero (1.e. that certain expansion functions have been dropped where it 18 felt that they are not needed). For now we will treat the calculation as if all expansion functions are used everywhere.

When the dust settles, the synthesis equations are:

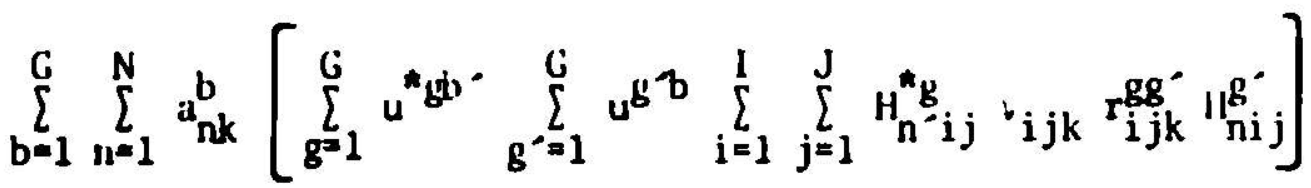$$
+\sum_{b=1}^{G} \sum_{n=1}^{N} a_{n k}^{b} \Delta z_{k}\left[\sum _ { g = 1 } ^ { G } u ^ { \star g b } u ^ { g b } \left\{\sum_{j=1}^{J} \|_{n=1 j}^{n g} d_{1 j k}^{x g} \Delta y j\left(: l_{n 1 j}^{g}-\|_{n 0 j}^{g}\right)\right.\right.
$$$$
+\sum_{i=2}^{I} \sum_{j=1}^{J}\left(H_{n}^{*} g\left(j-H_{n i-1 j}^{*}\right) \quad d_{i j k}^{x g} \Delta y_{j}\left(H_{n i j}^{g} \cdot H_{n i-1 j}^{8}\right)\right.
$$

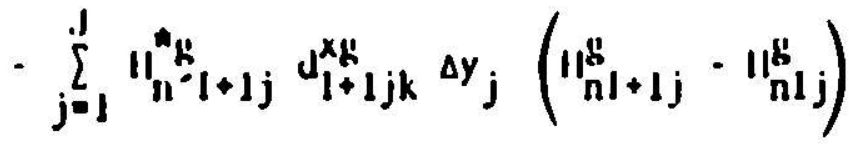

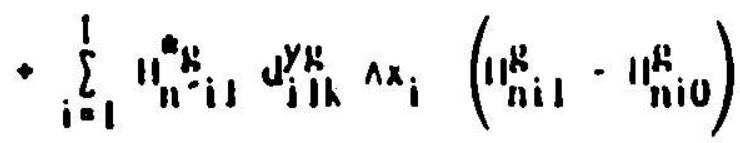

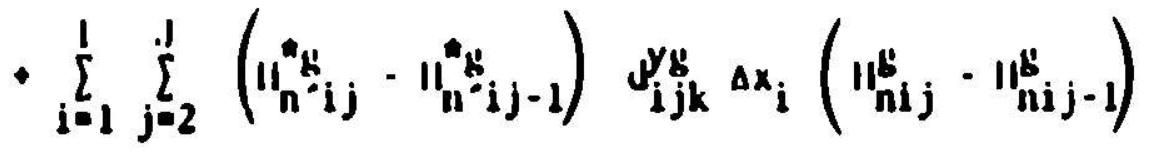

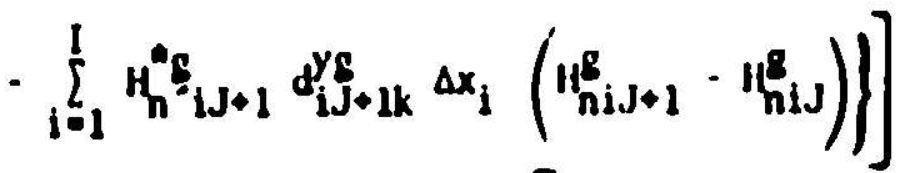

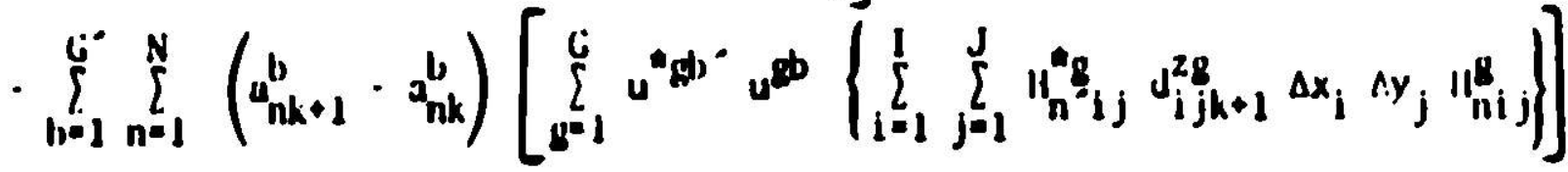

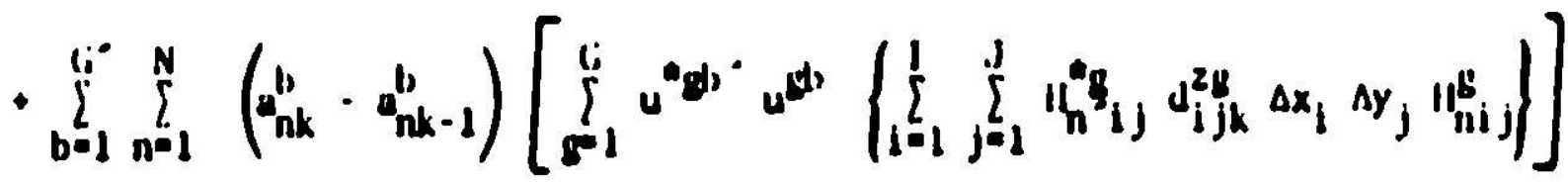

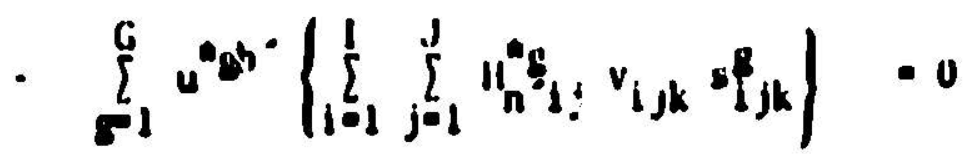


for each combination of $k, b^{\prime}$ and $n^{\prime}$ for which a welghting was performed.

To reduce Eq. (19) to a form wh1ch is a conventent basts for a practical computer code we will restrict the axial boundary conditions to the form given in Eq. (2) (zero flux, zero current or extrapolated boundary conditions) and introduce new notation. Perlodic conditions will not be allowed at the top and bottom of the model, which means that

$$
a_{n 0}^{b}=a_{n K+1}^{b}=0
$$

for $a 11 \mathrm{n}$ and $\mathrm{b}$ in Eq. (19).

We Introduce a new subscript, $m$, which identifies a unique combination of collapsed group (b) and expansion function (n).

$$
a_{m k}=a_{n k}^{b}
$$

The maximum value of $m$, which $1 s$ the maximum number of combining coefficlents associated with a single mesh interval, $18 \mathrm{M}$.

$$
M=1 i^{\circ} \times N .
$$

There is a comparable Index, $m^{\prime}$, associated with the weighting functions. By redefining some of the multiple summations in Eq. (19) we can write the synthesis equations.

$$
\begin{aligned}
& 0=-\sum_{m=1}^{M} \frac{1}{\Delta z_{k}} D_{m i m k} a_{m k-1}-\sum_{m=1}^{M} \frac{1}{\Delta z_{k+1}} D_{m i m+1} a_{m k+1} \\
& +\sum_{m=1}^{M}\left[\frac{1}{\Delta z_{k}} D_{m-m k}+\frac{1}{\Delta z_{k+1}} D_{m-m k+1}+\Delta z_{k} R_{m-m k}\right] q_{m k}-\Delta z_{k} S_{m-k} \cdot \\
& m^{*}=1 \ldots M, K=1 \ldots K,
\end{aligned}
$$

ubject to the condition given by Eq. (20). The delinitione of the entrices

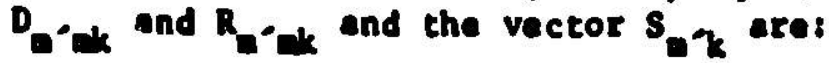

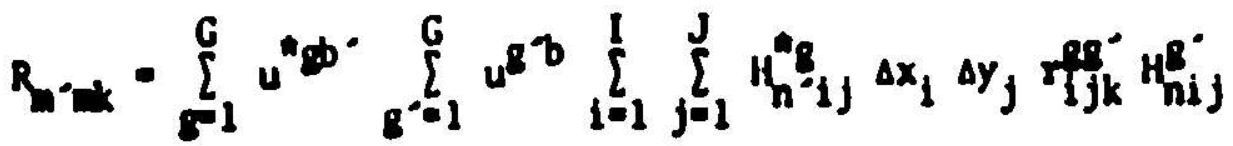

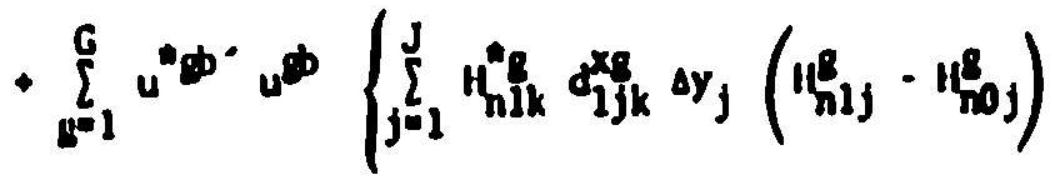




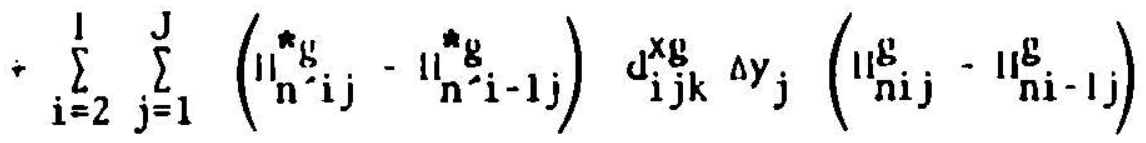

$$
\begin{aligned}
& -\sum_{j=1}^{J} H_{n}^{\star} g\left(+1 j d_{I+1 j k}^{x g} \Delta y_{j}\left(H_{n I+1 j}^{g}-H_{n I j}^{g}\right)\right. \\
& +\sum_{i=1}^{I} H_{n-i 1}^{n g} d_{i l k}^{y g} \Delta x_{i}\left(H_{n i 1}^{g}-H_{n i 0}^{g}\right) \\
& +\sum_{i=1}^{I} \sum_{j=2}^{J}\left(H_{n-i j}^{* g}-H_{n-i j-1}^{* g}\right) d_{i j k}^{y g} \Delta x_{i}\left(H_{n i j}^{g}-H_{n i j-1}^{g}\right) \\
& \left.-\sum_{i=1}^{I} \| I_{n-i J+1}^{k} d_{i, j+1 k}^{y g} \Delta x_{i}\left(\|\|_{n i J+1}^{g}-\|_{n i J}^{g}\right)\right\}
\end{aligned}
$$

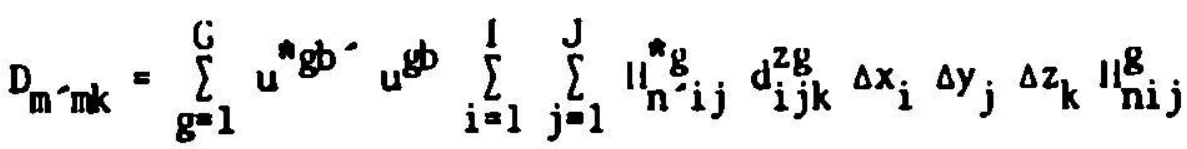

$$
\begin{aligned}
& s_{m k}=\sum_{g=1}^{G} u^{m g} \cdot \sum_{i=1}^{I} \sum_{j=1}^{J} H_{n+i j}^{*} \Delta_{i} \Delta x_{j} s_{i j k}^{g} \text {. }
\end{aligned}
$$

In order to define $D_{\text {pak }}$ by a single expression it ls necessary to define $\Delta z_{k+1}$ in $D_{m}-a k+1$. The definition 10 arbitraty, oince $1 t$ is cancelled by the Inverse meah spacing when $D_{\text {eask+1 }}$ 1s wed In Eq. (23).

We polnted out earlier that expansion functions can be elialnated fron the trial function over ranges of exial wesh intervals by setting thelr corblaing coefficlente 1dentically equal to zero. We can modify Eq. (23) to 1 iply this $1 f$ we define the symol

$$
\sum_{k} a t
$$

to wean the ev over only those velues of a at axial wath Interval $k$ which cortespond to aonzero cominins coefficiente, an. When the nuber of unknown is reduced in this way it become necestery to reduce the number of equations. In order that the reduced set of synthesis equet lone rene Ins In a block-tridlegonal fore which is conventent for numertcel invereton, we w11l require that when a cobintas confliclents is elletineted the correspondlns equation that wat be dropped be one eseocleted with the ean wah polnt. Therefore, the "m" - 1 ... M" In Eq. (23) le replaced by "a" ot k". Inplying that Eq. (23) Is uritten only for certela value of $a^{\circ}$ et each eneh Intervel: 
The final form of the synthesis equations can now be written,

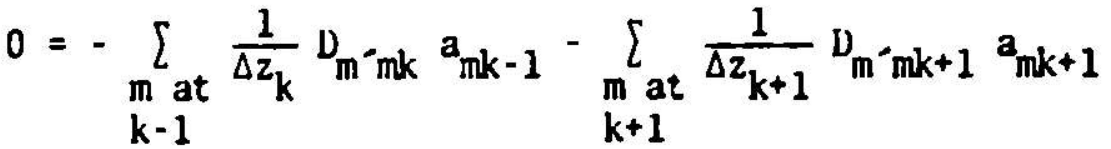

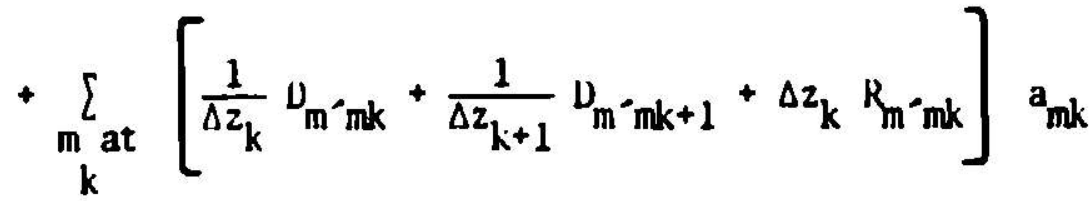

$$
\begin{aligned}
& -\Delta z_{k} S_{m k}, \quad m^{*} \text { at } k, \quad k=1 \ldots k
\end{aligned}
$$

\section{A Vartational Derivation}

Corsider the following functional:

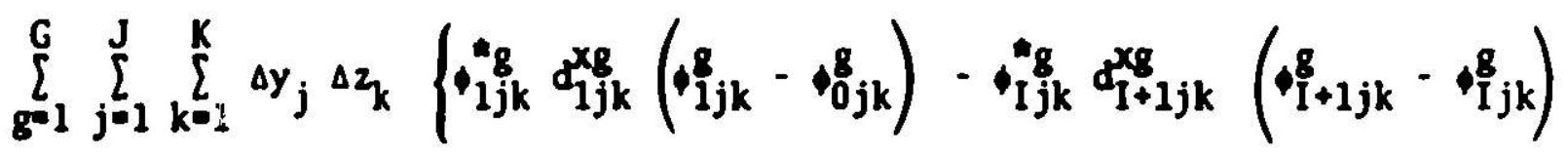

$\left.+\sum_{i=2}^{I}\left(\phi_{i j k}^{*}-\phi_{i-1 j k}^{8}\right) d_{i j k}^{x g}\left(\phi_{i j k}^{g}-\phi_{i-1 j k}^{g}\right)\right)$

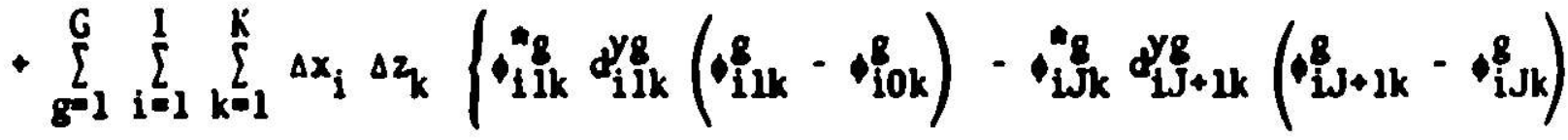

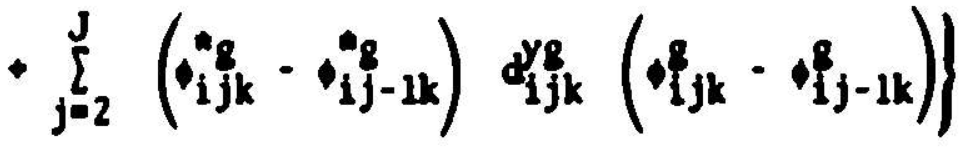

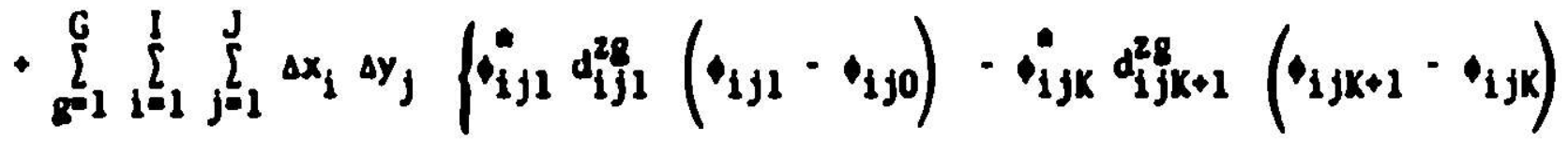

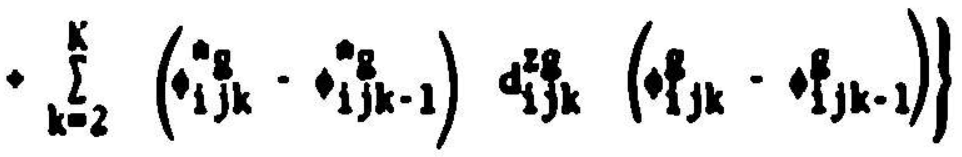

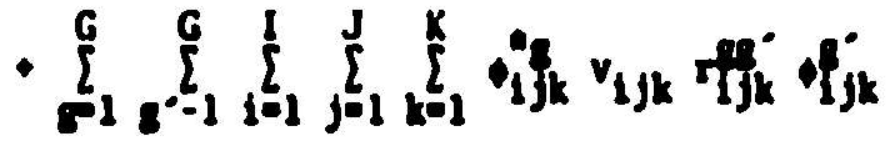

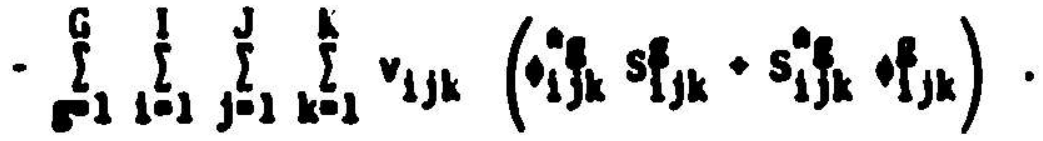


be stationary with respect to arbitrary varlations of the discrete adjoint fluxes leads to the set of difference equations given in Eq. (1) for any of the allowed types of boundary conditions.

For boundary condftions in the form of Eq. (2) recall that the extertor fluxes ( $\phi_{j k}^{8}, \phi_{1}^{8}+1 j k$, $\phi_{10 k}^{8}$, etc.) are 1 dentically zero. When those terms are dropped from Eq. (29) the symetry of the remaining expression should make it clear that requiring varlations with respect to the direct flux be zero leads to the usual adjoint difference equations. To show that the $s$ ame is true when there are periodic boundary conditions one must replace the exterior discrete fluxes in Eq. (29) by the appropriate internal fluxes before calculating-the varlations. For example, if an $x-y-z$ geometry model has quarter-core symmetry the boundary conditions are periodic at the surfaces 1 - 1 and $f-1$. The external fluxes are redef 1 ned by

$$
\begin{aligned}
& \phi_{0 j k}^{8}=\phi_{j l k}^{g}, \quad \phi_{i 0 k}^{8}-\phi_{i k}^{8},
\end{aligned}
$$

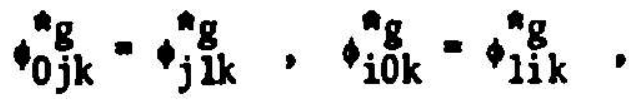

There are also identities relating the coefflcients in the leakage terms at the periodic boundary.

$$
\begin{aligned}
& \Delta x_{i}=\Delta y_{i} \quad i=1 \ldots I, \quad \Delta x_{0}=\Delta y_{1}=\Delta x_{2}=\Delta y_{0} \\
& d_{1 j k}^{x g}=\frac{2 D_{j j k}^{g} D_{1 j k}^{g}}{\Delta x_{1} D_{j j k}^{g}+\Delta x_{0} D_{j k}^{g}}=\frac{2 D_{j l k}^{g} D_{1 j k}^{g}}{\Delta x_{1} D_{j l k}^{g}+\Delta y_{1} D_{l j k}^{g}}=d_{j l k}^{g} .
\end{aligned}
$$

With the 1dentities shown in Eqs. (30) and (31), one can show that adjoint equations with perlodic boundary conditions can be derived from the funct lonal given by Eq. (29).

To derive the eynthesis equations, firet substitute the trial functions for the direct flux [Eq. (16)] and adjoint flux [Eq. (17)] Into the functlonal [Eq. (29)]. One can reduce the result to

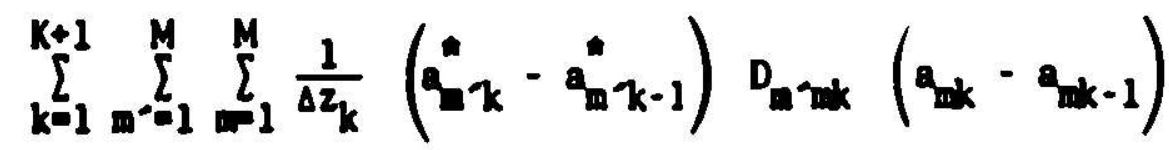

$$
\begin{aligned}
& +\sum_{k=1}^{K} \sum_{n=1}^{M} \sum_{1}^{M} \Delta z_{k} a_{k k} R_{m+m k} a_{m k} \\
& -\sum_{k=1}^{K} \sum_{n=1}^{M} \wedge z_{k} a_{a k}^{*} s_{n-k} \cdot \sum_{k=1}^{K} \sum_{m=1}^{M} \Delta z_{k} z_{k} s_{k \alpha}
\end{aligned}
$$


by using the definitions given in Eqs. (24) - (26) and

$$
S_{m k}^{*}=\sum_{g=1}^{G} u^{g /} \sum_{i=1}^{I} \sum_{j=1}^{J} H_{n i j}^{g} \Delta x_{i} \Delta y_{j} s_{i j k}^{* g} .
$$

Setting the variations of this functional with respect to nonzero, adjoint combining confficlents equal to zero leads directly to the direct synthesis equations derived in the last stction [Eq. (28)]. Following the same procedure with the direct combining coefficients leads to a set of adjoint synthesis equations.

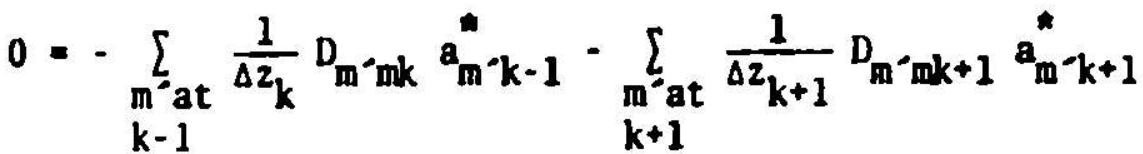

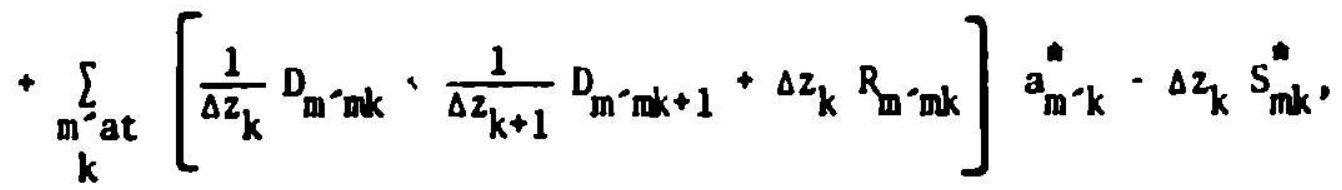

$$
\begin{aligned}
& \text { m at } k, k=1 \ldots k \text {. }
\end{aligned}
$$

It should be emphasized that the adjolnt variables In a synthesis calculation are combining coefficients, and not flisree. Whether or not the adjolnt trial function [Eq. (17)] is a good approxdantion to the adjoint flux depends on the user's cholce of weighting function. It is very common in practical calculations to we the expansion function for welghting functions also, and chts alght be a poor cholce in situations where the adjolnt is required. In perticular, when oodiu vold reactivity dietributions are to be calculated by perturbation theory it any be necessary to generate weighting functions frov two-dimensional adjolnt calculations.

When the groups are not collasped in ayntheeis calculation the adjoint combining coefficiente will, a best they can, reproduce the edjoint epectrun. If the eroupe are partially collapeed and direct tlux velghting is ued, however. It y1ll be virtually leposelble for the adjolat trial function to yleld reasoneble spectra. It has been found that reaulte can be Improved $1 f$ the direct flux expeneion coefficlente are ecaled before being wed a velghtiag functions.20,21

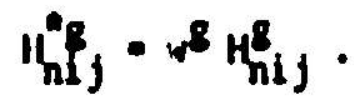

\section{The Solution of the Synthesis E1genvalue Equations}

Equation (28) can be uritten in the fore of an eleanvalue problea 18

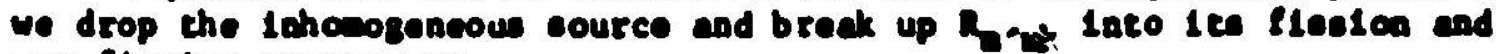
non-tlasion conponento. 


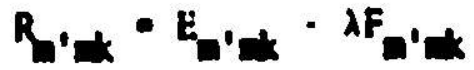

$$
\begin{aligned}
& \mathbf{n}^{\prime} \text { et k, } k=1 \ldots k
\end{aligned}
$$

t. Includes the planer laakage, ecaterlas and beorption componente of

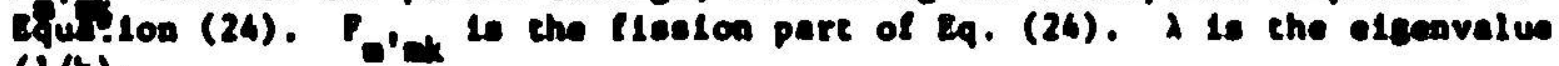
(l/k).

\section{Fisston Sostce Iteration with Wielandt Acceleration}

Irusp eolve Eq. (28), wodlfied by the Eq. (36), by the lleelon surrce iteration wethod with the convereance accelerated by Hielandt (or Irectical) iceretlon. 22 The ecetemat of one leeration of the colution cen be viteten - entrix cquetion.

$$
-A_{k-1}^{*} \cdot A_{k+1}^{*} \cdot k_{k}^{0} \cdot s_{k}, k \cdot 1 \ldots x_{0}
$$

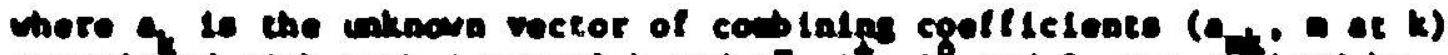

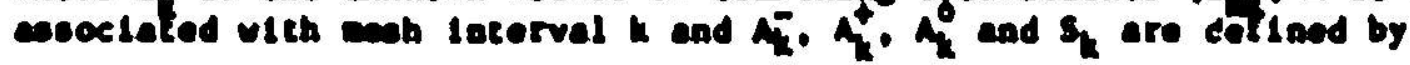

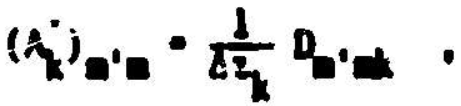

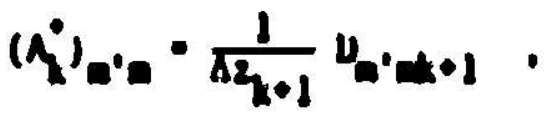

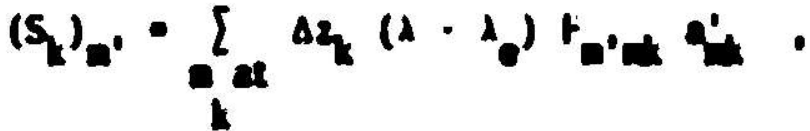

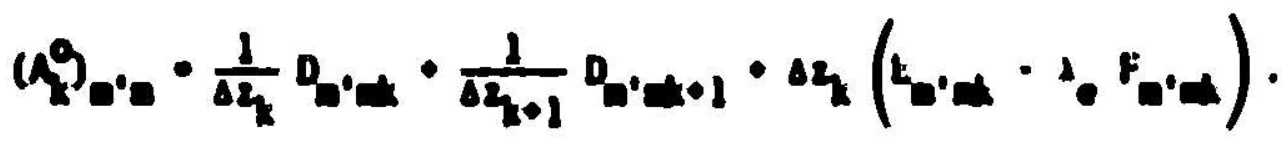

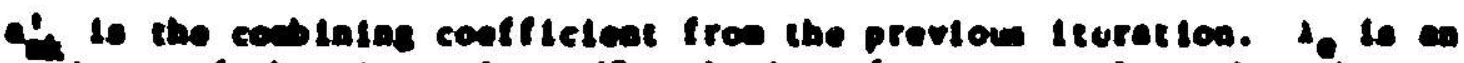

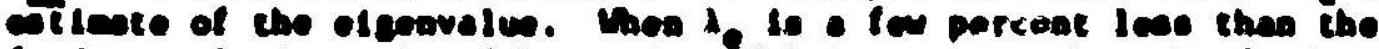

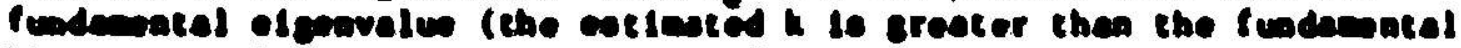

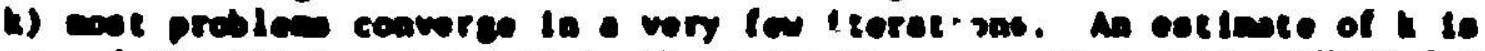

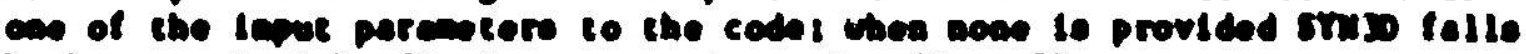
beck on etralche flecto souree leer-tion $\left(A_{\bullet}-0\right)$.

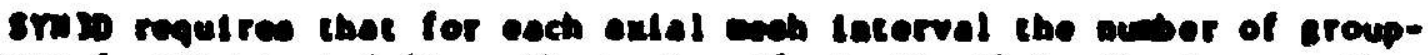

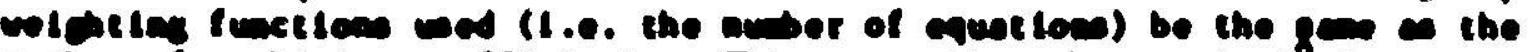

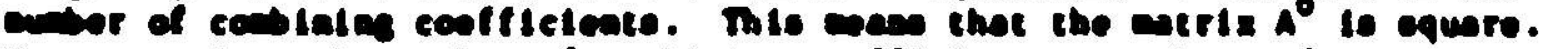

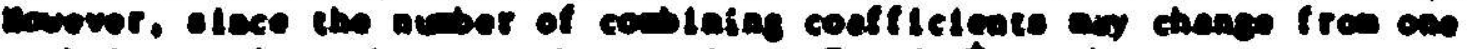

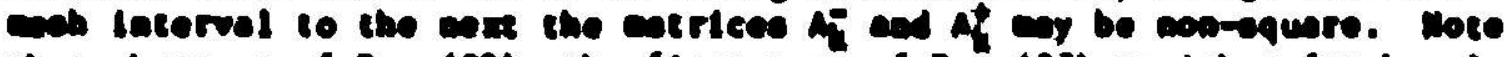

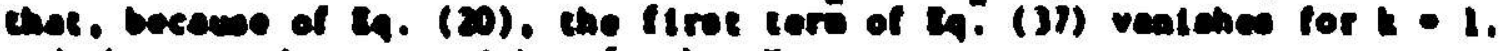

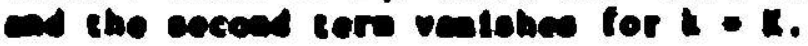

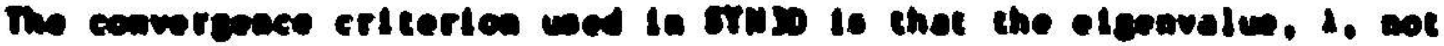

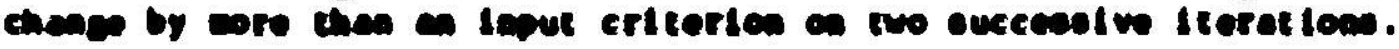


Solution by Fonverd Ellminetion, Beckward Substitution

The solution of the block-tridiegonal source problem (Eq. (37)) is perfornd by the forvard elinination, backerd eubetitution technique (a apecielization of Gawes reduction). 23 The firet otop 1s to oweep through the axial weh generating the following set of atrices, $H_{k}$, and vectora, $Q_{k}$.

$$
\begin{aligned}
\text { at k }=1, \quad H_{1} & =\left[A_{1}^{0}\right]^{-1} A_{1}^{+} \\
Q_{1} & =\left[A_{1}^{0}\right]^{-1} S_{1} \\
\text { at } k=2 \ldots k-1, \quad H_{k} & =\left[A_{k}^{0}-A_{k}^{-} H_{k-1}\right]^{-1} A_{k}^{+} \\
Q_{k} & =\left[A_{k}^{0}-A_{k}^{-} H_{k-1}\right]^{-1}\left[A_{k}^{-} Y_{k-1}+S_{k}\right] \\
\text { at } k=1, \quad Q_{k} & =\left[A_{k}^{0}-A_{k}^{-} H_{k-1}\right]^{-1}\left[A_{k}^{-} Q_{k-1}+S_{k}\right]
\end{aligned}
$$

The second step, the beckuerd subet1tut10a, is

$$
\begin{array}{ll}
\text { at } k=k, & a_{k}=Q_{k} \\
\text { at } k=k-1 \ldots 1, & a_{k}=Q_{k}+H_{k} a_{k+1}
\end{array}
$$

\section{Scallng and Differencing}

The realltice of compter erlthestc cen lead to two probles with the eyacberese cquations. The 11 ret occure whan nubers generated during the calculation exceed the Exieus or aintere enenltudes allowed by the conuter. Thle cen happen durtas the lavervion of Eq. (37) when the nonallsation of the expenolon functions are muvully lare (or enell) and/or wan the

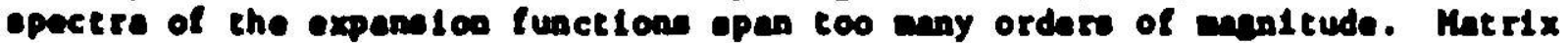

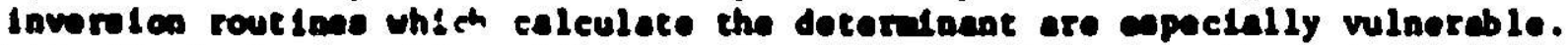
Thle Is elply a proble vith orrelisetion; whon lt occure there 10 probebly nothlag fuaderatally urons ut the eynthesle celculation.

The eecond problen, llwar depondence, vee wry eerly recogalaed a - poteaciel auleance. 7 but to our knowledge it he never ceused euch Aificuley. If - eet of apanoion functicas in cae group 15 "almos"

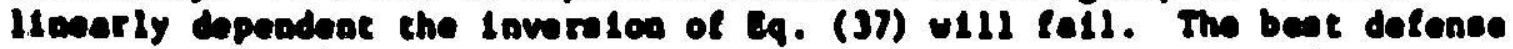
centest thls, of course. Is to know enouch bout the expaneton functions

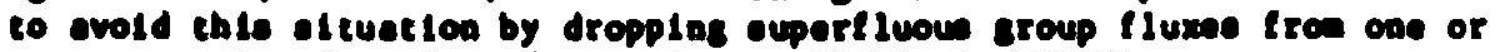
core expenston function (an optica evalleble in 8miso). 
As 1:18urance agalnst elther of these two problems arising, a transformation is performed on Eq. (37) during 1 ts solution. The transformation has the effect of a change of variables from the original synthesis approximation

$$
\phi_{i j k}^{*}=\sum_{n=1}^{N} a_{n k}^{g} H_{n i j}^{g},
$$

where $H_{n}^{8}$ is the input expansion function, to

$$
\phi_{i j k}^{g}=\sum_{n=1}^{N} b_{n k}^{g} G_{n i j}^{g},
$$

where the transformed expansion functions, $G_{n}^{8}$, are defined

$$
\begin{aligned}
& G_{i j j}^{8}=H_{l i j}^{g} / s_{1}^{g}, \\
& G_{n i j}^{g}=\left(H_{n i j}^{g} / s_{n}^{8}\right)-\left(H_{l i j}^{g} / s_{l}^{8}\right), n-2 \ldots N
\end{aligned}
$$

$8^{8}$ is a scaling factor used to change the normalization. At each axial mesh Interval and in each group this transformation has the effect of:

(1) renormalleing whichever expansion function has been designated $n=1$ (Eq. (49)), and (2) renormalizing and differencing the other functions with respect to the first ( $\mathrm{Eq}$. (50)). This differencing scheme 18 a sort of poor man's orthogonalization.

The relationships between the original and transformed combining crefficlents are

$$
\begin{aligned}
& b_{1}^{8}-s_{1}^{8} a_{1}^{8}+\sum_{n=2}^{N} b_{n}^{8} \\
& b_{n}^{8}-s_{n}^{8} a_{n}^{8}, n=2 \ldots N, \\
& a_{1}^{8}=\left(b_{1}^{8}-\sum_{n=2}^{N} b_{n}^{8}\right) / s_{1}^{8}, \\
& a_{n}^{8}-b_{n}^{8} / s_{n}^{8}, n \cdot 2 \ldots N .
\end{aligned}
$$

The cransformation of the matrices In Eq. (37) te governed by 


$$
\sum_{g=1}^{G} \sum_{n=1}^{N} A_{\min }^{g^{\prime} g} a_{n}^{g}=\sum_{g=1}^{G} \sum_{n=1}^{N} B_{m n}^{g^{\prime} g} b_{n}^{g}
$$

where $A$ represents any of the matrices $\left(A^{-}, A^{+}\right.$or $A^{0}$ ) operating on the combining coefficlents and $B$ represents a transformed matrix. The $r \approx$ lationships between $A$ and $B$ are

$$
\begin{aligned}
& B_{m l}^{g^{\prime} g}=A_{m l}^{g^{\prime} g} / s_{1}^{g}, \\
& B_{m n}^{g^{\prime} g}=\left(A_{m n}^{g^{\prime} g} / s_{n}^{g}\right)-\left(A_{m l}^{g^{\prime} g} / s_{1}^{g}\right), n=2 \ldots N, \\
& A_{m l}^{g^{\prime} g}=s_{1}^{g} B_{m l}^{g^{\prime} g}, \\
& A_{m n}^{g^{\prime} g}=s_{n}^{g}\left(B_{m n}^{g^{\prime} g}+\left(A_{m l}^{g^{\prime} g} / s_{1}^{g}\right)\right), n=2 \ldots N .
\end{aligned}
$$

The scaling factors, $8^{8}$, used were taken from the set of axdal leakage 1ntegrals, Eq. ${ }^{n}(25)$.

$$
s_{I 1}^{\prime}=D_{m^{\prime} m k}
$$

where $m$ ' is the composite Index for the appropriate group and "first" welghting function, $\mathrm{H}_{1}^{8}$, and $m$ is the composite Index for the oame group and $n$ 'th function. This cholce was made because (1) the integrale $D_{m}$ mk were avallable and (2) the elements of the trainsformed matrices in the synthesis equations were on the order of unity.

\section{E. Other Calculations}

\section{Multichannel Synthesio}

Multichannel synthesis is an extension of the single-channel approxdmation in which different combining coefficients are assigned to an expansion function in separate regions of the $x-y$ plane. 15 The multichannel trial function can be written,

$$
\phi_{i j k}^{g}=\sum_{n=1}^{N} \sum_{c=1}^{C_{n}} a_{\text {nck }}^{g} f_{\text {nci }}^{g} H_{\text {ni }}^{g}
$$

Equation (61) differs from Eq. (11) by the additional summation over the index c (for "channel") and the multichannel basis functions f $f_{\mathrm{nc}}^{8}$. Note that Eq. (61) permlts the number and definitions of the sets of basis functions to differ flum one expansion function to another. 
Two constraints should be pleced on the choice of bauls functions. The first is that the expression on the right in Eq. (61) aust be einglevalued for each $(1, f)$. The second to the spatial analos to the reacriction placed on the group-collapsing matcix (Eq. (15)). Because it it destrable ihat the planar flux shape of each expansion function. Hg. be recoverable from the sunthesis trial function for the three-dieanaional flux, $p$.

$$
\sum_{c=1}^{C_{n}} f_{n c i j}^{g} \text { - the same value for all } g, i \text { and } j \text {. }
$$

Our original Intention was to of fer aultichannel synches is as an option In SYN3D. After some experience with andl teet problen and large. fast-critical models we concluded that the advantage of ieproved accuracy was outwelghed by the dieadvantage of longer running ciase and core comlex trial functions, and SYN3D was not carried beyond the aingle-chanas ecace. For experimental purposes and for speciel appllcations $1 \mathrm{t}$ is poselble to perform multichannel calculations with SYH30 by factorins in the alcichanael basis functions outside the code,

$$
H_{\text {nij }}^{g} \rightarrow f_{n c i j}^{g} H_{n i j}^{8}, c=1 \ldots C_{n} \text {, }
$$

and treating each product, $\epsilon_{n c}^{B} H_{n}^{B}$, as a eeparate expansion function.

Perturbation Theory

The derivation of a perturbation theory expreselon for the change in an eigenvalue due to a change in the model, cerried out uithin the fremvork of - Ingle-channel flux eynthesis, leads to the sav result one obtalm vith derivation based on the orisinal difference equations. Therefore. any perturbation theory code which 1s beaed on the finlte-difference equetion in Eq. (1) can be wed with fluxes and adjolnte calculeted with srinjo. It 1s Important to remerber, however, that a different Interpretetion ast be given the results. A perturbation theory calculation based on oynthesls flures and adjointe enowere the question "What happens to the esnthenle calculation when one perturbe the eodell" and got neceseer1ly that happere to the finite-difference celculationi"

\section{USER CONSIDERATION8}

This eection is a discusalon of the exchanlce of running srm3o from

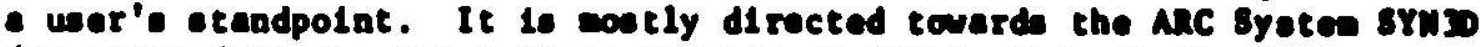
(as oppoeed to the etead-elone version aval leble throuch the Argonne Code Center). Users who have the Code Center vernion should read section V bafore Section III.

A. CCCC scandardy and the ARC syeter.

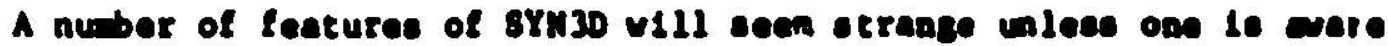
of the ground rules under which the code vas writeen. In recent yeers 


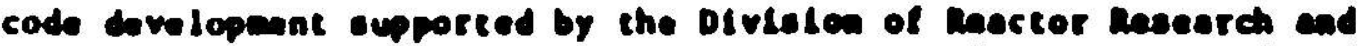

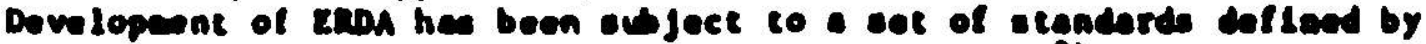

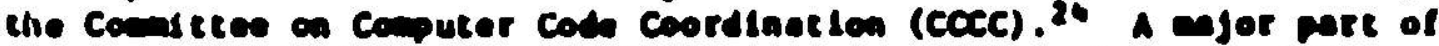

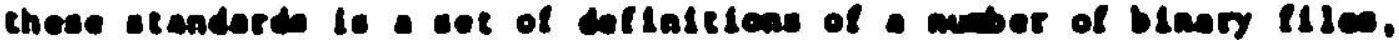
called scaderd Interface Illes. which ceatela wet of the dete required

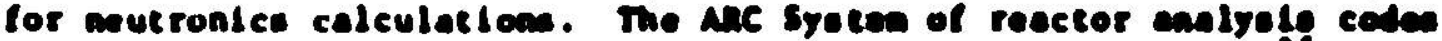

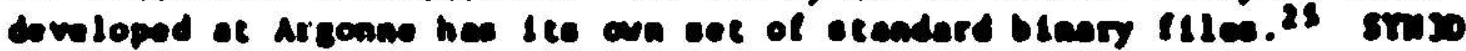

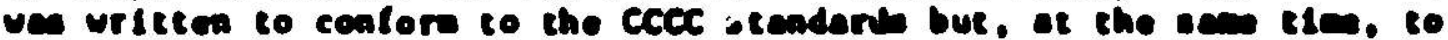

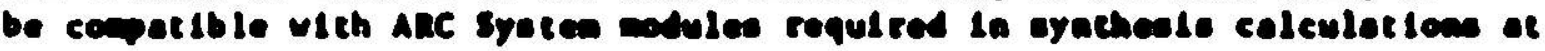
Argeane.

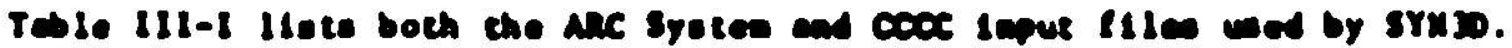

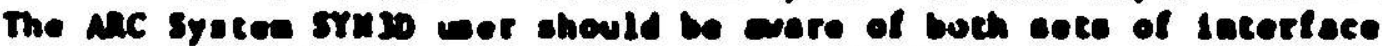
Itles; wers of the Code center vereten of ermss aced only be cencernod with the cocc illes.

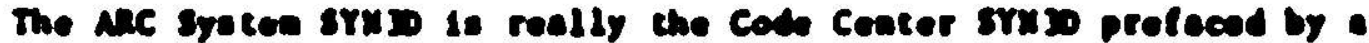

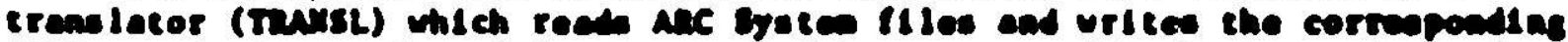

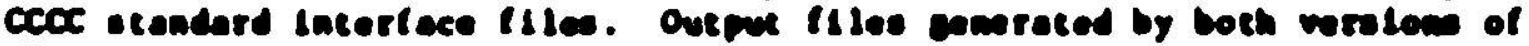
Iruss are oll la the cocc loreste.

\section{- Basic Input Requi reenents}

\section{Expans Ion Functions}

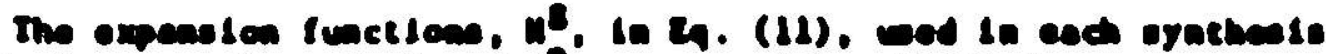

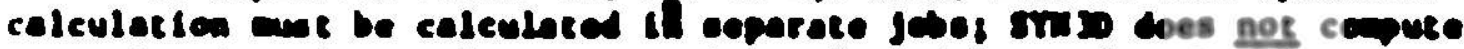

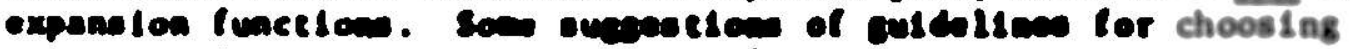

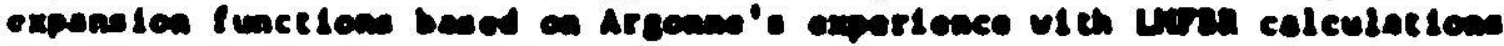
ere el wa la section III-H.

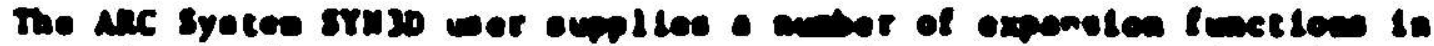

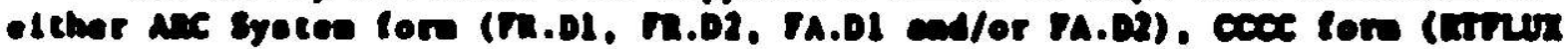

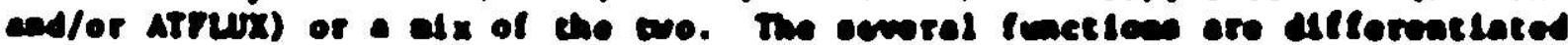

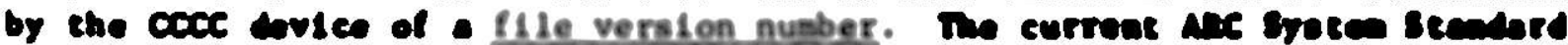

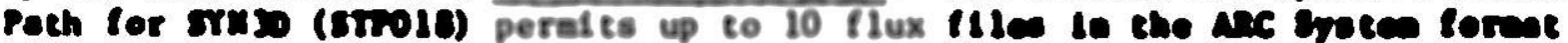

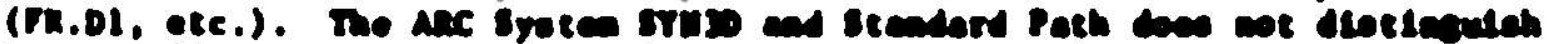

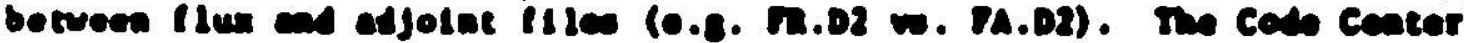

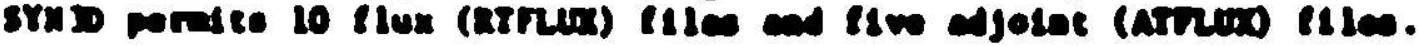

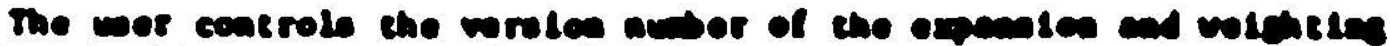

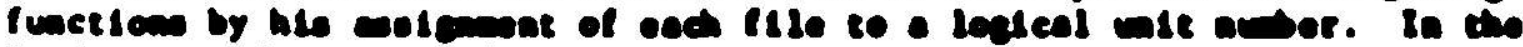

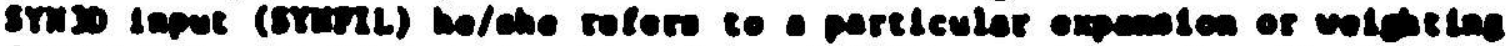

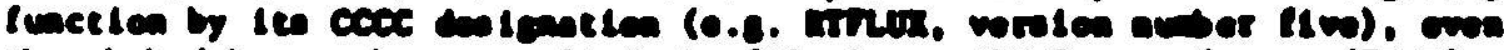

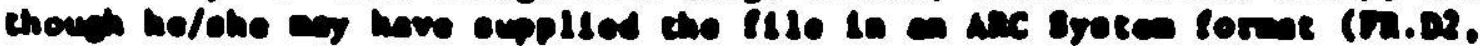
wreten mater live).

\section{Cross Sections}

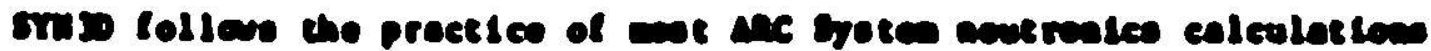

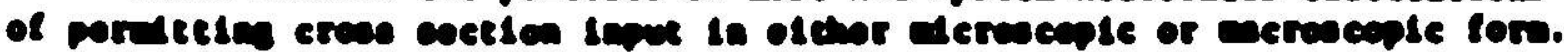

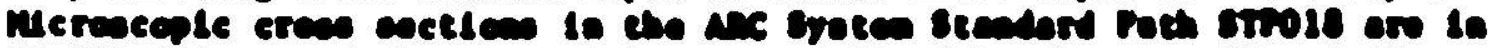

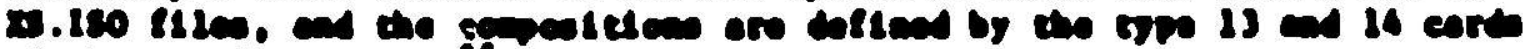
of the en lise A.mis. is 
TALLE III-1. ANC Systen and OOC Input Files for SYN3D. These are not all required; sco are penerated by SWN3D or its ANC syste stendard Path, and others my nover be noaded at all

\begin{tabular}{|c|c|c|c|}
\hline $\begin{array}{l}x \text { sysen } \\
\text { Do }\end{array}$ & $\begin{array}{l}\text { NCC Srsten } \\
\text { Minngy } \\
\end{array}$ & $\underline{\infty} 0$ Binux & Contents \\
\hline \multirow[t]{2}{*}{ A.NIP } & $\begin{array}{l}\text { ExO } \\
\text { Bdyox }\end{array}$ & 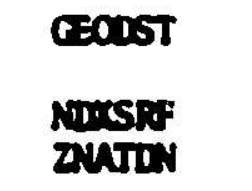 & $\begin{array}{l}\text { Modol Cocostry } \\
\text { Coposition Dofinitions }\end{array}$ \\
\hline & 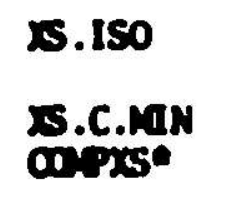 & $\begin{array}{l}\text { ISOTxs } \\
\text { conpxs" }\end{array}$ & $\begin{array}{l}\text { Microscople Cross Sections } \\
\text { Meroscople Cross Sections }\end{array}$ \\
\hline \multirow[t]{3}{*}{ SHTLL } & snoense & snicon & Shisd Control Dats \\
\hline & $\begin{array}{l}\text { FR.DI } \\
\text { FR.DQ }\end{array}$ & rerux & Flux Files \\
\hline & $\begin{array}{l}\text { FA.DI } \\
\text { FA.DZ }\end{array}$ & ATrux & Adjolnt flux filles \\
\hline
\end{tabular}

"copes and sncer are cols-depandent, binary files thich are not officlally part of el thior the NAC or cooc system. 
STPO18 wes the sodule HOrOC to areate the encroscople crose section f11. XS.C.MIN, and the ARC Syetem-to-CCCC tranelator In SYN3D, TRANSL, converts XS.C.MIN to CorPXS. Elther XS.C.MIA or CorPXS cen be Input directly. In whlch case the preceding steps in the croes section eanatation procedure will be sk1pped. CorpXs can accomodate drectionel diffusion coefficients and "power" croese ections; othervlee lt lo eldiler to XS.C.MN.

The Code Center veralon of SYA3D can run elther froe the CCCC

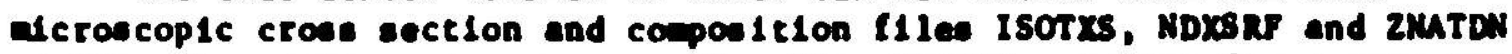
or I ron the acroscoplc crose eection t1le conpus. In the t1ret case the SYN 30 overlay HighC v1ll creace a corpXs 11 le.

\section{Geantry}

SYN30 bulld up a threo-diesaelonal novel of a reactor by stackins user-supplied two-dienelonel planes. Thle approsch vas chosen for two reasons:

(1) At the t1m SYN3D was etarted, Argone had no wer-orteated, three-dimaslonal seomery input procescor. We did have e vell etabllshed, one- and two-dienensonel laput proceseor In the ARC Syeter eodule GiIP. 26

(2) The wer was golas to have to set up two-dienaslonal ceoneries for the expand on function calculations enyway, and te vould be conventent if he/she could elply reuse that date vithout chengen.

The ARC Syotee Input procedure is particularly sulted to cenerating

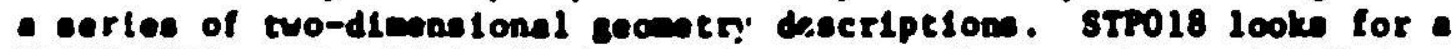
BLock-Geon card. If It tlads one lt expecte there to be an A.MTP data set epecllied for a plana. GIP procesese the A.MIP date to a palt of GEOM and BC Illes (verution nuber 1) and TRNisL converte then to a CEODST 11le (ocaln, verelon nuber 1). 8TP018 then looke for another Blockeceon and a corresponding A.HIP for the next plenar seonenty description (chls tie produclng - GEODST, veraton nuber 2). Th1s procedure continuss

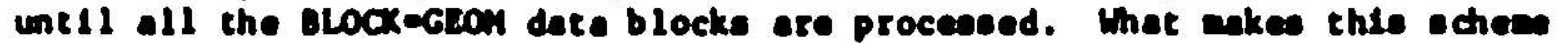

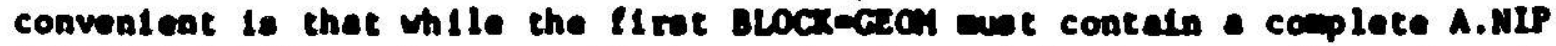
(DATASET-A.MIP), elbequent block need oaly coatain the type is cerd unique

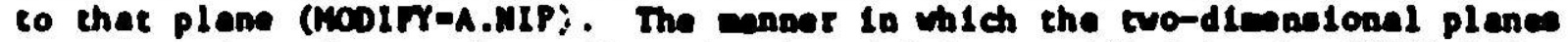

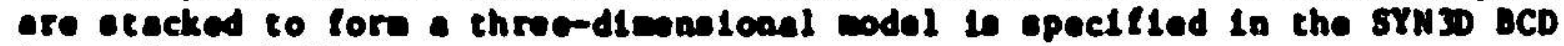
Inpue IIle sruril.

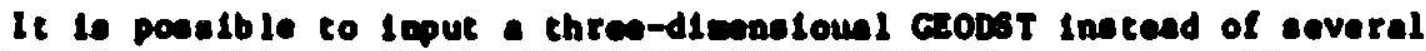

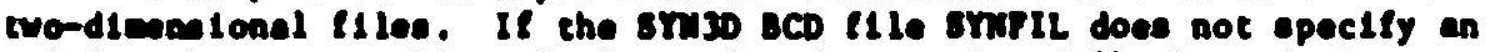
axial anh or a secklas of planes (card types $b$ and 3 ) the code interprets

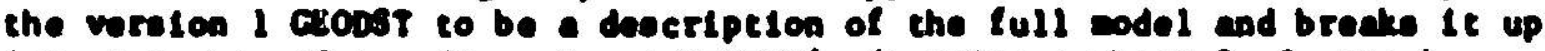
lato a nuber of two-dienesional Geost's (vereton nubers 2, 3, etc.). This vill oaly vork when the expandon fuections are elso laput in CCCC

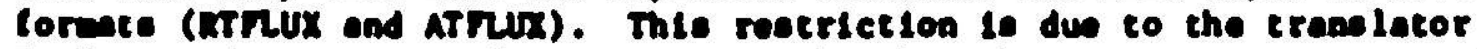

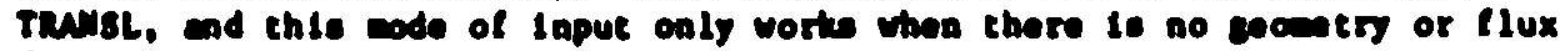
lile tran lation requltred. 
In deecribing the geomery input we have been using the exaple of chree-diensional eodals. The uan input procedure worke for two-

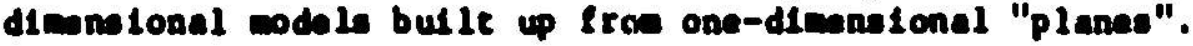

\section{Code Dependent Input - SYNFIL}

The special BCD Input required by SXN30 is defined by the BCD f1le SYWFIL. Appendix D 1o a file deecription for SMint. SWIFIL vuet be included In the ARC Syeten Input in a data block BLOCKeSYW3D.

\section{c. Running the ARC System SYN 3D - ARCP01:8}

The catalogued procedure for SXN3D on the Argonne 370/195 1s ARCP018. The procedure 1s listed In Append1x C. ARCSPO18 executes the aynthesis standard Path STP018, which 10 lleted In Appendix B and diecuesed briefly In Section IV.

\section{Inout and Ourput Date Sete}

TA I. III-2 IIsts all the Input and output date sets that are of Interesi to were. Besides the flles already entioned in Section III-B the liet lacludes the direct and adjoint cobining coefficient filee DCCOEF and ACCOEP, the pointwise power denalty PWDINT, the compositionaveraged flux t11e R2FUX and the eynthesio Integral library flles INTTOC, VOLINI and DIFIMT. Scratch date eete are discuseed In Section IV.

F1le description for the date cote lieted in Table III-2 can be found In one of three places:

For the following ARC System Files see ANL-7711 (Ref, 25) GEOM, BC, FR.D1, FR.D2, FA.D1, FA.D2, XS.C.MIN, A.NIP, XS.ISO

For the following CCCC Standard Interface F1lee see Append1x I. Geodst, RTFLU, ATrLux, PWDINT, RZFLUX

For the followins code-dependent flles see Appendices D and $\mathrm{E}$. SYNFIL, CONPXS, INTTOC, VOLINT, DIFINT, DCCOEF, ACCOEF

\section{Job Control and Symbolic Parameters}

The SYN3D catelogued procedure ARCSPO18 (see Append1x C for 11sting) 16 designed for the conventence of were operating frou ARC System data cets. Table III-2 liste the eybollc parametere avallable and their default values.

\section{Sample Input}

F1gure III-1 10 a lieting of an Input deck. The problem 1t representa 10 Seple Problea 3 of the Code Center SYN3D package (see Section V-E), a three-dicomional sodel with control rods. There are elx BLOCK-GEOH data blocks dallating rodded and unrodded core, blanket and reflector planea. The tour expanion tunctions are in the PR.D2 formet, and the crosa sections are eanerated frov an 48.180 ILle. 


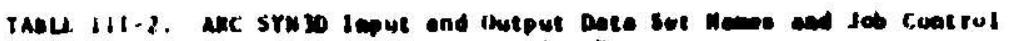
sobetiutsis syebollc Parionetert

\begin{tabular}{|c|c|c|c|c|c|c|c|c|c|}
\hline \multirow{2}{*}{\multicolumn{2}{|c|}{ 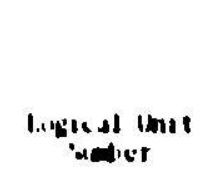 }} & \multirow[b]{2}{*}{ 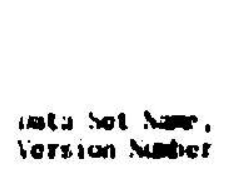 } & \multirow[b]{2}{*}{ MIASI.T" } & \multicolumn{6}{|c|}{ Jut Conlgul Sebstilution } \\
\hline & & & & Int s tiet & Disposition & lobler & late set & Uisposition & Voluraeen \\
\hline & is & ian, 1 & (a) & (בND) & (a) ISFU & a.trugl & (1). & (NM, (H:WT) & \\
\hline & d: & inturl.: & 12.180. & IJIND: & alnio: & Githo: & MAIND: & , Wis, If J.tI J & \\
\hline & . & . & . & . & . & $\cdot$ & • & • & \\
\hline & • & . & $\cdot$ & $\cdot$ & $\cdot$ & $\cdot$ & • & , & \\
\hline & $\dot{y}$ & dien, II) & 1active & 12.îlu & axisino & 1.17it. Ju & uaitutu & (v), indu) & \\
\hline & $\therefore 1$ & a14:1. 1 & (d) & & & & & & \\
\hline & . & . & . & & & & & & \\
\hline & ;i & diveri, wo & deckilu & & & & & & \\
\hline & 31 & $m \cdot 1$ & Hul & HU! & EIs/01 & m.MNO: & G|Ld| & 1.8h, I1.1.12.6 & \\
\hline & • & . & • & · & $\cdot$ & • & $\cdot$ & $\cdot$ & \\
\hline & $\therefore$ & & $\therefore$ & & & & & (2) & \\
\hline & $\mathbf{u}$ & $: 4.10$ & in 10 & int du & mat'su & 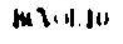 & wit J11 & (Wh, intett) & \\
\hline & $\$ 1$ & HK.HL, 1*0 & HUXI! & Huixul & HJEIU] & AlIMUI & ฟ.川III & [H]d, (A)\} & \\
\hline & . & - & • & . & . & . & . & $\cdot$ & \\
\hline & sis & H.W., U1, & 11.20 & II.Ux lu & 11.1siplo & Flisin lat & काओ & 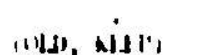 & \\
\hline & i) & Nolluix, I & kIIIS! & & & & & & \\
\hline & . & . & . & & & & & & \\
\hline & (d) & kilux, |v & Hili lu & & & & & & \\
\hline & $6 !$ & INII, 1 & sI.MII. & & & & & & \\
\hline & $0:$ & uns'x, I & IANSS & & & & & & \\
\hline & os & $1 \times 7+1 x, 1$ & IXfIII & INTIIXI & IIXISI'] & fxith.d & MIt.나IL & ((M.), NIJ) & \\
\hline & wt & $1.01 \% 4,:$ & ISHI: & Isitur: & IXusp? & Txxill: & 41.57นx: & $(12 \mathrm{~N}, 141.111)$ & \\
\hline $0:$ & $\| 100$ & ki.t...yll, 1"ane & N.L.NII & UAs'xsl & (XsIns) & (x) & txes:IINI & INA, It.J1.TL) & \\
\hline $6:$ & $\| 1 \mid k \therefore$ & " & " & undxs: & " & " & Gxiscills: & $\cdots$ & \\
\hline & us & $\mid(\| .|x|, \mid$ & โ14.1.। & IXLIX] & |xils'] & |xเาเห.| & WILIJ:HL. & ((1), NLP) & \\
\hline & by & |(1).ISI, : & IUl.1.: & WULINT: & Nilsl: & ทาหนเ: & HUL.IRT: & (Nth, 14:1171) & \\
\hline & u & UtIINI, I & $|1 t||M|$ & ט]เ।M! & INTs!' & IMTILL & aㅐ난 & $\left.(t)(\alpha), \quad \mathbf{N} \perp H^{3}\right)$ & \\
\hline & 1 & 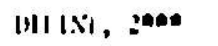 & IItI. & แ11:1.77: & INILS?: & INTVU.: & GHIFI: & $(\mathbb{N}$, IH」IL) & \\
\hline & 74 & Isifx).J I & |xiny & Ixint.| & |XLJS|' & mitul & Glicull.1: & (Nh, It.L.72) & \\
\hline & is & Mull. I & Nituld & viut & Mijs! & Mitul. & wNort.t & (AM), if.Lt:Jt) & \\
\hline & 77 & $1.110,1$ & A.NII & & & & & & \\
\hline$y$ & (file 1$)$ & $x i .1: x, 1$ & $x \mathbf{s},|\dot{x}|$ & NIciexs1 & & NItakt). & NiLLFIL. & (124), Ald.t') & \\
\hline $7 y$ & lite 21 & " & " & Minus: & & $"$ & NuLlollat & " & \\
\hline & 91 & All-I.UX, 1 & NIIX & & & & & & \\
\hline & 92 & |nu|si. $\mid$ & [H]IIAI & & & & & & \\
\hline & 9.3 & KIIAN, 1 & K:HWX & & & & & & \\
\hline
\end{tabular}

"IMIASLT" is the niwa of the fille as it should he spelled when specified under Blachaots,

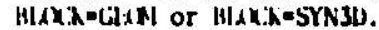

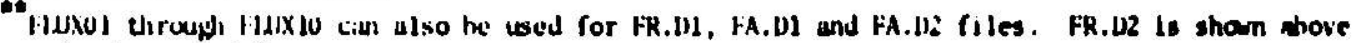
ailly as iut cximple

"the followiln! symbolic parmeters are associated with certain of the chove files. They did not fit conveniently into the table and are inclubed here.

\begin{tabular}{|c|c|c|c|c|}
\hline $\begin{array}{l}\text { logical unie } \\
\text { Numer } \\
\end{array}$ & $\begin{array}{l}\text { Lata Set Nane, } \\
\text { Vursian Neper }\end{array}$ & $\begin{array}{l}\text { Sybolic } \\
\text { Paraster }\end{array}$ & Lefault & Lesciription \\
\hline $\begin{array}{l}07 \text { (ijice } 1) \\
07 \text { (1) } 1 \text { ile } \\
\text { of } \\
7 !\end{array}$ & $\begin{array}{l}\text { XS.L.MIN, } 1 \\
\text { UILINI, } \\
\text { IIIIISI; } 2\end{array}$ & 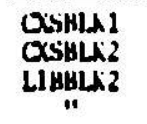 & $\begin{array}{l}1028 \\
0 ! 30 \\
12280 \\
11\end{array}$ & $\begin{array}{l}\text { BLASIZI. } \\
\text { BLASIZI } \\
\text { BLSSIZE } \\
\text { " }\end{array}$ \\
\hline & & 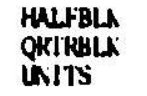 & $\begin{array}{l}6130 \\
3064 \\
\text { BATCNISK }\end{array}$ & 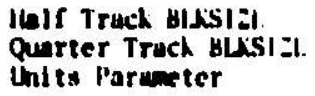 \\
\hline
\end{tabular}




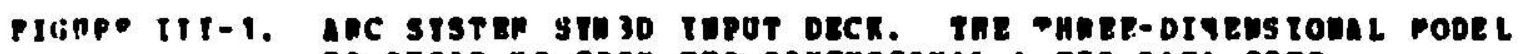

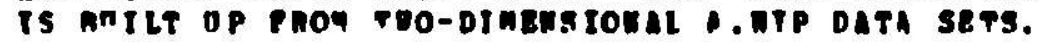

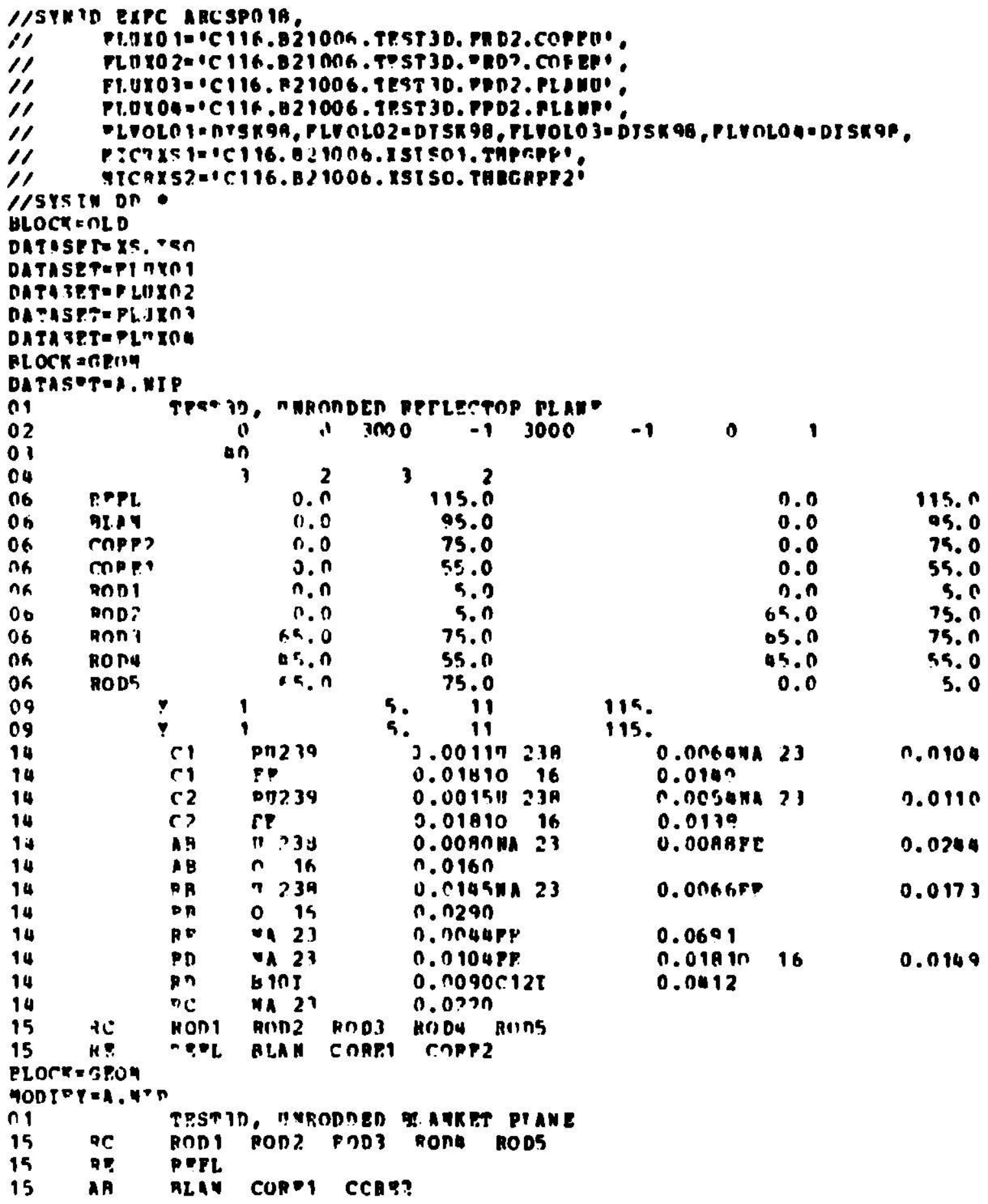




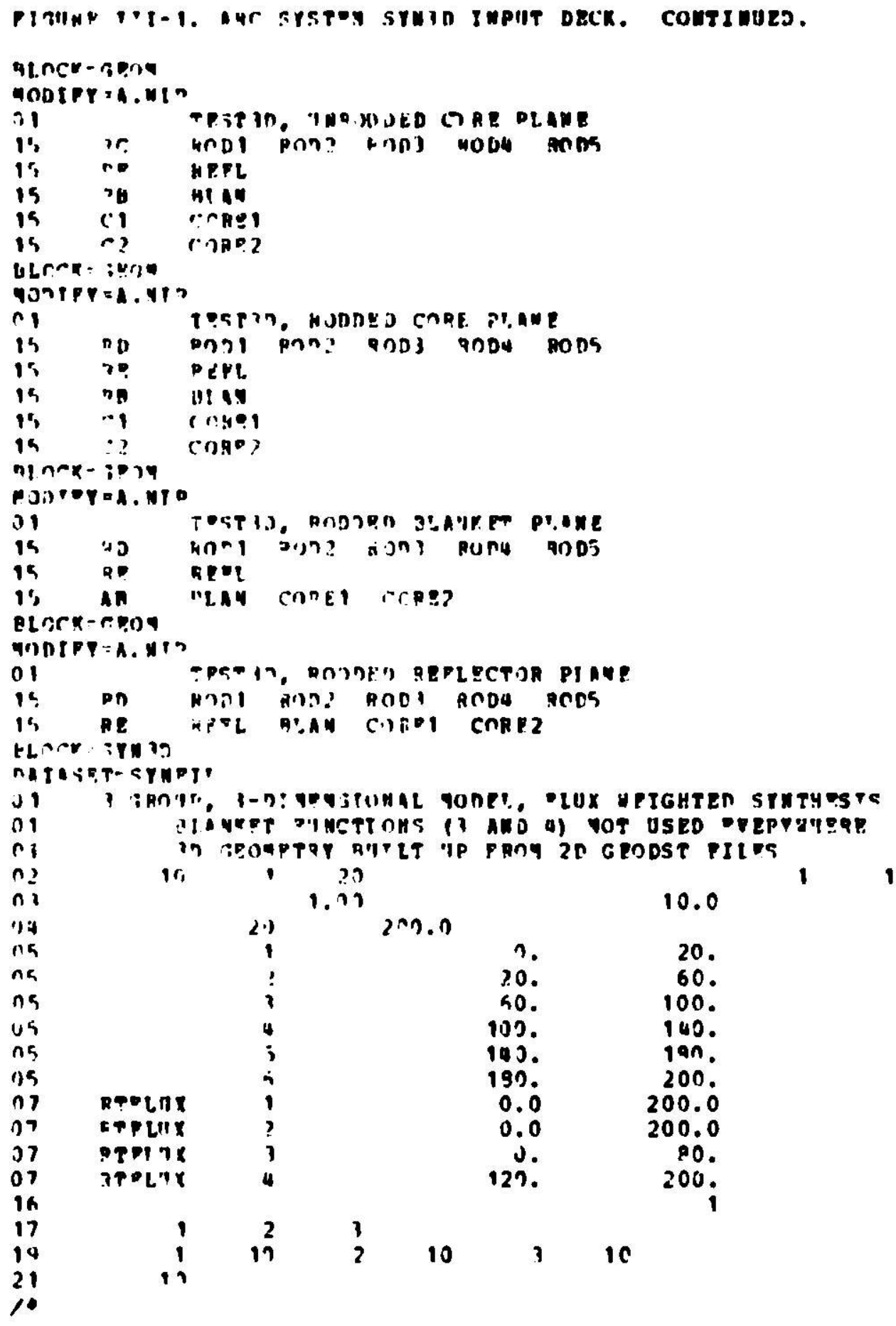


D. Mult1ple Problems and Restarts

For most problems the most expensive part of a SYN3D calculation 1s cenerating the Integrals (Eqs. (24) and (25)) wh1ch form the coefficients of the aynthesis equations. If the same integrals can be used for a number of synthesis calculations the user can save a significant amount of time.

\section{Mut 1iple Problems}

The sioplest way to reuse integrals is to run several problems in a single Job. The ARC System SYN3D does this automatically by looping on Bl.OCK-SYN3D data blocks. A problem defined by aecond BLOCK-SYN3D uses Integrals generated under the first BLOCK-SWN3D, calculating additional lntegralo if required. The output flux file from each loop can be saved by specifying different version numers for the output RTFLUX (Bee SYNFIL card type 16). Only the last aet of coubining coefficlents can be saved, however, since SYN3D always writes them to DCCOEF version number 1.

Th1s mitiple paso feature is not avallable in the Code Center SYN3D. Code Center SWND users w11l have to use the wore furmal restart procedure described in the next paragraph.

\section{Res tarte - INITOC, VOLINT and DIFINT}

The Integrals SYN3D calculateg are stored in a library consisting of three f1les: INTTOC, VOLINT and DIFINT. SYN3D always writes these filew with a version number of 2 . If these files are input with a version number of 1 the code w1ll merge the old Integrals with whatever iritegrals 1t still must calculate before writing the output librarles. The veralon 1 flles are not changed.

File descriptions for the library files are in Appendix $E$. INTTOC 18 a short file containing the table of contente for VOLINT and DIFINT as vell a the general problem data. DIfINT containo the Integrale associated with the axial leakage. $D_{\text {gink }}$ (Bq. (25)). VOLINI contalns four types of Integrals which are referred to in the coding and In the SYN3D output as REM, FIS, POH and FLUX. REM and FIS are, respectively, the renoval and flesion components of $R_{\text {pruk }}$ (see Eqs. (24) and (36)). POW is the planar power Integral.

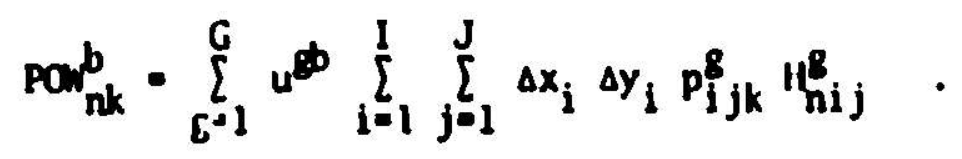

where ply 1s a "power" crose enction upplied in the cotpXs 111 . Eq. (64) Is written for an $x-y$ plane; one can obtaln the expreesion for other seoucties by replacing $\Delta x_{1} \Delta y$, by the approprlate volue element.

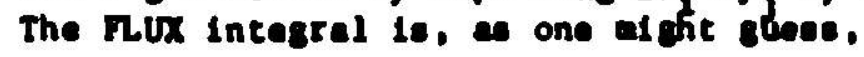

$$
F u x_{n}^{b}-\sum_{g=1}^{G} u^{b s} \sum_{i=1}^{l} \sum_{j=1}^{j} \Delta x_{j} \Delta y_{j} \mid t_{n j}^{b} .
$$


The Index b refers to a collapsed group. Recall that when group collapelns 18 not used $u^{86}$ is the Kronecker delta ( $u^{8 b}=1$ when $8-b,-0$ otherw1se).

One can regtart SYN3D to do another aythesis calculation or alaply to obtaln further edits for a problem run previously. In the lat ter case DCCOEF and/or ACCOEF must be among the Input data sets.

SYN3D cannot be restarted in the middle of the synthesis integral calculation or the middle of the solution routine. If the job terminates before completing one of those two stages, that particular tage wust be repeated.

\section{E. Edits and Output Optlons}

SYN 30 has sowe standard edits, over whlch the wer has no control, and some optional edits. Appendix $H$ contains output from the saple problem In the Code Cencer package (Section V-E).

\section{Standard Output}

SYN3D always 11sts the SYNFIL Input date and two pages describing the model and synthesis trial function (In ters of CCCC files). When logarithmic boundary conditlons are used the constante $C_{1}$ and $C_{2}$ listed in the edite refer to Eq. (2) in Section $U$.

$$
c_{1}^{8} D^{8} \hat{n} \cdot \nabla \phi^{8}+c_{L}^{8} \phi^{8} \cdot 0 \text {. }
$$

In addItIon, SYN 3D edits the Integral tables of contents, the elgenvalue and the combining coefficlents $\left(c_{\text {ik }}\right)$.

The standard output flles are:

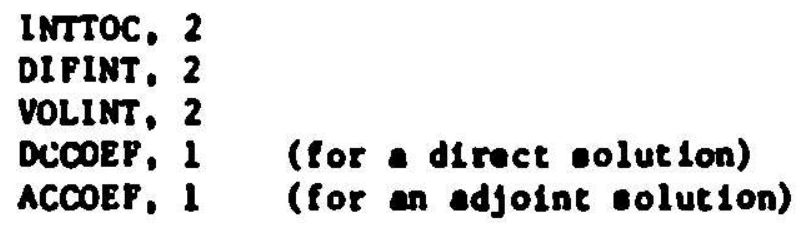

\section{Optlonal Outpur}

SYNFIL card type 16 through 21 epecify output optlon. Flux and adjoint edite may be epecifled by group and plane. Polntwiee pover denstcy edits ay be requested by plene. SYN3D vill also edlt the comoeltion-averaged group lluxes (the contents of the Rzpux 111 ) and the perturbation theory dononinator.

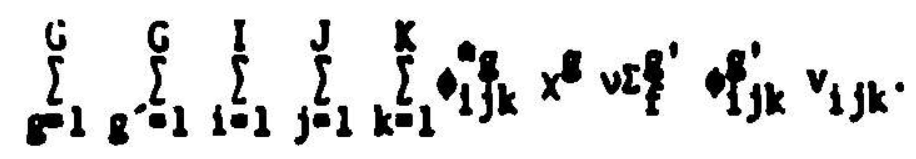

where the aybols vere deflned lor Eqe. (1) and (6). 
The optional output llle ares

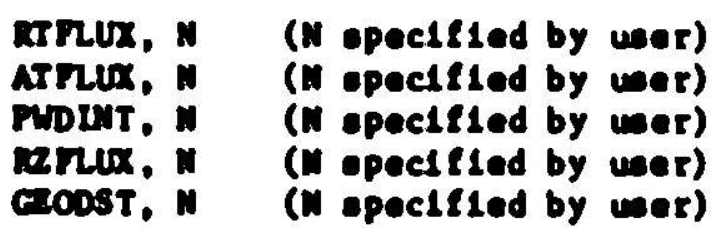

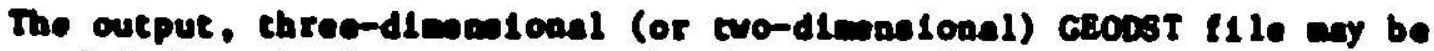
watul when the laput exomen hen been epeclfled by a set of two-

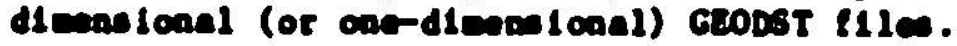

\section{Combining Coefficlent Plots}

orm3 w1ll edst priater plote of the ardal power dietribution,

$$
(p a w r)_{k} \cdot \sum_{n=1}^{N} \sum_{b=1}^{\prime} p_{n k}^{b} d_{k k}^{b} .
$$

and the extel group llume (alter group collapalan)

$$
(\operatorname{Iux})_{k}^{b} \cdot \sum_{n=1}^{N} \operatorname{sun}_{h}^{b} b_{k}^{b} .
$$

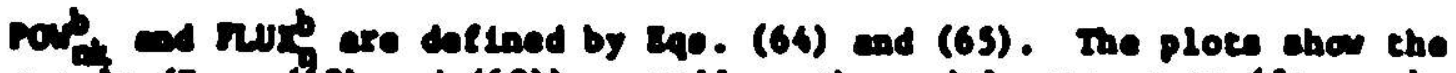

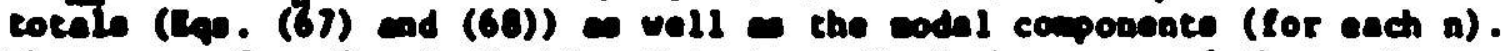
The outpue fros seple Problea 3 is Appendix II chave one of these ploce.

\section{F. Error Messages}

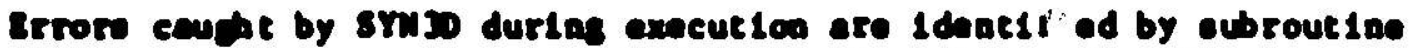

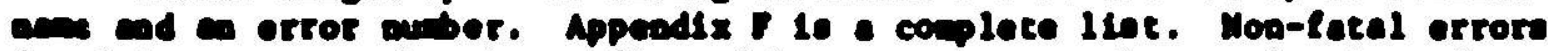

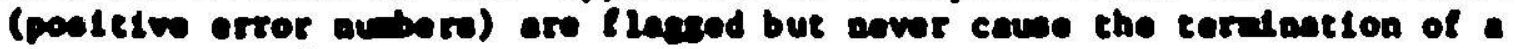

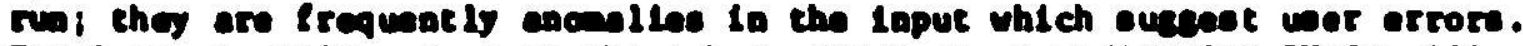

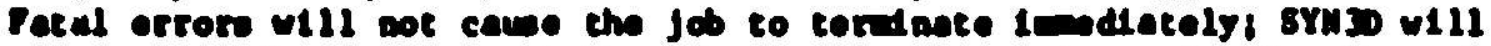

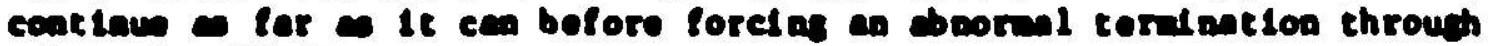
octroution indion.

\section{G. Storage Requi resents and Running times}

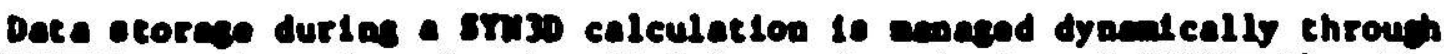

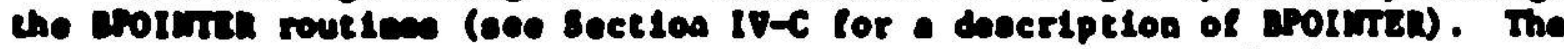

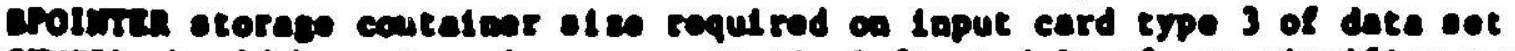

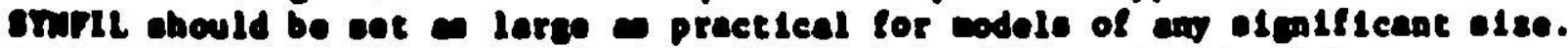

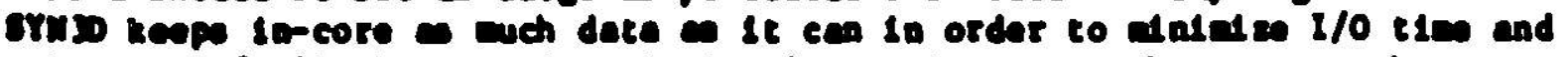

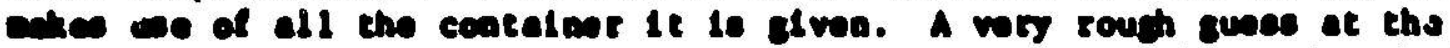

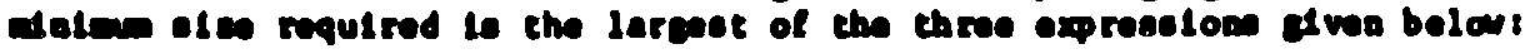




$$
\begin{aligned}
& 5000+70 \cdot G+7 \cdot G^{2}, \quad 2 \cdot I \cdot J, \\
& \text { or } 5000+7 \cdot(N \cdot G)^{2} \text {. }
\end{aligned}
$$

C 1s the number of groups. I Is the number of f1rst-dimension mesh intervals, $J$ 1. the number of second-dimention mesh Intervals, and $N$ is che maximum number of expansion functions ued simultaneously at any one axial mesh Interval. Usere of the CDC version of the Code Center SYN3D may run Into trouble at about $N \cdot G$ - 50 . Some coding changes are suggested in Section V-F which will alleviate the problen.

Runalng tine can very dranatically, depending on the couplexity of the odel and the synthesis schem wed. The time required to do the Integrals 1s proportional to the square of the number of groups (before group collapelns). the number of planar wah polats, the number of different axial 2ones, and the square of the numer of expeneion functions. The time for the -olution of the eynthes 1s equatlons 1s proportional to the number of 1terations, the nuber of axial wah intervals, the cube of the nuber of groups (after sroup collapeing) and the cube of the nuber of expanaton functions.

Table III-3 shous runalng time for two fast critical assembly nodels.

H. Applications of Synthesis

\section{Chooe 1ns Expane1 on Functions}

The cholce of expansion functions 10 very 1portant to the euccese of the synthes is approxisetion, but we w111 touch on that subject only very briefly In this report. The experiences of any usere can be found in the Rets. 7, 9, 16, 19, 20, 27-30. He v1ll eunarize here ean of Argonne's recent experience vith sYM30 calculatione of fast critical aseabiles.27-29

We have eettled on different prescrlptions for high-reactivity (cora) and lor-reactivlty (blenket and reflector) planes of a nodel. For hichreactivity planes the beet cholces ere critically buckled, elgenvalue calculations. It lo not peceseary to fino-tune the buckling to force the wo-dienneionel el igenvalue to be exectly that expected for the threedienestonal codel; 12 or $2 x$ differences are probebly close enough. We have tried expansion functions which are calculated with group- and reglordependent bucklinge deternined from an $r-2$ eodel; eyptheals calculation besed on these expencion functions give better resulte than calculations beeed on untformly buckled expanton functione, but the edvantages are probably outvel thied by the nuleance of eettins up the extre r-s eodel. Our current prectice is to choose a elngle, contant buckling.

$$
B^{2}-(\pi / L)^{2}
$$

based on an effective unreflected core height, $l$, which is within $10 \mathrm{cal}$. of the value that would be required to get the expected criticel elsenvalue. 
TABLE III-3. ARC System SYN3D Running Times and Storage Requirements for Two Fast Critical Assembly Models on the IBM 370/195. The GCFR Model was Run at Two Different Container Sizes

\begin{tabular}{|c|c|c|c|}
\hline Model & \multicolumn{2}{|c|}{ GCFR } & ZPPR3 \\
\hline $\begin{array}{l}\text { Groups } \\
\text { Spatial Mesh }(x-y-z) \\
\text { Axial Zanes } \\
\text { Expansion Functions } \\
\text { Iterations }\end{array}$ & $\begin{array}{r}11 \\
25 \times 27 \\
4 \\
2 \\
5\end{array}$ & $\times 18$ & $\begin{array}{c}28 \\
\times 25 \times 22 \\
3 \\
3 \\
4\end{array}$ \\
\hline $\begin{array}{l}\text { BPOINIER Container } \\
\text { REGION Size (K-bytes) }\end{array}$ & $\begin{array}{r}40,000 \\
650\end{array}$ & $\underset{3,000^{*}}{8,75}$ & $\begin{array}{r}60,000 \\
800\end{array}$ \\
\hline $\begin{array}{l}\text { CP Time (min) } \\
\text { WAIT Time (min) } \\
\text { Total Tims (min) }\end{array}$ & $\begin{array}{l}0.9 \\
1.7 \\
2.6\end{array}$ & $\begin{array}{l}0.9 \\
2.4 \\
3.3\end{array}$ & $\begin{array}{r}8.9 \\
3.3 \\
12.2\end{array}$ \\
\hline
\end{tabular}

This was the minimm container size, rounded to the next 1000 words, for which the GCFR model would run. 
For low-reactivity planes such as a blanket zone, or no-reactivity planes like a reflector, an eigenvalue calculation is a poor (or even impossible) way to generate characteristic planar shapes. Our current practice is to obtain expansion functions from inhomogeneous calculations in which the fixed source is the product of the diffusion coefficient in the zone of interest times the expansion function characteristic of the adjacent, higher-reactivity plane. The philosophy behind this choice is that the most Important source of neutrons in a low-reactivity plane is the leakage from a high-reactivity plane, and that leakage source is roughly proportional to:

(1) the neutron distribution in the high-reactivity plane, and

(2) the ability of neutrons to diffuse into the low-reactivity plane.

We have applied this prescription almost entirely to axlal blankets; we are not usually so interested in reflector zones that it is necessary to supply a reflector expansion function.

\section{Blanket Functions - STP016, AJC10 and ARCSP016}

An ARC System Catalogued Procedure, ARCSP016, and Standard Path, STP016, have been written to set up a fixed source for a subsequent DIF1D or DIF2D calculation of a low-reactivity expansion function. ARCSP016 is listed in Appendix J, and STP016 is 1isted in Appendix K. Basically, STP016 calls the usual ARC System geometry and cross section processin, modules to generate GEOM and XS.C.MIN f1les and then calls the module AJC010. AJC010 multiplies an input flux distribution (FR.Dl or FR.D2) by the local diffusion coefficlents and writes a fixed source f1le (ES.D1D or ES.D2D). The symbolic parameters for ARCSP016 are 11 ted in Appendix $\mathrm{J}$.

An ARCSP016 Job step is usually followed immediately by an ARCSP001 (DIFID) or ARCSPO03 (DIF2D) job step. Figure III-2 shows an input deck for calculating a blanket function for the sample problems described in Section V-E. Quirks in the DIF2D Standard Path make it necessary to include a type 19 card in A.NIP (even though the data on that card 1s not used) and to include DATASET-ES.D2SH in the DIF2D BLOCK=OLD (even though no such data set exista). Note that the A.NIP created in the first step Is passed to the second.

\section{CODE STRUCTURE AND PROGRAMMING CONSIDERATIONS}

This section describes the structure of SYN3D from a programer's standpoint. It is a survey of the several distinct code blocks making up SYN3D and 18 intended as an ald to users who wish to make changes to the code or who wish to understand the flow of the calculation.

A. The ARC System SYN3D

The differences between the Code Center SYN3D and the ARC System SYN3D are in operating environment; the bulk of the coding (specifically, 


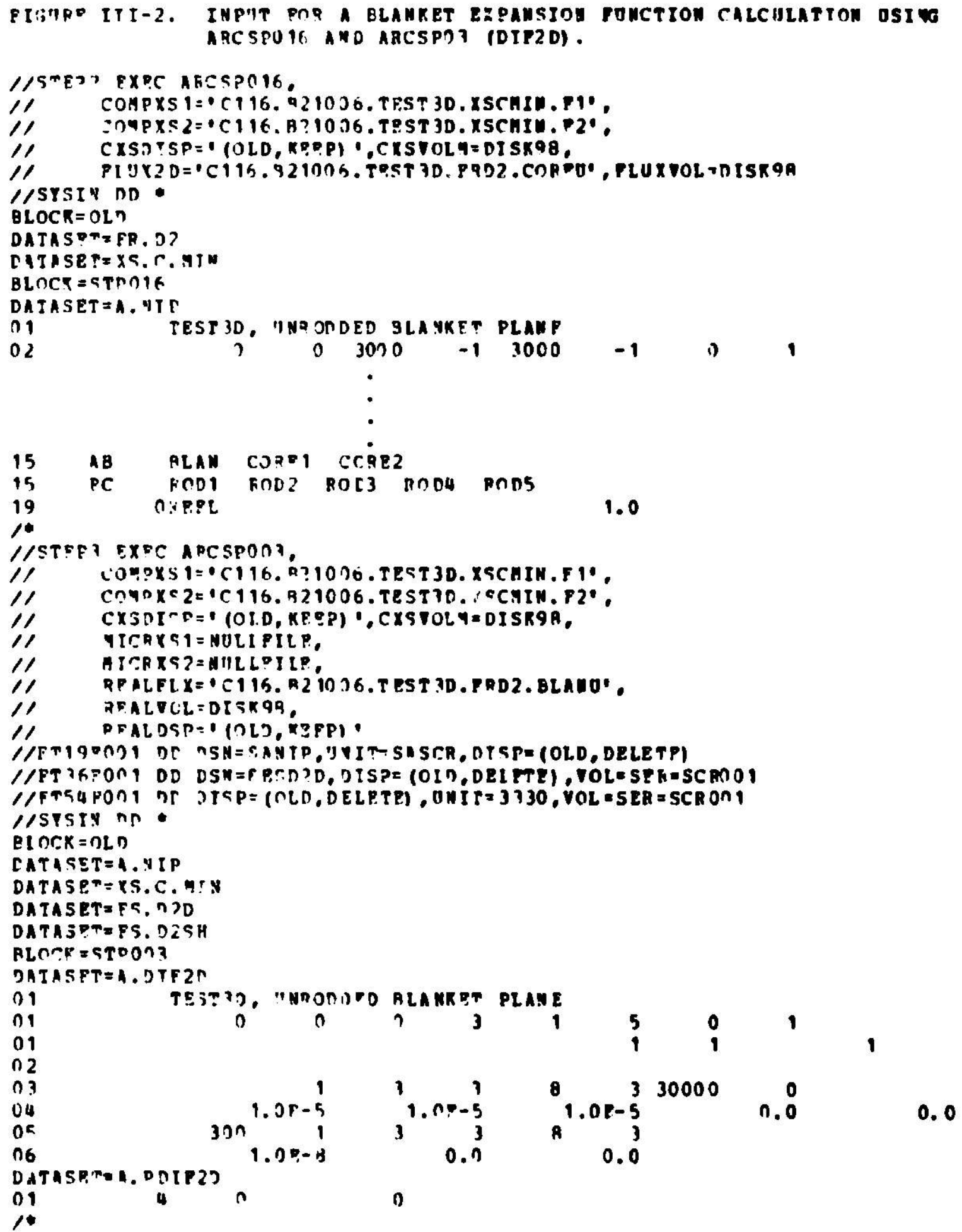




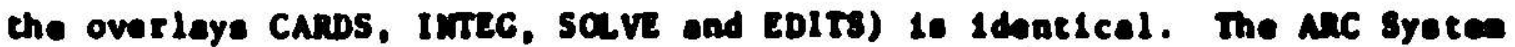
oynthea la Standard Pach, STro18, calle a nuber of woiules (anose tho:e

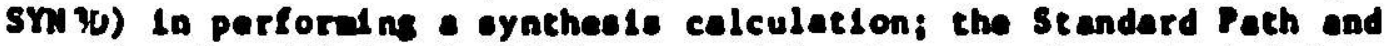
eseclated, edditluas ARC Syeter eodules heve not been lacluded in the Code Center SYN 30 pectrage.

\section{STPO18}

Appendix to a listing of the ARC syoten ayatheese steadard Path,

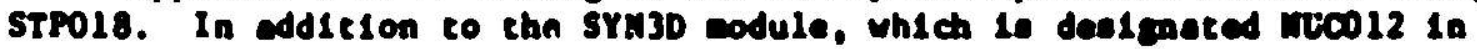
the ARC Syeten, STPO18 ary execute one or core of the follarlat eodulee:

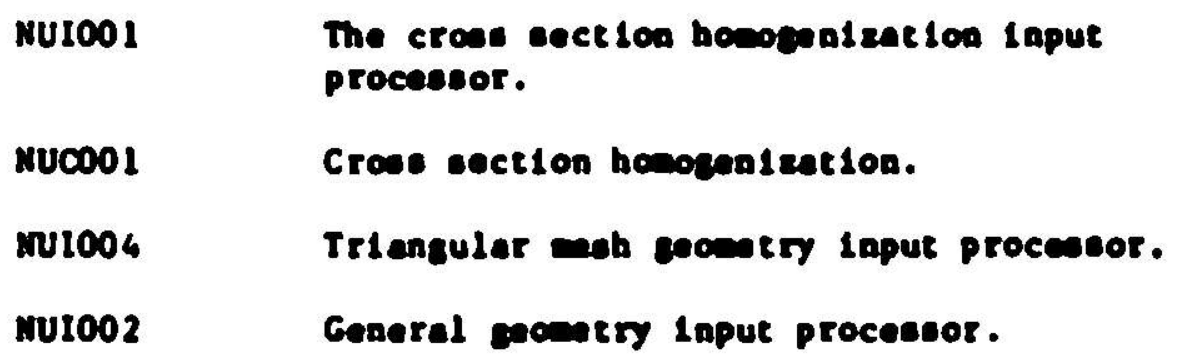

\section{File Definitions}

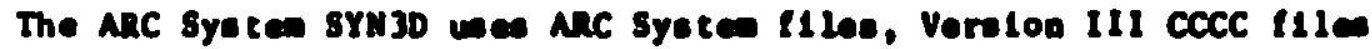
and a nuber of ecratch I11es. The ARC syeten and COCC IIles ere discuseed In Section III of thls report. The ofllclel deflatelons of the requitred Version III CCCC t1les are fiven in Appandix I elons with a discuselon of

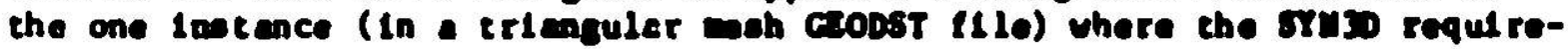
ance and the offlelel deflatisions differ. Scratch flles are daflaed in Appendlx E.

\section{B. Overley seructure}

Tigure IV-1 10 a diagren of the sYM30 codule Indient las the cellins sequences of the overlaye and ubrout lace. The Code Conter vervilon of

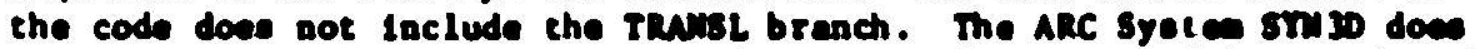
not contala the uncsc brench. The functlone of the ant driver and anch of the elx priang overlaye ere decuneed belou. Table IV-1 llete each ubroutine and comon block and lacludes a brial deceripelon of funcelon perloresd.

\section{Man Driver}

The enin Arivere of the Code Coater and ARC syeter verniose of striso

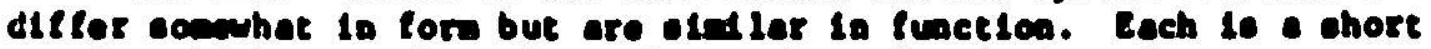
routine whlch sets the values of a nuber of coda dopadent paremeter and then calle the prienry overleve whlch pertore the eyatheale celculetion.

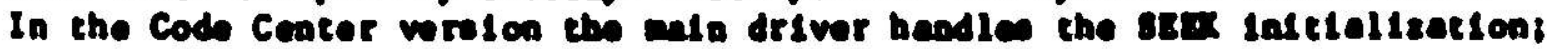
In the AnC syoten this function to eccomilebed in the stapdard Path.

\section{Tr.ngl}

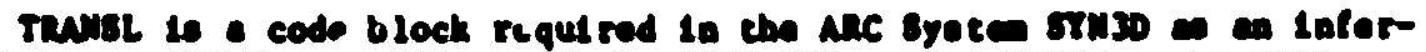

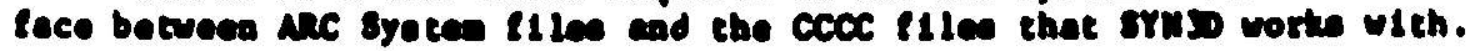




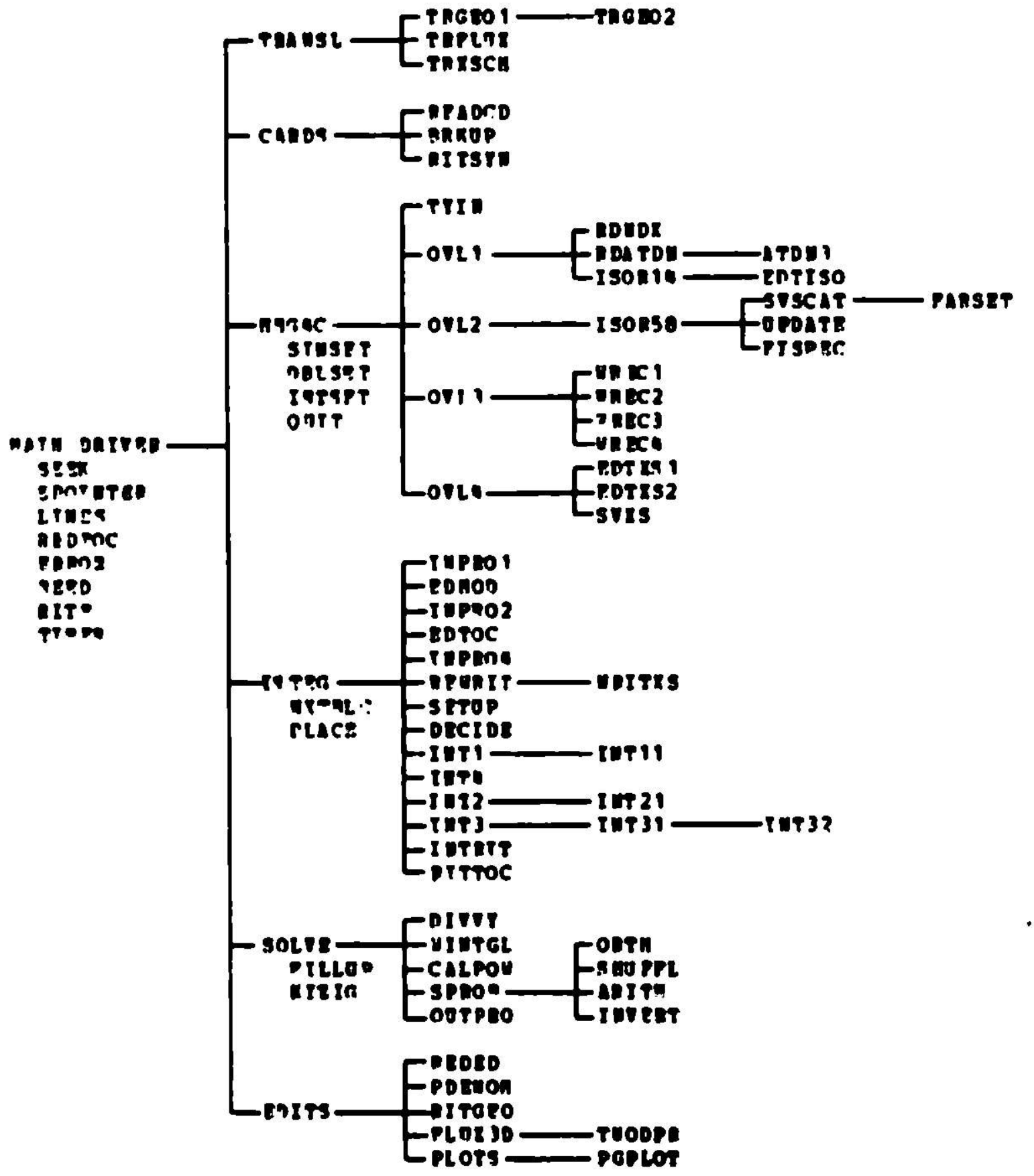

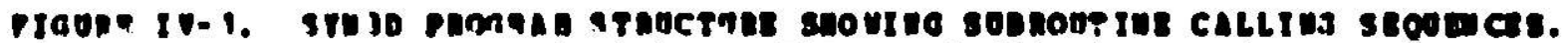

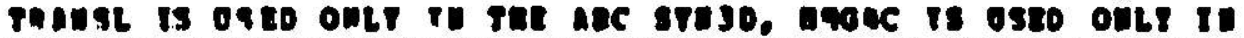

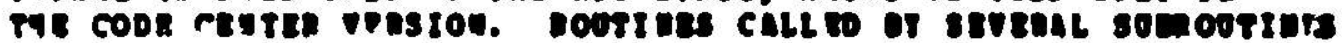

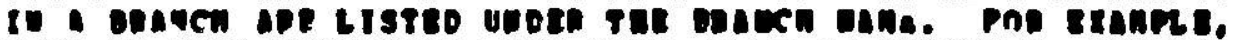

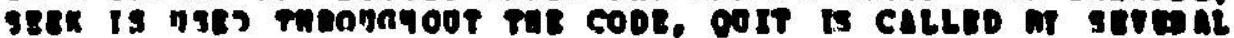
sobon tives it mugec. Etc. 


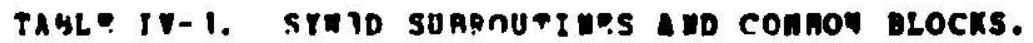

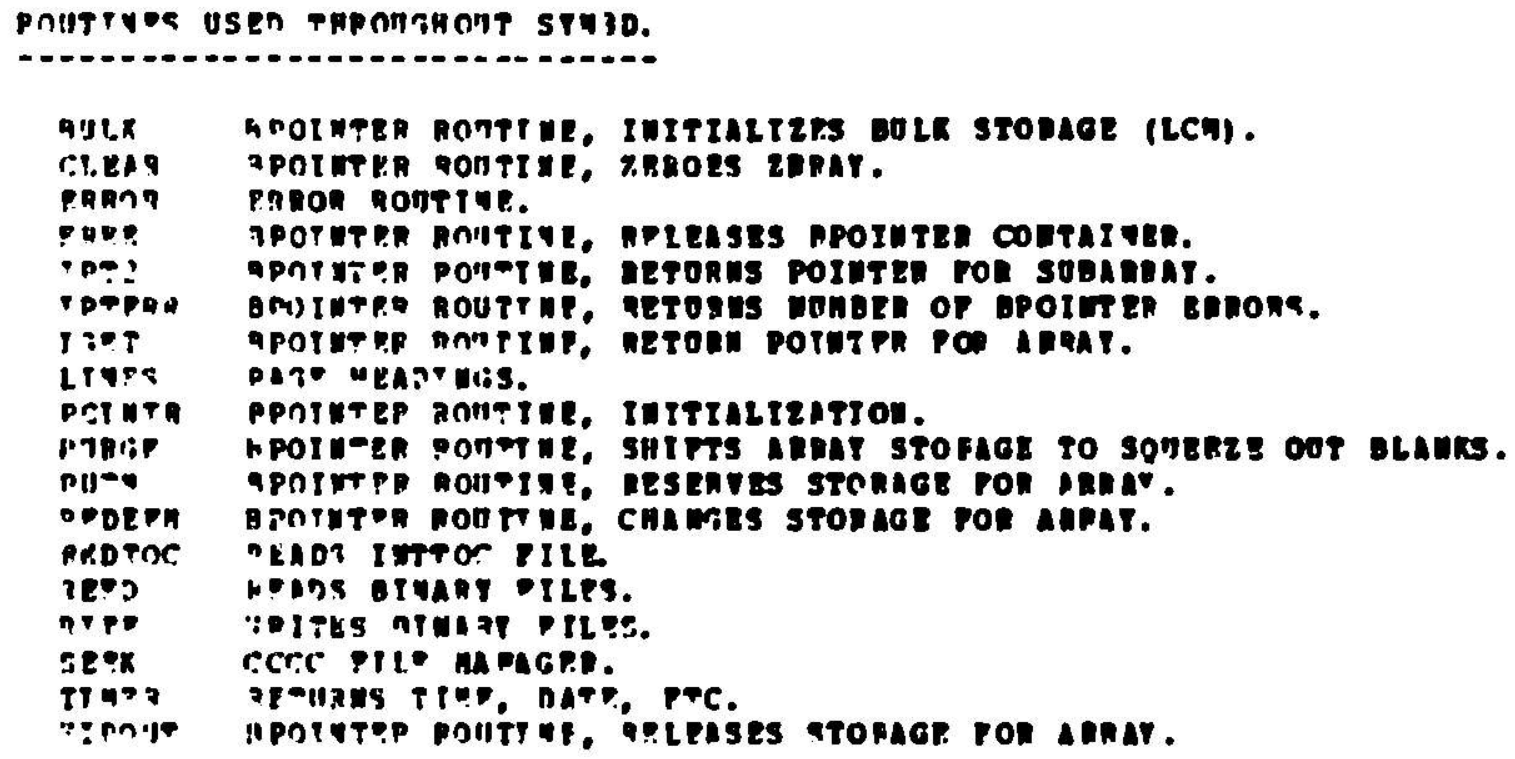


TABLF TV-1. SYN 3D SUBROUTINES AND COHHON BIOCKS. CORTINOED.

INTFG - CALCIIATES SYNTHESIS IATEGRALS.

DECIDE CHOOSPS INTEGRALS TO BE DONE ON EACH PASS TIROTGH INTEG.

EDMOD FDITS MODEL DESCRIPTION.

FDTDC TDITS TNTEGRAL TABLE OP CONTENTS.

TNPRO1 PROCESSES CODE-DEPENDENT INPUT PROH SYNCON.

INPRO2 DETERMINES HAT INTEGRALS MOST BE CALCULATED.

INDRO4 MAKES DATA MANAGPMENT DECISIONS.

INTRIT KRTTES RECORDS OP OTTPOT INTEGRAL FILE.

INT 1

INT 11

IN T 2

INT 21

TNT T

INT 31

IบT3?

I NT 4

NYTPLC

PLACE

CAICHLATION OF SCATTERING, ABSORPTION AND FISSTON INTEGRALS.

CAICULATION OP SCATTERING, ABSORPTION AND PJSSION INTEGRALS.

CALCULATION OF PLANA LEAKAGE INTEGRALS.

CALCILATION OF PLANAR LEAKAGE INTEGRALS.

CALCULATTON OP AXIAL LEAKAGE INTEGRALS.

CAICULATTON OP AXIAL LEAKAGE INTEGRALS.

CALCOLATION OP AXIAL LEARAGF INTEGRALS.

C'LCILLTION OP PIOX AND POWER INTEGRALS.

PËURNS DATA RERTITE DAPAMETERS.

RE"RTT RELHITES FIOTES, GEOHETRY DATA AND CROSS SECTIONS.

RITTOC VPITES INTTOC PILE.

SFTOP OPFNS OUTPOT INTEGRAL FILES.

WRT TYS PROCESSFS CROSS SECTIONS POP REVRIT.

SCLVF - SFTE UP AND SOLVES SYNTHESTS EOUATIONS.

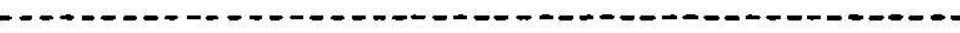

ARITH MATRIX ARITHAETIC.

CALPO: CALCULATFS TOTAL POWER.

DTVVY MAKES DATA MANAGEMENT DECISTOUS.

PILLIP BIILD EONATTON COEPPICIENT MATRICES PROH INTGLS FILE.

IVVPRT MATRIY TNVERSION.

KI?IS RETURNS AXIAL MESH DATA.

ORTH CEANGF OF VARIABLE TRANSFORMATION OF SYNTHESTS EOTATIONS.

ONIPRO FDTTS, WRITFS COHEINING COEPPICIENT PILE.

SHIPPL S!IFTS INTEGRALS IN PQQTATTUN COEFPICIENT MATRICES.

SPROR [ITREC 25 SOLJTTON OF SOIIRCE PROBLEM.

IINTII. PENRTTFS INTEGRALS TO TNTGLS BILE.

EDITS - DDIT PACKACE.

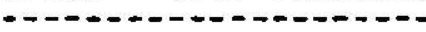

PLTX 3 RTFLIIX, ATPLTX, ENDINT AND RZFLOX EDITS AND OUTPUT PILES. PDENOA PFRTURBATIOA DENOMINATOR.

PFPLOT PPTNTPR PLOTTER.

PLOTS SETS IP COMAINING COEPPICIENT ELOTS.

REDER TNPITT PROCESSDR FOR EDITS.

RTTGFN VRTTES GRODST.

TWODLH TABLE ENITS. 
When there are Input GEOM and BC files TRANSL translates the data into corresponding GEODST f1.les. When there are 1nput FR.D2 (or FR.D1) f1les TRANSL creates the corresponding RTFLUX files. It distinguishes between FR.D2 and FR.D1 by checking the dimensionality of the GEODST f1les. Finally, TRANSL rewrites the data in an Input XS.C.MIN f1le into the COMPXS format.

\section{CARDS}

The maln purpose of CARDS is to read BCD data and write the binary file SYNCON. The value of the integer variable IWHERE (defined in the main driver and transmitted to CARDS through the common block HOWIN) Identifies the operating environment (ARC System or Code Center) and determines where the BCD data comen from.

In the Code Center version (IWHERE $=1$ ) the SYN3D input, starting with the cards-yer-card-type data (see section $V$ of th1s report), is read from the card input file. The logical unit number of the card input file, NFLIN, 18 set in the maln driver and transmited to CARDS through the common block HOWIN. In the ARC System SYN3D (IWHERE = 2) the BCD Input is contained in the ARC System BCD file SYNFIL. In this case the logical unit number is determined through a call to SEEK.

The subroutine READCD reads and stores all the BCD data. The subroutine RITSYN writes the SYNCON file, which is essentially a binary version Cf SYNFIL (see Appendix E). The first record contains a single number, the largest card type number. The second record contains the number of input cards for each card type. Each subsequent record contains the data on an input card, with the card type number (columns 1-2) onftted.

If the user wishes to Install some other input procedure, CARDS can be eliminated entirely, fust so long as it is replaced with some other method of generating SYNCON.

CARDS performs one other function. SYN3D normally operates with separate GEODST files for each of the planes of a model plus additional data in SYNCON apecifying how the planes are to be stacked together. When a single GEODST file is Input, and the "stacking" Instructions (card types 4 and 5) are onitted, subroutine BRKUP converts the single Input GEODST to a number of GEODST files of lower dimensionality and constructs the necessary card type 4 and 5 data before writing SYNCON.

HMG4C

HMG4C 1s used in the Code Center version of SYN3D to create macroscoplc cross sections from input microscoplc data; In the ARC System environment this calculation 1s performed outside the SYN3D module by the ARC System modules NUIOOI and NUCOO1, and HMG4C 1a not used. HMG4C reads the three CCCC f1les NDXSRF, ZNATDN and ISOTXS and writes the macroscopic cross section file COMPXS (see Append1X E). When a COMPXS f1le 18 input to the code, the main driver recognizes the fact and onlts the call to HMG 4 C.

After reading ZNATDN, NDXSRF and the Lotope Independent data of ISOTXS, tnto core HMG4C attempts to hold all the macroscoplc arrays which 
are to be computed in the remaining BPOINTER container space. If this 18 possible a single pass is made through the ISOTXS file and the contribution of each lsotope is added to each macroscoplc cross section of each compusition contalning that 1sotope. If all the macroscopic data will not fit in the avallable core, the code determines the maximum number of compositions which will fit in a single pass. As many passes through ISOTXS are then made as are required to process all the data. The results of each pass are written to a scratch file (HFILE) for temporary storage before being written to the output COMPXS.

The COMPX; file has provision for directional diffusion coefficient data. HMG4C only supplies default values for this data - unity for the multipliers and zero for the additive terms (see Appendix E). To use directional diffusion coefficients in SYN3D the user must supply ar: appropriate COMPXS file from outside the code.

\section{$\underline{\text { INTEG }}$}

The Integrals required for the synthesis equations (see Section II of this report) are calculated by the INTEG overlay. These integrals are written into the library files VOLINT and DIFINT, with a table of contents and supporting data for the model written to the INTTOC file (st:e Appendix E).

Subroutine INPRO1 reads Input data from SYNCON and checks it for errors. Subrout1nes INPRO2 and INPRO4 Inspect the mode1, determine what integrals are required and make data management decisions for the calculation of the integrals.

REWRIT rewrites the expansion and weighting function fluxes and the planar geometry descriptions into the REQRLX file (see Appendix E) and res.rites the required macroscopic cross sections into REQXST (see Appendix E). All the point group fluxes and mesh interval data associated with a number of adjacent rows of mesh intervals are combined into each record of REQFLX. The size of the records and, therefore, the number of rows represented in each record are determined at run time and depend on the avallable BPOINTER contalner space. The macroscopic cross sections are rewritten with the diffusion coefficlents segregrated (in separate records) from the removal and fission data. Again, the REQXST record size is determined at run time. Each record of removal/fission data contalns cross sections for all groups for as many compositions as the record size allows. Each record of diffusion coefficient data contains coefficients for all compositions for as many groups as the record size allows.

The integrals are calculated Inside a nest of loops over records of REQFLX and REQXST. Space 18 reserved for as many output records of Integral library files (VOLINT and DIFINT) as can $f 1 t$ in core with one record of REQFLX and one record of REQXST. The Integrals to be 8 aved in those output records are bullt up during loops over REQFLX records (the Inner loop) and REQXST records (the outer loop). The order in which the integruls are to be done is determined in subroutine DECIDE; in an effort to minimire arithmetic, Integrals requiring the same two functions are done olmult aneous ly. 
The manner in which the Input fluxes, geometries and cross section data are rewritten for a particular job 18 described in the SYN3D output under the heading "DATA MANAGEMENT PARAMETERS FOR INTEGRAL CALCULATION". The table of contents of the output DIFINT and VOLINT files 1 s also edited.

Although the exact size of each VOLINT and DIFINT record depends on the integrals contalned, a maximum record $81 z e$, LENINT, is set in the main driver. The current value of LENINT has been arblerarily set at 2000 words (REAL $\star 8$ words on IBM machInes).

\section{SOLVE}

Overlay SOLVE. sets up and solves the synthesis elgenvalue problem. In a series of calls to subrout Ine FILLUP the rode determines the order in which Integrals are golng to be needed during the sweep through the axial mesh (see section II-D for the solution algorithm). Whenever possible, integrale required to set up equations at one mesh interval are saved and reused at the next. The required integrals from VOLINT and DIFINT are rewritten to a scratch file INTGLS in the order in which they are to be needed. Data managewent declsions required to set up the Integral rewriting and later solution are madr in subroutine DIVW. The incegrals are rewritten in WINTCL.

The Inhomogeneous problem solution which is the basis of the eigenvalue calculation (see Section II-D) 18 carried out in subrout ine SPROB. SPROB gets up the synthesis equations with the aid of subroutine FILLUP, now operat ing in mode in which it retrieves integrals frow the INTGLS file, and subroutine SHUFF, whlch rearranges clements of the equation watrices in order to reuse integrals during the sweep of the axial wesh. During the forward-elimination part of the oweep the H matrices (see Rqs . 42 and 43 ) are scored in the file HFILE.

After the eigenvalue iterations subroutine OUTPRO edits the cosbining coefficlents and writes the combining coefficient files, DCCOEF and ACCOEF.

\section{EDITS}

The EDITS overlay handles all the optional output edite and filce.

\section{BPOINTER, A Lynamic Storase Allocstion Subprosram Packere}

BPOINTER is a general, FORTRN subprogram package which was developed to alleviate bookkeeping chores asociated with the use of dynanlc storagu allocation techniques. 25

Programe which we BPOINTER tend to be etructured in ecbroutine form. A control routine 18 used to define one or two lerge blocks of storage (called the contilnar array) and to ake the appropriate calle to BPOINTER to control the ellocation of etorage within the block(s). Calle to calculational subroutir te tranealt polnters corresponding to appropriate erray locatione through the calling sequences. All BPOINTER capabilities ara acceseed through an appropriate call to an entry point, subroutine or function eubprogran. The following cupabilltioe are avalleble in tiee BPOIMTER eysten: 
(a) Storage of data in and retrieval of data from the container array, via user defined variable arrays.

(b) Purge of variable arrays stored in the container array.

(c) Automatic "cleanup" of the contalner array when more storage is required.

(d) Re-definition of array sizes without loss of data already stored in the array.

(e) Array dump of selected Inceger, floazing point or BCD arrays in a prescribed forwat.

(f) Trace dumps of BPOINTER activities.

(8) Status reporto of the BPOINTER tables.

Detalled program documentation Including flow charts, common block Information ind subprogram descriptions 18 avallable in Ref. 25. Th1s section is intended to provide a brief description of how the program package operates. The major differences between the IBM and CDC standalone versions of the progran package are also noted.

The short example 11sted in F1g. IV-2 is intended to 1llustrate the structure of a program using the BPOINTER package. This example shows the manner in which a contalner is allocated, pointers defined and used, and the container released.

Brief descriptions of all the BPOINTER entry polnts, subroutines and functlons are given in Table IV-2.

All dy namlcally allocated array" are addressed relative to the comm block /ARRAY/ which contalns a single array elesent, BLK(1). In the IBM version of the code the element mast be declared DOUBLE PRECISION. In sowe versions of the CDC BPOINTER (not the version eccospanying the Code Center SYN30, which does not use LCM) accond comon block /ARRAY2/ Is used to eddrese ar.ays allocated to a large coro menory contalner. In versions of BPOINTER which use LCH this comon block also contalne a ingle array elesont, BLKECS(1), which ant be declarid a LEVEL 2 vartable. In the SYN3D BPOINTER package BLKECS appeare In the coding but is equivalenced with BLK. The equivalent of the large core meory contelner on IBM equipaent is a second coatelner which wa be alven a HIARCiY 1 location but 18 addresied in precisely the ean maner as the flrst (SCM) container. The one word assigned to the contalner by the source lenguage progree provides a reference addrese. At execution $t$ in enchine language rout Ines (ALLOC1, ALLOC2 on IBY, MAMGETI, VEMGET2 on CDC) are uned to ob te in the addreseses of core which are avallable to the progra for the allocation of date arzays. These blocke of core are alloceted in the following anner: 
PIARRE IV-2. ERAMFLF OP BPOINTER ISE.

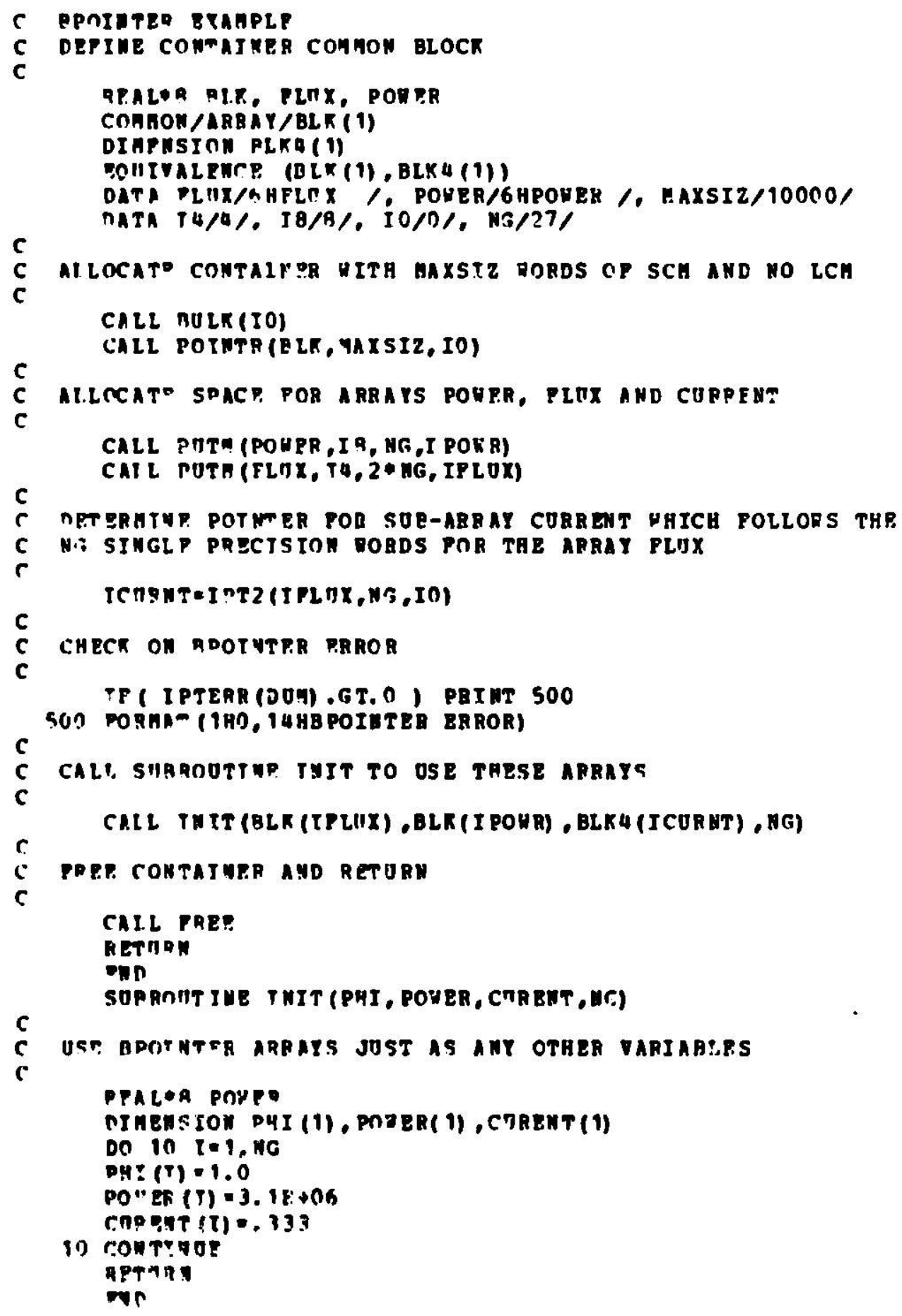


TABLE IV-2. BPOINTER Subprogram Descriptions

\begin{tabular}{|c|c|}
\hline POINTR & $\begin{array}{l}\text { Initializes tables of dynamic allocation program pack- } \\
\text { age and calls ALLOC1 and ALLCC2 to allocate container(s) } \\
\text { for variably dimensioned arrays. }\end{array}$ \\
\hline PUTPNT/PUTBLK & Dummy routine cajis PUTM to allocate array storage. \\
\hline BULK & Sets number of waids of BULK(LOM) core to be allocated. \\
\hline FREE & $\begin{array}{l}\text { Calls FREEl and FRLE } 2 \text { to release container allocated } \\
\text { by calls from subroutine POINTR. }\end{array}$ \\
\hline WIPOUT/CLEAR & $\begin{array}{l}\text { Deletes a named array from BPOINTER tables; zeroes all } \\
\text { locations assigned to a named array. }\end{array}$ \\
\hline GETPNT/GETN/DUMP & $\begin{array}{l}\text { Returns pointer for a named array; returns index in } \\
\text { BPOINTER tables of a named array; controls printing of } \\
\text { a named array. }\end{array}$ \\
\hline IGET & Returns pointer for a named array. \\
\hline IPT2 & $\begin{array}{l}\text { Returns pointer to a sub-array relative to a single } \\
\text { precision word length container. }\end{array}$ \\
\hline PUTMI/PUTB & $\begin{array}{l}\text { Enters named arrays into fast and BUIK(LOM) containers } \\
\text { respectively. }\end{array}$ \\
\hline IPTERR/NNAMSF & $\begin{array}{l}\text { Returns number of BPOINTER errors, returns number of } \\
\text { named arrays in BPOINTER tables. }\end{array}$ \\
\hline ILAST/ILASTB & $\begin{array}{l}\text { Returns word number of first available word in SCM/LCM } \\
\text { container. }\end{array}$ \\
\hline REDEF & $\begin{array}{l}\text { Dumny routine calls REDEFM to redefine size and/or } \\
\text { location of named array. }\end{array}$ \\
\hline REDEFM/REDEFB & $\begin{array}{l}\text { Redefine the size and/or location of named array within } \\
\text { BPOINTER tables and containers. }\end{array}$ \\
\hline PURGE/PURGEB & $\begin{array}{l}\text { Sift storage in SOM/LOM containers to eliminate unused } \\
\text { blocks created by WIPOUT calls. }\end{array}$ \\
\hline STATUS & Edits status of BPOINTER tables. \\
\hline PRTI 1 & Prints half word integer array from SCM container. \\
\hline PRTIIE & Prints half word integer array from LCM container. \\
\hline PRTI2 & Prints full word integer array from SCM container. \\
\hline PRT I 2E & Prints full word integer array from $\mathrm{LCM}$ container. \\
\hline PRTR1/PRTA1 & Prints full word real array from SCM container. \\
\hline PRTRIE/PRTAIE & Prints full word real array from LCM container. \\
\hline PRTR2/PRTA2 & Prints double word real array from SCM container. \\
\hline PRTR2E/PKTA2E & Prints double word real array from $L O M$ container. \\
\hline
\end{tabular}




\section{IBM Allocation}

The standard IBM macro instructions GETMAIN and FREEMAIN are used to allocate and free consecutive words of core which are avallable to the program. The designations subpool 1 and 2 are assigned to the bulk (LCM) and fast (SCM) containers, respertively. Since allocations are performed in units of 256 (eight byte) words, it is most efficient to request blocks of core in such multiples.

\section{CDC Allocation}

The COMPASS routine MEMGET uses the standard CDC macro instruction MEMORY to determine the Job's SCM and LCM field lengths. The top of the user's SCM field length is used for the BPOINTER SCM container. The user is responsible for providing enuugh $S C M$ memory to accommodate both the program and the BPOINTER container; there is currently no effective check to make sure that data stored in the BPOINTER container does not overlap code. It is assumed by the CDC version of BPOINTER that the level 2 common block /ARRAY2/ is addressed as the first word of LCM and the entire LCM field length is assumed to be avallable to BPOINTER for 1 ts LCM container.

The letters $M$ and $B$ are used as neumonics within BPOINTER to designate routines which operate on the SCM and LCM containers, respectively. Thus PUTM allocates an array in the SCM container while PUTB (which is not used In SYN3D) allocates an array which must be referenced on CDC equipment as a LEVEL 2 array. On IBM equipment without HIARCHY support (e.g. 370/195) the two contalners are equivalent. The distinctions noted above between the two dynamic containers are important on CDC equipment where the contalners are addressed quite differently and on IBM equipment with HIARCHY support where access to the BULK container (HIARCHY 1, subpool 1) is significantly slower than access to the MAIN core container (HIARCHY 0 , subpool 2).

\section{THE ARGONNE CODE CENTER VERSIONS OF SYN3D}

SYN3D is avallable on magnetic tape through the Argonne Code Center for both IBM and CDC mach1nes. Th1s section describes the contents of the tapes and outlines the steps necessary to 1mplement the code in 8 tandalone form (w1thout understanding very much about synthesis or the code 1tself). The Code Center package Includes several test problems; this section also contains descriptions and the solutions of these test problems.

\section{A. The SYN3D Package}

The Code Center SYN3D package consists of this memo and a magnetic tape containing four BCD files. There are separate tapes for IBM and CDC versions; Table $\mathrm{V}-1$ describes the format of each tape and the contents and length of each $B C D$ file. 
TABLE V-1. Description of SYN3D Tapes and the BCD Files they Contain

\begin{tabular}{lll} 
& \multicolumn{1}{c}{ IBM Tape } & \multicolumn{1}{c}{ CDC Tape } \\
Type & 9 trk. & 7 trk. \\
Density & $800 \mathrm{bpi}$ & $556 \mathrm{bpi}$ \\
Character Code & EBCDIC & BCD \\
& $(029 \mathrm{keypunch})$ & (026 keypunch)
\end{tabular}

In both casas there are no internal labels, there are 80 characters per card image and and the blocking is 3200 (Forty cards per block).

\begin{tabular}{|c|c|c|c|}
\hline \multirow[b]{2}{*}{ File Number } & \multirow[b]{2}{*}{ Contents } & \multicolumn{2}{|c|}{ Number of Card Images } \\
\hline & & IBM Tape & CDC Tape \\
\hline 1 & SYN3D FORTRAN source code & 19163 & 19163 \\
\hline 2 & Additional BPOINIER routines & 501 & 130 \\
\hline 3 & CDFILE FORTRAN source code & 665 & 665 \\
\hline 5 & $\begin{array}{l}\text { Interface files in CDFILE } \\
\text { format }\end{array}$ & 1418 & 1418 \\
\hline
\end{tabular}

TABLE V-2. SYN3D Segments

\begin{tabular}{cl}
$\begin{array}{c}\text { Overlay } \\
\text { Name }\end{array}$ & \multicolumn{1}{c}{$\begin{array}{c}\text { Card } \\
\text { Numbers }\end{array}$} \\
MAIN & $1-2154$ \\
CARDS & $2155-2971$ \\
HNG4C & $2972-6278$ \\
INTEG & $6279-12981$ \\
SOLVE & $12982-16363$ \\
EDITS & $16364-19163$
\end{tabular}




\section{SYN 3D}

The first two f1les combine to form the SYN3D code. The first file 1s SYN3D proper. The IBM and CDC versions are derlved from the same source code. Statements that are unique to IBM computers (e.8. REAL*8) are surrounded by pairs of comment cards starting with the characters "CIBM" in columns 1-4 and are commented out in the $C D C$ version. Statements that are unfque to CDC computers (e.g. OVERLAY) are surrounded by "CDC " comment cards and are commented out in the IBM version.

The card number (columns 73-80) of a particular FORTRAN instruction in the IBM veraion is the same in the CDC version. Th1s was done to avold the nulsance of maintaining entirely separate versions of the code. Future corrections to the code will be specifled in terms of this numbering system.

\section{ADDITIONAL BPOINTER ROUTINES}

BPOINTER is a set of dynamic storage allocation subroutines used in SYN3D to manage fast memory. The bulk of the coding is in FORTRP $\mathrm{s}$, 18 comon to both IBM and CDC versions of SYN3D, and is included in the SYN3D source file (cards 902-2154).

A few of the BPOINYER routines, however, are machine dependent, and these are included in file 2 of the Code Center tape. For the IBM version these additional routines are all in assembler language. For the CDC version they are partly FORTRAN (the first 108 cards of f1le 2) and partly COMPASS (the last 22 cards).

The additional BPOINTER routines can be assembled (and for the CDC version compiled) separately and Included in the main overlay of SYN3D (cards 1-2154 of file 1) at load time.

\section{CDFILE}

CDFILE (file 3) 1s a short, stand-alone, FORTRAN code which provides a crude way of generating CCCC binary interface files from BCD card Input. File 4 contains the CDFILE BCD Input file needed to produce binary interface files for a number of sample problem. If the user has other means of writing CCCC Interface files he/she may choose to isnore files 3 and 4 .

\section{B. Code Structure}

The discusetion of the structure of SYN3D Included here w1ll fust cover those aspects which af fect the linking and execution of the code in a atraightforward, stand-alone form. The functions of the several overlaye of the program are covered in more setall in Section IV.

The almplest overlay scheme (other than none at all) 1e a division Into a main overlay and five primary overlays. The names of the overlays and the corlseponding card numbers in the source coding (file 1 of the Code Center tape), are given in Table V-2. The additional BPOINTER routines (file 2) should be included in the maln overlay. 
The CDC version of SYN 3D Includes OVERLAY cards at the beginning of each of the segments 11sted in Table V-2 and, therefore, can be complied directly from tape to a load file. For those compllers which permit a mix of FORTRAN and assembler language $1 \mathrm{t}$ may be conventent to splice the additional BPOINTER routines (f1le 2 on the Code Center tape) Into the SYN 3D source file after card 2154. Alternatively, one can coup1le SYN3D and the additional BPOINTER routines separately and merge the two el ther by Inserting the additional BPOIMTER relocatable object code the proper place in the SYN3D load file or, for loadera that permit 1t, by providing the additional routines tlirough a user library.

The IBM version of SYN3D has been run at Argonne by compling the segments 1loted in Table V-2 and aseenbling the additional BrOIMTER routines to a partitioned data set and then overlaying at load time.

C. File Number Assignments

All binary f1les (Input and output Interface f1les and scratch f1les) used by SYN30 are handled through the CCCC scandard subroutines SEEK, REED and RITE. The assignment of file numbers to file names and the Initiallzation of the SEEK tables 18 done fron the SYN3D driver routine (cards 1-170 of the source code).

The file aseignents in the Code Ceater version of SYN3D are listed in Table V-3. Multiple vereions of ane files are required. Printer output 1s witten to file 6; BCD Input (1f required) is read froe file 5 . File aselgnaents can be easily rearranged by changling the coding in the anin driver; no other routines need be codifled.

All files are written eequentially. All bu one f1le (HFILE) lo read sequentially. At different etagea of the celculation HFILE 10 read both forwards and backwarda. SYN30 does not require direct accese f1les.

D. Running the Code Center SYN3D as a Stand-alone Program

The Code Center vereion of SHi3D is eet up to execute In environemate that any never have heard of the CCCC etendards. Hoet of the Input date are contalned in CCCC standard Intersace binary flles, and a anall prosran, CDFLE, 1e providad (f1le 4 of the Code Center tepe) to convert laput from BCD carde or a card lange file to the aeceseary blanty flles. Those Installatione which already can write CCCC Illes can Ifnore CDFILE. A enell anount of date epecifying laput blang f1le nubere and additional, codedependont date are reed tron cards. Even these BCD date can be elininated If destred (aee section $V-F$ ).

\section{CDPILE}

Th1e ut1lity progren we writen largely a a crude lapuc procaseor for the Code Center vereice of 8xw3D. It only procenses the eix CCCC f1les

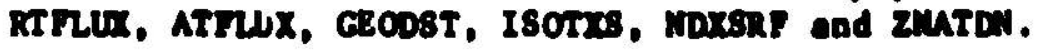

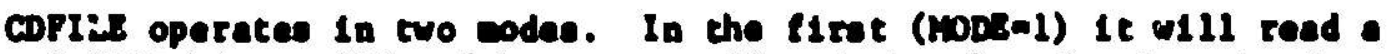
nuber of CCCC blang l1les (thoee typee lieted bove) and urlte the date In BCD card 1enge form to a elngle BCD I1le. In the second (MDE-2) it 
TABLE V-3. Files Required by the Code Center Version of SYN3D (GEODST through ZNATUN are COCC files. The rest may be treated as scratch files.)

\begin{tabular}{|c|c|c|c|}
\hline $\begin{array}{l}\text { File } \\
\text { Name }\end{array}$ & $\begin{array}{l}\text { File } \\
\text { Version } \\
\text { Nos. }\end{array}$ & Use & $\begin{array}{l}\text { Logical Unit } \\
\text { No." }\end{array}$ \\
\hline GEODST & $1-10$ & $\begin{array}{l}\text { These are the several two-dimensional } \\
\text { GEODST files required to describe a } \\
\text { three-dimensional model. GEODST, I can } \\
\text { be a three-dimensional file, in which } \\
\text { case the code will wri te two-dimens ional } \\
\text { files GEODST,2...CEODST,N. }\end{array}$ & $11-21$ \\
\hline RTFUX & $1-11$ & $\begin{array}{l}\text { RTFuX files containing expansion and/or } \\
\text { weighting functions. }\end{array}$ & $21-31$ \\
\hline ATFUX & $1-5$ & $\begin{array}{l}\text { ATFuX files containing expansion and/or } \\
\text { weighting functions. }\end{array}$ & $32-36$ \\
\hline PWDINT & 1 & Output power density, by mesh volume. & 37 \\
\hline RZFux & 1 & Zane average fluxes. & 38 \\
\hline ISOTXS & 1 & Input microscopic cross sections. & 39 \\
\hline NDXSRF & 1 & Cross-section reference. & 40 \\
\hline ZNATDN & 1 & Zone atom densities. & 41 \\
\hline INTTOC & 1 & $\begin{array}{l}\text { Input synthesis integral table of } \\
\text { contents (optional). }\end{array}$ & 42 \\
\hline INTTOC & 2 & $\begin{array}{l}\text { Output synthesis integral table of } \\
\text { contents. }\end{array}$ & 43 \\
\hline VOLINT & 1 & $\begin{array}{l}\text { Input synthesis VOLINT integrals } \\
\text { (optional). }\end{array}$ & 44 \\
\hline VOLINT & 2 & Output synthesis VOLINT integrals. & 45 \\
\hline DIFINT & 1 & $\begin{array}{l}\text { Input synthesis DIFINT integrals } \\
\text { (optional). }\end{array}$ & 46 \\
\hline DIFINT & 2 & Output synthesis DIFINT intograls. & 47 \\
\hline DOOOEF & 1 & Direct synthes is conbining coefficionts. & 48 \\
\hline ACOOEF & 1 & Adjoint synthes is combining coefficients. & 49 \\
\hline conpxs & 1 & Macroscopic cross sections. & so \\
\hline
\end{tabular}


TABLE V-3. Contd.

\begin{tabular}{|c|c|c|c|}
\hline $\begin{array}{l}\text { File } \\
\text { Name }\end{array}$ & $\begin{array}{l}\text { File } \\
\text { Version } \\
\text { Nos. }\end{array}$ & Use & $\begin{array}{l}\text { Logical Unit } \\
\text { No. }\end{array}$ \\
\hline REQFFLX & 1 & Rewritten fluxes. & 51 \\
\hline REOXST & 1 & Rewritten macroscopic cross sections. & 52 \\
\hline INTGLS & 1 & Rewritten synthesis integrals. & 53 \\
\hline IFILE: & 1 & $\begin{array}{l}\text { Scratch file used during solution. (Also } \\
\text { used by } I M G A C \text { if multipass mode is used. }\end{array}$ & 54 \\
\hline SYNCON & 1 & The imput data in binary form. & 55 \\
\hline SYNFIL & 1 & $\begin{array}{l}\text { The imput data in BCD card images (used } \\
\text { with ARC System input routines). }\end{array}$ & 56 \\
\hline
\end{tabular}

เ

These are the flle number assignments ade in the min overlay of the Code Center version of SYN3D by the Initielization call to SEEK. Since the rest of the code always uses SEEK to deteraine file nubere, it is a reletively simple job to assign entirely different file numbers by defining new SEEK cables. 
will read $B C D$ card tmages from a single $B C D$ file and write a number of binary files. File 4 of the Code Center tape is a BCD file written by CDFILE in the first mode and represents the binary files necessary for several test calculations. Section V-E describes these test calculations run by first executing CDFILE w1th MODE $=2$ and file 4 of the Code Center tape as Input and then executing SYN3D with the resulting binary files as 1nput. Table $v-4$ describes the contents of the two input cards, and Table V-5 shows exaiples of the modes in which CDFILE can be run.

CDFILE can process any number of files. The BCD file (LUNBCD) contains blocks (decks) of card 1mages stacked in the order Indicatel by (LUN(I),I-1,NFILES). There is no form of separator between blocks.

Installations with any sort of a network of reactor analysis codes can find a more efficient procedure for generating CCCC binary interface files than the CDFILE program. We will not encourage the general use of CDFILE by listing in this report the card 1mage formats for those CCCC files the code can handle. Users who have no other way to generate Interface files are referred to the CCCC standard file descriptions (see Appendix I) and to the FORTRAN source coding of CDFILE. It sufflces to say that the program oweeps sequentially through a binary file reading and writing integer and floating point data as they are encountered.

It 18 suggested that CDFILE and the test problems supplied in the Code Center SYN3D package be used as a preliminary check of the code when it is initially 1mplemented at any installation. Examples of the use of CDFILE on the ANL IBM-370 and the Lawrence Berkeley Laboratory CDC 7600 are Included later in this section.

\section{SEEK Table Initialization}

SYN3D determines file numbers for all files (except card input and printer output) by calls to the CCCC standard subroutine SEEK. Among 1 ts several functions SEEK retums an "existence flag" which specifies whether or not a file "exists" (1.e. has been previously written). Files can exist because they are Input to the code or because SYN3D writes them 1 tself. There the some mechan $18 \mathrm{~m}$, therefore, to flag an input file as "existing" In the tables kept by SEEK.

The Code Center version of SYN3D does this with a single input card, read by the main driver (at card number 134 in the SYN3D source code). Each column of this card represents a logical unit number, and a non-zero Integer in a particular colum means that the corresponding file is an existing, input file. SYN3D then sets the exiotence flag for that file through a call to SEEK with an operation code of 1 . Th1s SEEK Initialization card 18 the first card read by SEEK.

\section{The SYN 3D BCD Control Date}

Obviously, there 18 input required by SYN3D that cannot be accomodated by the CCCC etandard Interface files alone. The Code Center version of SYN 3D 1s set up to read a certain amount of data from cards placed after the SEEK Initialization card. 
TABLE V-4. CJFILE Input Data

$\begin{array}{ccc}\frac{\text { Card }}{1} & \text { Contents } & \text { Format } \\ 3 \mathrm{I} 3 \\ 2 & \text { NFILES, LUNBCD, MODE } & \text { (LUN(I) , I=1,NFILLS) } \\ \end{array}$

NFILFS $=$ The number of CCCC binary interface files to be processed.

LUNBCD $=$ The logical unit number of the $B C D$ file to which $B C D$ card images are to be written (MODE=1) or from which $B C D$ card inages are to be read $(M O D E=2)$.

MODE $=1$, data from binary files is written to the BCD card image file (file number $L U N B C D$ ). 2, data from the $B C D$ card image file is written to binary files.

LUN $(I)=$ The logical unit number of the CCCC binary interface file from which (MODE=1) or to which $(M O D E=2)$ the Ith block of data on the $B C D$ file number $L N B C D$ is to be transferred.

TABLE V-5. Examples of CJFILE Modes of Operation. These Examples Assume File 5 is Card Input, File 6 is Printer Output and File 7 is Punch Output

\begin{tabular}{|c|c|c|}
\hline Mode & $\underline{\text { LNBCD }}$ & CDFILE Function \\
\hline 1 & 6 & Reads binary files and prints contents. \\
\hline 1 & 7 & Reads binary files and punches contents. \\
\hline 2 & 5 & $\begin{array}{l}\text { Reads cards punched by a previous CDFILE run } \\
\text { (MOJE }=1 \text {, LUNBCD=7) and writes binary files. } \\
\text { The card deck should be placed inmediately } \\
\text { after the two cards described in Table V-4. }\end{array}$ \\
\hline 2 & 10 & $\begin{array}{l}\text { Readi card images from the file on logical unit } \\
10 \text { (e.g. the fourth file on the Code Center tape) } \\
\text { and writes binary files. }\end{array}$ \\
\hline
\end{tabular}


These data are provided on cards which have numbers in column 1-2 which 1dentify a particular card type. In many cases several cards of the same type may be required. The cards must be arranged in order of ascending card type number. Immediately after the SEEK initlalization card, and before the first numbered card, a card must be provided which defines (with format 24I3) the number of cards included for each card type. The number of type 1 cards is puncted in columns 1-3, the number of type 2 cards in columns $4-6$, etc.

The contents and formats of the numbered cards are given in the file description of the BCD file SYNFIL (see Appendix D). The user is also referred to the sample problem Input shown later in this section.

\section{Examples of Input Decks with Control Cards}

Figures V-1 and V-2 show Input decks set up to execuss CDFILE and SYN3D. Figure V-1 is a job run on Argonne's IBM 370/195 which link edits SYN3D from a partitioned data set (C116.B21006.EXPORT.SEGLIB) containing the segments listed in $\mathrm{T}$ able $\mathrm{V}-2$ and BPOINTER. The member ASSEM contains the additional BPOINTER routines. Figure V-2 is a job run on Berkeley's IDC 7600 which loads SYN3D from a load file (PROG) complied by FTN4.5.

\section{BPOINTER}

Storage for almost all the dimensioned arrays used in SYN3D 1s managed through the dynamic atorage allocation routine BPOINTER. At run time BPOINCER reserves a section of memory, called the "container", the length of which is specified in the input (card type 2). On the IBM 370/195 BPOINTER actually requests space from the system, and if the REGION size Is too small to hold both the program and the contalner an error message 1s printed. On CDC aystems error messages may not occur when there is Insufficlent field length for the contalner until the code tries to store data outside the designated field length for the job.

The version of BPOINTER included in the CDC package can be used to allocate storage only in SCM; at present SYN3D only uses SCM.

E. Sample Problems

\section{Model Descriptions}

The test calculations Included in the Code Center SYN 3D package are based on the three-dimensionsl, simplifled LMFBR model shown in F18. V-3. A set of three-energy group cross sections 18 supplied, as are geometry and expansion function files required for several SYN3D calculations. The model Includes rods which are banked at the midplane. The cross section data files contain microscoplc cross sections for seven lsotopes and number densitles for seven compositions. Table V-6 defines the compositions.

\section{File 4 of the Code Center Tape}

The card 1mages supplied in file 4 of the Code Center tape represent the CDFILE Input "deck" required to generate 17 aeparate b Inary Interface f1les. A description of each file 10 given in Table $\mathrm{V}-7$. The "sequence 
PIGURO, V-1. INPUT DECK UITH CONTROL CARDS POF THE TBM 370/195. EXECUTE CDPTLE TO GENFPATE INTER PACE PILES, LINR EDIT SYH3D AND EXECUTE SAMPLE PROBLEM 4. THE SOURCE CODE POR CDPILE IS IM THP PILP SCDPILE AND THP CDFILE INPUT IS IN THE PILP 6 DATA. TNTERPACE PILES NAT NEEDED JN THIS JOB ARE COPIED TO THE PILE ENOHP.

// EXEC FTHCLG

//FTH. SYSIN DD DS N=8CDPILE, DISP= (OLD, PASS), UNIT=SASCR

$/ / G O$. PTO9POO1 DD DSK=EDUMP,DISP= (HEH, PASS), UNIT=SASCR,

1/ $S P A C P=(C Y L,(1,1)), D C B=(R E C P H=\nabla P S, L R E C L=X, B L K S I Z E=6136)$

//GO.PT1OP0O1 DD DSH=EDATA, DISP $=(O L D, P A S S)$, ONIT=SASCR

//GO. PT11PON 1 DD OSN=EGEODST1, DISP= (NPV, PASS), UNIT = SASCR,

$1 / \quad S P A C F=(C Y L,(1,1)), D C B=(R E C P A=V B S, L R E C I=X, B L K S I 7 E=6136)$

//GO. ZT22POO 1 DD DSN=ERTPLUX1,DI SP= (NEH, PASS), UNIT=SA SCP,

$1 / \quad S P A C E=(C Y L,(1,1)), D C B=(A E C P H=V B S, L R E C L=X, B L K S I Z E=6136)$

/ /GN. FT23PON 1 DD DSH=ERTFLOX2,DISP= (NP., PASS), UNIT=SASCR,

$1 / \quad S P A C E=(C Y L,(1,1)), D C B=(R E C P Y=\nabla B S, L R E C L=X, B$ LKSIZE $=6136)$

$1 / 30.724 P 001$ ND DSN=8.RTPLUX3,DI SP= (NEW,PASS), UNIT=SASCR,

$1 / \quad S P A C B=(C Y L,(1,1)), D C B=(R E C P A=\nabla R S, L R E C L=X, B L K S I Z E=6136)$

//G..PT25PO01 DD DSN=ERTPLUX4,DTSP= (NEW,PASS), UNTT=SASCR,

I) SPACP- (CY L, $(1,1) 1, D C B=(R E C P H=V B S, L R E C L=X, B L R S I 2 E=6136)$

//GO. FT32PO01 DD DSN=FA TPLUX1,DISP=(HER, PASS), UNIT=SASCR,

$1 / \quad S F A C F=(C Y L,(1,1)), D C B=(R B C P M=V B S, L R E C L=X, B L K S I Z D=6136)$

//GO. FT 33FOO 1 DD DSH=6ATPLUX2, DISP= (NEK, PASS; , ONTT=SA SCA,

$1 / \quad \operatorname{STACP}=(C Y L,(1, ?)), D C B=($ RECPH= VRS, LR ECL $=X, B L K S I Z E=6136)$

//GN.FT39F001 DD DSH=ETSOTXS,DTSP= (NEW, PASS), OHIT=SASCR,

$1 / \quad S$ S ACP $=(C Y L,(1,1)), D C B=(R E C P A=V P S, L R E C L=X, B L$ LSIZP =6136)

//GO.PIUNPJOI DN DSN=FNDXSRP, DTSD= (HEW, PASS), ONIT=SASCR,

$1 / \quad S P A C P=(C Y L,(1,1)), D C B=(R E C P M=V B S, L R E C L=X, B L K S I Z E=61.36)$

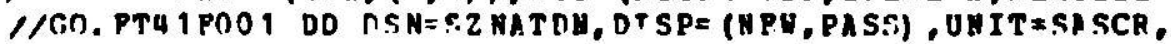

$1, \quad S P A C E=(C Y L,(1,1)), D C B=(R E C P H=V B S, L R E C L=X, B L K S$ IZE $=6136)$

/ /GO. SYSTN DC *

17 in?

$\begin{array}{lllllllllllllllll}22 & 23 & 24 & 25 & 32 & 33 & 11 & 9 & 9 & 9 & 9 & 9 & 9 & 9 & 40 & 41 & 39\end{array}$

1.

// RXEC FTXEP, EITTOPTS= I NULY'

//BDT. SYSLMNA OD DSM= EMODLIB (SYY3D), DISPE (MEN, PASS), OATT=SASCR,

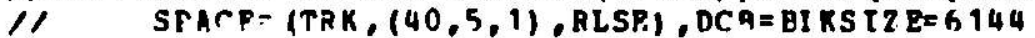

//EDT. SPGLIB ND NSH=C116. B21036. EXPORT.SEGLIB,DISP = (OLD, KEEP)

//PD". SYSIV DD *

ENTFY HAT

THCL.'IRE SEGLTA (HA JH, ASSFM)

OVEOLAT LPVELI

THCLUNB SERTTR(CARDS)

OV ORLAY LRVELI

IHCI. TDE SEGLIB (HAGUC)

OVERLIY LEVEI I

THCLUNE SEGLTB(THTES)

OVERLAY LEVELI

INCL TDE SEGLIA (SOLVP)

OVERLAY LEVELI

THCLNOB SEGLIA (EDTTS) 
FIG'JRE 7-1. TMPUT DECK AITH CONTHOL CARDS FOR THE IBY 370/195. (CONTD.)

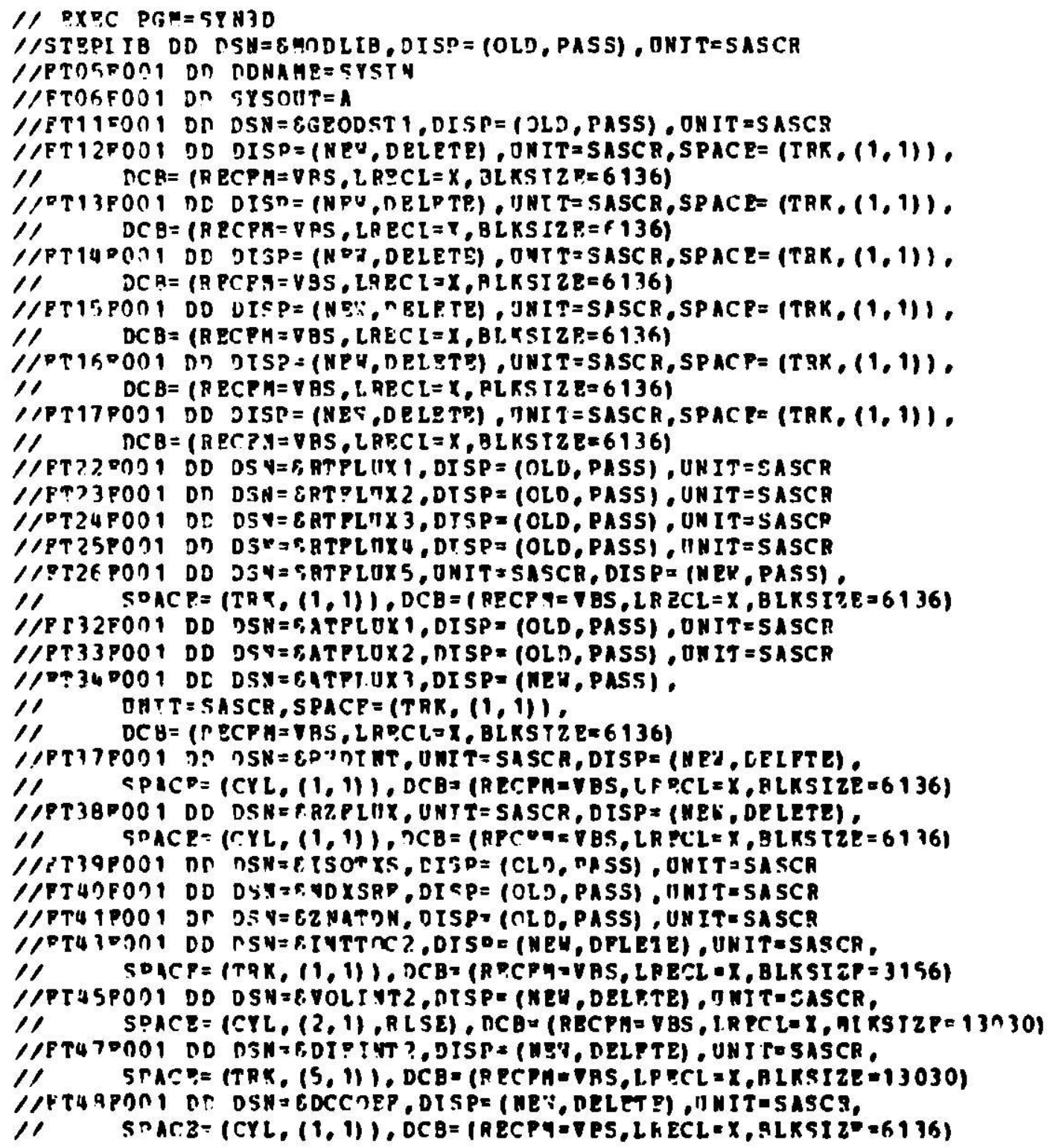


FIGIIO v-1. TNPUT MPCK UI TH CONTROL CARDS POR THE IBN 370/195. (CONTD.)

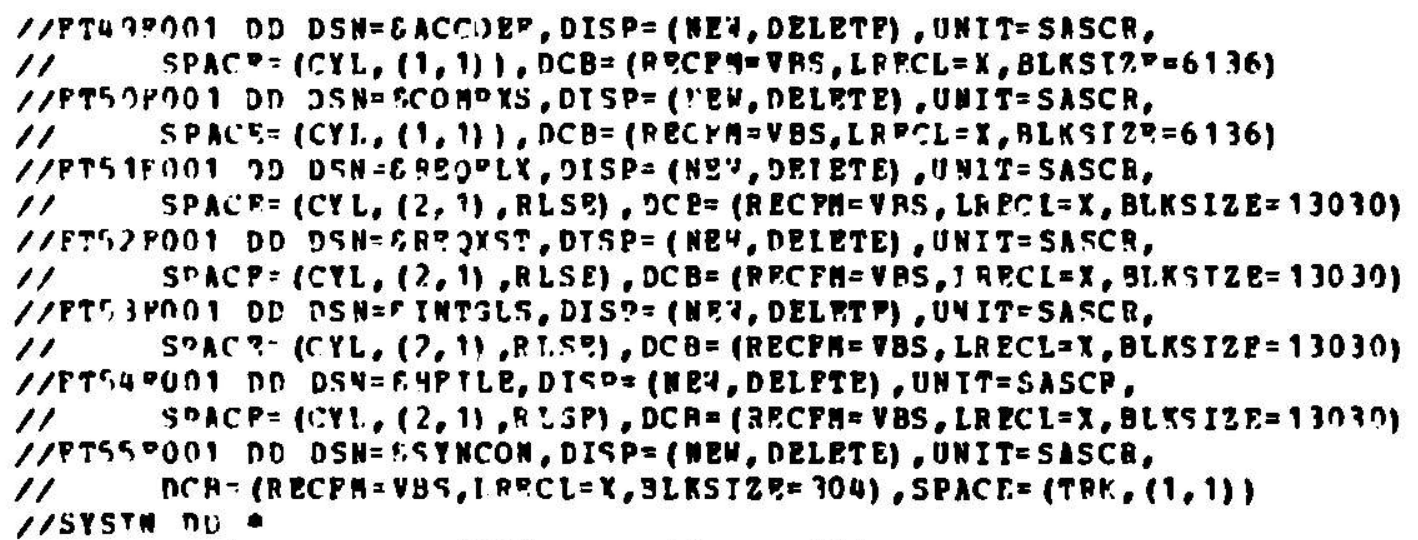
IISYSTH no

$1111 \quad 11 \quad 111$

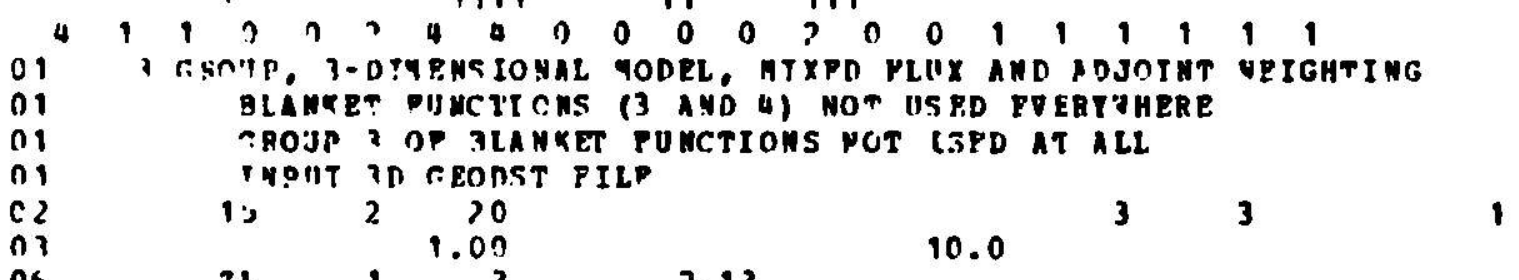

\section{6}

ne

กา

กา

07

\section{7}

กค

19

U8

13

17

16

17

19

19

20

21

3

3

2.13

2.13

0.0

0.0

0.0

100.0

0.0

0.0

$0 . n$

100.0

200.0

200.0

100.0

$2 n 0.0$

200.0

200.0

100.0

200.0 PTLI
3

3

31

1

$\begin{array}{lllll}11 & 2 & 9 & 7 & 8 \\ 11 & 2 & \text { A } & 3 & 9 \\ 18 & & & & \end{array}$




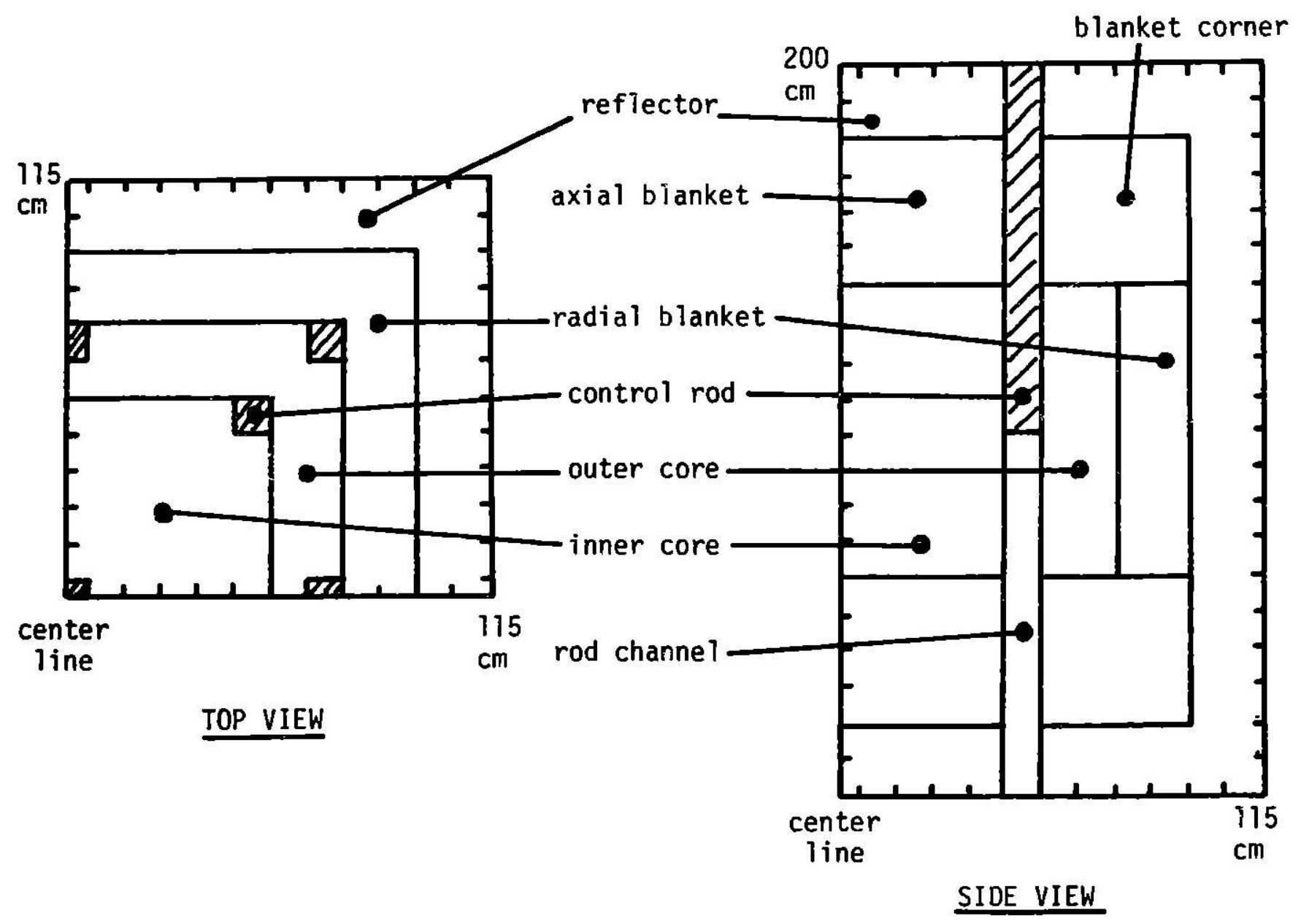

Fig. V-3. The Geometry of the 3D Test ModeI ANL Neg. No. 116-75-171. 
TABLE V-6. Compositions Used ir Test Problems

Isotope Number

Isorope Name

\section{Composition}

\begin{tabular}{cl} 
Number & Description \\
\hline 1 & inner core \\
2 & outer core \\
3 & axial blanket \\
4 & radial blanket \\
5 & reflector \\
6 & control rod \\
7 & rod channel
\end{tabular}

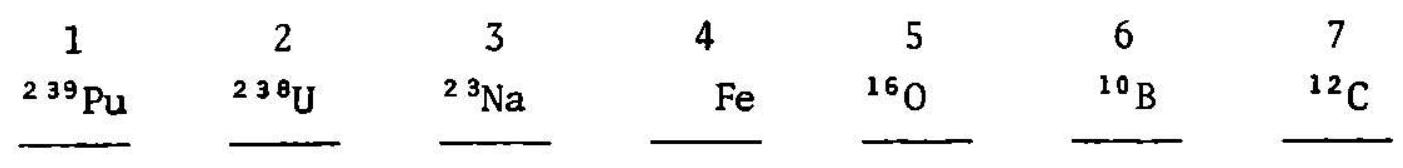

Atom Densities (Atoms/cc * 1.E-24)

\begin{tabular}{llllllll}
\hline .0011 & .0064 & .0104 & .0181 & .0149 & & \\
.0015 & .0054 & .0110 & .0181 & .0138 & & \\
& .0080 & .0088 & .0244 & .0160 & & \\
& .0145 & .0066 & .0173 & .0290 & & \\
& & .0044 & .0691 & & & \\
& & .0104 & .0181 & .0149 & .0090 & .0412 & 心 \\
& & .0220 & & & & &
\end{tabular}


TABLE V-7. Description of the CDFILE BCD Data Blocks in File 4 of the Code Center Tape

Sequence
Number

1

2

3

4

5

6

7

8

9

10

11

12

13

14

15

16

17
Interface

File

Nane

RTFLUX

RTFLUX

RTFLUX

RTFLUX

ATFLUX

ATFLUX

GEODST

GEODST

GEODST

GEODST

GEODST

GEODST

GEODST

GEODST

NDXSRF

ZNATLN

ISOTXS

\section{File Description}

A 2D flux solution in the unrodded core plane of the mode1. A buckled (transverse distance $=120 \mathrm{~cm}$. ) eigenvalue calculation $(k=.99596)$.

A 2D flux solution in the rodded core plane. A buckled (transverse height $=150 \mathrm{~cm}$.) eigenvalue calculation $(k=1.00914)$.

A 2D flux solution in the unrodded, axial blanket plane. An inhomogeneous calculation.

A 2D flux solution in the rodded, axial blanket plane. An inhomogeneous calculation.

A 2D adjoint solution in the unrodded core plane.

A 2D adjoint solution in the rodded core plane.

A 3D geometry description of the model.

A 2D geometry description of the unrodded reflector plane.

A 2D geometry description of the unrodded axial blanket plane.

A 2D geometry description of the unrodded core plane.

A $2 \mathrm{D}$ geometry description of the rodded core plane.

A 2D geometry description of the rodded axial blanket plane.

A 2D geometry description of the rodded reflector plane.

A 2D geometry description of a $12 \times 12$ mesh, uniform plane with zero-current boundary conditions.

Cross section reference data.

Atom density data.

Microscopic cross sections. 
number" indicates the order in which the card image blocks for each binary file are arranged in the card image file.

\section{Sample Problem 1}

The first sample problem is a fundamental mode calculation for the infinite medium elgenvalue and spectrum for composition 1 , the material in the Inner core of the model (see Table V-6). One of the GEODST files (sequence number 14 in Table V-7) represents a homogeneous, reflected plane containing compositinn 1 . The synthesis calculation uses this GEODST file, a flat expansion function ( 1.0 everywhere in space and energy) and zero-cu rent axial boundary conditions.

This first sample problem requires four input interface files: the uniform plane GEODST mentioned above, NDXSRF, ZNATDN and ISOTXS. The GEODST file is used only in this calculation; the other three files define the compositions and cross sections and are used in all four sample problems. The SYN3D BCD input for the job is shown in F1g. V-4.

Appendix $\mathrm{H}-1$ is the complete output (16 pages) from sample problem 1. In this one case the macroscopic cross section edits (card type 2) have been turned on to provide a printed record of their values. The infinite medium fundarnental elgenvalue for composition 1 is 1.3017 , and the eigenvector (from the synthesis combining coefficlent edits) is

$$
1.000,1.400,0.04585
$$

\section{Sample Problem 2}

One of the RTFLUX files in file 5 of the Code Center tape (sequence number 1 in Table V-7) was generated from a buckled, 2D diffusion theory calculation in the unrodded core plane of the 3D model. The buckling corresponded to a transverse slab thickness of $120 \mathrm{~cm}$., and the $2 \mathrm{D}$ eigenvalue was .99596 . Sample problem 2 is a synthesis calculation of a 3D model which is axially unfform and is described in the plane by the 2D GEODST file defining the unrodded core plane (sequence number 10 in Table V-7). The model is $60 \mathrm{~cm}$. high and has zero current and zero flux boundary conditions on the first and second $z$ boundary planes, respectively.

The unrodded core RTFLUX file is provided as the only expansion function, and the flat (UNIT) welghting option is used. Since the expansion function is "perfect" for the problem, and the flat weighting reduces the synthesis equations to the balance satisfled by the original "' calculation, SYN3D should reproduce the $2 D$ elgenvalue and yleld combining coefficients which are cosine shaped and equal in magnitude in all thrie groups. Figure $V-5$ lists the input interface files and shows the BCD input.

Appendix H-2 shows the complete output (6 pages) from this sample problem. The elgenvalue $1 \mathrm{~s} .99600$ and the combining coefficients are essentially equal in all groups. The output shown in Appendix H-2 comes from a fob run on an IBM 370/195; the same Job run on a CDC 7600 gave an eigenvalue of .99599. Small deviations are to be expected because of the finite axial mesh and the fact that on IBM machines the cross sections are stured in SYN3D in REAL*4 words. 


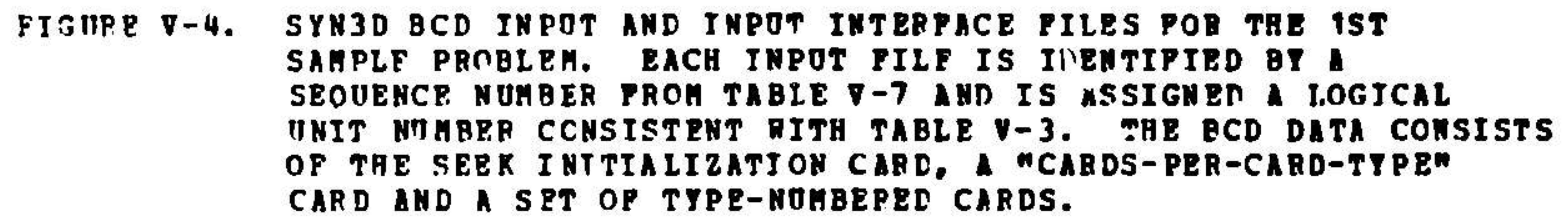

TNPUT INTERPACE FILES

SYN $3 D$ LOGICAL TNIT NUMBER 11394041

PIIE SFQUENCE VITABER (TABLE $\nabla-7$ ) 14171516

BCD INOTT

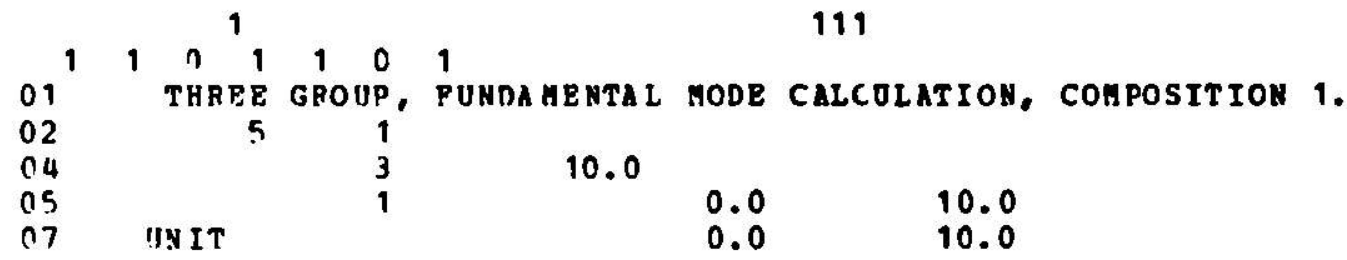

FIG ORP V-5. SYN3D BCD INPOT AND IVPOT INTERPACE FILES POR THE 2ND SAHPLE PBOBLEH. EACH INPOT PILE IS IDENTIPIED BI A SEOUENCE NOHBER PROH TABLE V-7 AND IS ASSIGNED A LOGICAL UNIT NUHER CCHSISTENT VITA TABLE V-3. THE BCD DATA CONSISTS OP THE SEER INITIALIZATION CARD, A "CARDS-PER-CARD-TTPE" CAPD AND A SET CF TYPE-NOHBPRED CARDS.

INPOT TM:BRPACE PILES

SYN3n IOGICAL UNIT NUMBER 1122394041

PTLE SEQOENCE NHABER (TABLE $\nabla-7) \quad 10 \quad 1 \quad 171516$

BCD TNDOT

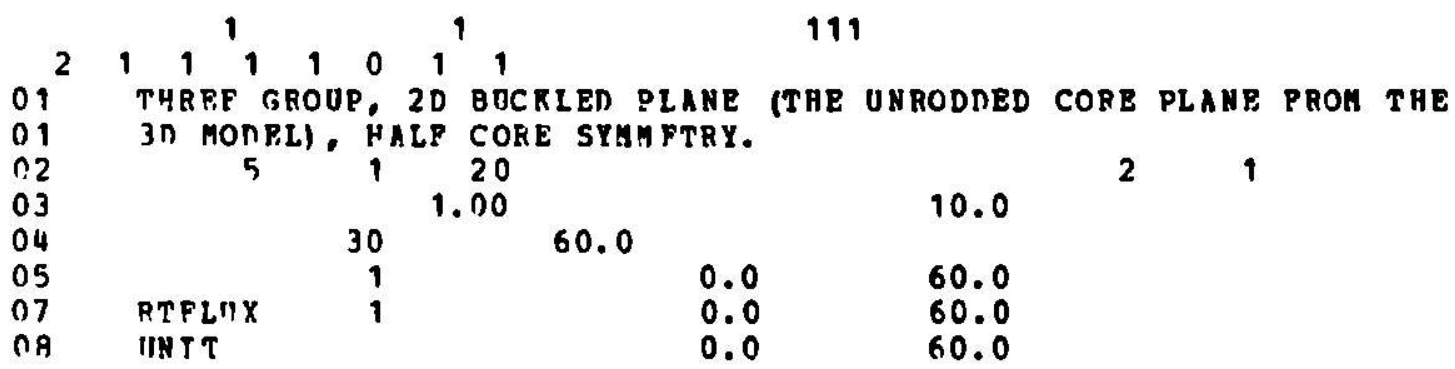


While of little practical interest, this sort of calculation is useful as a debug tool and as a consistency check between SYN3D and whatever diffusion theory code $1 \mathrm{~s}$ used to generate expansion functions. Significant discripancies might indlcate that the two codes are based on different finite-difference formulations.

\section{Sample Problem 3}

This is a calculation of the full, three-dimensional model shown in Fig. V-3. The approach used 1llustrates the way SYN3D has been used to calculate a varlety of fast reactor models. The three-dimensional model is described in terms of the $81 x$, unique axial zones (reflector, blanket and core planes, each of wh1ch may be either rodded or unrodded). The six Input GEODST files are sequence numbers 8-13 of Table V-7. Four expsnsion functions (s.2quence numbers 1-4) are provided. Two are buckled, eigenvalue calculations in the unrodded and rodded core planes. Two are from Inhomogeneous calculations in the axial blankets in which the fixed source is the product of the expansion function assoclated with the adjacent core zone and the blanket diffusion coefficient distribution. Typically, the solution in the reflector is of little interest, and reflector expansion functions are not included.

Figure V-6 11sts the Input interface f1les and shows the $B C D$ input. The core expansiton functions are used everywhere, but each blanket function 1s used only over $40 \%$ of the helght of the model. It is unlikely that a rodded (top) blanket function could contribute significantly to the unrodded (bottom) axial blanket. Economies of this sort can significantly reduce running times with 11 ttle sacrifice of accuracy.

Appendix H-3 shows selected pages of the output for this $\mathrm{Job}$. The elgenvalue is .97506 (v. .97532 for a 3D finite-difference calculation). Samples of the flux, power denst.ty and zone average flux edits are included, as is a ample printer-plot of the contributions from each expansion function to the axial flux distribution (1.e. the 3D flux inlegrated over the $x$ and $y$ dimenslons). Selective use of these plots can help identify poor cholces of expansion functions and anomalous solutions.

\section{Sample Problem 4}

Th1s last calculation is intended to 1llustrate some of the other options avallable in SYN3D. Figure V-7 11sts the Input interface files and shows the BCD Input. The model geometry is the same as that of sample problem 3, but now there is a single, three-dimensional input GEODST file (sequence number 7 in Table V-7). At the top and bot tom boundarles the boundary conditions are now logarithmic. The same four expansion functions used in problem 3 are used in problem 4 , but each blanket function $1 \mathrm{~s}$ used over half the helght of the cor's, and the group 3 flux of each blanket function is not used at all. Two of the four welghting functions are now adjolnt fluxes (sequence numbers 5 and 6 in Table V-7), and both direct and adjoint synthesis problems are solved. Sample problem 4 ls intended as an 1llustration of some of the more exotic options in the code and should not be iaker as a recomendation. Sample problem 3 is a more typical example of an application of SYN3D. 
FIGUDE V-6. SYN3D BCD INPOT AN D INPOT INTERPACE PILES POR TRE 3RD SAMPLF PROALEH. FACR IMPET FILE IS IDENTIPIED BT A SEQUENCE NUNRER PROA TABLE $\nabla-7$ AUD IS ASSIGNED A LOGICAL INIT NHABER CCXSISTENT NITH TABLE V-3. THE BCD DATA CONSISTS OP THF SEPK INIT TALIZATION CABD, A "CARDS-PER-CABD-TYPE" CARD AVD A SET OF TYPE- HTHBERED CARDS.

INPIT INTERPACE FILES

SYN 3D LOGICAL NNTT NUHBER

$\begin{array}{lllllllllllll}11 & 12 & 13 & 14 & 15 & 16 & 22 & 23 & 24 & 25 & 39 & 40 & 41\end{array}$

FILE SEQUENCE NTMAER (TABLE V-7)

PCD INDIT

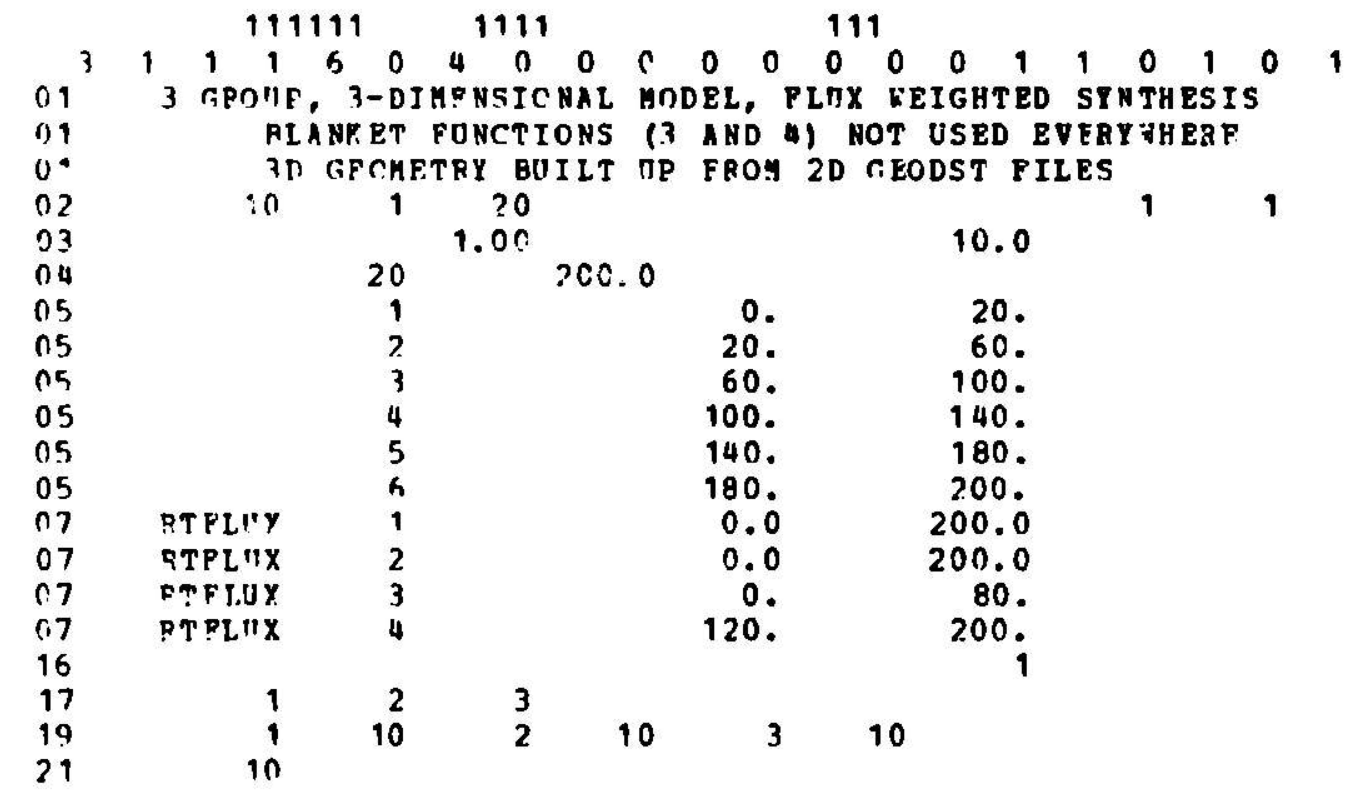




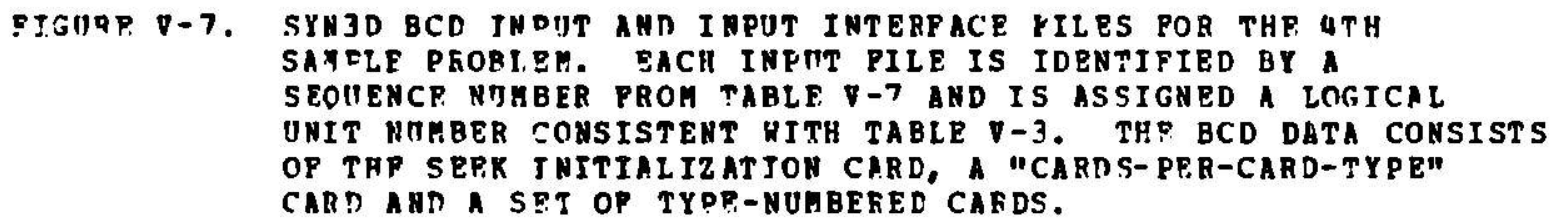

INPUN INTEP PACE F TLES

SYN 39 LOGICAL INTT NMMRER

$\begin{array}{llllllllll}11 & 22 & 23 & 24 & 25 & 32 & 33 & 39 & 40 & 41\end{array}$

RTIP SFCUFNCF NUMAFR (TABLF $V-7$ )

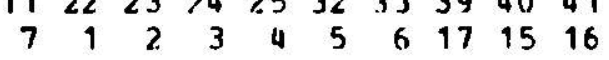

BCD +N PII

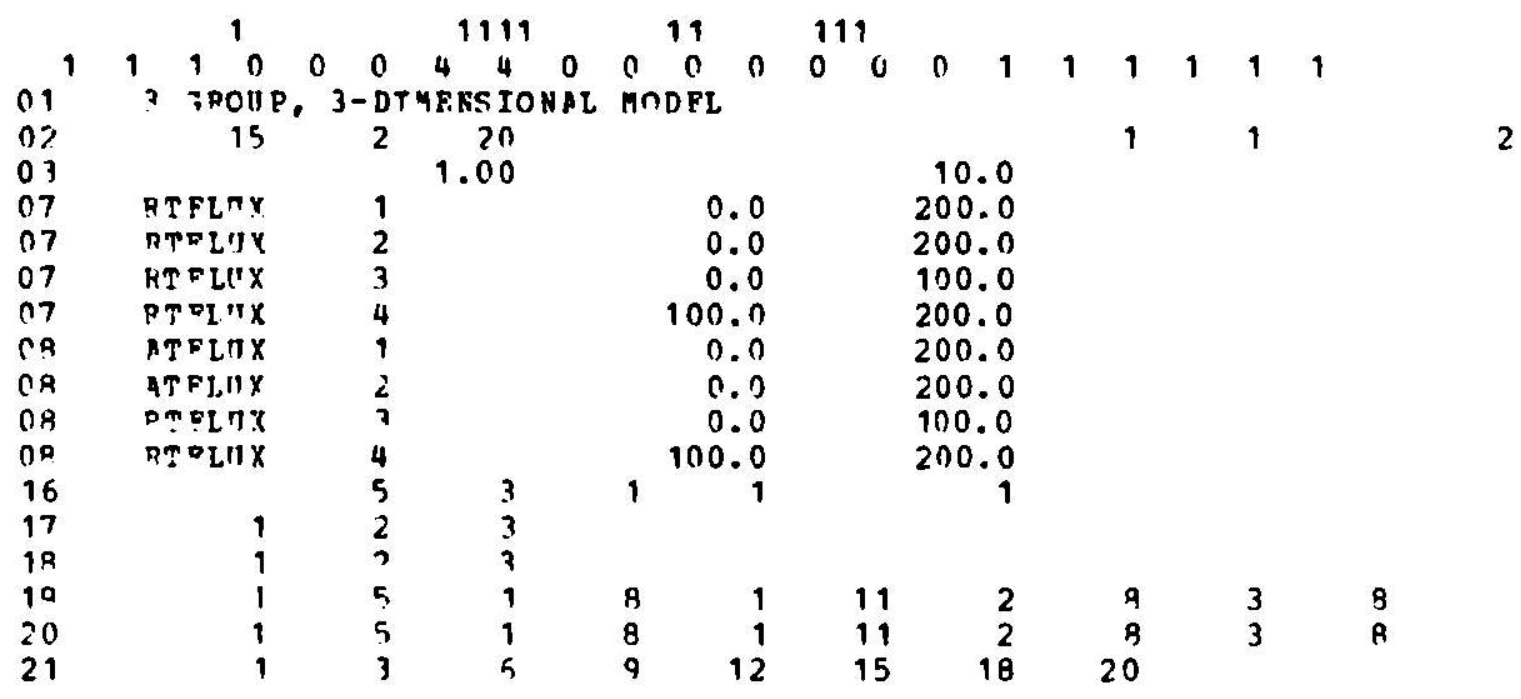


Appendix H-4 shows selected pages of output for this job. The eigenvalue is .97520 (vs. .97532 for a 3D finite-difference cajculation). The Input decks shown in Figs. $\mathrm{V}-1$ and $\mathrm{V}-2$ are set up to run this sample problem.

F. Suggested Modifications to the Code

\section{TIMER}

TIMER is a CCCC subroutine with a variety of options for returning elapsed and clock time, job identification, data, etc. Every computer Installation has its own set of FORTRAN callable system routines for providing some or all of this information, and so no universal TIMER can offer all options. The version of TIMER included in both IBM and CDC versions of the Code Center package returns elapsed $C P$ time; in addition the IBM version returis the date and wall clock time. SYN3D uses TIMER to determine the time spent in the scveral parts of the calculation and to provide the date and clock time for file identification and page headers.

\section{SEEK Inftialization}

Those installations which have their own SEEK and an established SEEK initialization procedure will want to make some changes in the main driver of SYi3D. In the Code Center SYN3D the correspondence between file name and logical unit number is set by the DATA statements defining the elements of the arrays DSNAME and NREF. The file named DSNAME(N) is assigned to $\log 1 \mathrm{ca} 1$ unit number $\operatorname{NREF}(\mathrm{N})$.

On the first call to SEEK (with an operation code of 3 ) the entire DSNAME array (up to the \$), as well as the NREF array, is transferred to a table in the subroutine. Files with the same names are assigned version numbers in ascending order. Blank file names are Ignored. Existence flags are initialized to 0 (the file has not been written).

The main driver then reads the SEEK initialization card and looks for columns which contain a number greater than zero. It interprets column numbers as logical unit numbers and for a non-zero entry in a column requests the corresponding filf: name from SEEK (with an operation code of 5 ). When it has the file name and version number it calls SEEK with an operation code of 1 to set the existence flag.

Changes to any part or all of this inftialization procedure can be made by recoding the main driver and SEEK. No other routines are affected.

\section{Eliminating BCD Input Data}

Some 1nstallations may prefer to run SYN3D in a mode that completely eliminates direct. BCD card input. LASL, fnr example, uses a general input processor which converts $B C D$ cards to binary interface f1les; ANL has the ARC System input processors SCAN and STUFF which convert BCD cards to BCD files.

The first overlay in SYN3D, CARDS, reads BCD data ef ther from the BCD card input file or the BC: disk file SYNFIL, depending on the value of the 
sentinel IWHERE set in the main driver. CARDS then rewrites the input data to the binary file SYNCON (see the Appendix $E$ for the file description). SYNCON is a binary version of the BCD card input; the data on each card is rewritten to an unformatted record. The user can write SYNCON outslde of SYN3D and drop the call to CARDS from the main driver. The rest of the code is unaffected.

CARDS provides one function which is lost if the overly is eliminated. For historical reasons, SYN3D was set up to bulld 3D (or 2D) geometries from 2D (or 1D) GEODST files. After the code was written an option was added to permit an 1nput 3D (or 2D) file. CARDS was coded to break up an input 3D (or 2D) GEODST into the required number of 2D (or 1D) f1les and to create the additional, required BCD input data (cards types 4 and 5) before writing SYNCON. If CARDS is eliminated the user must specify 3D (or 2D) models in terms of 2D (or 1D) GEODST files.

\section{Matrix Inversion and Multiplication Subrout 1nes}

The matrix inversion routine INVERT and matrix arithmet1c rout1ne ARITH which are supplied with the Code Center SYN3D are coded to minimlze running time for large problems (many groups and/or expansion functions) when the code is complled under the IBM FORTRAN H Extended compller and run on the $370 / 195$. There may be nore efficlent routines avallable for other computers.

Restrictions on P: oblem Size in SOLVE

It is unlikely that the problem size 1imitations (see Section III-G) will affect users who have large IBM computers; more than enough fast core should be avallable. CDC users (with a 50K core limitation), however, may reach the problem size limit when the number of energy groups (after group collapsing) times the number of expansion functions used concurrently at any one axial mesh interval is about 50 .

The difficulty is with the solution overlay SOLVE. As 1 t is currently written SOLVE must have enough storage to keep six matrices in-core at the same time. These matrices are $A_{k}^{-}, A_{k}^{0}, A_{k}^{+} H_{k}, R E M$ and FIS (see Eqs. (38), (39), (4i), (42), (43) and Section III-D). With a modest investment in programming some or most of these matrices could be kept in LCM. 
APPENDIX A

Code Abstract

1. Name or Des1gnation - SYN3D

2. Computer for which Program 1s Designed and others upon which it is Operable - IBM 370/195, CDC 7600 .

3. Description of Problem or Function - SYN3D solves the direct and adfoint, diffusion theory, static eigenvalue equations in two and three dimensions. The geonetrles avallable are $x-y, r-z, x-y-z$ and triangular-z.

4. Method and Solution - SYN3D uses single-channel spatial flux synthesis to calculate approximate solutions to the three-dimensional (or twodimensional) diffusion theory difference equations. Synthesis expansion functions must be supplied by the user from two-dimensional (or one-dimensional) finite-difference calculations performed by some other code. SYN3D sets up the synthesis equations and solves them by power iteration with Wielandt acceleration. Each 1teration 18 an exact inversion of the block-tridiagonal synthesis equations by forward-elimination, backward-substitution.

5. Restrictions on the Complexd ty of the Problem - For the most part, SYN3D uses vartably dimensioned arrays and disk scratch filcs to manage data for any size problem in the avallable fast core. The only serious 11mitation is on the product of the number of groups and the naximum number of expansion functions used at any particular axial elevation; fur CDC users (w1th a $64 \mathrm{~K}$ machine) this product is 1 imited to about 50 .

6. Typical Running Time - Exclusive of the time required to generate expansion functions SYN3D w11l solve an 11-group, 12,000 mesh point model with two expansion functions in .9 minutes (CPU). A 28-group, 30,000 mesh point model with three expansion functions requires 8.9 minutes (CPU). These times are for jobs run on an IBM 370;i95. For large problems the PP time is less than the CPU time.

7. Unusual Features of the Program - The difference equations SYN3D solves are the mesh-interval-centered type. Expansion functions should be generated using diffusicn theory codes solving the same equations (e.g. 2DB, CITATION, VENTURE). The code is designed with restart capabilities which reduce, on the averige, the running times for Individual problems when a serles of similar problems ls to be run. SYN3D requires input cross sections, expansion functions and geometry descriptions in the Version III formats defined by the Committee on Computer Code Coordination (CCCC). Speclal options Include group collapsing and the use of different expansion functions in different axial zones of the model. 
8. Related and Auxillary Programs - SYN3D requires binary Input files contalning cross sections, expansion functions and geometry descriptions. Although a small program is provided with the code to read these data from cards, the user may wish to use other programs which generate CCCC files. A finite-difference, diffusion theory program is required to generate expansion functions.

9. Status -

10. References - C. H. Adams, "SYN3D - A Single-Channe1, Spatial F1ux Synthesis Code for Diffusion Theory Calculations", ANL 76-21, Argonne National Laboratory (1976).

11. Machine Requirtments - The code requires at least a $35 \mathrm{~K}$ full-bi: rd core to execute small problems and runs more efficiently with larger storage. SYN3D does not use BULK (IBM) or LCM (CDC) storage. Depending on the complexity of the problem, SYN3D may require up to 45 logical units.

12. Programming Language Used - FORTRAN IV. Both IBM and CDC version of SYN3D contain a few routines written in assemb ler language.

13. Operating System or Monftor under which Program is Executed - The IBM version of SYN3D has been complled and executed under OS-370 with the FORTRAN H Extended compiler. The CDC SYN3D has been complied and executed at Berkeley Laboritory under the COKE System with the FORTRAN FTN4.5 compller.

14. Any Other Programing or Operating Information or Restrictions -

15. Name and Establishment of Author -

C. H. Adams

Applied Physics Division

Argonne National Laboratory

Argonne, Illinols 60439

16. Materlal Avallable - Separate tapes are avallable for the IBM and CDC verstons of SYN3D. The SYN3D package Includes:

Source decke for SYN3D and auxillary Input program, Input for sample problems, Reference report.

17. Category - C

Keywords - two-dimensional, three-dimenslonal, diffusion equations, synthes1s, $x-y, r-z, x-y-z$, triangular-z. 
APPENDIX 9. STPOIO - TYE ARC SYSTEM STANDARD PATH POR SYNSD.

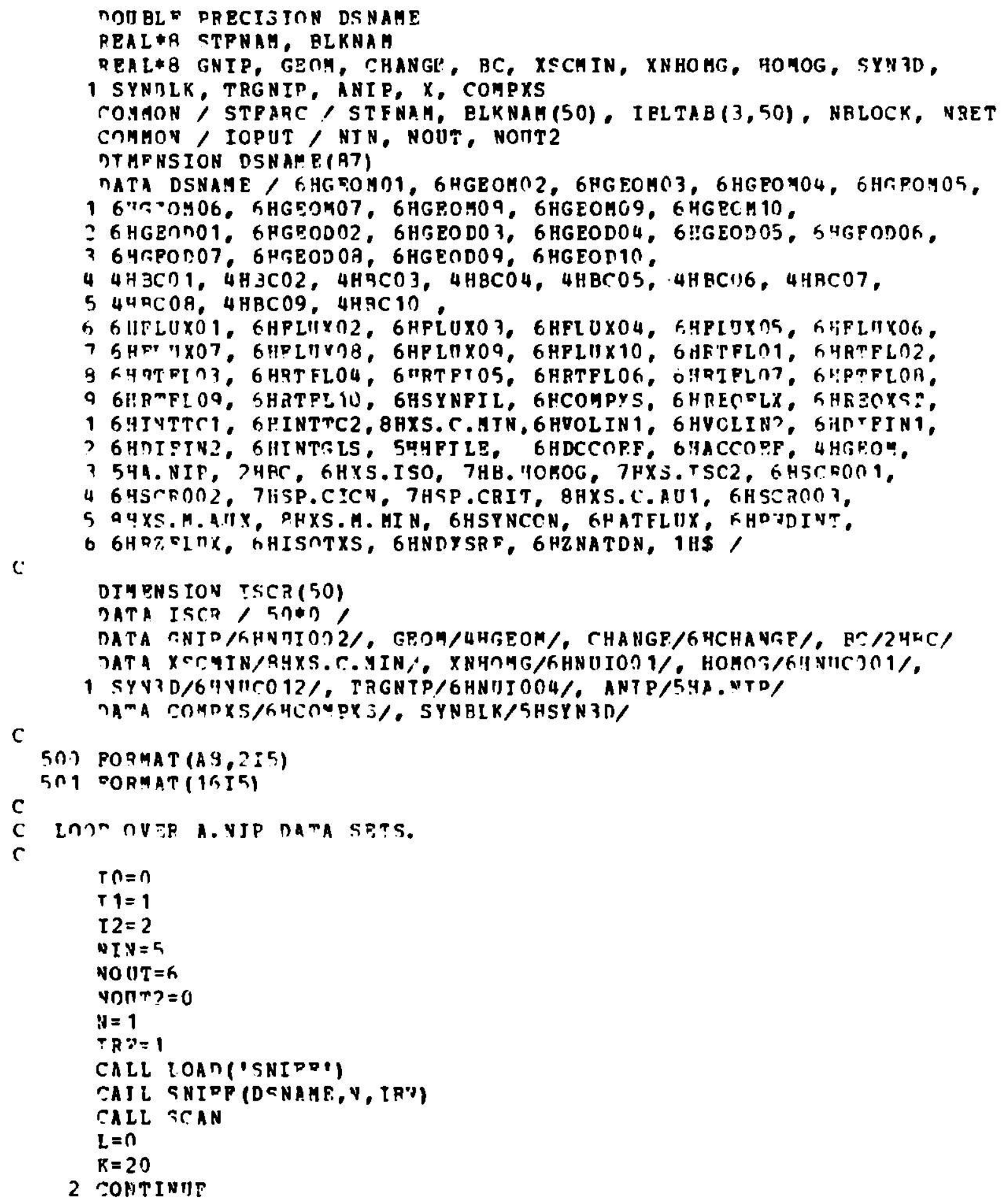


APPEYDIX B. STP018. CONTINTED.

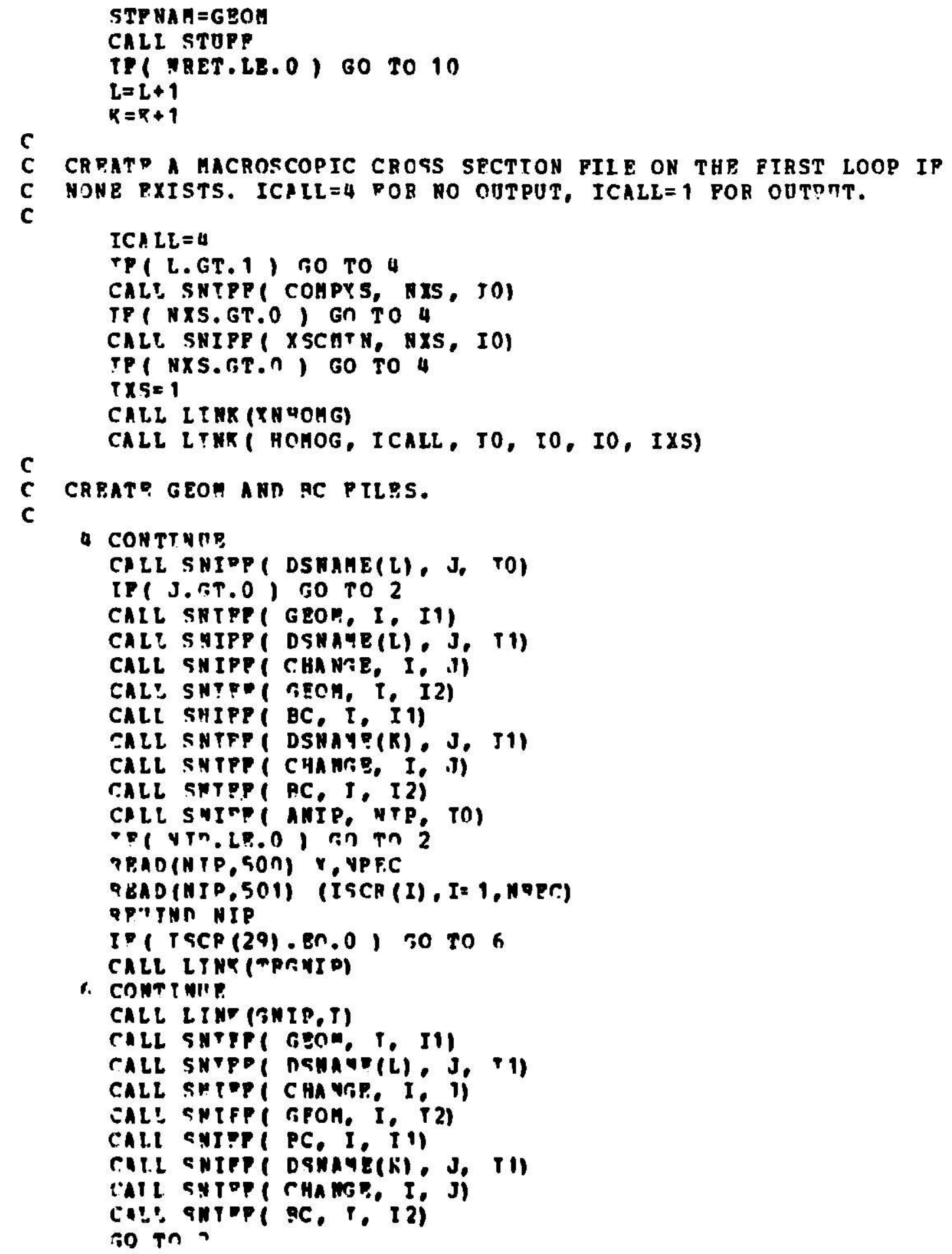




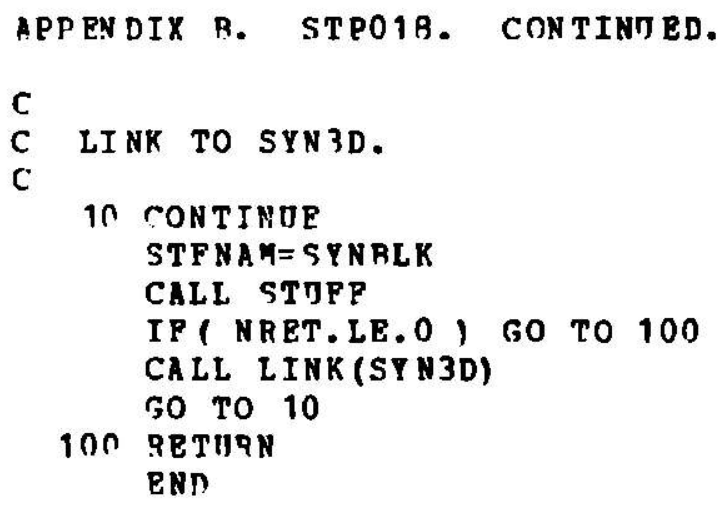


APPENDIX C. ARCSP018 - THE ARC SYSTEA CATALOGUED PROCEDIJE FOR SYN3D.

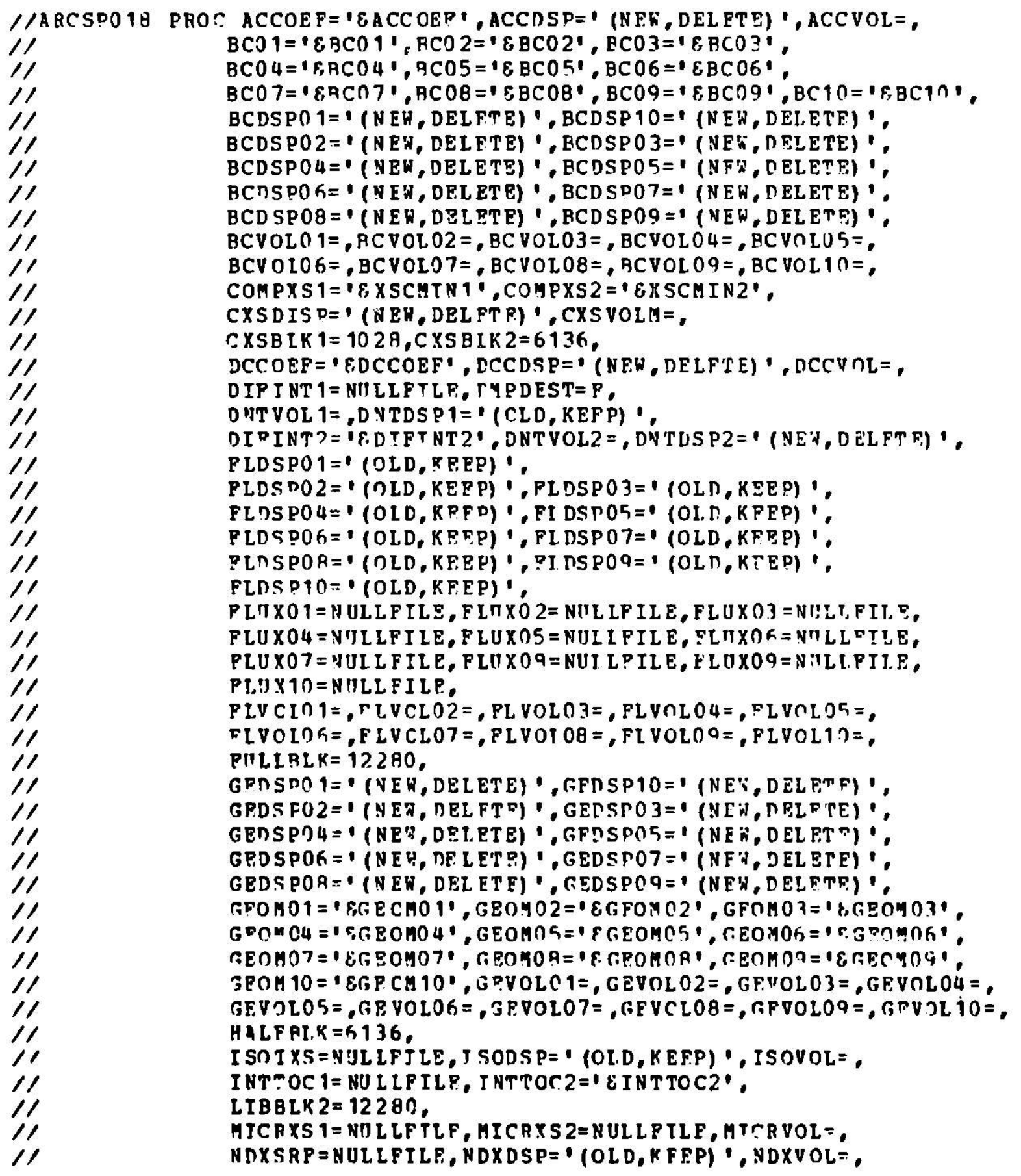


APPENDIX C. ARCSP018. CONTINUED.

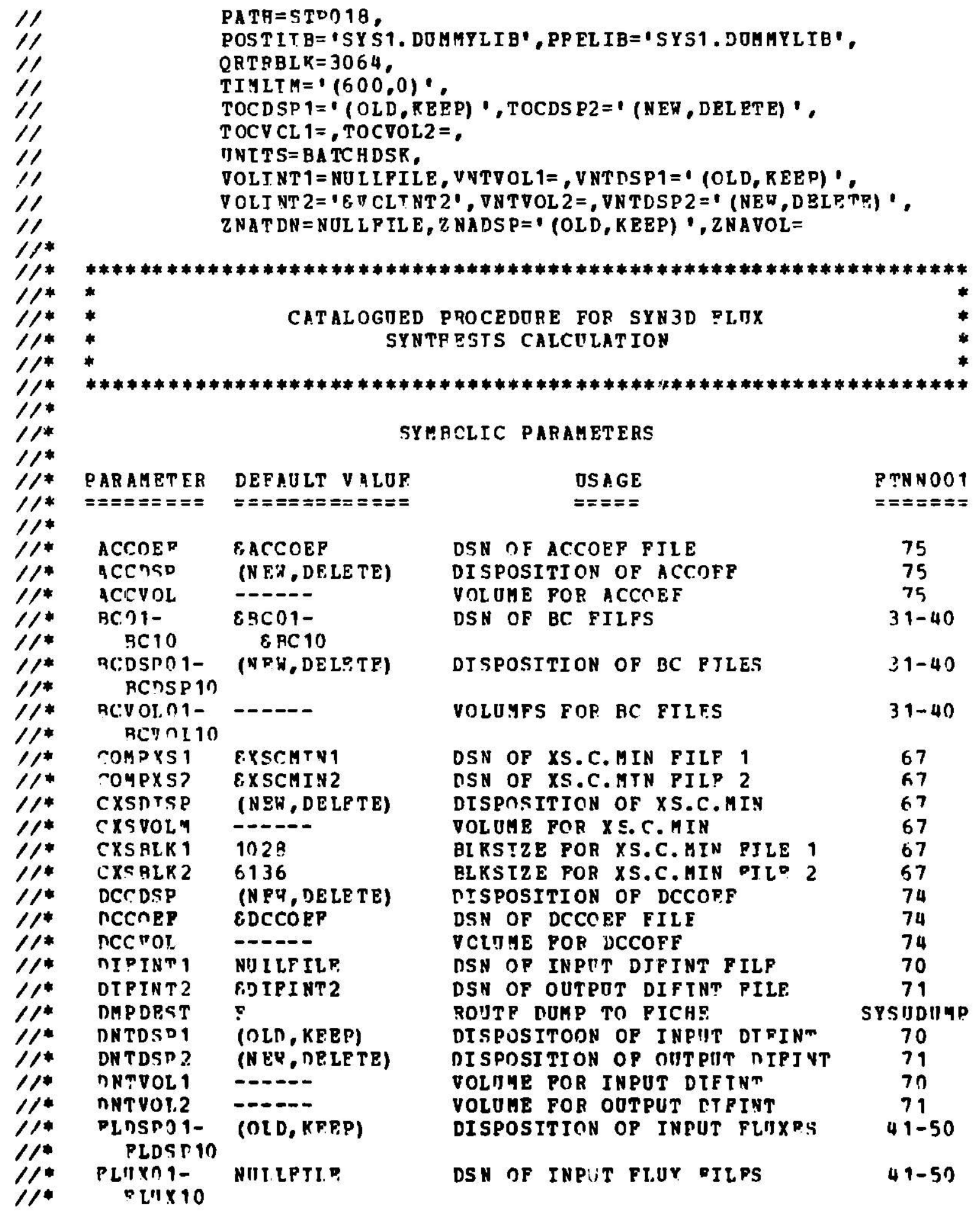


APPENDIX C. ARCSPO18. CONTINOEC.

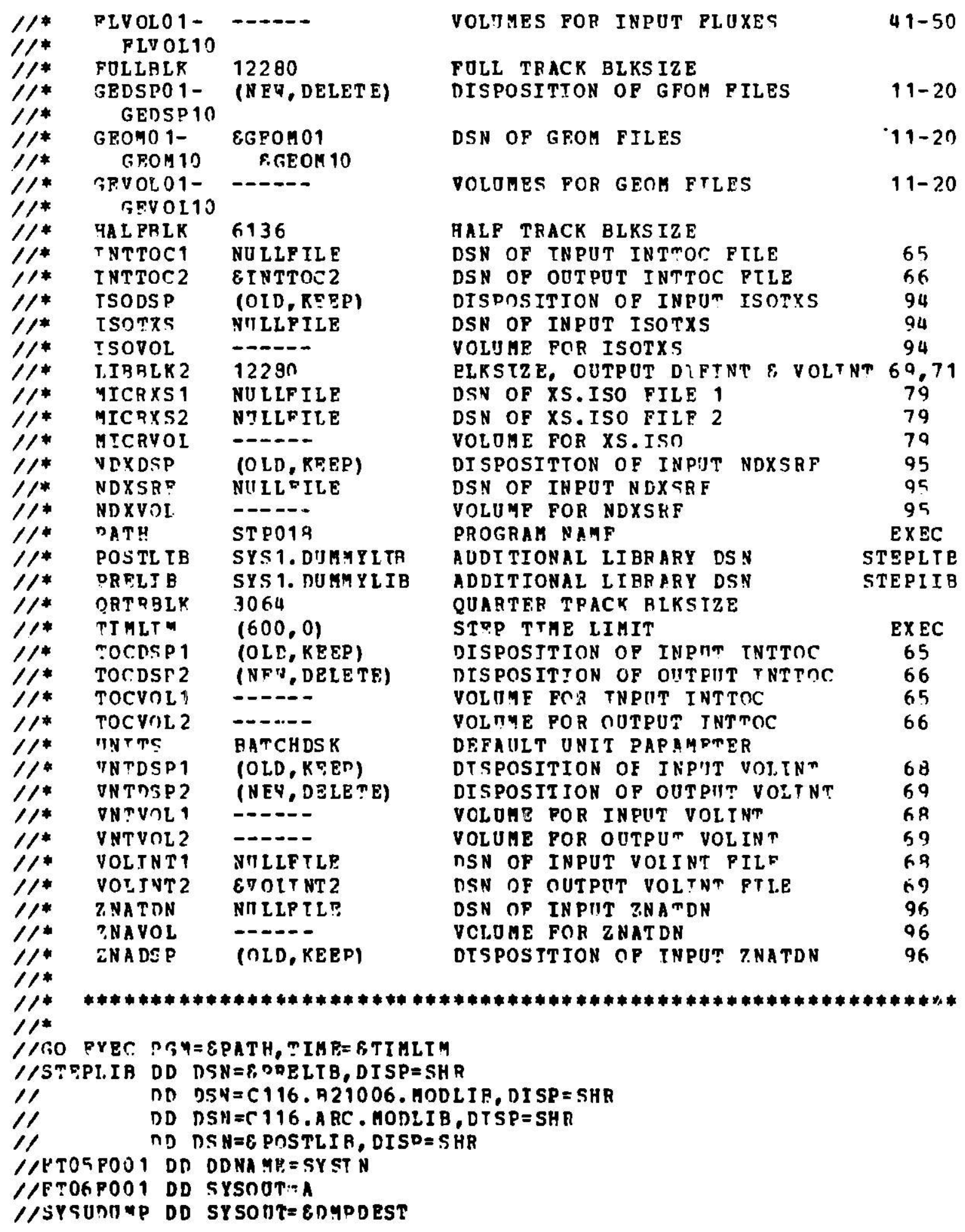


APPFNDTX C. ARCSP018. CONTINIFE.

$/ /$ PT09D001 DN UNIT $=2314$, SNACE $=(C Y L,(1,1))$,

$1 / \quad D C B=(R E C P M=V E S, L R E C I=84, B L K S I Z F=3.364)$

$/ / F T 11 F 001$ DD $D S N=\varepsilon, G E O Y 01, V O L=S B R=E G F V O L 01, D I S P=E G E D S P O 1$,

// UNTT=EINTTS, SPACE= $(C Y L,(1,1))$,

1/ DCB $=(\cap F C F M=V B S, L R F C L=X$, BLKSIZP=EHALFRÉK)

$1 / *$ FILFS 11 TURU 20 ARE GEO* FILES

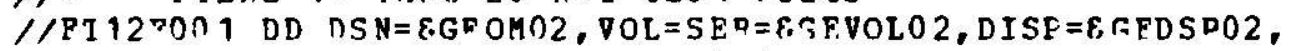

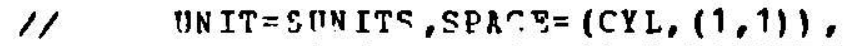

/ 1 DCR= (DECFM=V GS, LPECL=X, RLKSTZF=EHALFAL )

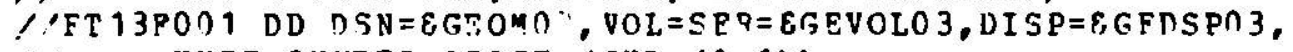

$\prime \quad$ ONIT $=E$ !NTTS, SE CE $=(C Y L,(1,1))$,

1. $D C B=(R E C F M=V B S, L B E C L=X, B L K S I Z R=\mathcal{Q}$.HALFBLK)

$/ / F$ T47001 DD DSN=5, CF OYO4, VOL=SER=5,3EVOLO4, DISP=EGEDSPO4,

$/ / \quad$ TNIT $=E \| N I T S, \operatorname{SPACE}=(C Y L,(1,1))$,

// $D C B=\left(P E C F M=V B S, L R E C I=X, R L K S T 2^{\circ}=8 . H A L F B L K\right)$

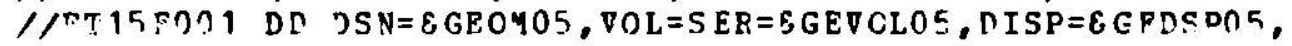

$/ / \quad$ ISTTT=, 1$] N I T S$, SPACE $=(C Y I,(1,1))$,

$1 / D C B=($ RECPM $=$ VAS, LRECI $=X, B I K S I Z P=$ E.HALY PLK $)$

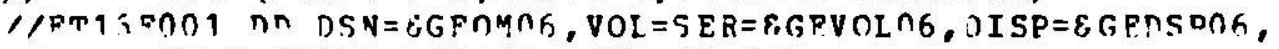

/1 IIVTT=S,INITS, SPACF: $($ CYI., $(1,1))$,

// $D C B=(F E C F H=V B S, T, R E C I=X, B L K S T Z E=8, H A L F B L K)$

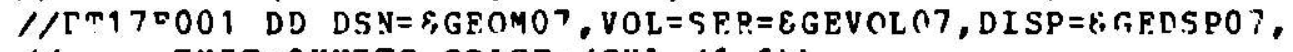

/I TNI $T=E^{\prime \prime N T T S, ~ S O A C F ~}=(C Y L,(1,1))$,

// $D C B=($ DFPFM=VBS, L RFCL $=X$, BLKSTZ $E=E H A L P B L K)$

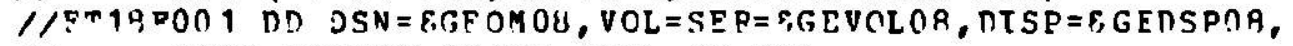

$1 / \quad T N T T=E U N T T S, S$ DAC $=(C Y I,(1,1))$.

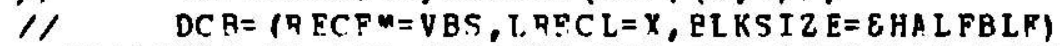

//F"19P001 DD DSN= SGPOM09, VOL=SFP= SGEVOLC , DI SP=EGFDSPCQ,

// UNIT $=$, INTTS, SPACE $=(C Y L,(1,1))$.

$1 / \quad D C B=(R E C F M=V B C, L$ PF CL=X,BLKSIZ $I=E H A L F R L K)$

$/ / F T 2 C F O 31$ IDD $D S N=E G F \cap M 10, \nabla O L=S E Q=6 G B V O L 10$, IISF=EFFDSP10,

$1 / \quad$ UNIT $=$ F,INIT 9, STAC $=(C Y L,(1,1))$.

$1 / \quad J C B=(R E C P M=V$ DS, I. RECI $=X, B I \mathrm{KST} Z \mathrm{Z}=\varepsilon H A L F B L X)$

1/* PILPS 11 THRII 20 ARE GEOM PTLPS

//FT? 1FOO1 ND DSN= S.GFODSO 1, DISP = (NPW, DFIETF), SPACE $=(C Y L,(1,1))$, .

$1 / D C B=(R E C P M=V B S, L R F C I=X, B L K S[Z E=E H A(F R L K), U N I T=S A C C P$

1/* PII.S 21 THRII TO ARE CCCC RIFOST FILPS

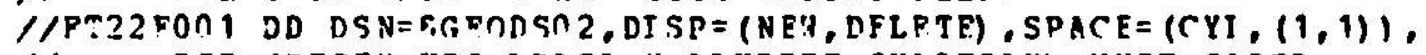

// $D C R=(R F C P M=V B S, L R F C L=X, 8 L K S[Z F=\varepsilon H A L F B L K), \| N I T=S A S C R$

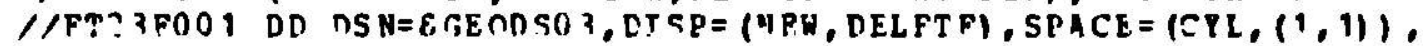

$1 / \quad D C R=(R E C S M=V B S, L R E C I=X$, RLPSIR.E $=E H A L F B L K), \| N I T=S A S C ?$

//FT24FON1 DD DSN=8.GEONSO4, DTSP = (NEW, DELFTF), SPACF $=(C Y L,(1,1))$,

$1 / D C B=(P, E C P M=V B G, L R$ ? $C L=X, P L K S T Z E=E H A L F B L K)$, IINJ $T=S A$ SC०

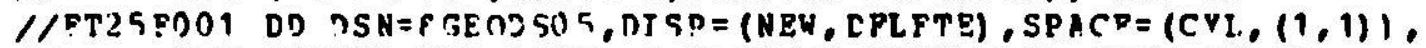

$1 / \quad$ DC B $=($ REP $I=V A S, L Q E C L=X, B I . K S T Z=E H A L F B L K), \| N T=S A S C R$

I/FT2F POO 1 DN NGN=EGCODSOR, DTSP= (NEN, DFI RTP), SFACE = (CYL, $(1,1) i$,

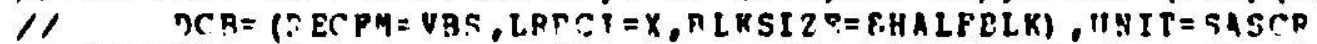

/NT27POO 1 DD DSY= \&GFODSC7, DTSF= (NEH,DELFTE), SPACE= (CYI, $(1,1) 1$,

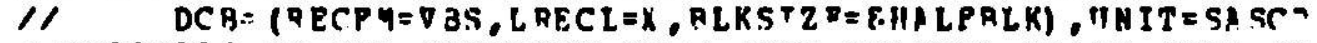

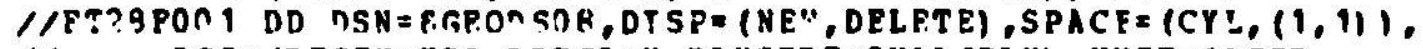

$/ / D C B=(F E C P V=V B S, I . R P C L=X, B I K S T Z R=F H A L P P L K), J N I T=S A S C D$ 
A PPENDIX C. ARCSPO18. CONTINTED.

//PT29F001 DD DSN= EGEODS09, DISP = (NEW, DELETE), $S P A C E=(C Y L,(1,1))$,

$1 / D C B=(R E C F M=V B S, L R E C I=X, B L R S I Z E=E H A L P B L K), U N I T=S A S C R$

//FT39FON1 DD DSN $=8$ GEODS10, DISP $=($ NEW, DELETR $), \operatorname{SPACE}=(C Y L,(1,1))$,

$1 / D C B=(R E C P H=\nabla B S, L R E C L=X, B L K S T Z E=E H A L P B L K), U N I T=S A S C R$

$1 /$ PILES 21 THRT 30 ARE CCCC GEODST FILPS

$/ / \mathrm{FT} 31 \mathrm{~F} 001$ DD DSN $=\varepsilon B C 01, \mathrm{VOL}=S \mathrm{ER}=\varepsilon \mathrm{BCV} 0 \mathrm{O} 01, \mathrm{DISP}=\varepsilon \mathrm{BCDSP0} 1$,

$/ / \quad$ ONIT=EONITS, SPACE $=(T R K,(1,1))$

$1 / \quad D C B=($ RECFM $=V B S, L R E C L=X$, PLRSIZ $P=304)$

//* PILES 71 THRD 40 ARE THE BC FTLES ASSOCIATED WITH THE GBOH

$1 / 1^{*}$ PILES (11 THRD 20)

$/ / \mathrm{FT} 32 \mathrm{FO0} 1$ DD $D S N=\varepsilon$ BC $02, V O L=S B R=\varepsilon B C V O L 02, D I S P=\varepsilon B C D S P 02$,

$1 / \quad$ DN IT $=$ SUNITS, SPACE $=(T R K,(1,1))$,

$1 / D C B=(E R C P H=V B S, L R E C I=\bar{X}, B L K S I Z E=304)$

//FT $33 F 001$ DD $\cap S N=8, B C 03, \nabla 0 I=S E R=\varepsilon B C V O L 03, D I S P=\varepsilon B C D S P 03$,

$1 /$ ONTT $=8$ UNITS, SPACE $=($ TRK, $(1,1))$,

$1 / \quad D C B=(B E C F H=V B S, L R E C L=Y, B L K S I Z P=304)$

$/ / F T$ 7 4 P 001 DD DSN $=\varepsilon B C 04, V O L=S E R=\varepsilon B C V O L 04, D I S P=\varepsilon B C D S P 04$,

$1 /$ ONTT = EUNITS, SPACE $=(T$ TKK, $(1,1))$.

$/ / D C B=(R E C P M=V B S, L R E C I=X, B L R S I Z E=304)$

//PT35P001 DD ISN=E BCO5,VOL=SBR=\&, BCVOI 05, DISP = \&, BCDSP05,

$1 / \quad$ ONIT=EINITS, SPACE $=(T R K,(1,1))$,

$1 / D C B=(R B C P H=V B S, L R E C I=X, B L K S I Z E=304)$

$/ / F=36 P 0 \cap 1$ DD DSN $=\varepsilon B C 06, \nabla O L=S E R=\varepsilon B C V O L$ N6, DISP $=\varepsilon B C D S P 06$,

$1 / \quad$ UNT $m=\varepsilon$ UNITS,SPAC B $=($ TRK, $(1,1))$,

$1 / \quad D C B=(R E C P M=V B S, L R C C L=X, 9 L K S I Z B=304)$

$/ / P T>7 F 001$ DD DSN=F.BC 07, VOL $=S E R=\varepsilon, B C V O L 07, D T S P=\& B C D S P 07$,

$1 / \quad$ UNI $T=F$, ONITS,SPAC $F=(T R R,(1,1))$,

$1 / D C B=(R E C P M=V B S, \angle R E C L=X, B E R S I Z E=304)$

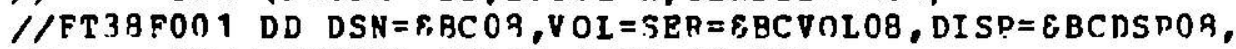

$1 / \quad$ UNIT $=\varepsilon$ ONITS , $\operatorname{SPACF}=(T R K,(1,1))$,

$1 / D C B=(B B C P M=\nabla B S, L R E C I=X, B L R S T Z F=304)$

$/ / F T 39$ POO 1 DD DSN=8BCO9, $\nabla O L=S E R=\varepsilon$, BCVOLO9, DISP $=\varepsilon B C D S P 09$,

$1 / \quad$ ONTT $=5 \pi N I T S, S$ PACE $=(T R R,(1,1))$,

$1 / D C B=(R E C F M=V B S, L R F C L=X, B L K S I Z E=304)$

//FT40FOO 1 DD DSN=8.BC10,VDL=SER=8, ECVOL 10, DISP=EBCDSP1D,

$1 / \quad U N I T=$, ONITS, SPACE $=(T R K,(1,1))$,

$1 / \quad D C B=(R E C P M=V B S, L R E C I=X, B I K S T Z F=304)$

1/* PTLES 31 THRU 40 ARE THE BC PILES ASSOCIATED WITH THE GEOH

$1 /$ PILES (11 THA RI 20)

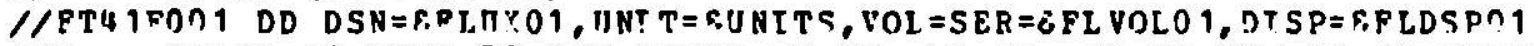

1/. PILES 41 THRI 50 ARE INPTT PR.D2, PA.D2, FR.D1 AND PA. D1 FILFS

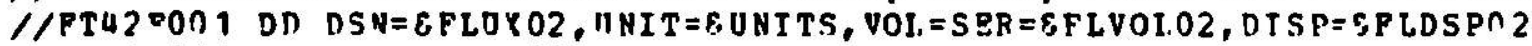

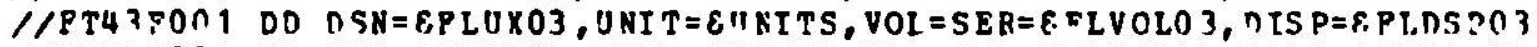

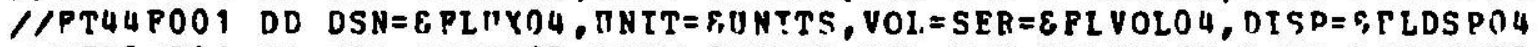

//FT45F001 DD DSN= F.PLUX05, UNT T=8, ONITS, VOL=S ER=E FLVOLO5, DI SP=S,PI.DSPOS

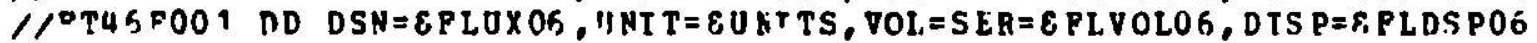

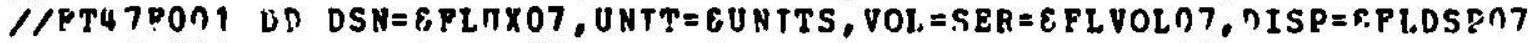

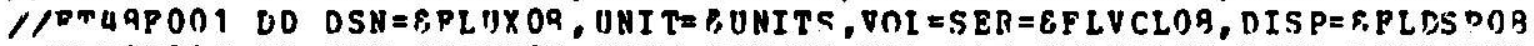

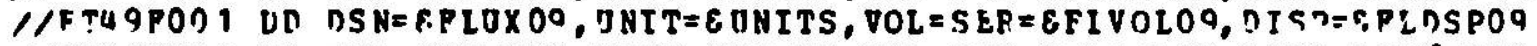

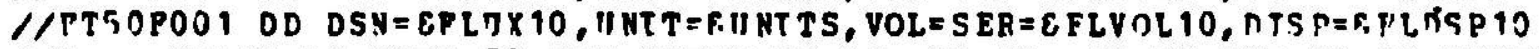

11. PTLRS 41 THRU 50 ARE IHPOT PR.D2, FA.D2, FP.DI ANO PA.DI PTLPS 
APPRNDTX C. ARCSPO18. CONTINOED.

//FT5 1P001 DD DSN=ERTPL01, ONI T=SASCR, DISP= (NEW, DELETE),

$1 / \quad \operatorname{SDAC} E=(C Y L,(1,1)), D C B=(R E C F M=\nabla B S, L R E C L=X, B L X S I Z E=E H A L F B L K)$

//* PILES 51 THPO 60 ARE CCCC RTPLOX AND ATPLUX FILES

//FT52F001 DI DSN=E RTFL02, UNI T=SASCR, DISP= (NEN, DEIETE),

$1 / \quad S P A C E=(C Y L,(1,1)), D C B=(B E C P H=V B S, L R E C L=X, B L K S I Z E=\varepsilon 4 A L F B L K)$

//FT53F001 DD JSN=ERTFL03, UNIT=SASCR, DISP= (NEW, DELETE),

/) SPACE $=(C Y L,(1,1)), D C B=(R E C P H=V B S, L R E C L=X, B L R S I Z E=\varepsilon H A L \square B L R)$

//FT54PCJ 1 DD DSN=8RTPLO4, ONI T=SASCR, DISP= (NEH,DELETR),

$1 / \quad S P A C E=(C Y L,(1,1)), D C B=(R F C P M=V B S, L R E C L=X, B L K \triangle I Z E=E H A L F B L K)$

//PT55F001 DD DSN=\&RTPL05, UNTT=SASCR,DISP=(NEW, DEIETE),

$1 / \quad S P A C E=(C Y L,(1,1)), D C B=(B E C F M=V B S, L K E C L=X, B L K S T Z E=8$, Y ALF BLK)

//FT56F001 DD DSN=ERTPL06, TNIT=SASCR,DISE=(NEV, DELETE),

$/ / \quad S P A C E=(C Y L,(1,1)), D C B=(R E C F M=\nabla B S, L R E C L=X, B L K S I Z E=6$ HALFBLK $)$

//FT57P001 DD DSN=F,RTPL07, ONTT=S ISCR, DTSP= (NEW, DELFTE),

// SPACE $=(C Y L,(1,1)), D C B=(R E C P M=V B S, L R E C L=X, B L K S I Z F=\varepsilon H A L F B L K)$

//FT5PF001 DD DSN=E.RTPLOB, UNTT=SASCR, DISP= (NEW, DELETE),

$/ / \quad S B A C P=(C Y L,(1,1)), D C B=(R E C P M=V B S, L R E C L=X, B L K S I] B=E H A L F B L K)$

//FT59F001 DD DSN= \&RTPL09, UNIT=SASCR, DISP= (NEW, DFLETE),

$1 / \quad S P A C E=(C Y L,(1,1)), D C B=(R E C P M=V B S, L R Z C L=X, B L K S T Z E=5 H A L \square B L R)$

//PTK0P001 DD DSN=ERT?L 10, UNTT=SASCR, DISP= (NE!, DELETE),

$1 / \quad$ SPACE $=(C Y L,(1,1)), D C B=(R E C P M=V B S, L R E C L=X, B L K S J 7, E=5, H A L F$ SK $)$

1/* FILES 51 THRT 60 ARE CCCC BTFLTX AND ATPLUX FILES

//PT61P001 DD DSN=ESYNFIL, DISP= (NEN, DELETE), JNIT =SASCR,

$1 / \quad D C B=(R E C F M=V B S, L R E C I=84, B L K S I Z E=3156), \operatorname{SPACE}=($ ? $9 K,(1,1))$

//* THE BCD INPJT PILE

//FT52F001 DD DSN=8,XSCMIN, DISP= (NEW, DFLETE), UNIT=SASCR,

$1 / \quad S P A C E=(C Y I,(1,1)), D C B=(R E C F M=\nabla B S, L P F C L=X, B L K S T ? E=6447)$

$1 / *$ A ONE-PTLE XS.C. तT N

//FT6 35001 DD DSN=8.RPOPLX, DISP=(NEH, DELETF), INIT=SASCR,

$1 / \quad S P A C E=(C Y L,(2,1)), D C B=\left(R E C F M=V B S, L R E C L=X, B L K S I T_{1} R=E F(U L L B L K)\right.$

//* SEWRITTEN FLIJXFS AND GEOHETRTES

//FT KUFDO1 DD DSN=EREQX ST, IISP= (NEH, DELETE), ONIT=SASCR,

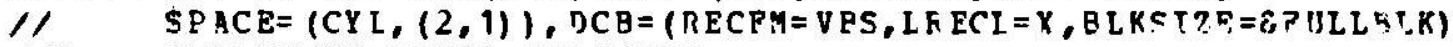

//* RENRITTEN CROSS SECTIONS

//PT65F001 DD NSN=8. INTTOC 1, VOL=SER=ETOCVOI 1,DISP=EIOCDSP1, INTT=R,UNITS

1/* THF TNPIIT INTTOC FIIE

//FT66P001 DD TSN=F. T NTT OC 2, VOI =SER=ETOCVOL2, nISP=ETOC NSP2,

$11 \quad S \cap A C F=(T R K,(1,1)), D C B=(P E C F M=V B S, L R B C L=X, H L K S I Z F=6 O R T R B L K)$,

$1 /$ UNIT=BINTTS

1/* THE OUTPUT TNTTOC FILF

//FTE7P001 DD DSN= \&COHOXS 1, ONIT $=\varepsilon U N I T S, V O L=S E R=\varepsilon C X S V O L,, D I S P=\varepsilon C X S D I S P$,

$1 / \quad S P A C F=(T R K,(1,1)), D C B=(R F C F M=V B S, L R E C I=X, A L K S=2 E=6, C X S R L K 1)$

1/* THE FIRST FILE OP THE TNPIIT, TWO-FILE XS.C. MTN

//FT67FnO2 DN DSN=8.COMPXS 2, UNTT $=8$ UNITS, VOL=SFR=8,CXSVOLM, D ISP=8,CYSDISP,

$1 / \quad S P A C Z=(C Y L,(1,1)), D C B=(R E C P H=\nabla B S, I R E C L=X, B L K S I 3 E=R, C X S B L R 2)$

1/* THP SECOND FILE OF THP INPIT, T\%O-FILE XS.C.MTY

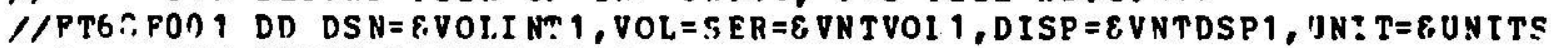

$11^{*}$ THE INPIIT VOITNT FILE 
APPENDTX C. ARCSP018. CONTINOED.

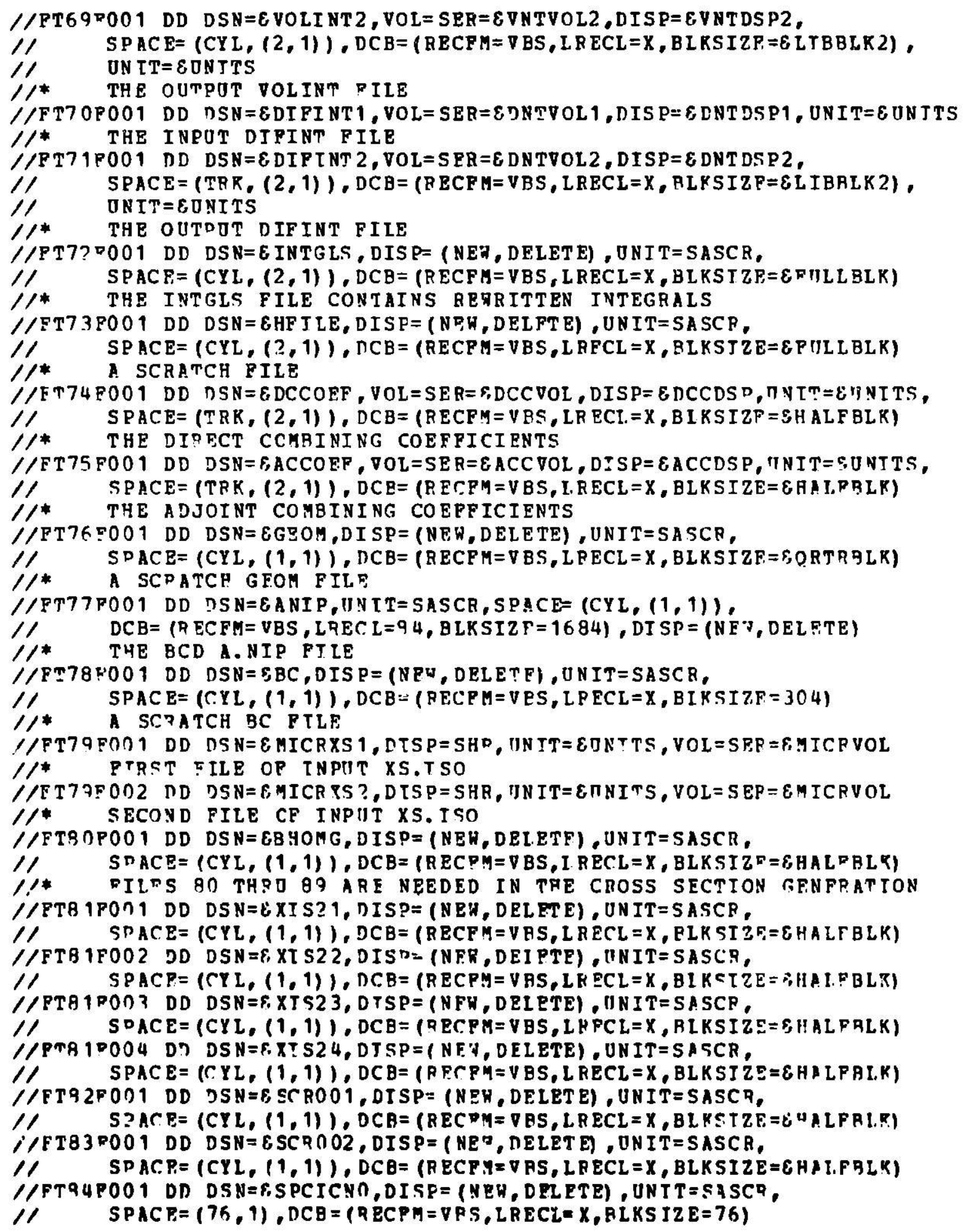


APPFNDTX C. ARCSP018. CONTINIPD.

//FT85D001 DD DSN = \&SPCRIT, DISP= (NER, DELET E), UHIT=SASCR,

// SPACE $=(T R K,(1,1)), D C B=(R B C F M=\nabla B S, L R E C L=X, B L K S I Z E=3 B R)$

$/ / F T 96 P 001$ DD DSN=EXSCAOX $1, D T: P=(N E V, D E L E T E), O N I T=S A S C R$,

/) $S P A C E=(T R R,(1,1)), D C B=(R E C P M=V B S, L R E C L=X, B L K S I Z E=516)$

//FT86P002 DD DSN=EXSCAUX2,DISP= (NEW, NELETE), UNIT=SA SCR,

$11 \quad S^{n} A C E=(C Y L,(1,1)), D C B=(R E C P M=V B S, I$ R ECL $X, B L R S I Z E=E H A L P B L K)$

//FTB7POU1 DD DSN=ESCR003A, DISP=(NBT, DELETE), UNIT=SASCR,

$1 / \quad$ SPACE $=(C Y L,(1,1)), D C B=(R E C P I=V B S, L R E C L=X, B L K S I Z E=\varepsilon H A L P B L R)$

//FT87F002 DD DSN=\&SCR003P,DISP= (NP耳, DEL ETE), ONIT=SASCR,

/) SPACE $=(C Y L,(1,1)), D C B=(R E C F M=\nabla B S, L R E C L=X, B L K S I Z E=E$ HAL $P B L K)$

//FTB9F001 DD ПSN=EXSHAUX, ELSP= (NEW, DELETE), UINIT=SASCR,

$1 / \quad S D A C E=(C Y L,(1,1)), D C E=(R E C E M=V B S, L R E C L=X, R E K S I Z Z=; Q R T R S L K)$

$/ /$ TP9F001 DD DSN=\&XSMMIN, EISP= (NEM, DELETE), UNIT=SASCR,

// $\quad S^{D A C E}=(C Y L,(1,1)), D C B=($ KECPM $=V P S, L B E C L=X, B I K S I Z E=E$ HALFBLR $)$

//* PILES 90 THRU 89 ARE NEEDED IN THE CROSS SECTION GENERATION

$/ /$ T $90 F O N 1$ DD DSN $=8 . S Y N C O N, D I S P=(N E Y, D E I E T E)$, DNIT=SASCR,

1) DCE $=($ PECFY $=$ VBS, LRECL $X, B$ LKS TZE=304), SPACE $=(T P K,(1,1))$

$1 / *$ THE PJNARY CCNTRCL FILE FOR SYN3D

//FT?1FOก1 DD DSN=EATPL01, TNTT=SASCR,DISP= (NEW, DELETE),

$/ / \quad S ? A C E=(C Y L,(1,1)), D C B=(R F C P M=V B S, L R E C L=X, B L K S T Z B=E H A L F B L)$

//* A CCCC ATFIJX FILE POR ADJCTNT FLUXES

//ETA2F001 DD DSN=E,PWDINT, IJ N T=SASCR,DISP= (NEW, DELETF),

/) SPACE $=(C Y L,(1,1)), D C B=(R P C F M=V B S, L R E C L=X$, PIKSTZE=EAALTBLK)

//* POAER TENSITY, CCCC PORMAT

//FT93F001 DD DSN=8,RZFLUY, UNI T=SASCR,DISP= (NFK, DEIETE),

1) SPACE = (TRK, $(5,2)), D C B=($ BECPM $=V B S, L R E C L=X, B L Y C I Z E=S$ H LFEIIK)

//* AVERAGE ?LJXES BY ZONE, CCCC PORMAT

//FT94P001 DD DSN=EISOTXS, ONIT= EONTTS, VOL=SER=EISOVOL, DISP=8, TSOJSE

//* INPII? MICROSCOPTC CROSS SECTIONS TN CCCC FOPMAT

//FT95FOO1 DD DSN=S. NDXSRP, ONI $T=E$, UNITS, VOL =SER=E, NDXVOL, DTSP=F. UDXDSP

$1 / *$ CROSS SECTICN PEPFRENCE. FILE, CCCC FOPMAT

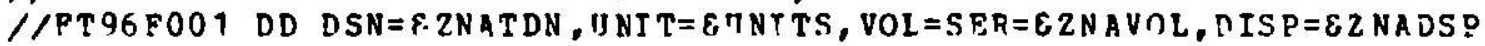

$1 / *$ ATOM DENSITIES, CCCC FORMAT

//FT97F001 DD DSN= XSCMTT 1, UNIT T SASCR,SPACE $=(C Y L,(1,1))$,

$1 / \quad D C B=($ EECP $Z$ =VES, LRECL $=X, A L Y S I Z E=E O R T R B L K)$

$1 /$ FILE 1 OP CCMPOSITTON CPOSS SFCTION SET XS.M. MI 1

//PT97F002 DD DSN=8,XSCMII 2, TNTT $=S A S C R, S P A C E=(C Y L,(1,1))$,

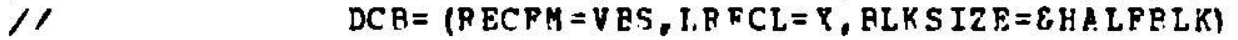

11

PILE 2 OP CCHPCSITTON CFOSS SECTION SET YS. M. MI 1

$11^{*}$

$1 / *$

$1 / *$

$11^{*}$

$1 / *$

$11 *$

$1 / *$

$11 *$

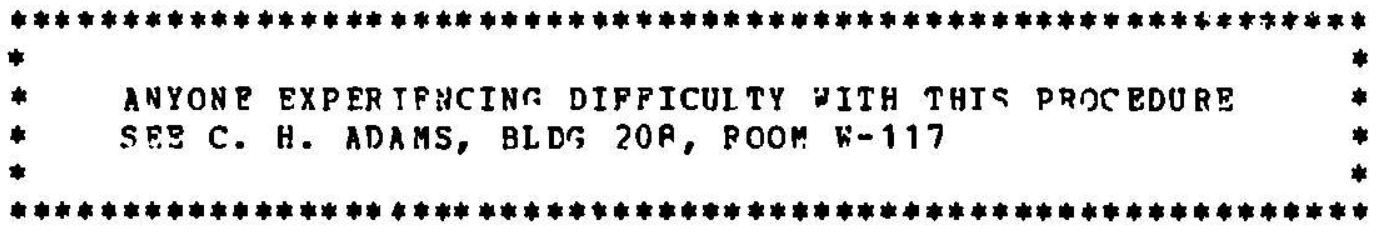


APPENDIX D. INITT DATA SET SYNFIL.
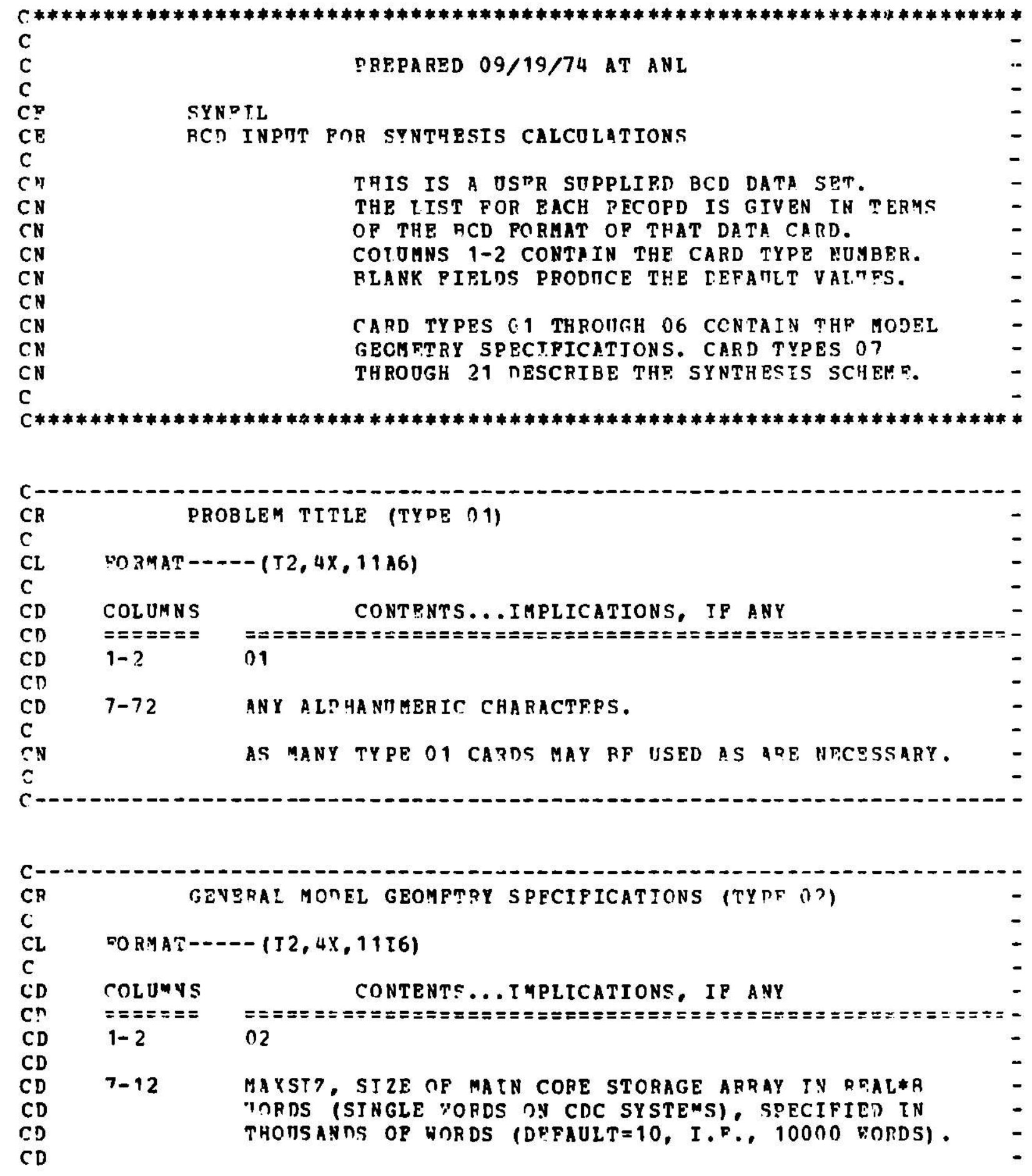
A PPENDTX D. INPET DATA SET SYHFIL. (CONTD.)

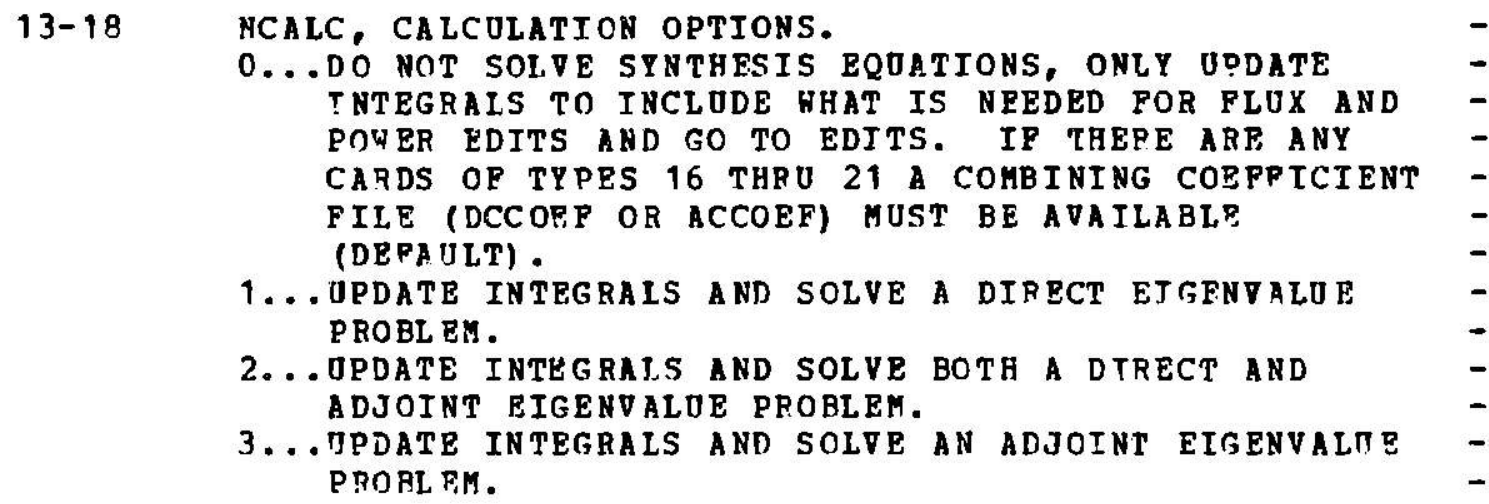


APPENDIX D. INETT DATA SET SYNFTL. (CONTD.)

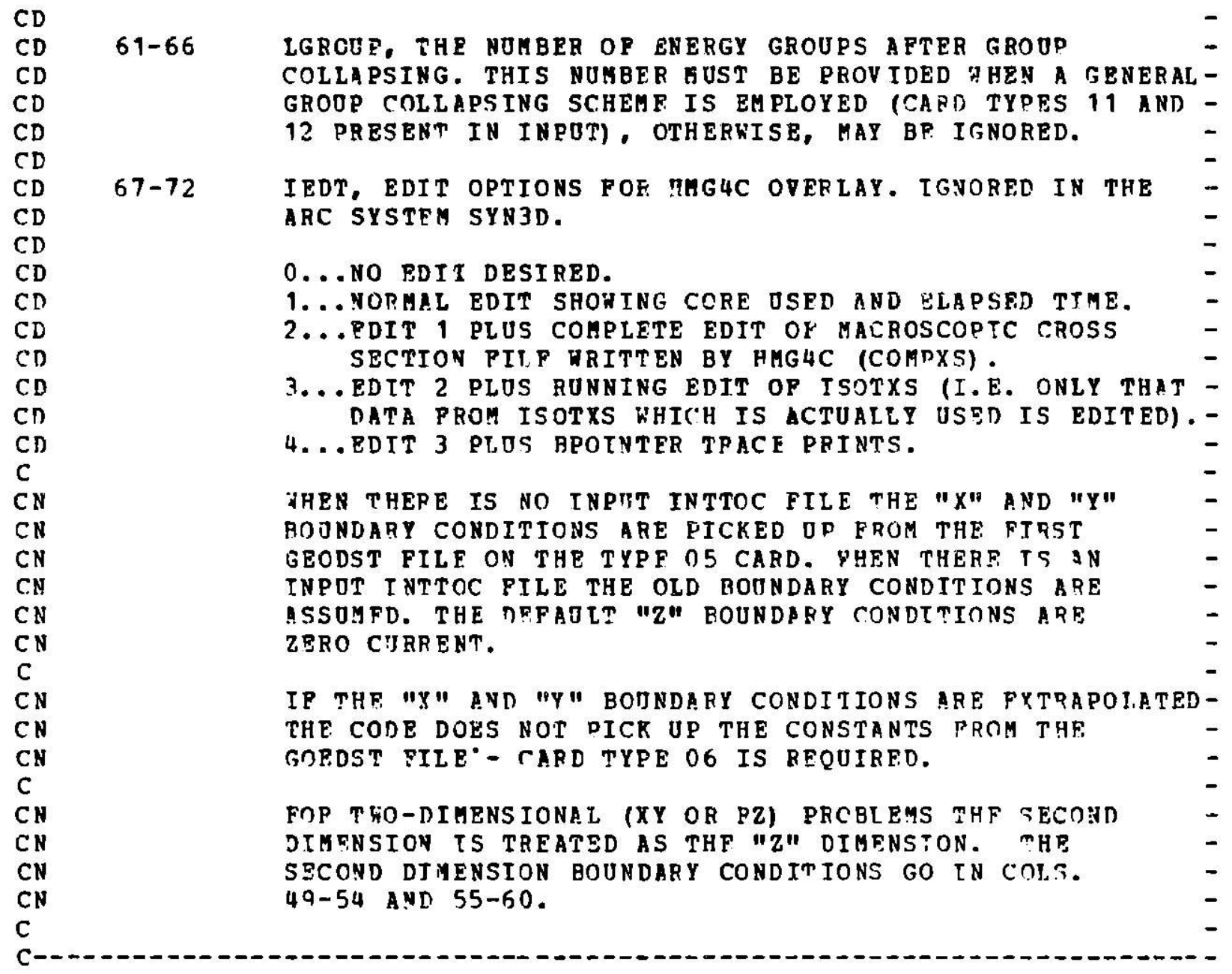

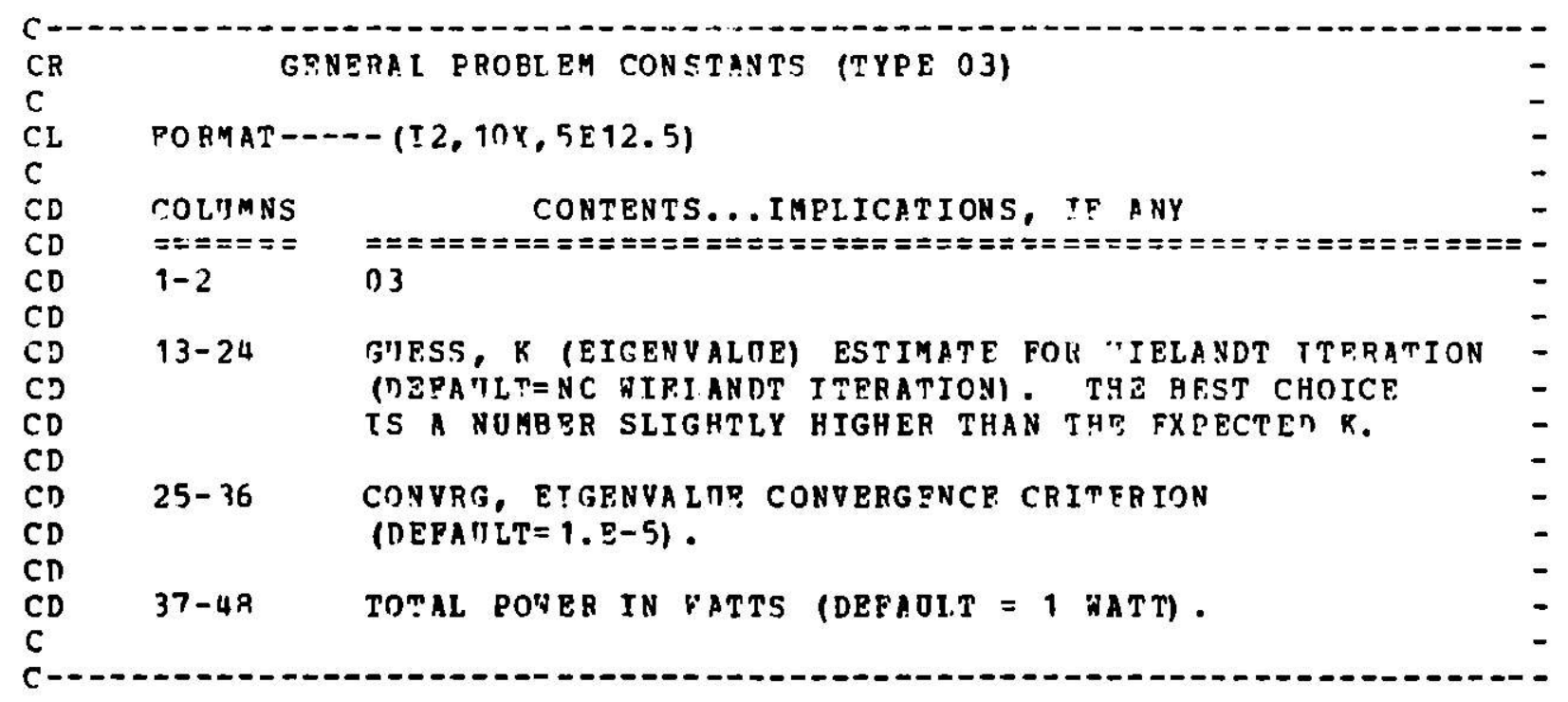


APPENDIX D. INPUT DATA SET SYNFIL. (CONTD.)

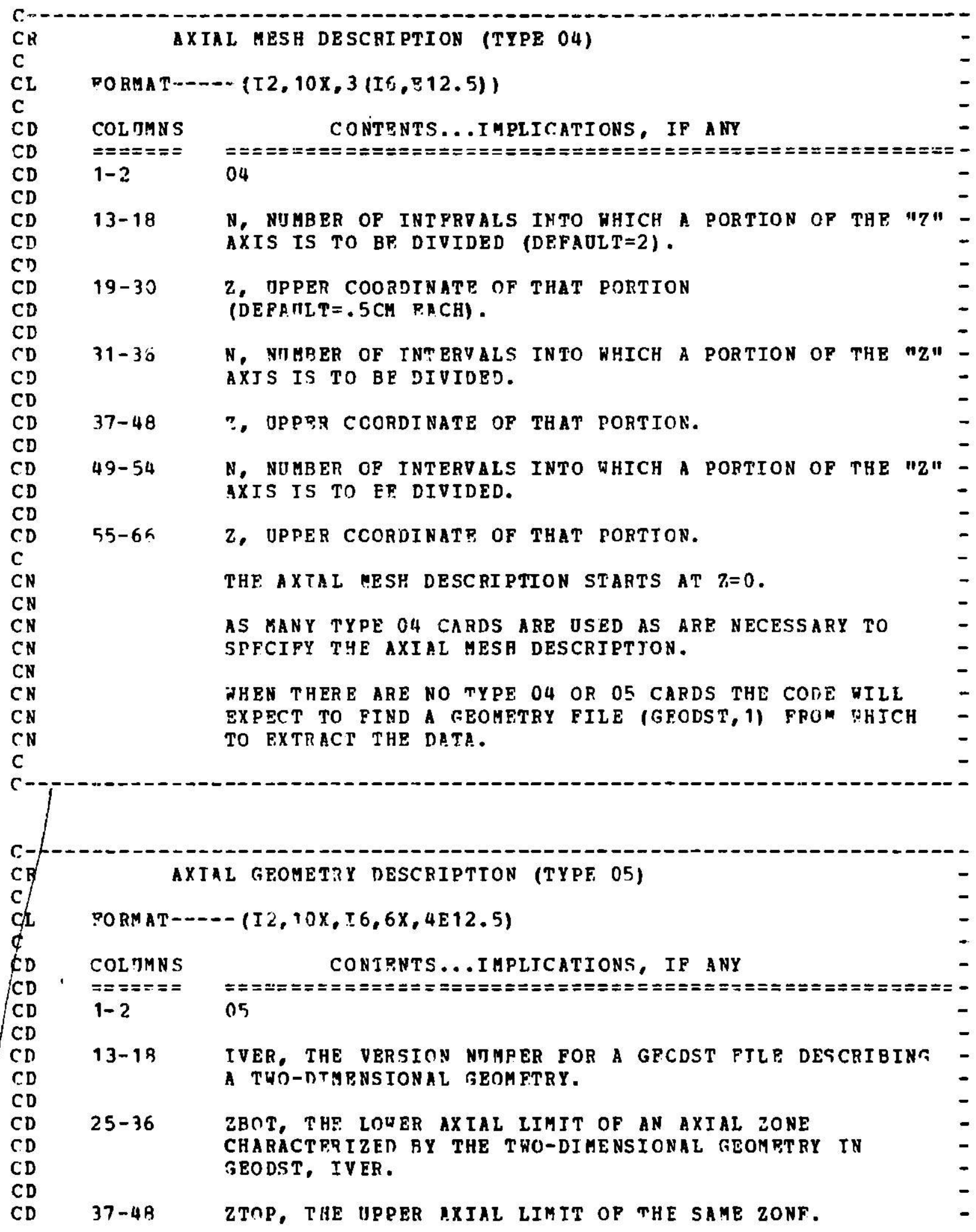


APPENDIX D. IMPOT DATA SET STUPIL. (COMTD.)

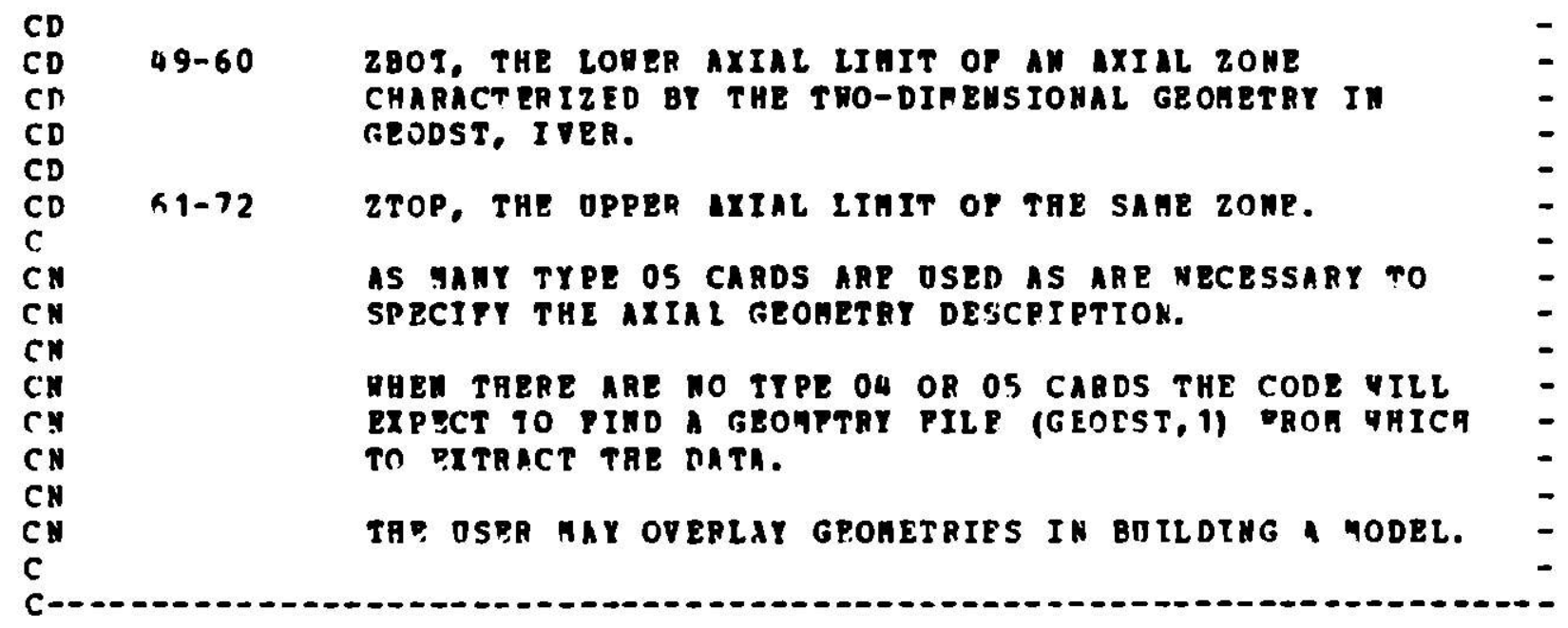

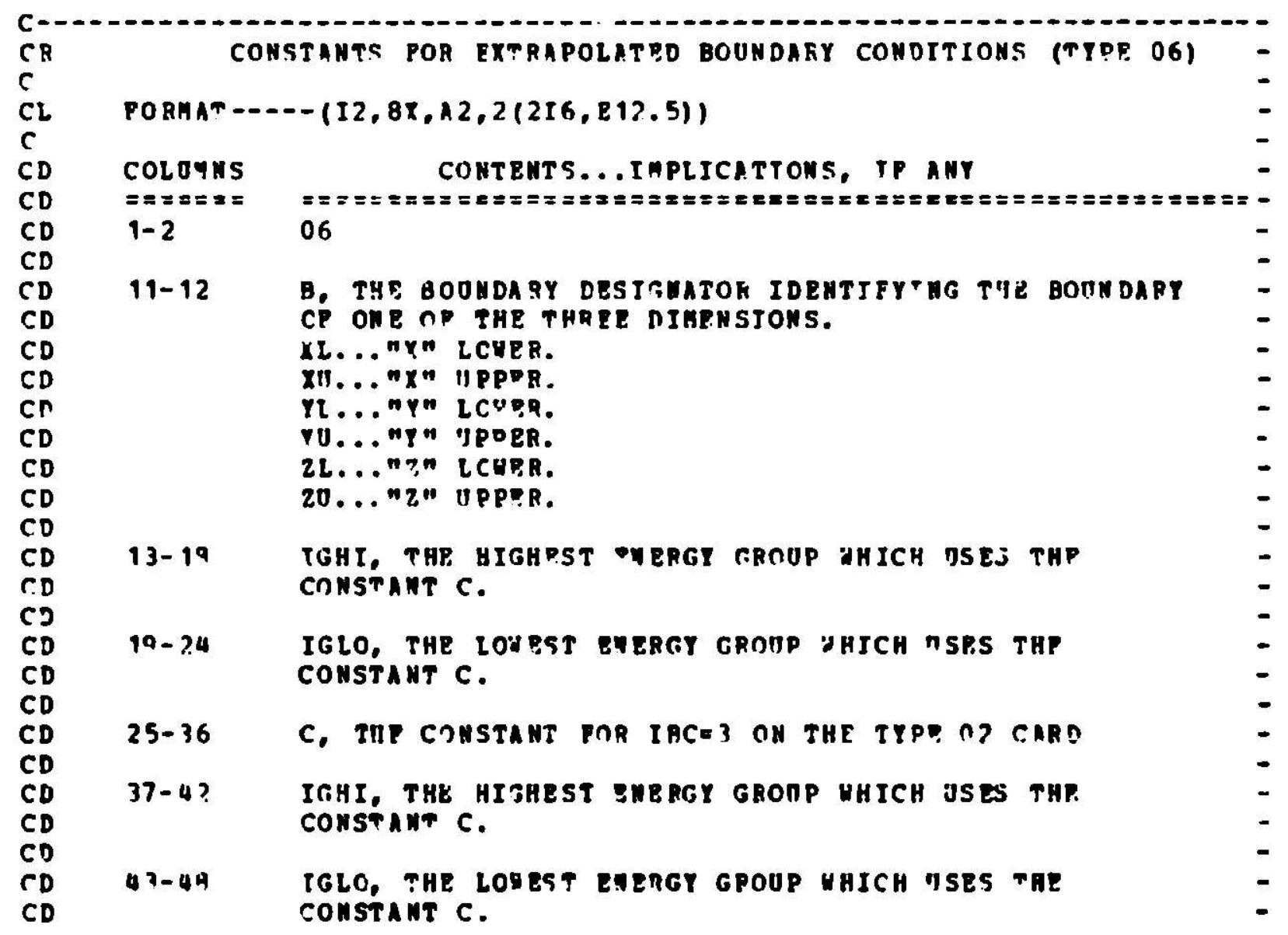


AnRTNOIX D. INPOT DATA SET SYAPII. (CONTD.)

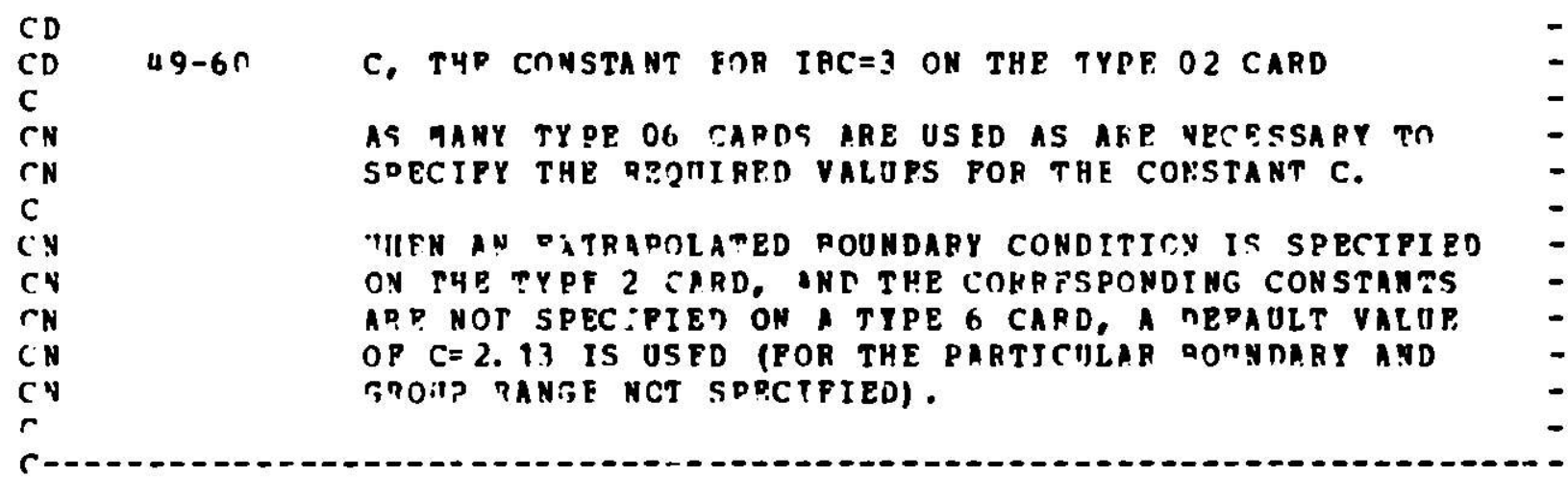

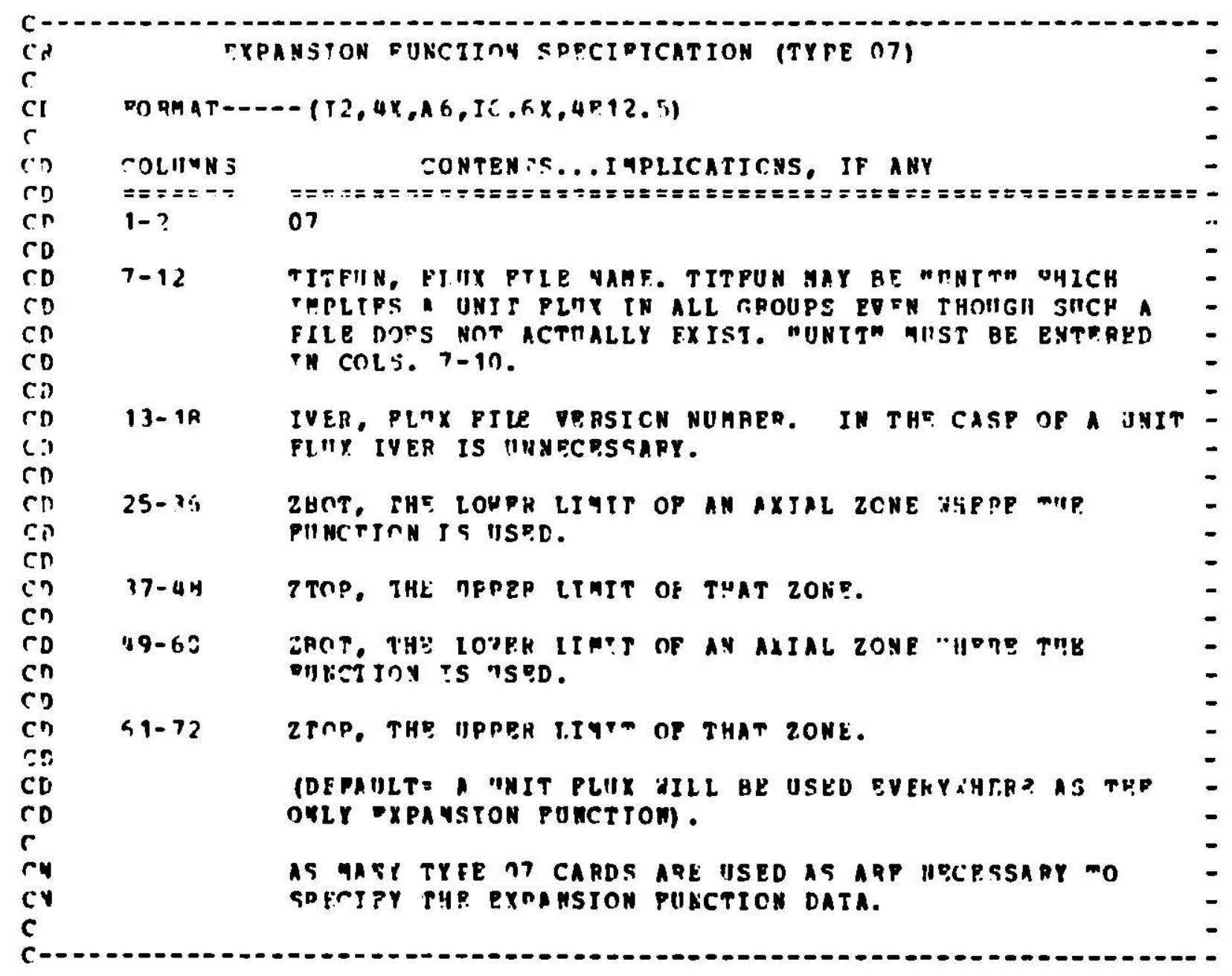


APPENDIX D. IMPOT DATA SET SYMPIL. (CONTD.)

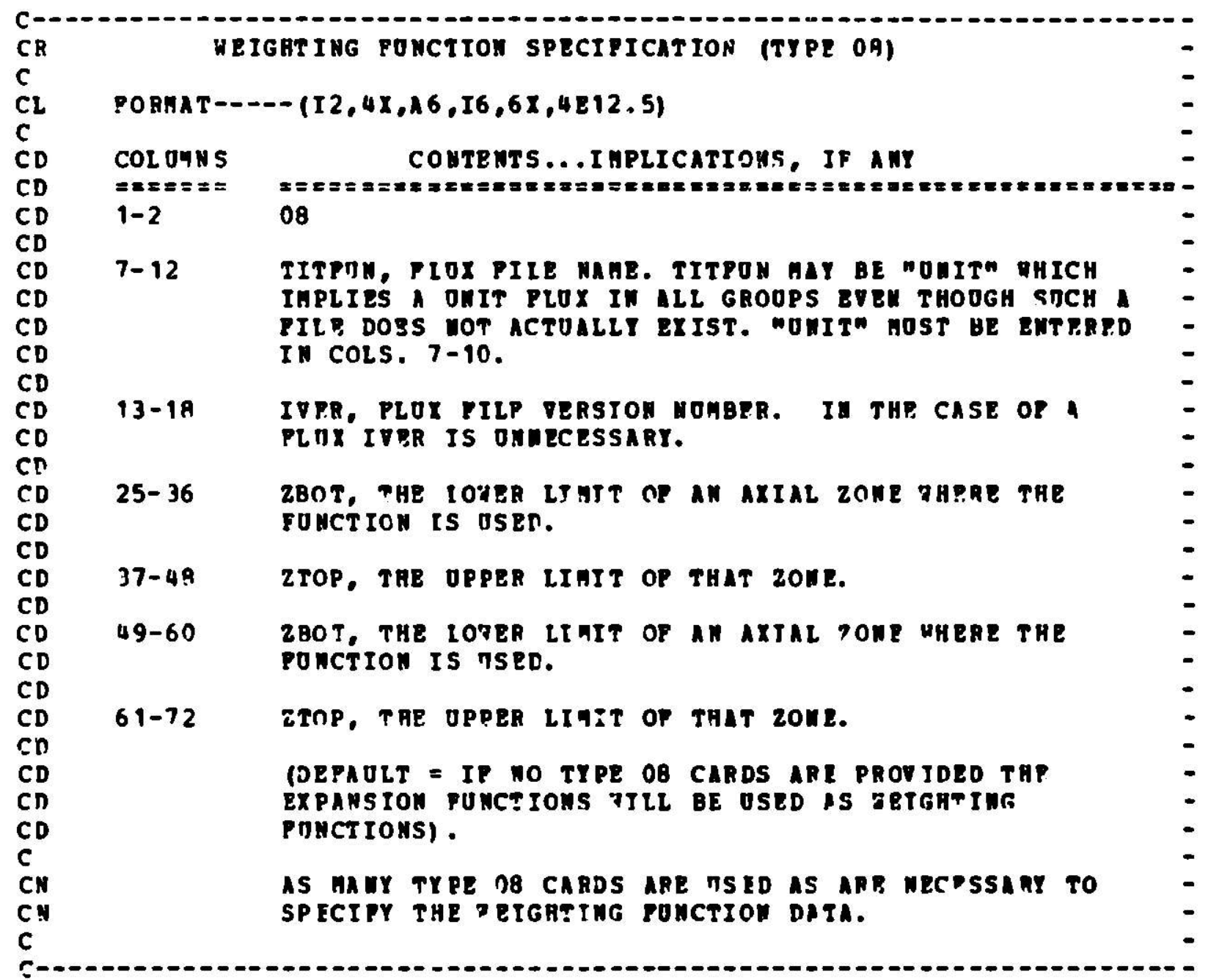


APPFNDIX C. INPUT CATA SET SYMPIL. (COMTO.)

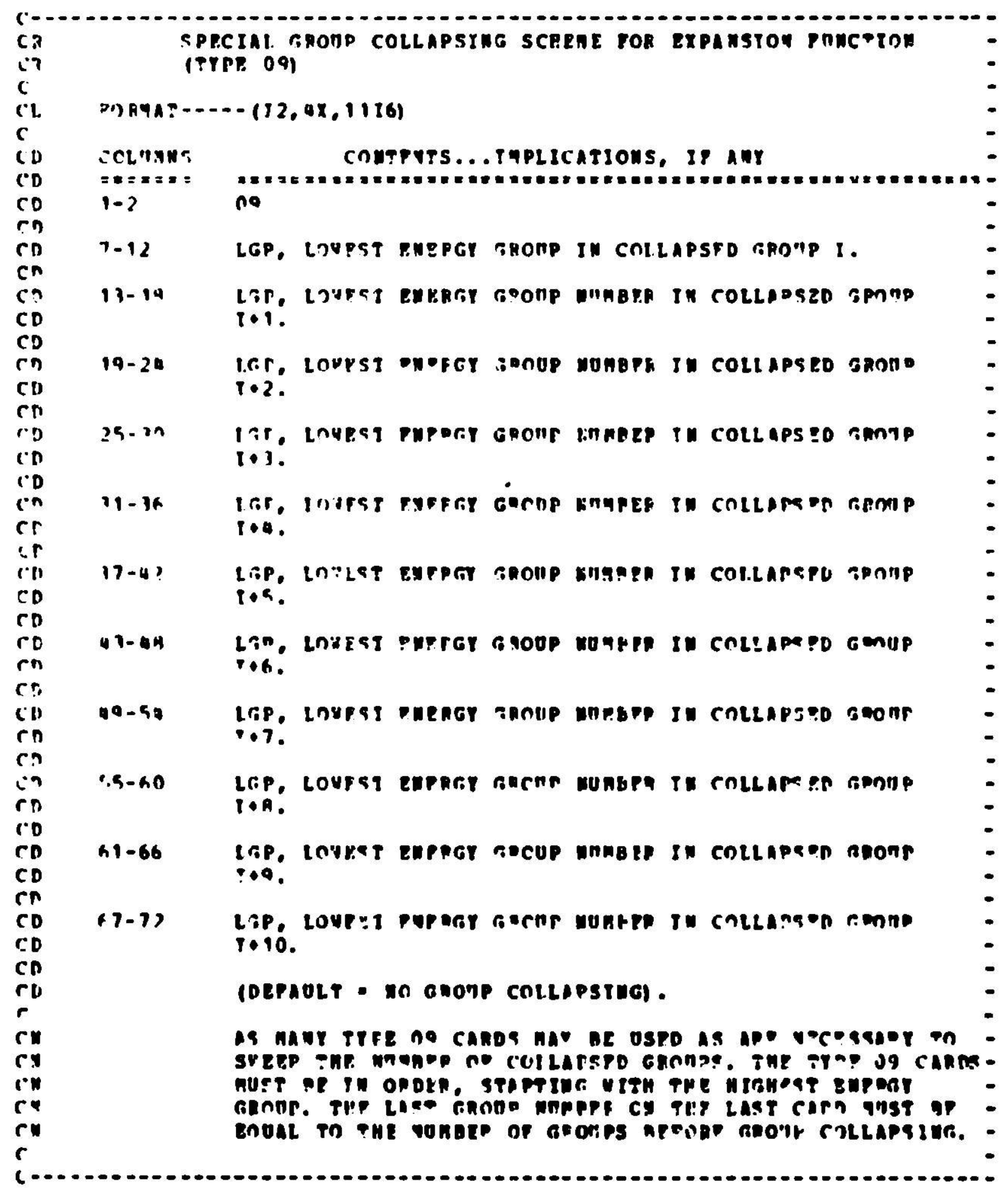


APPENDIX D. InPOS DATA SET SYUPIL. (COMPD.)

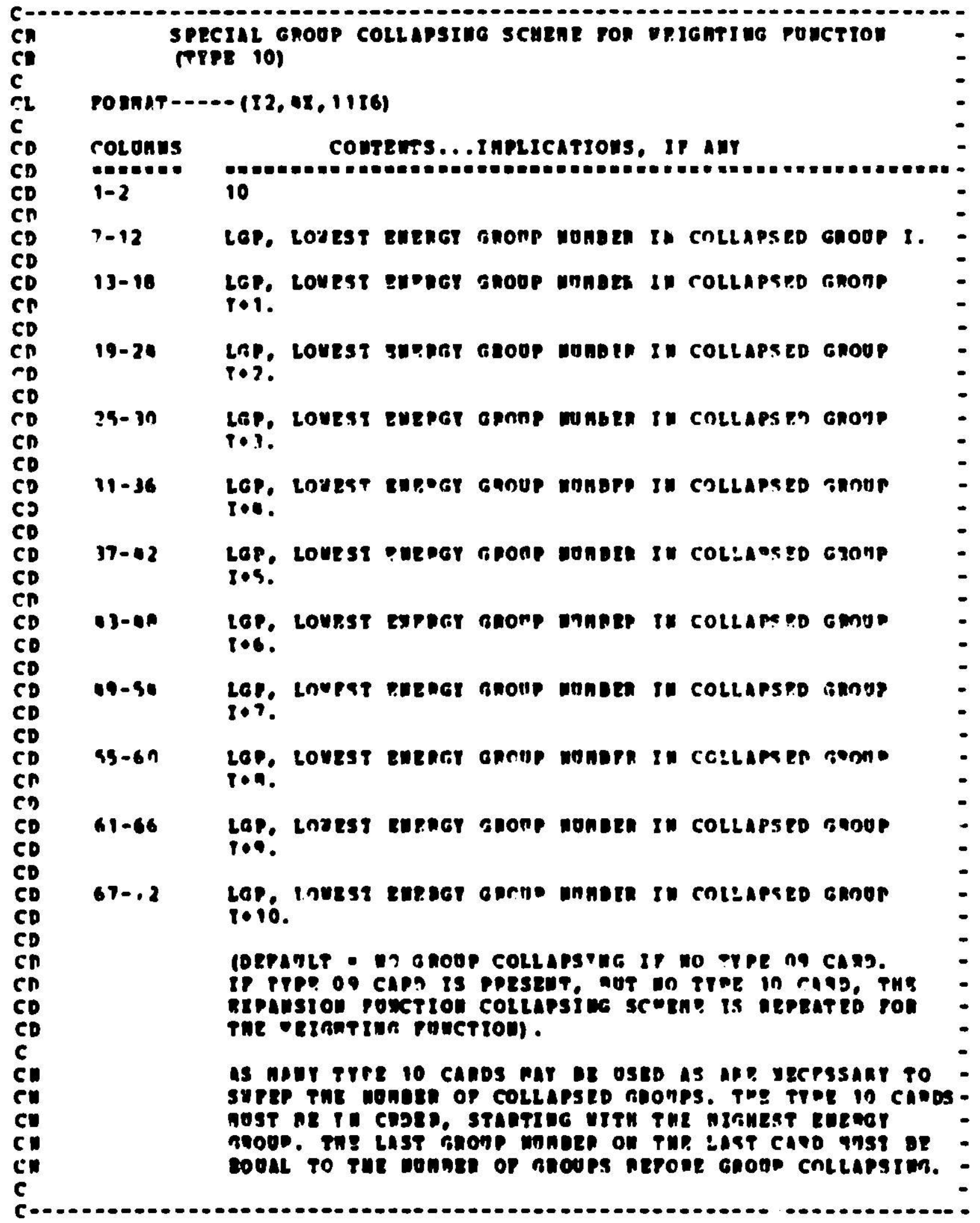


APPENDIX O. IAPUT DATA SET SYMPIL. (COMTD.)

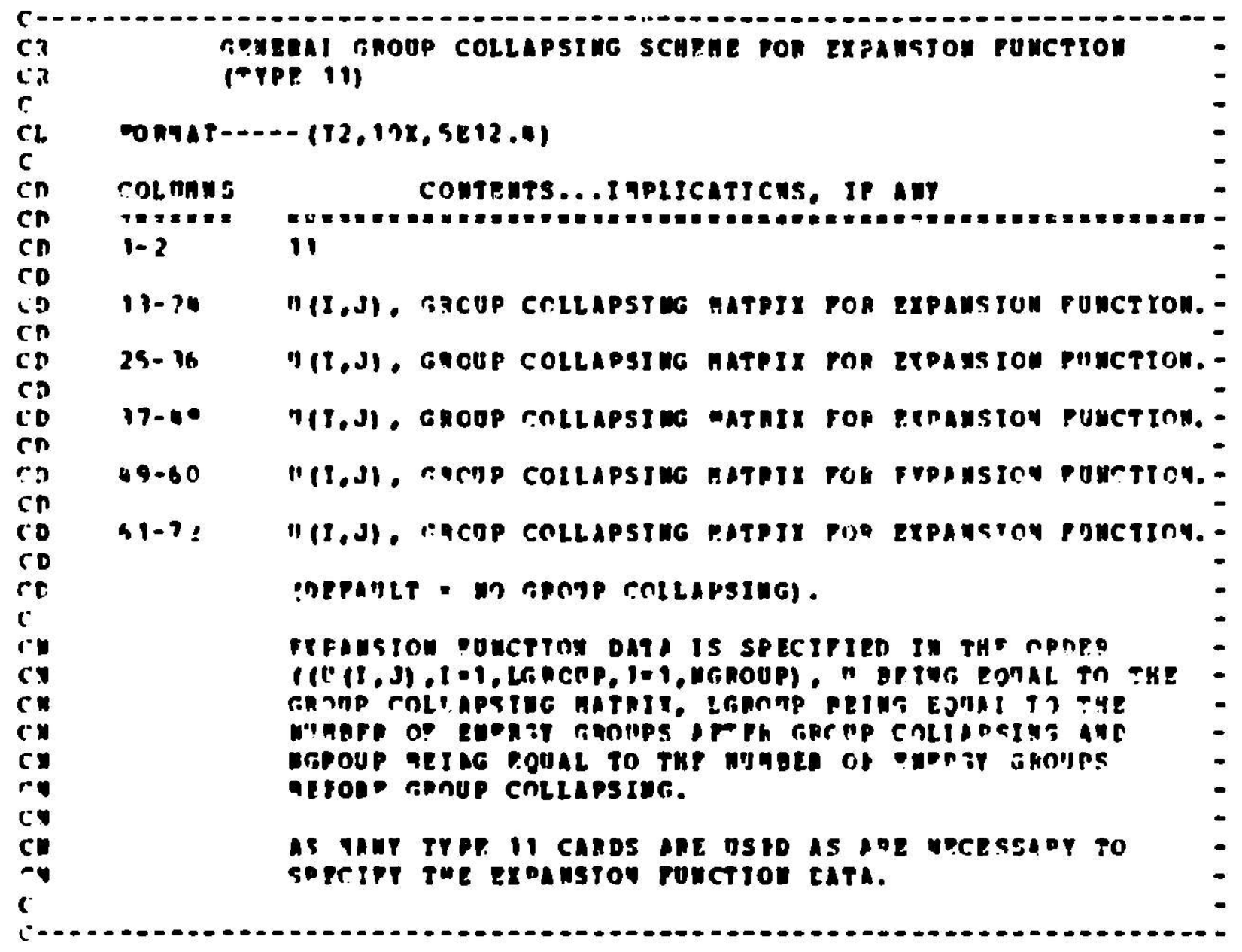


APPENDIX C. IMPUT DATA SET SYNEJL, (CONTD.)

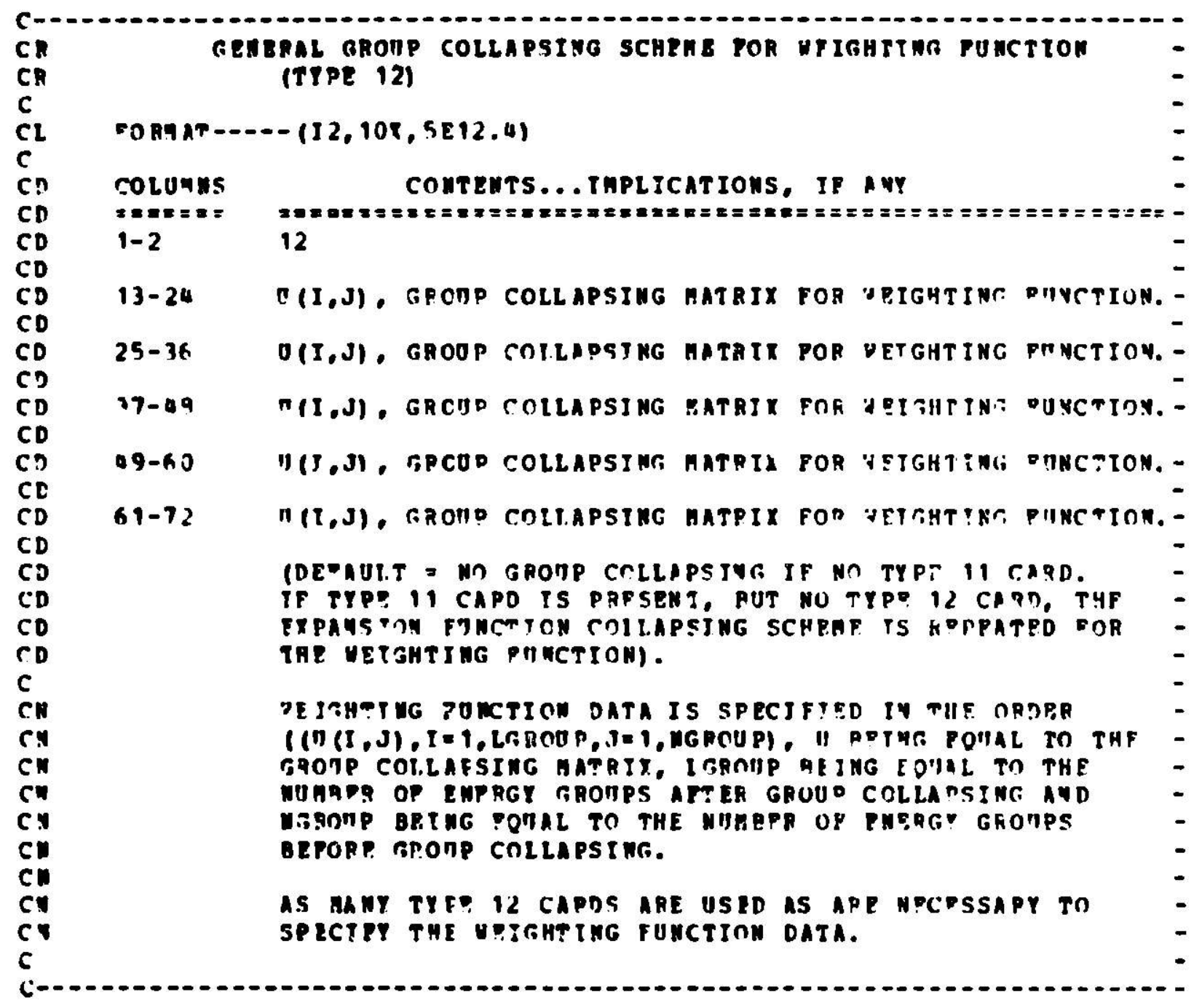


AEPENDIX D. INPOT DATA SPT SYNPIL. (CONTD.)

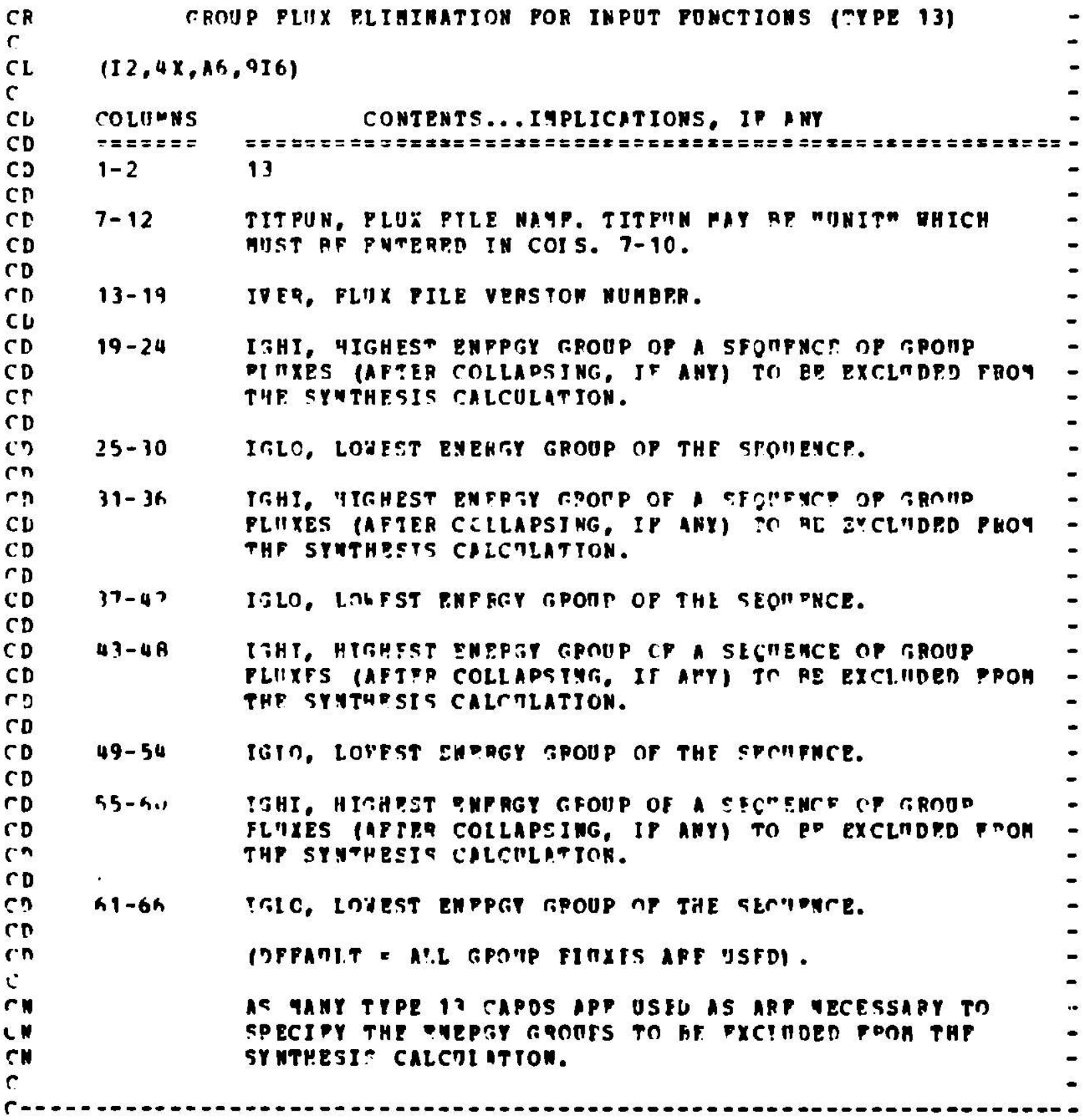


APPENDIX D. TMPO? DATA SET SYMFIL. (ENNTR.)

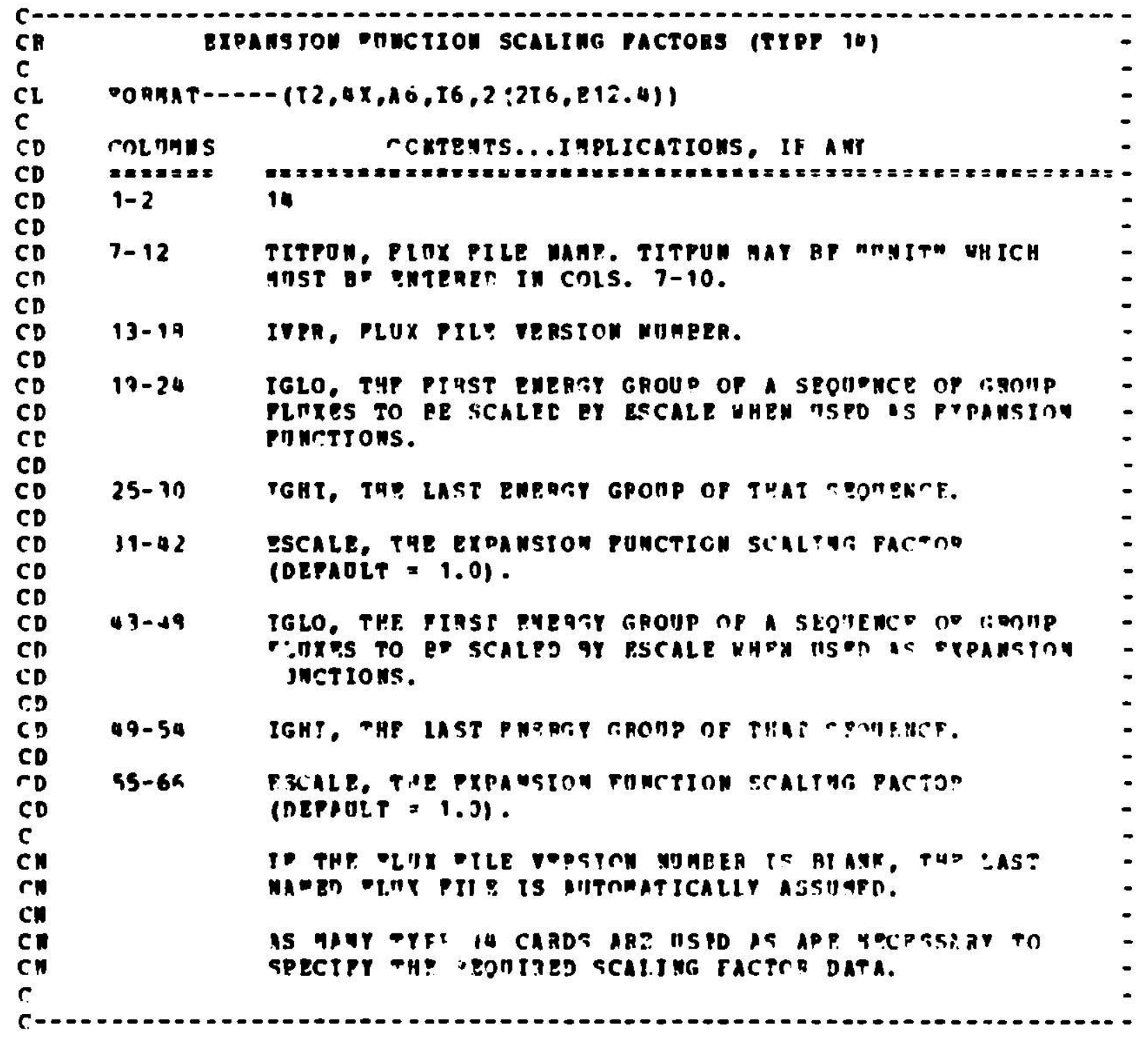


APPPNDYY D. INPOT NATA SET STHFTL. (CONTD.)

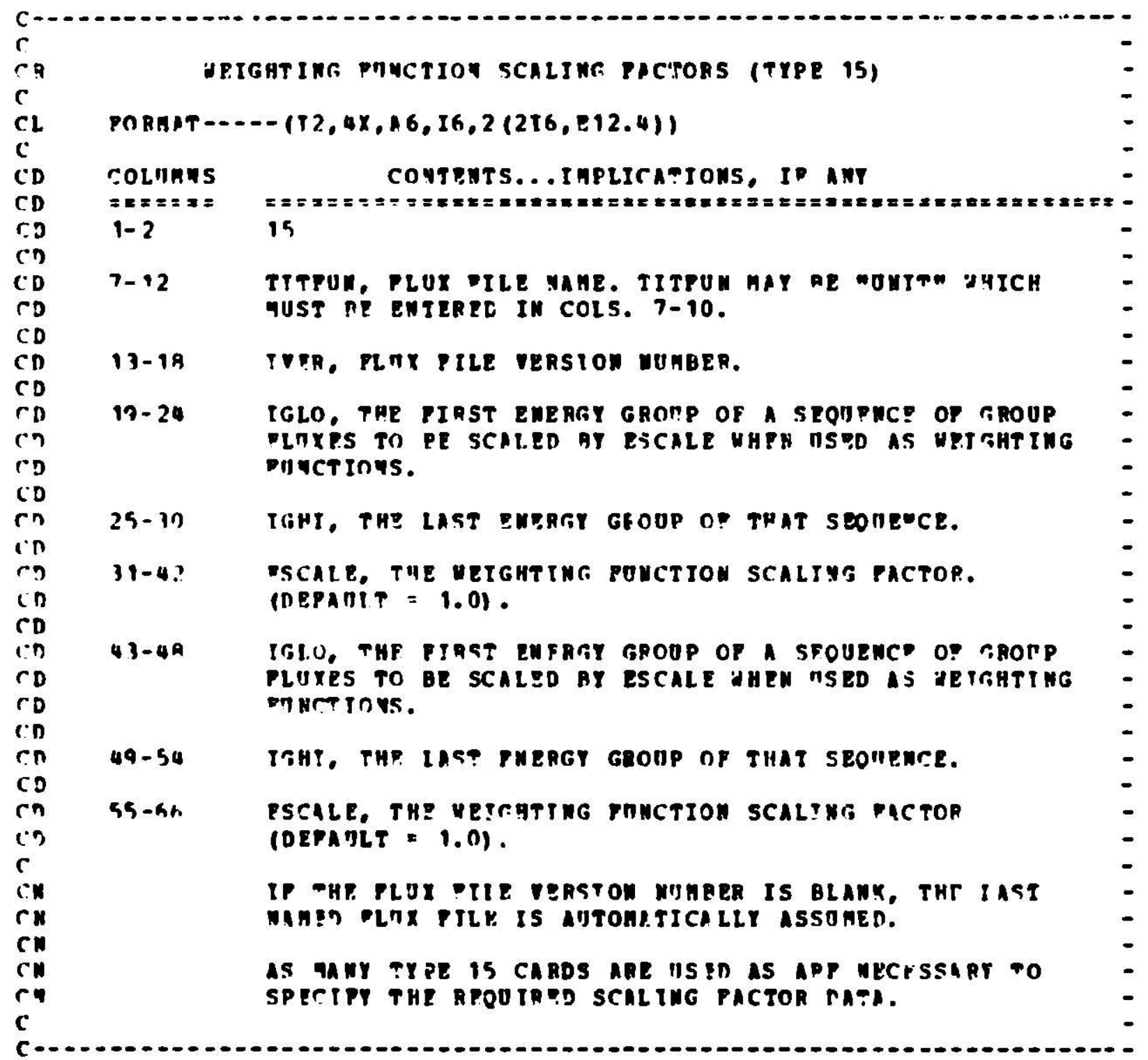


APPEWDTX D. INPOT DATA SET SIWYIL. (CONTO.)

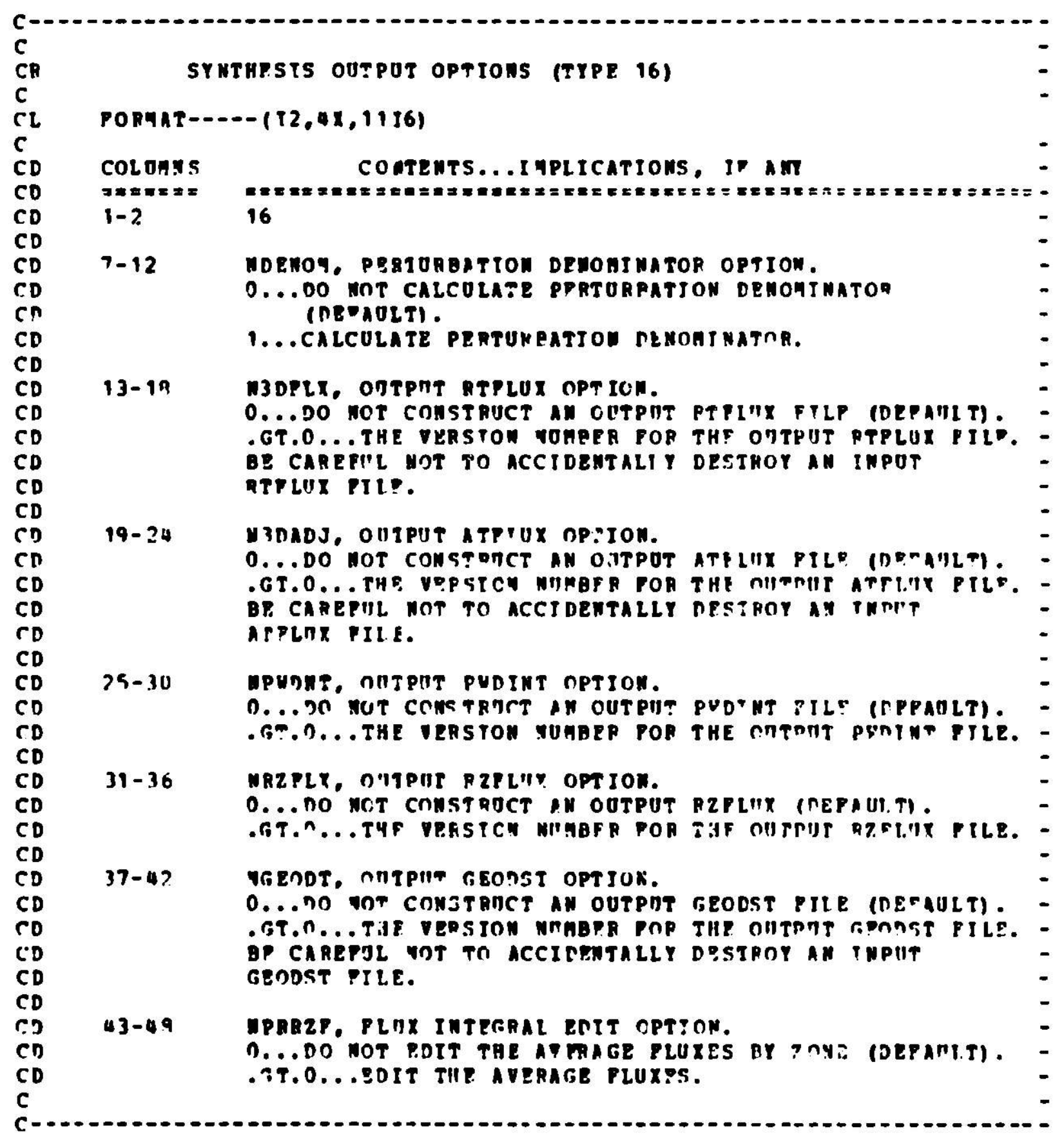


APPENIIX D. INPTT nATA SET SYNPIL. (CONTD.)

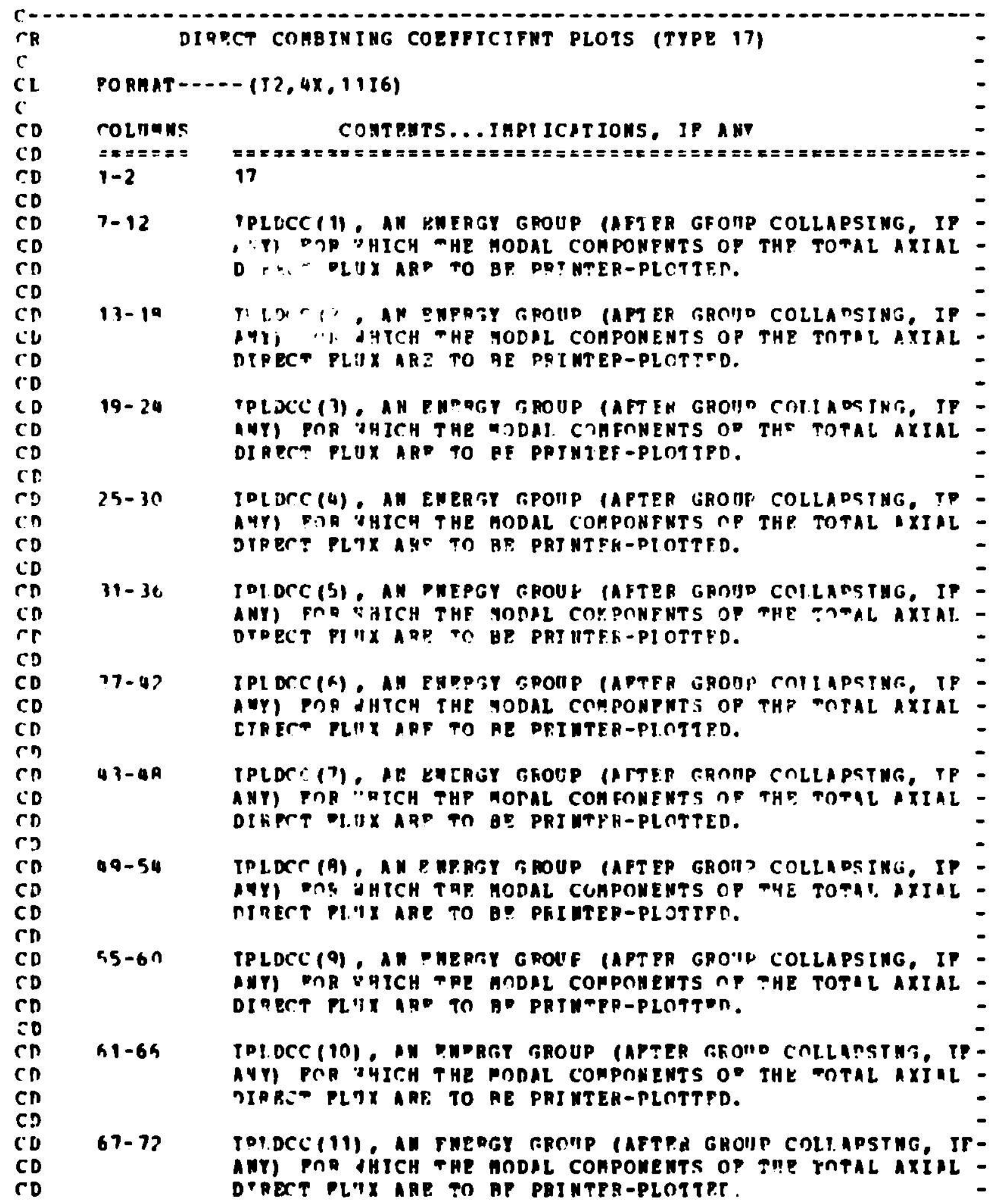


APPENDIX D. TNPUT DATA SET SYNFIL. (CONTD.)

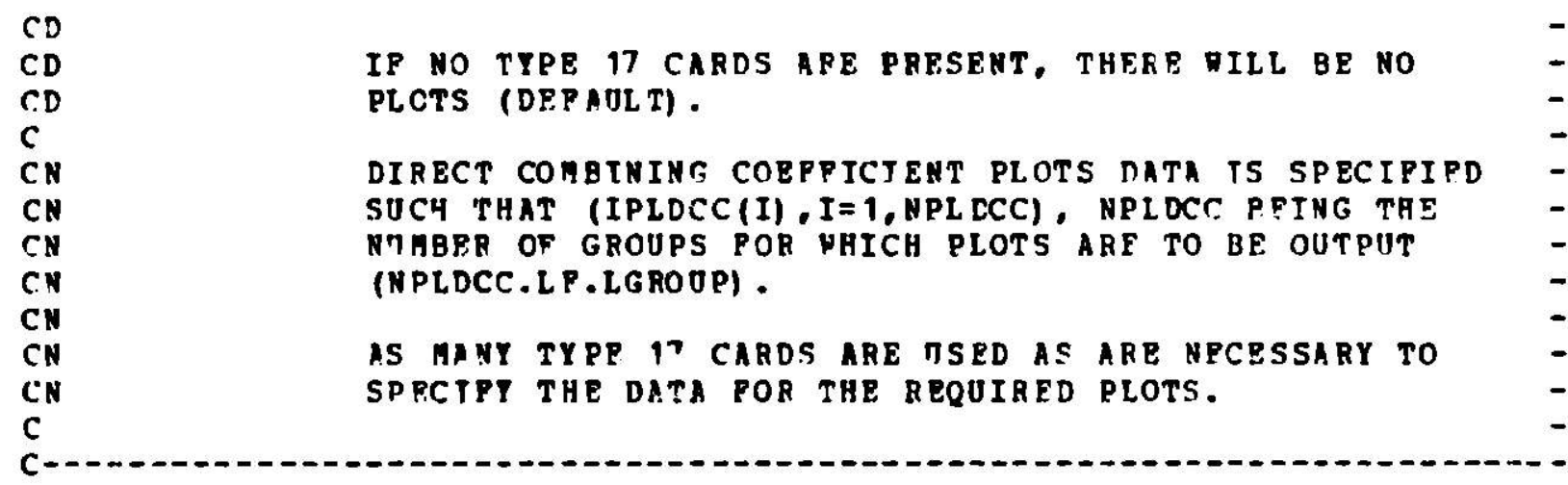

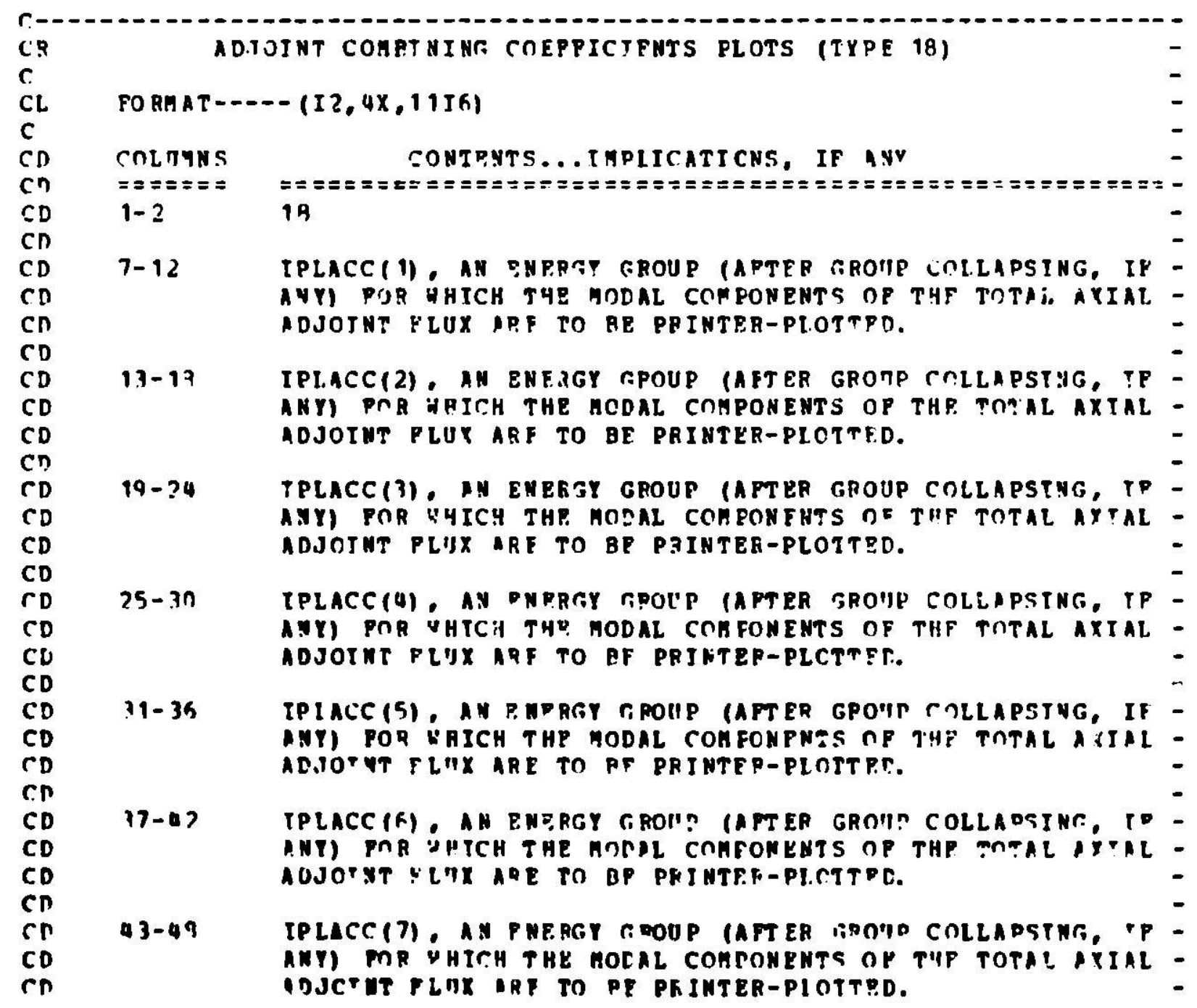


APPENDIX D. TNPOT DATA SET SYMPIL. (CONTD.)

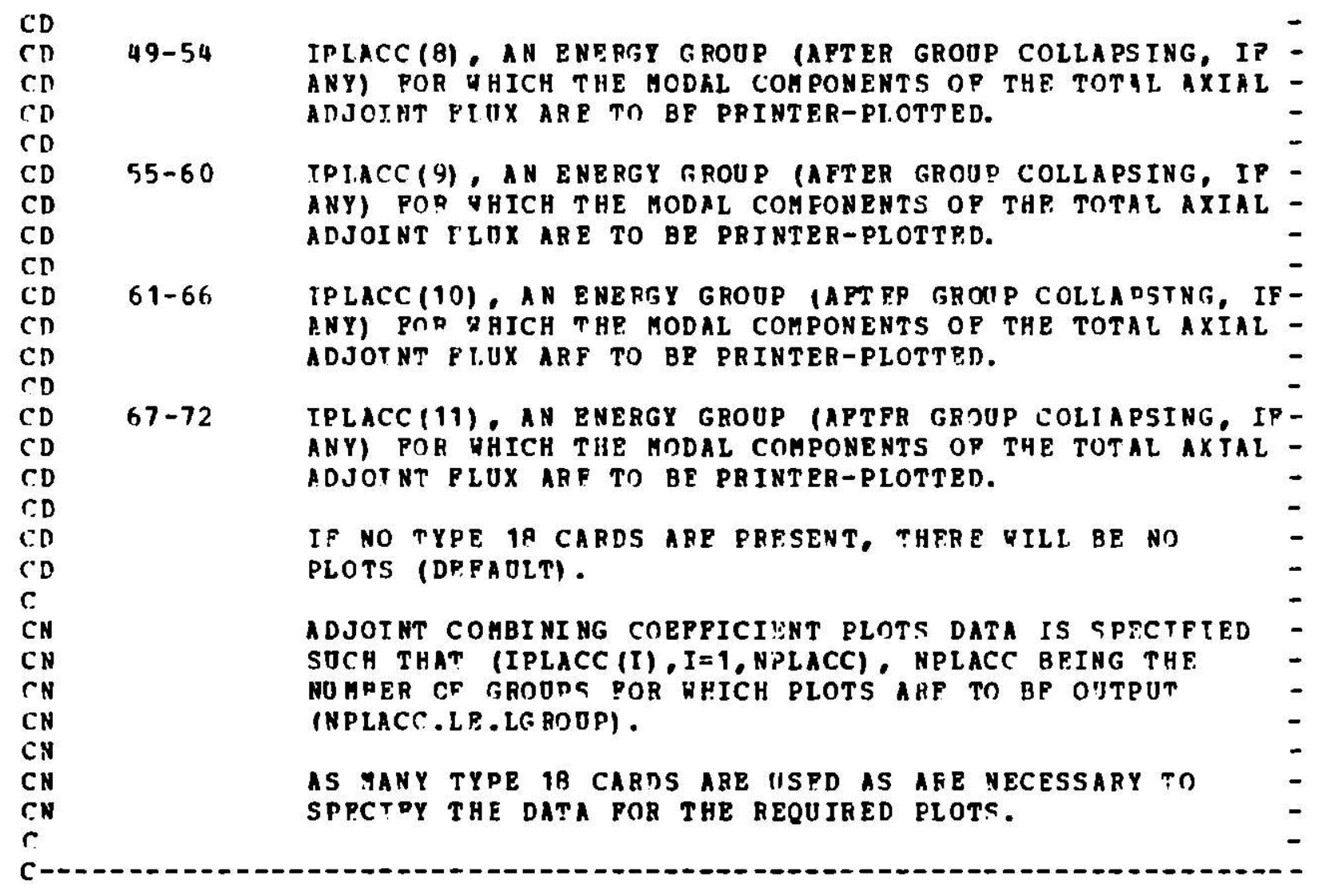


APPENDIX D. INPOT DATA SET SYHFIL. (CONTD.)

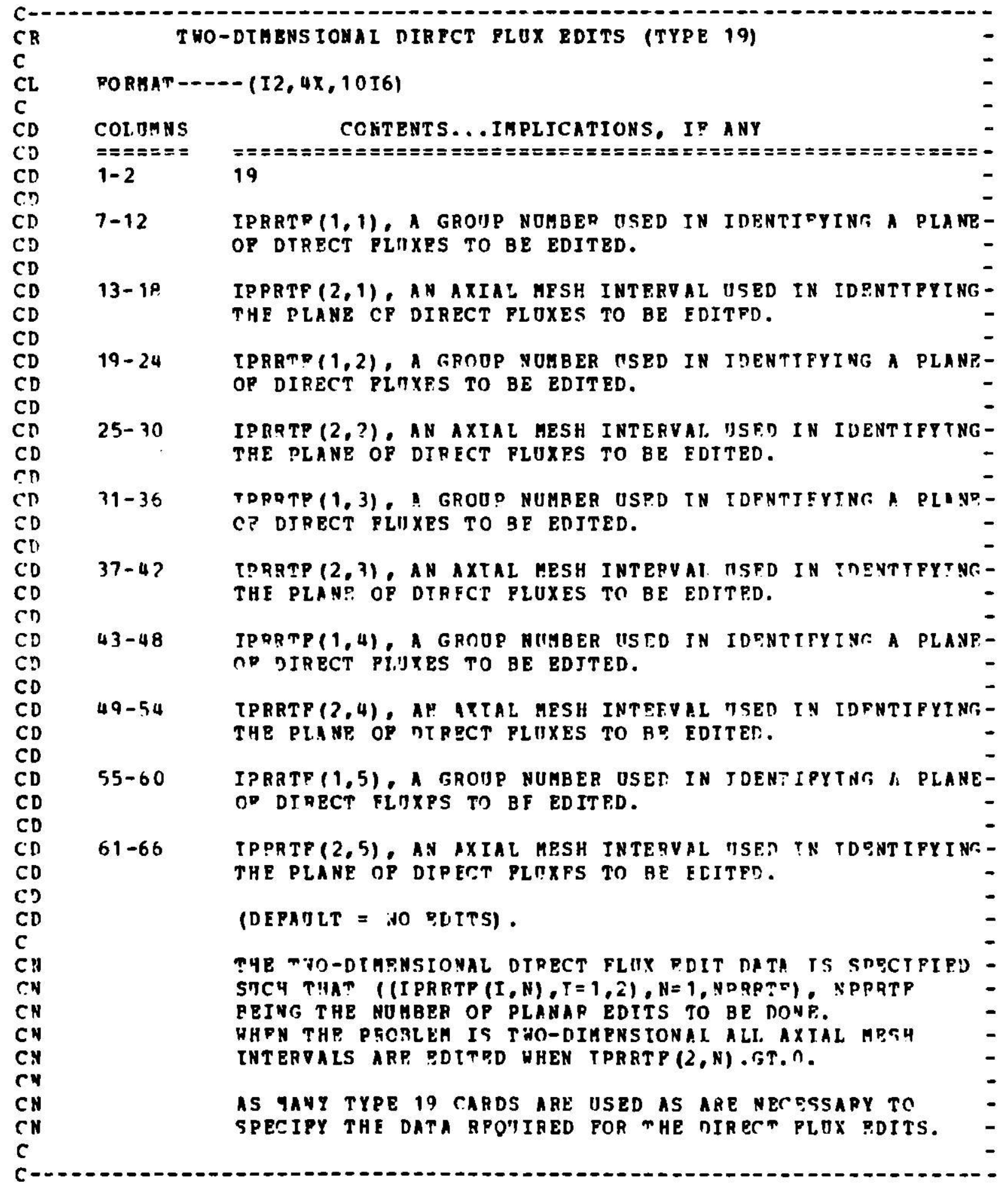


APPENDIX D. TNPUT DATA SET SYNPIL. (CONTD.)

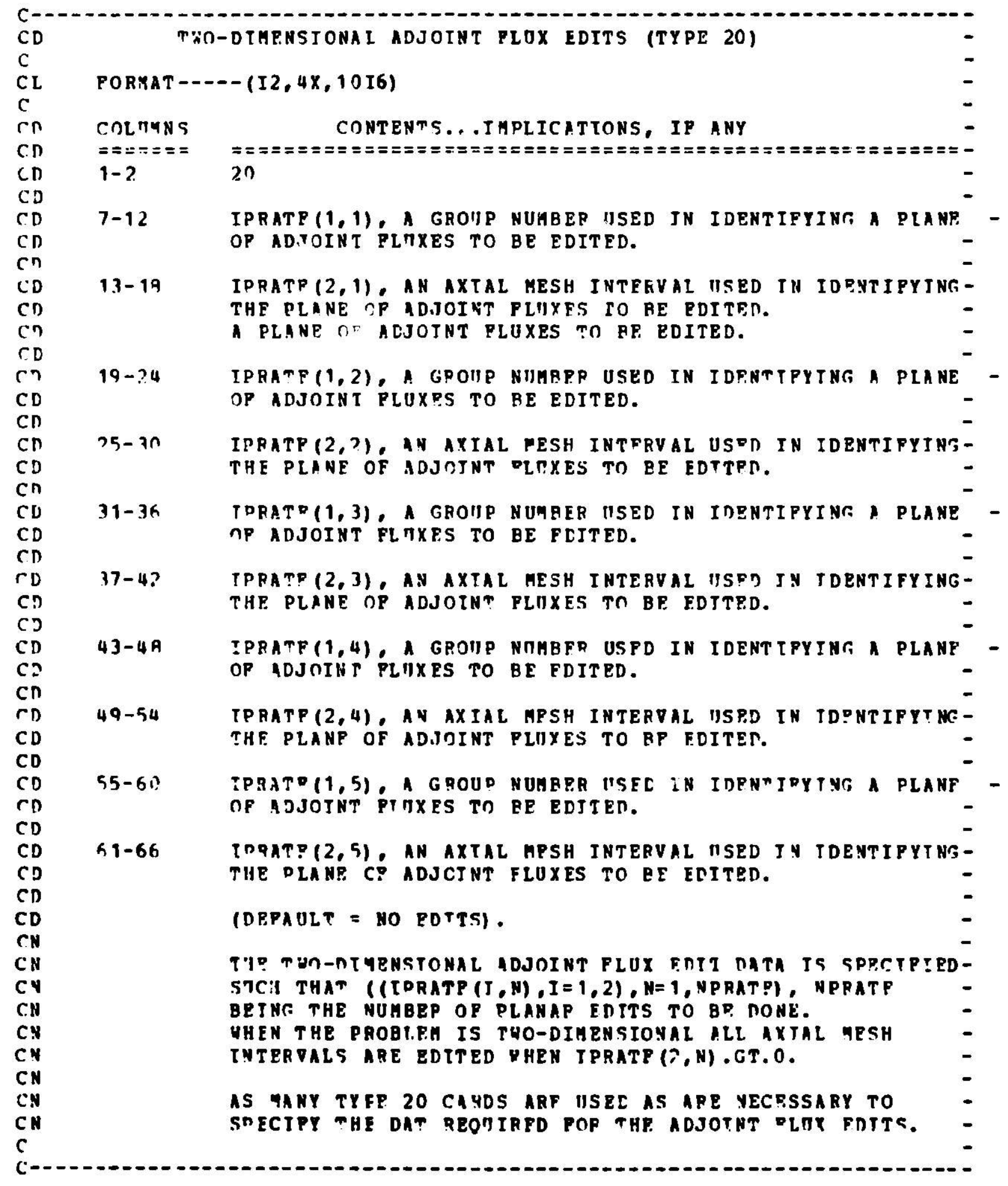


APPENDIX D. TAPUY DATA SET SYNPIL. (CONTD.)

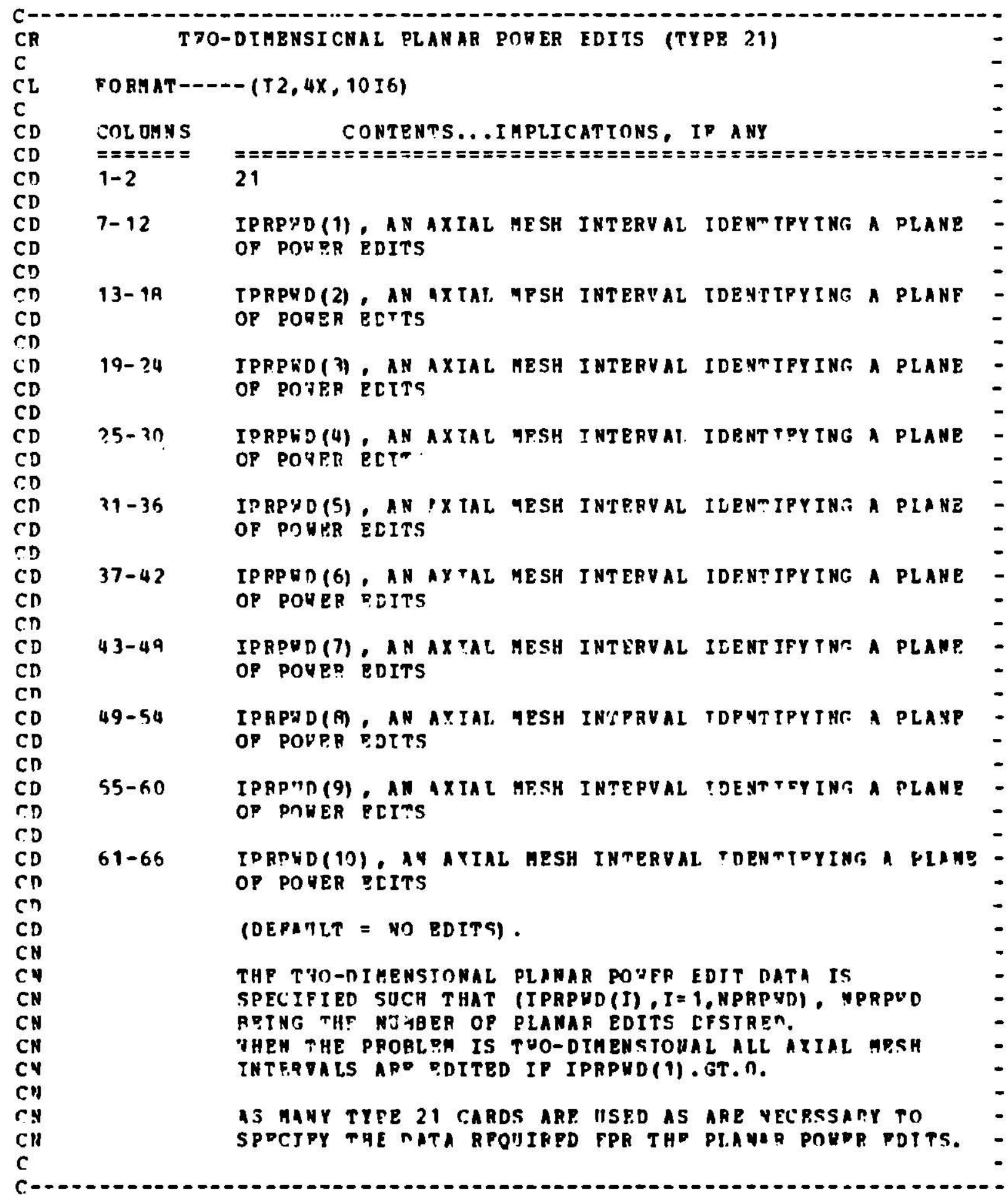

$\cos$ 
APPENDIX E. CODE-DEPENDENT BIMARY PILES. CONPXS.

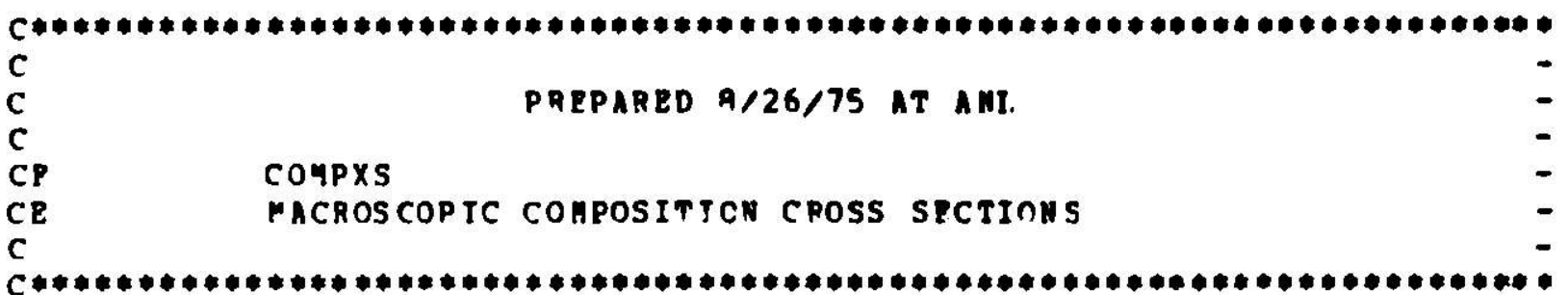

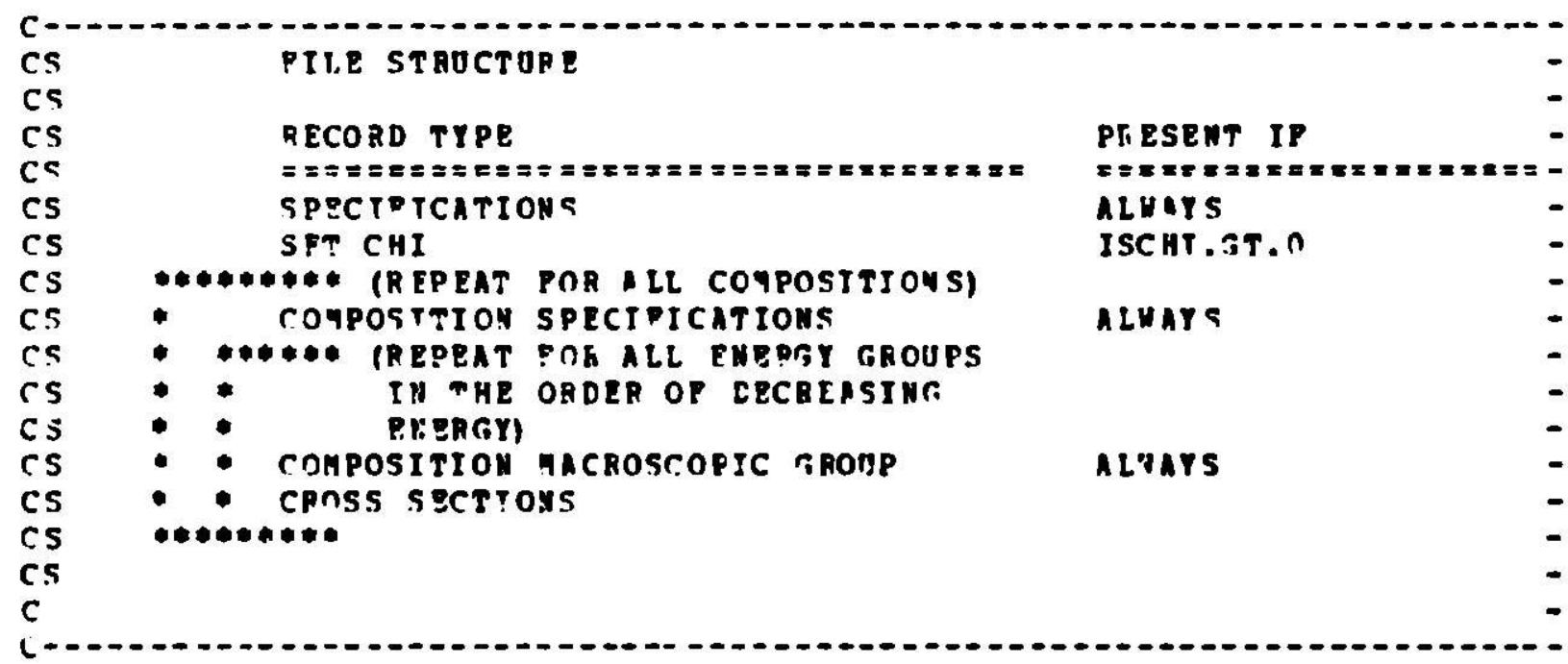

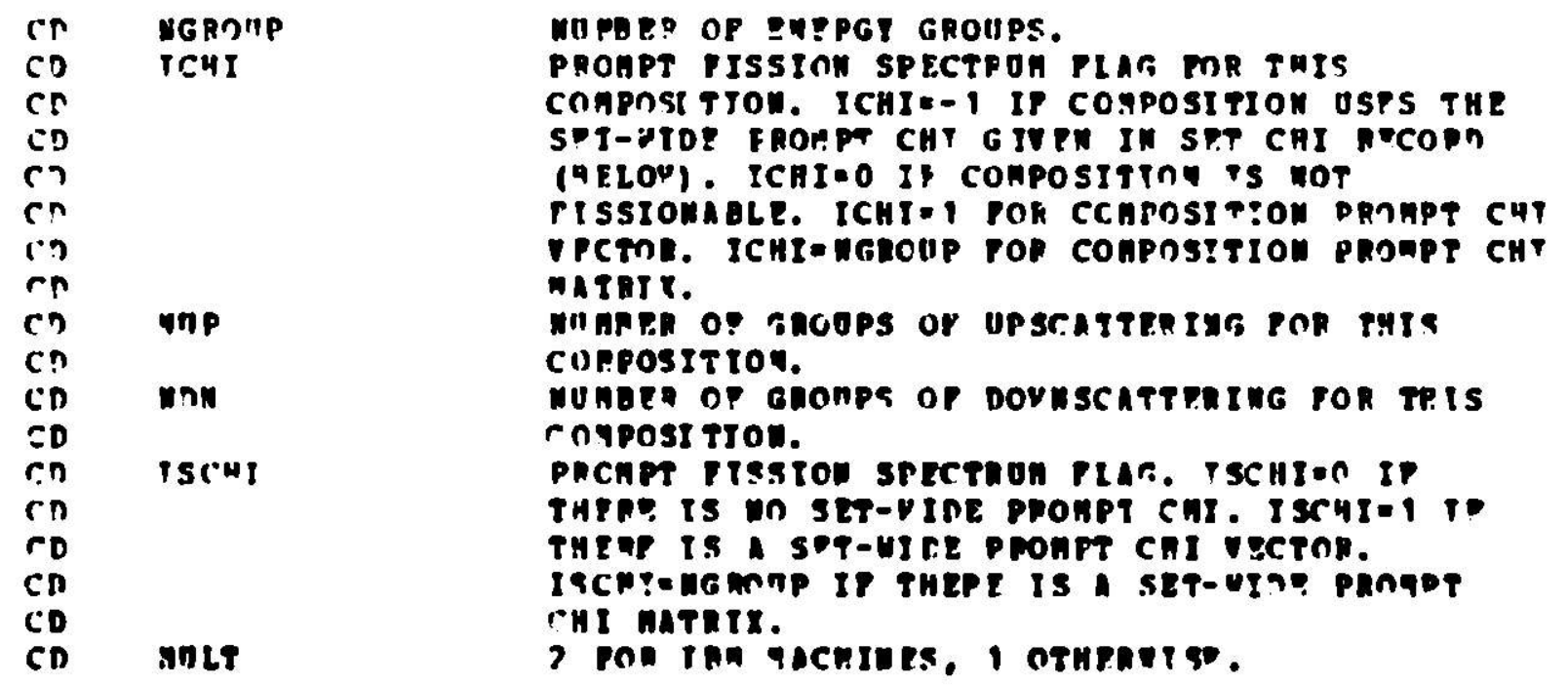


APPEUdi E. CODZ-DEPENDEnT RTMARY PILES (CONTD.). COAPXS.

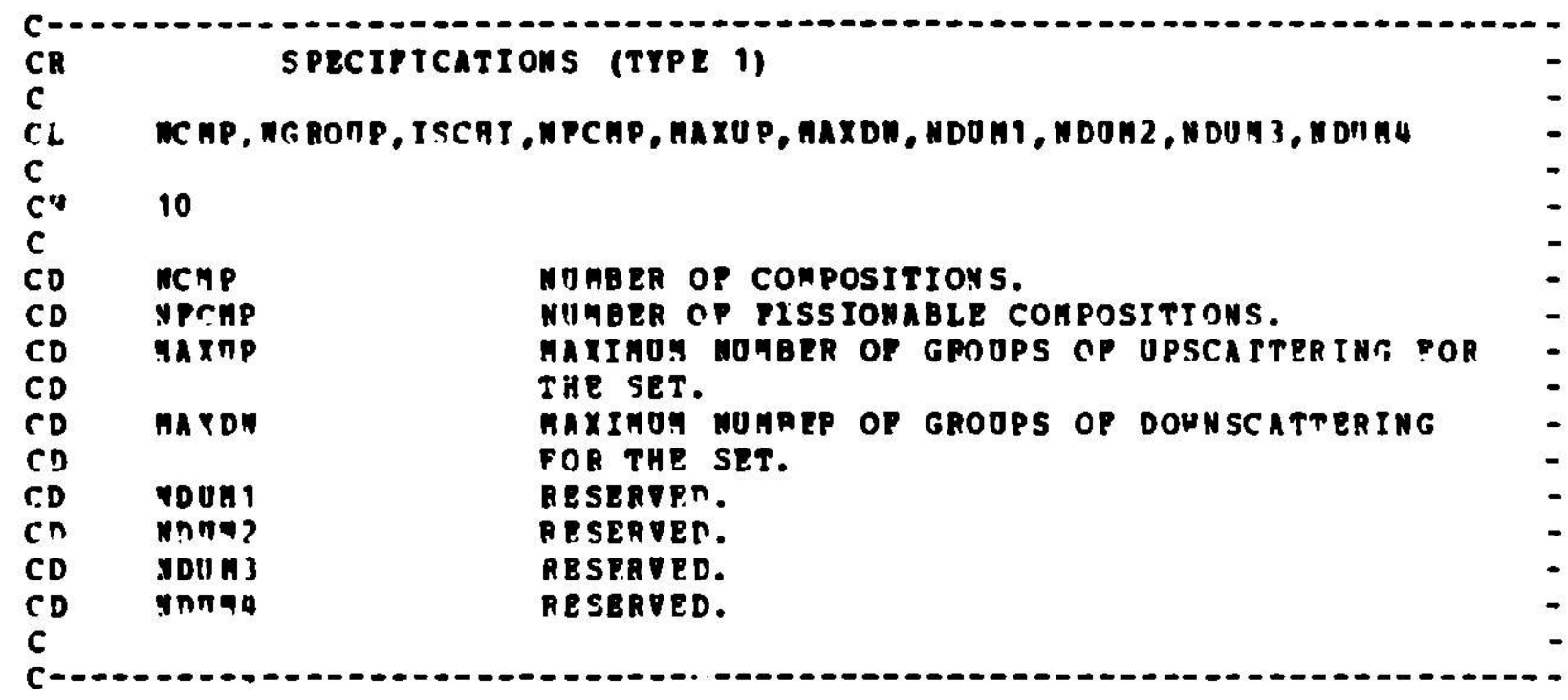
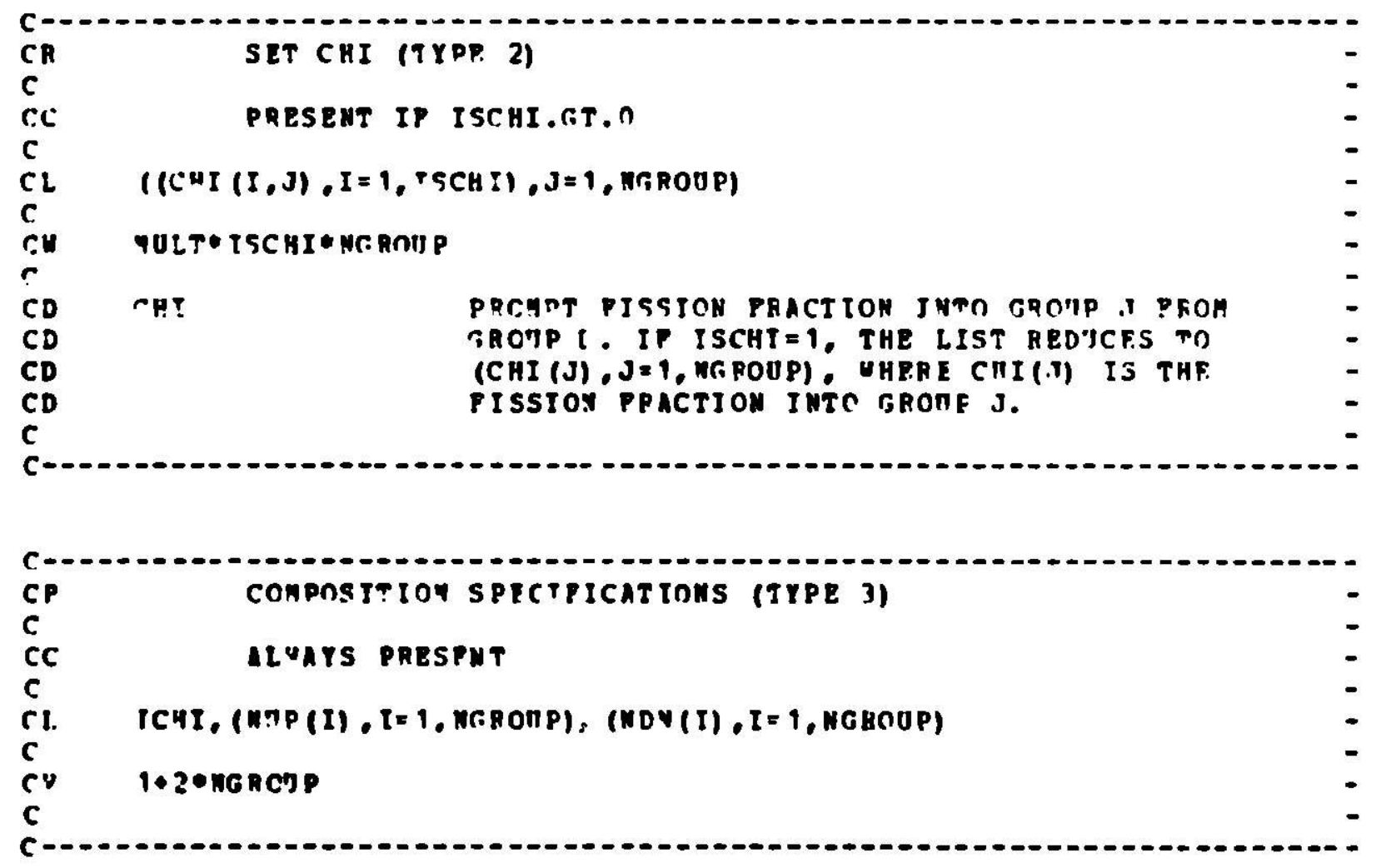
APPEYIIX E. CODE-DEPQNDENT BIAARY PILES (CONTD.). COMPXS.

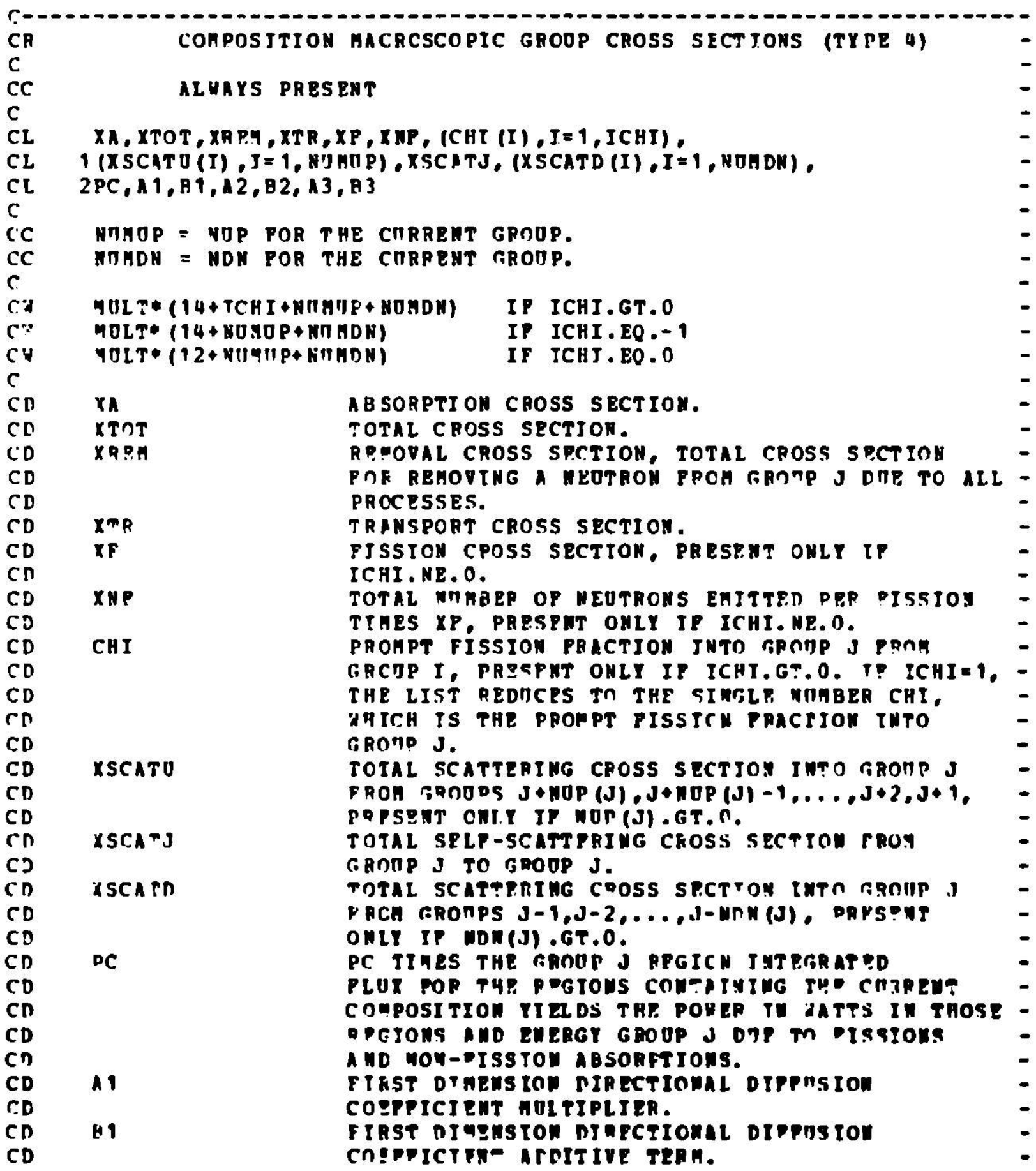


A PPENDIX E. CODE-DEPEHDERT BIMARY PILES (CONTD.). COMPXS.

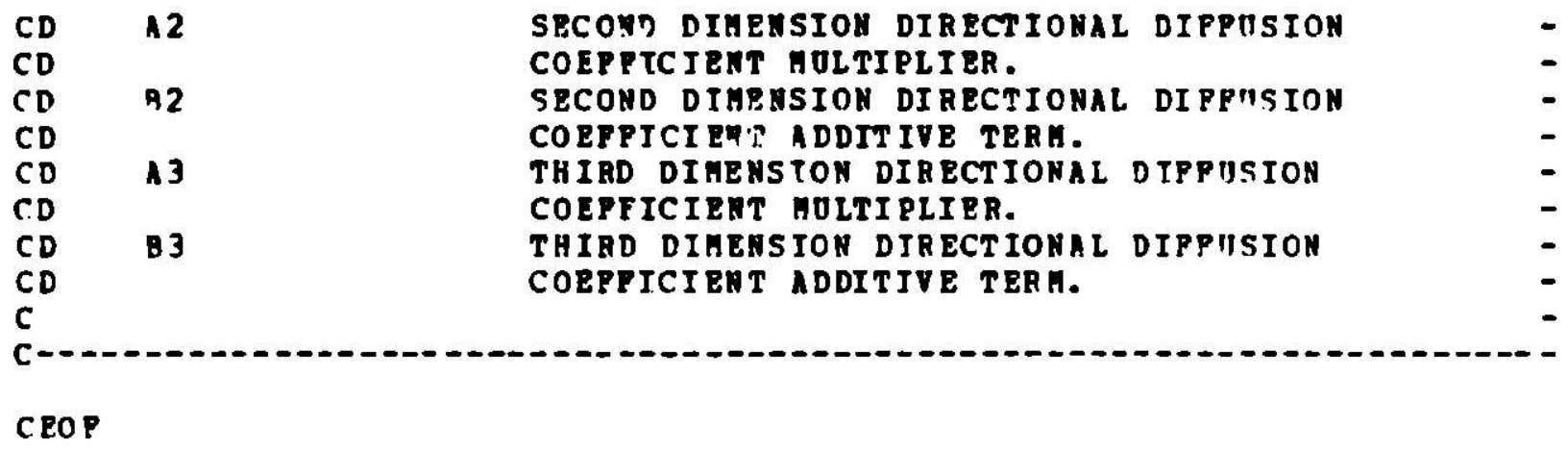


APPFN DIX R. CODP-DEPENDENT BINARY PILES (CONTD.). DCCOEP.

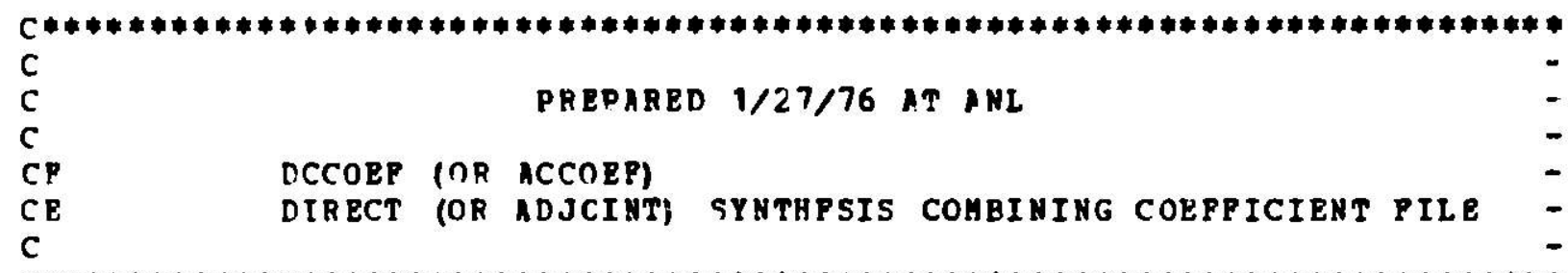

C

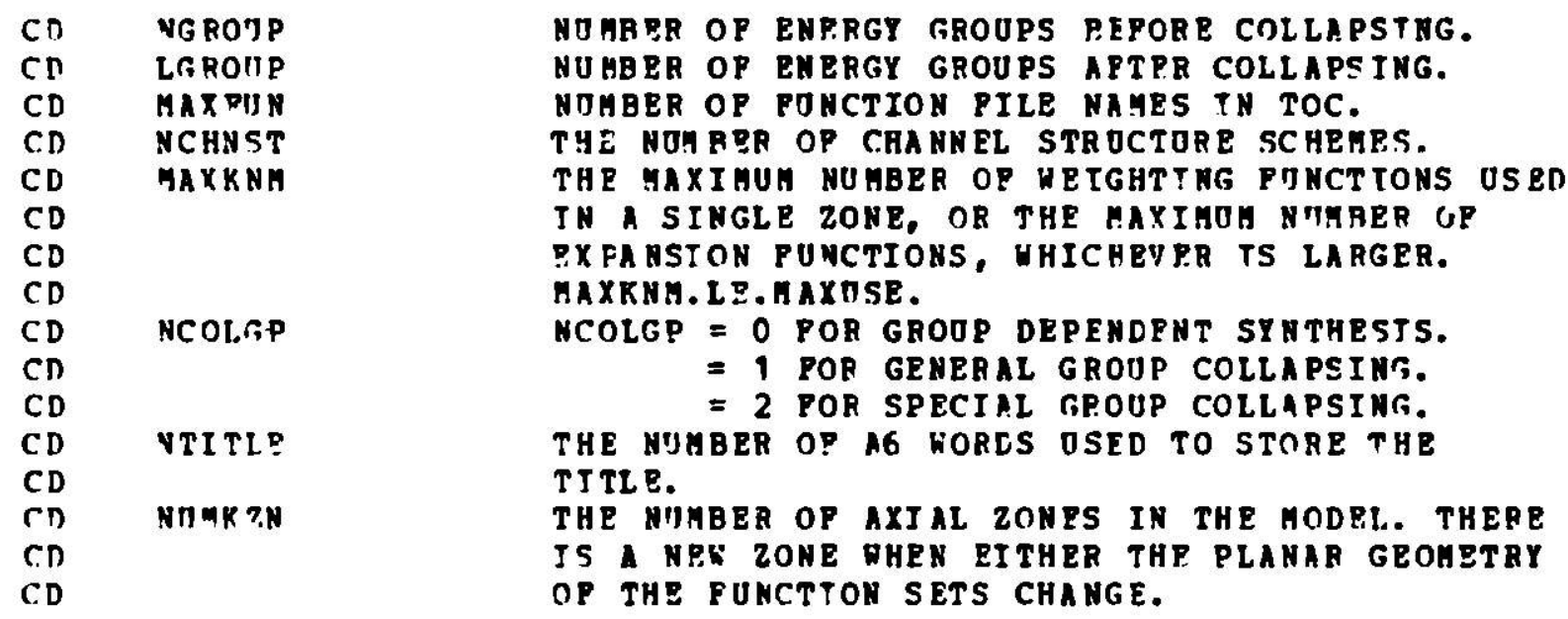

\begin{tabular}{|c|c|c|}
\hline Cs & PILP ST BUCTURE & - \\
\hline CS & & \\
\hline cs & RPCORD TYPP & PRESENT IF \\
\hline cs & 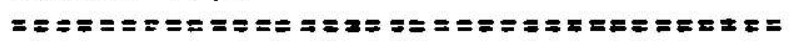 & 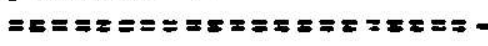 \\
\hline Ca & FILP INENTTPICATION & ALEAYS \\
\hline CS & SPECIPICATTONS & ALPAYS \\
\hline c's & FTYED POTYT ARAYY & ALYAYS \\
\hline CS & FLOATTYG POINT ARRATS & ALYAYS \\
\hline cs & COYATNING COEPITCIENTS & ALWAY \\
\hline
\end{tabular}

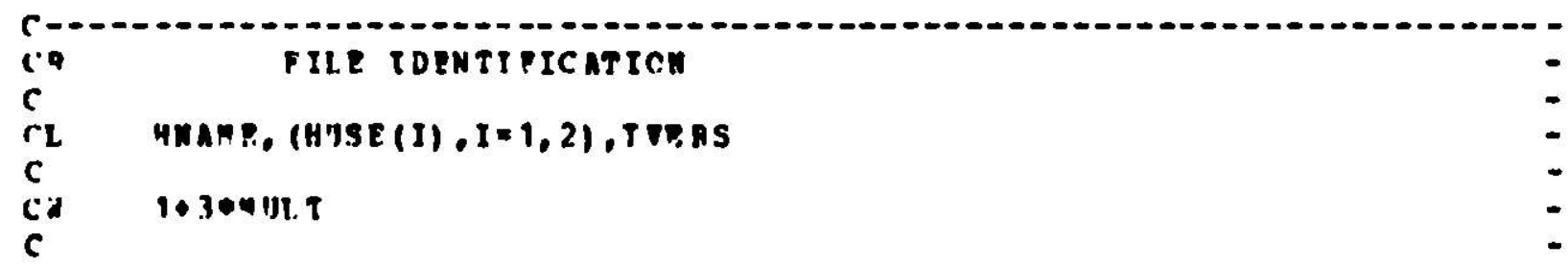


A PPENDIX E. CODE-DEPENDENT GI MARY PILES (CONTD.). DCCOEP.

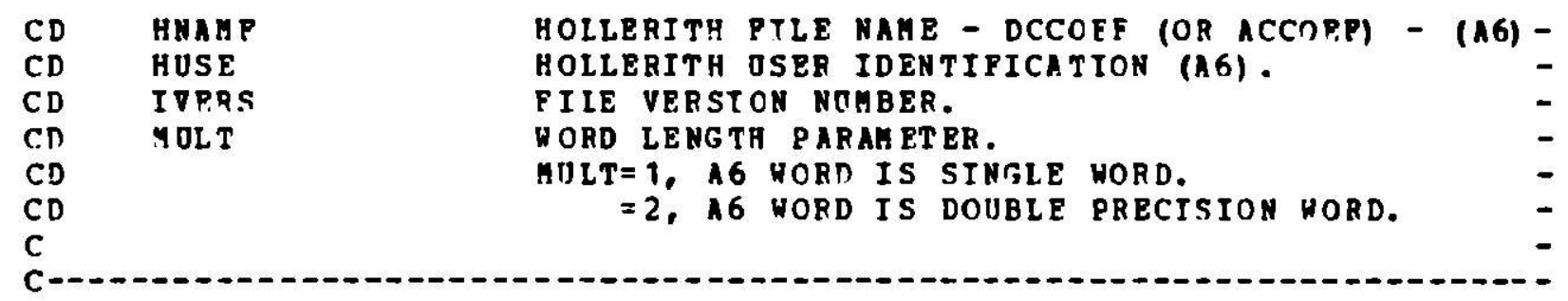

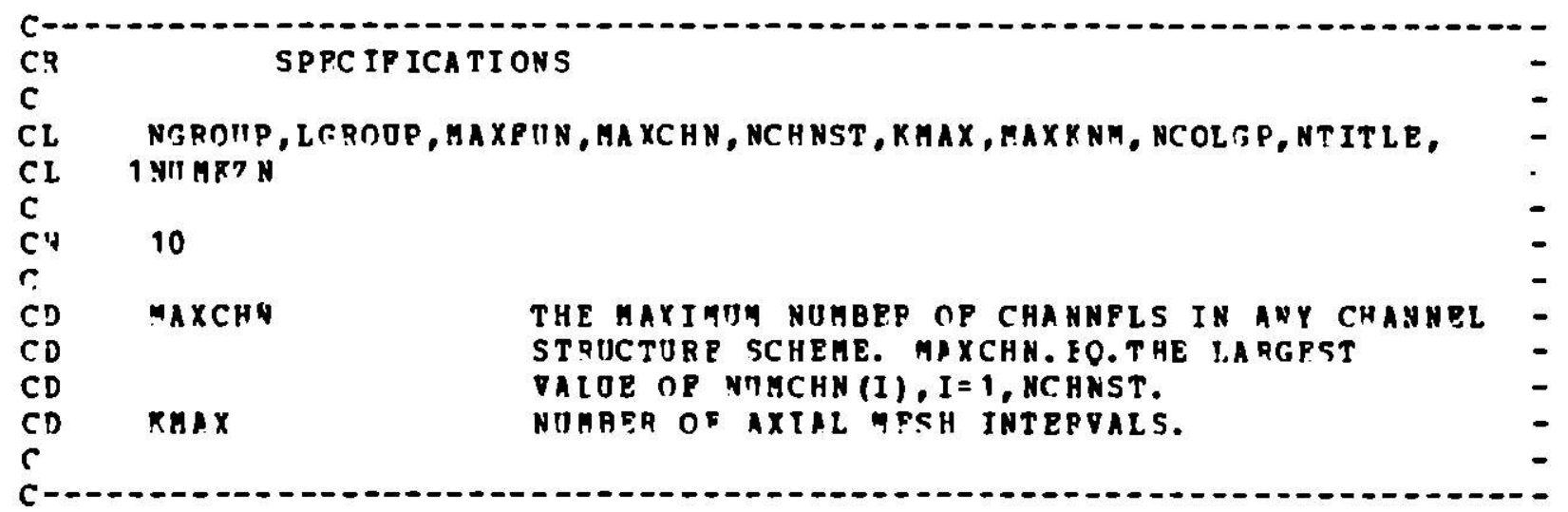

\begin{tabular}{|c|c|c|}
\hline $\begin{array}{l}\text { CR } \\
r\end{array}$ & PIYED POIN? & ARPATS \\
\hline $\begin{array}{l}C l . \\
C L \\
C L \\
C L \\
C L \\
C L \\
C\end{array}$ & 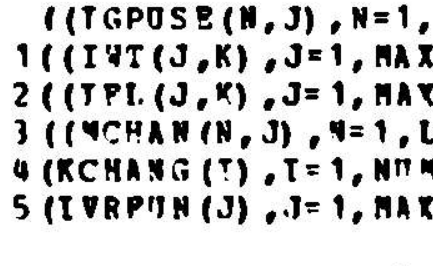 & 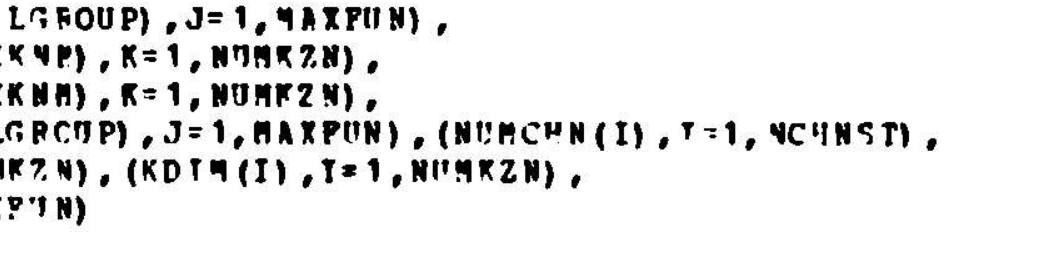 \\
\hline $\begin{array}{l}\text { c. } \\
\text { r }\end{array}$ & 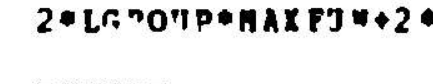 & MXKNM*NHAKZN+ HCHNST+2*NU HKZ N+HAXP\|N \\
\hline $\begin{array}{l}\text { CD } \\
\text { CD } \\
C D\end{array}$ & Tripise & 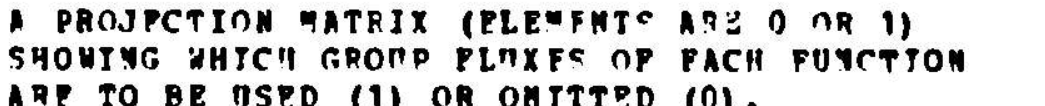 \\
\hline $\begin{array}{l}\text { cn } \\
\text { ch } \\
\text { ch }\end{array}$ & TVT & 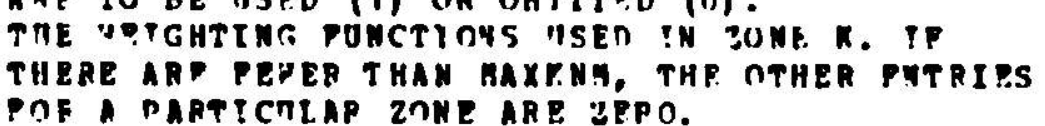 \\
\hline $\begin{array}{l}\text { CV } \\
\text { ro } \\
\text { rn }\end{array}$ & I PL & 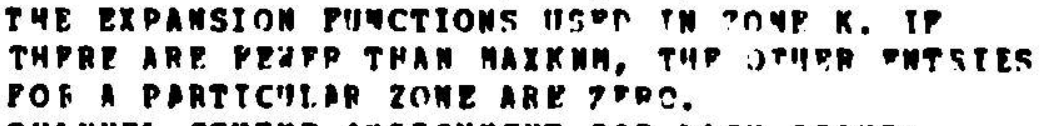 \\
\hline CD & MCHAN & $\begin{array}{l}\text { CHAWNEL SCHFYE ASSTGWHFWT POA EACH GROIIP- } \\
\text { COLLAPSED GROPP ELIXX. }\end{array}$ \\
\hline $\begin{array}{l}\text { CD } \\
\text { C }\end{array}$ & Мпюсни & $\begin{array}{l}\text { MOMGDR OF CHAMMELS IU CHAMYE: STRICTHAE } \\
\text { SCHEME T. }\end{array}$ \\
\hline
\end{tabular}


APPENDTI E. CODE-DEPENDENT BINART PILES (CONTD.). DCCOEP.

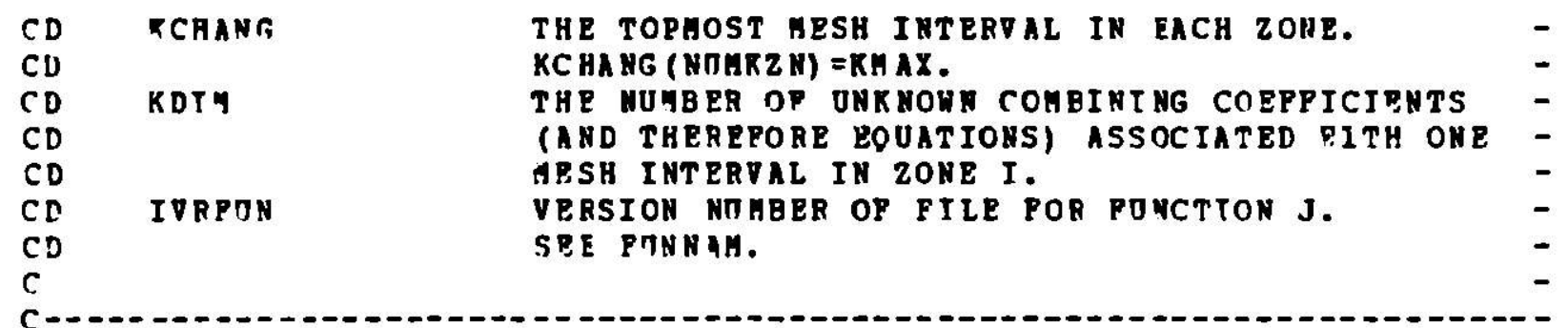

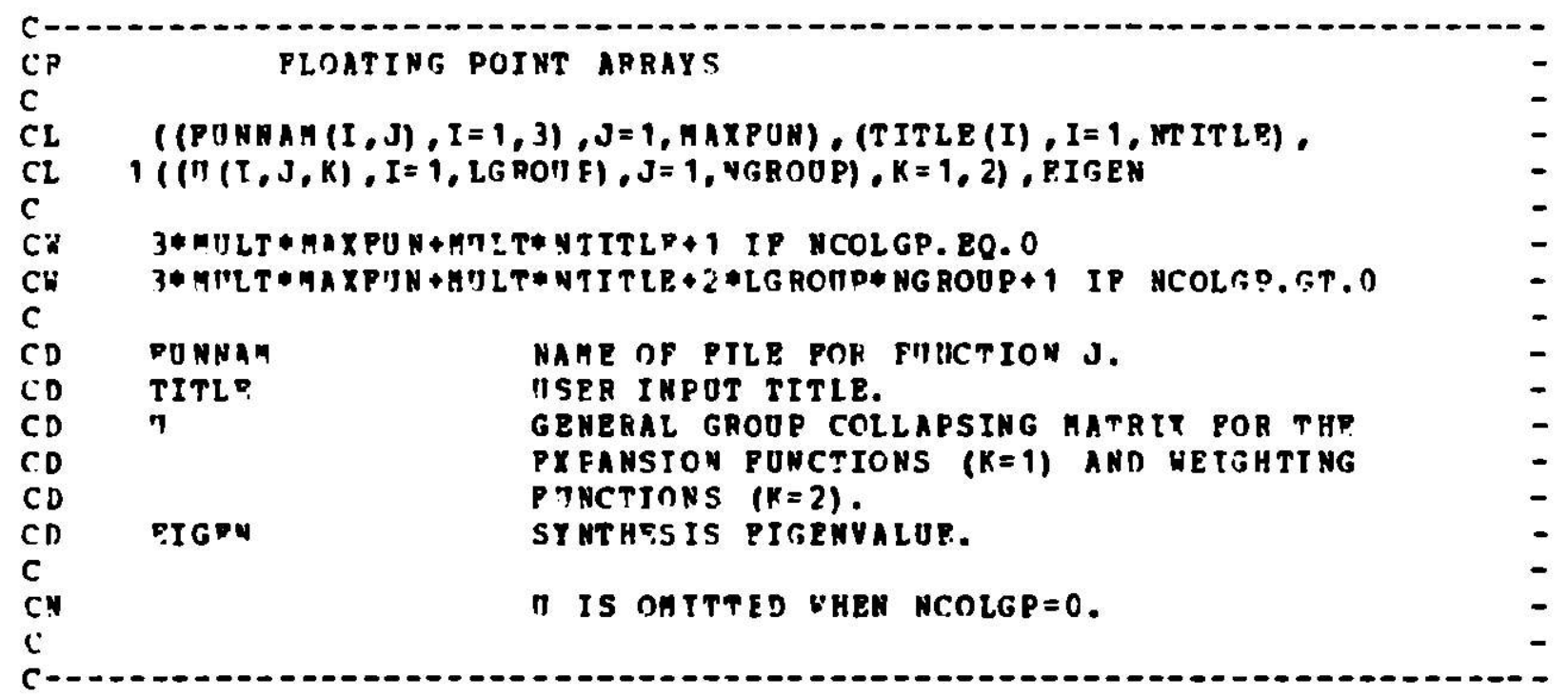


APPFNDTX E. CODE-DEPRNDENT BINATY EILES (CONTD.). DCCORF.

\begin{tabular}{|c|c|c|c|}
\hline $\begin{array}{l}\text { CR } \\
\text { C }\end{array}$ & COMB IN ING & CCEPFICIFNTS & $\overline{-}$ \\
\hline $\mathrm{CL}_{\mathrm{L}}$ & $(A(I), T=1, L Z N A)$ & & - \\
\hline C & & & - \\
\hline $\begin{array}{l}\mathrm{CH} \\
\mathrm{C}\end{array}$ & LENA & & - \\
\hline D & $\mathbf{A}$ & SYNTHESTS COMEINING COEFPICIENTS, PACKED TO & - \\
\hline$C D$ & A & $\begin{array}{l}\text { SYNIHESTS COHEINING COEFPICIENTS, PACKED TO } \\
\text { ELIATNATE ZEROS. }\end{array}$ & - \\
\hline $\begin{array}{l}C D \\
C D\end{array}$ & T.P.NA & $\begin{array}{l}\text { THE TOTAL NHMBER OP NONZERO COMBINING } \\
\text { COEPPICIENTS. }\end{array}$ & - \\
\hline C & & & - \\
\hline$C$ & & THR DIPECT COMPINING COEFFICIENTS, $\mathrm{CC}(\mathrm{H}, \mathrm{I}, \mathrm{K})$, & - \\
\hline $\mathrm{CN}$ & & ASSOCTATED WITH FACH COLLADSED GROMP (N), & - \\
\hline $\begin{array}{l}C N \\
C N\end{array}$ & & EXPANSTCN PONCTION (I) ANC AXIAL MPSH TNTERVAL & - \\
\hline $\begin{array}{ll}C N \\
C N\end{array}$ & & $\begin{array}{l}\text { (K) CAN BE UNPACKED FROM VECTOR A IN THE } \\
\text { POILCJING MANNER. }\end{array}$ & $\overline{-}$ \\
\hline $\mathbf{C N}$ & & & - \\
\hline $\mathbf{C N}$ & & DTMENSICN CC (LGROUP, MAXFON, KAAX) & - \\
\hline CN & & & - \\
\hline CN & & NPT $T=0$ & - \\
\hline CN & & K? $=0$ & - \\
\hline C. & & $\begin{array}{l}\text { no } 20 \quad L=1, N U M K Z N \\
K 1=K 2+1\end{array}$ & - \\
\hline CN & & & - \\
\hline CN & & DO $20 \mathrm{~K}=\mathrm{K} 1, \mathrm{~K} 2$ & - \\
\hline CN & & DO $20 H=1, \operatorname{MAXKNA}$ & - \\
\hline CN & & $I=T P L(N, L)$ & - \\
\hline : v & & $I=(I .50 .0)$ GO TO 20 & - \\
\hline CN & & nn $10 \mathrm{~N}=1, \mathrm{~L}$ (G) RODP & - \\
\hline CN & & $\operatorname{CC}(N, I, K)=0$ & - \\
\hline CH & & IF (IGPUSE (H,I),EQ,C) GO TO 20 & - \\
\hline $\mathrm{CN}$ & & NPT $=N P T+1$ & - \\
\hline $\mathrm{CN}$ & & $\operatorname{CC}(N, I, K)=A(N F T)$ & - \\
\hline $\mathrm{CN}$ & & 10 CONTTNES & - \\
\hline $\mathbf{r y}$ & & 20 CONTINIE & - \\
\hline $\mathrm{rh}$ & & POR TAP ADUYHT COMBTHTHG COEPPTCTPUT ITY THE & - \\
\hline CN & & ACORP PTLF) \#SE IUT $(H, L)$ INGTEAC OP IDI $(\Psi, L)$. & - \\
\hline C & & & - \\
\hline
\end{tabular}


APPENDIX E. CODE-DPPENDENT BINART PILES (CONTD.). DIPINT.

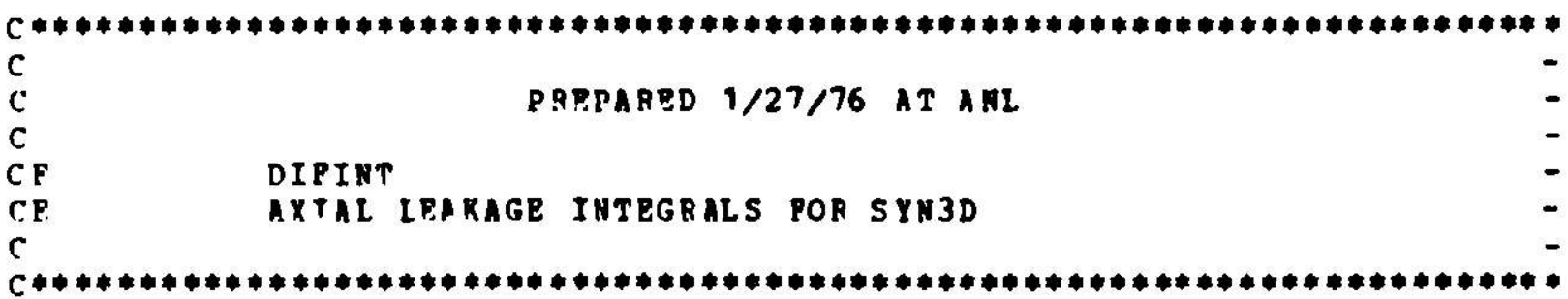

CD NRCDIP NOABER OP RECORDS IN DIPIAT PILE (SEE

CD SDECIPICATIONS RECORDS OP INTTOC PILE).

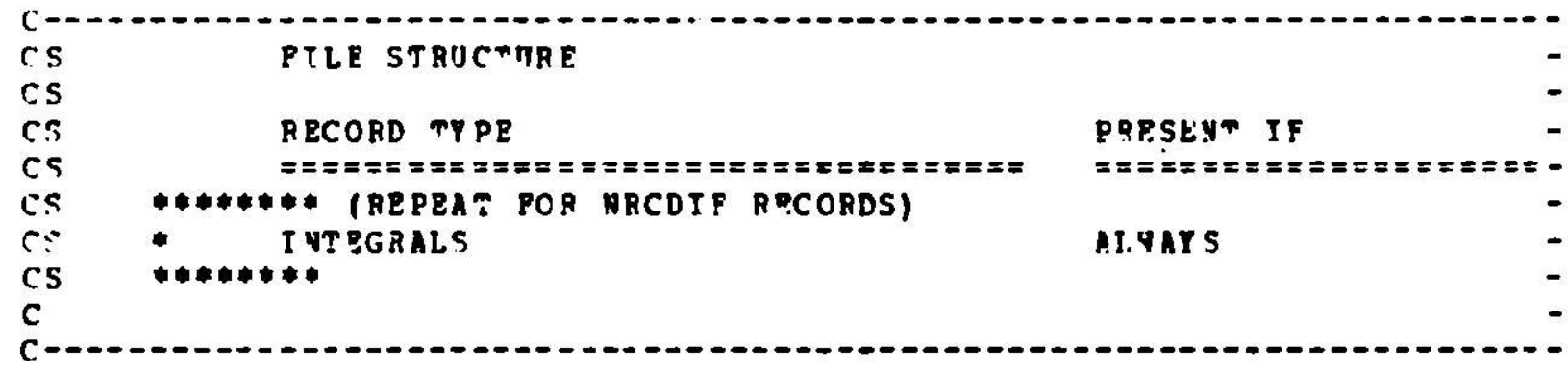

\begin{tabular}{|c|c|c|}
\hline $\begin{array}{l}C A \\
C\end{array}$ & TNTRGRALS & \\
\hline CL & $(X(I), I=1, L: N)$ & \\
\hline Cy & ATLT*I.F.N & \\
\hline$c$ & & \\
\hline $\begin{array}{l}C D \\
C D\end{array}$ & $\mathbf{X}$ & $\begin{array}{l}\text { A DIP THTEGRAL. SEE THE IHTEGRAL TABLE OP } \\
\text { COHTENTS IDIPTB IN THE IMTTCC FILP. }\end{array}$ \\
\hline CD & LP.H & RECORD L RHGTA. LFN=LERDIP(I) POR ARCARA I \\
\hline CD & LENTP & SBE FIXED POTMT ARRAYS IN INTTDC VILF. \\
\hline CD & & $\begin{array}{l}\text { THE DIP THTBGRALS ARE STORES TN THP FOLLOUJUG } \\
\text { PORHS. }\end{array}$ \\
\hline CD & & $\begin{array}{l}\text { I: MSTDJP } 0 \text { (ONLY IF THE DTP MATPIX IS } \\
\text { BIOCK DIAGONAL). }\end{array}$ \\
\hline $\begin{array}{l}C D \\
C D \\
C D\end{array}$ & & 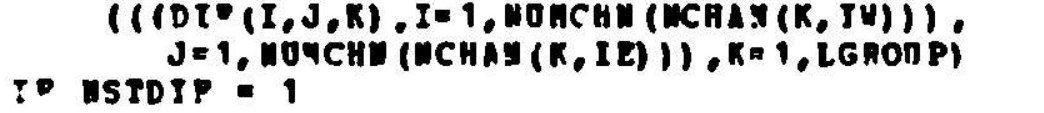 \\
\hline $\begin{array}{l}\text { CD } \\
\text { CD } \\
\text { CD }\end{array}$ & & 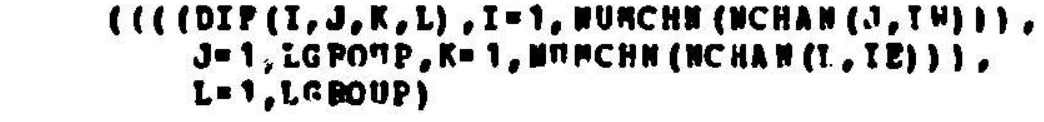 \\
\hline
\end{tabular}


APPENDIX E. CODE-DEPENDENT BTHARY PILES (CONTD.). DIFINT.

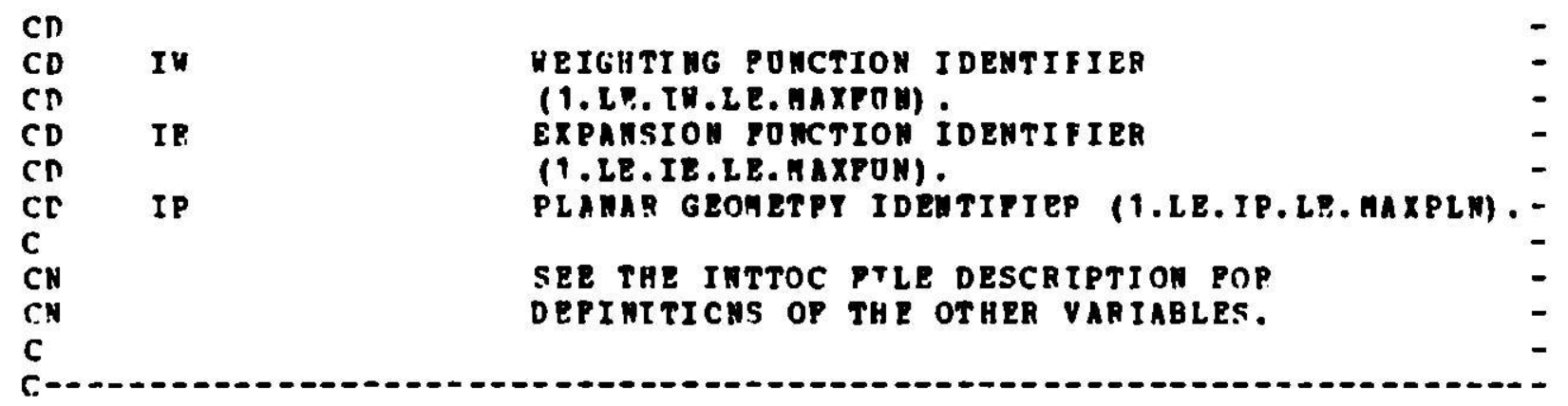

CEOP 
APPENDIX E. CODE-DEPENDENT BIMARY PILES (CONTD.). INTTOC.

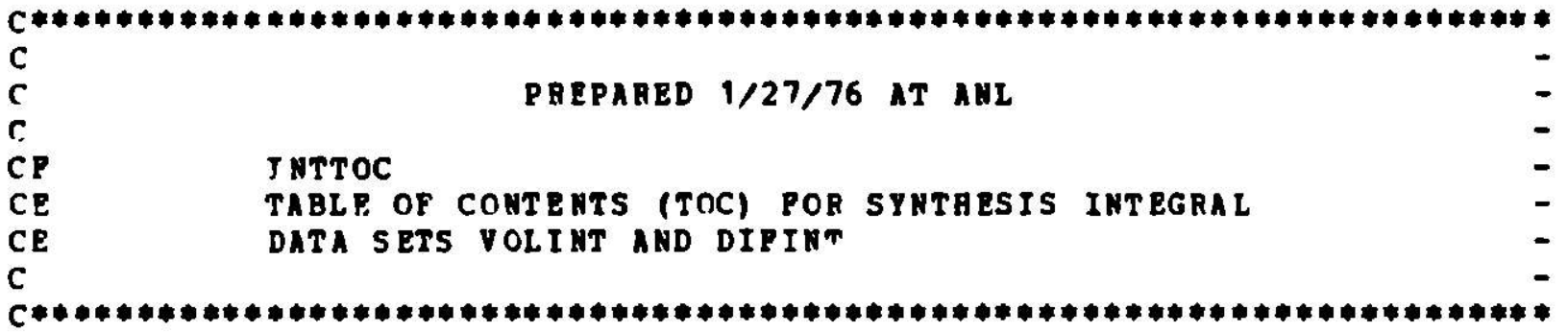

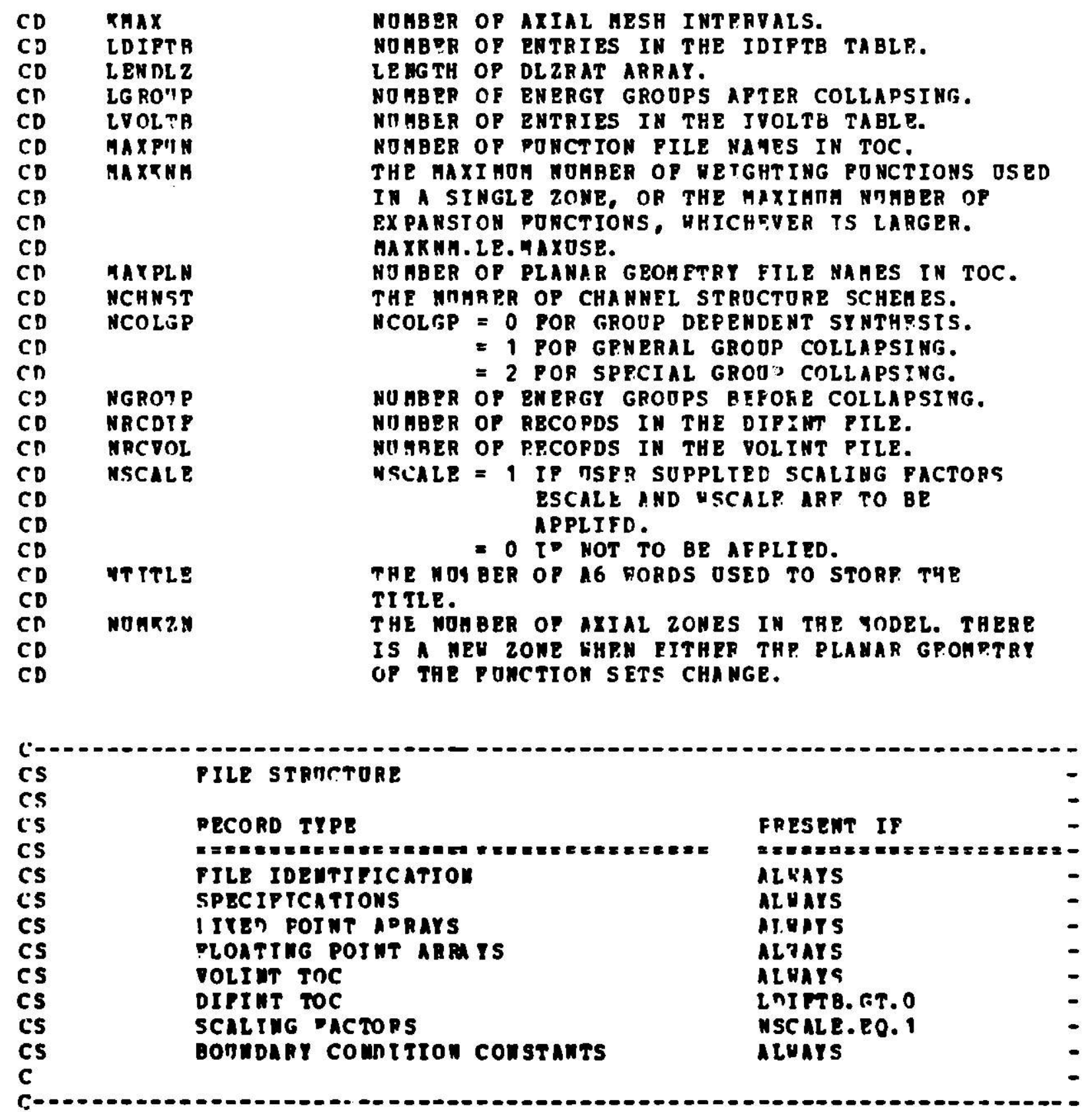


APPENDIX $\varepsilon$. CODE-dePENDENT BINART FILES (CONTD.). INTTOC.

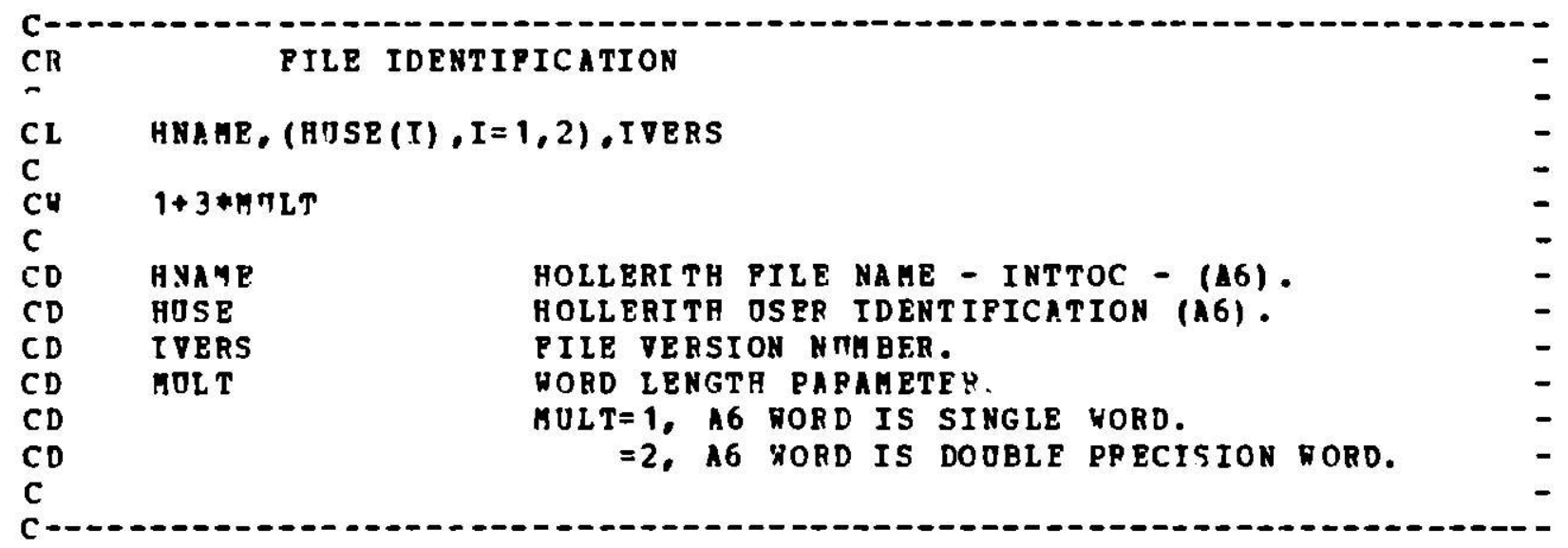

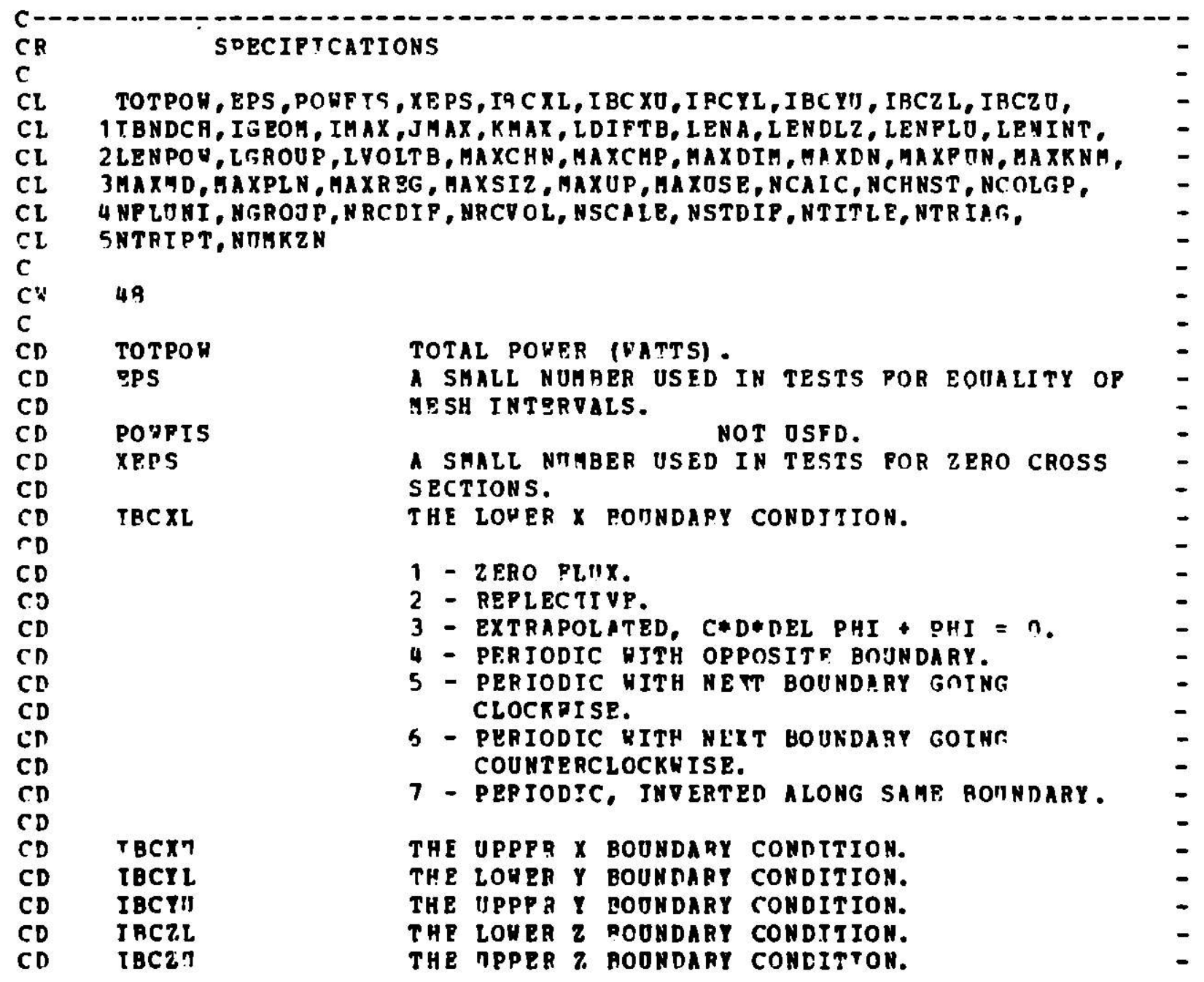


ADPENDIX ‥ CODE-DEPENDENT BTHART PILES (CONTD.). INTTOC.

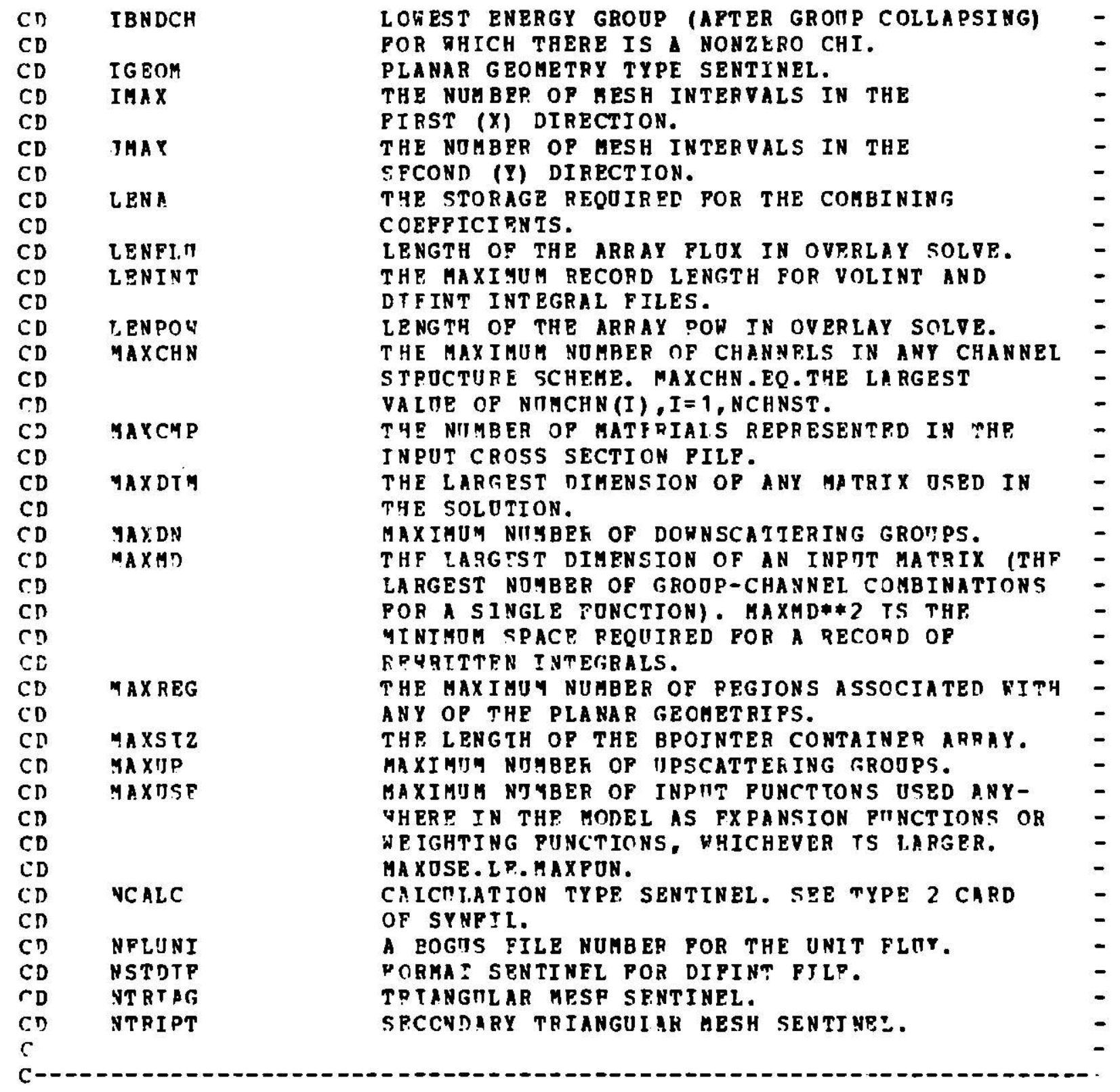


IPPEN RIX F. CODE-DEPENDENT BTNART PII.RS (CONTH.). TNTTCC.

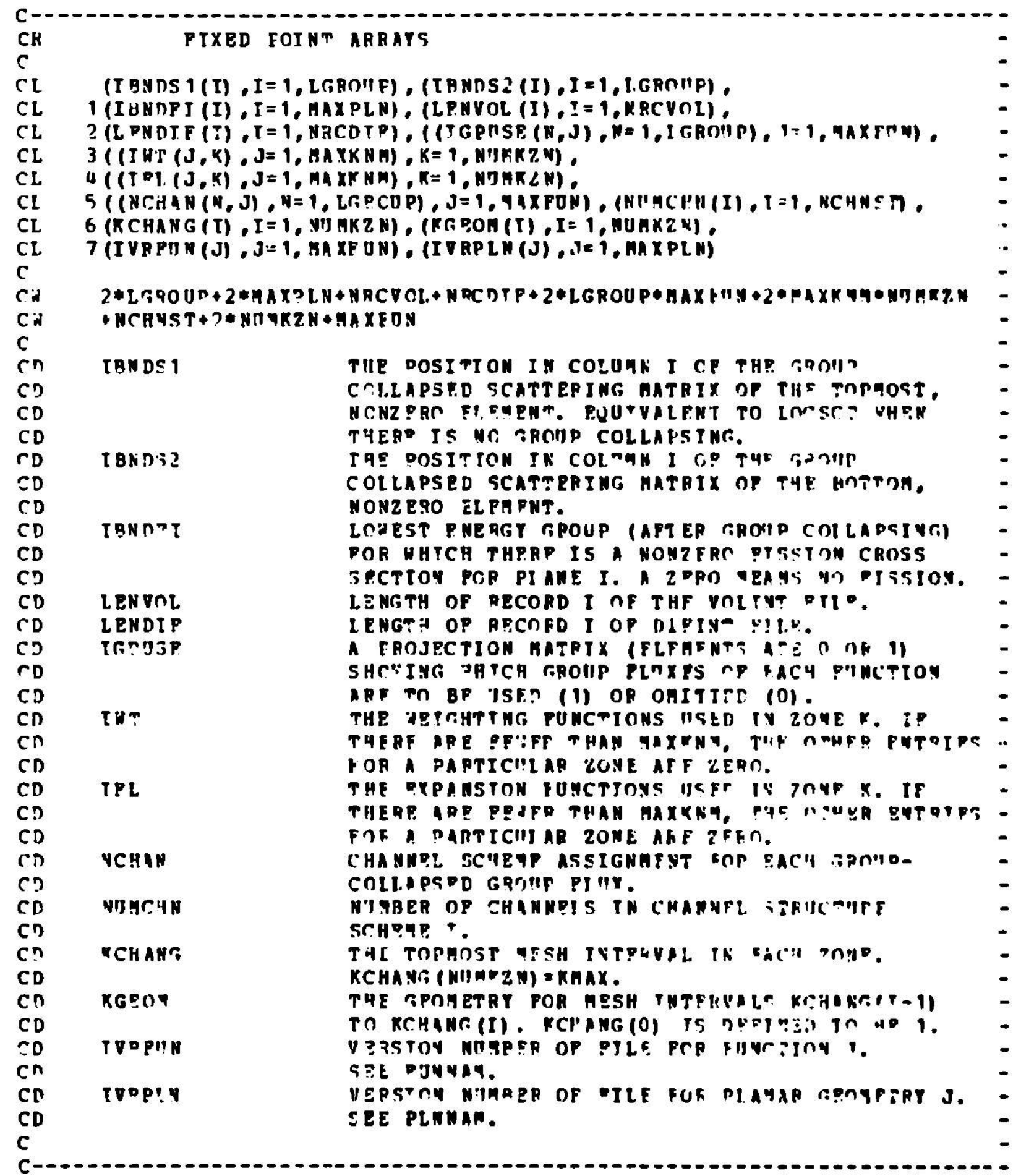




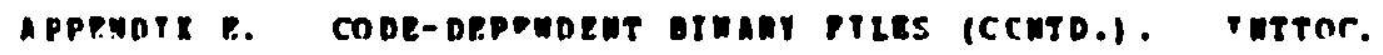

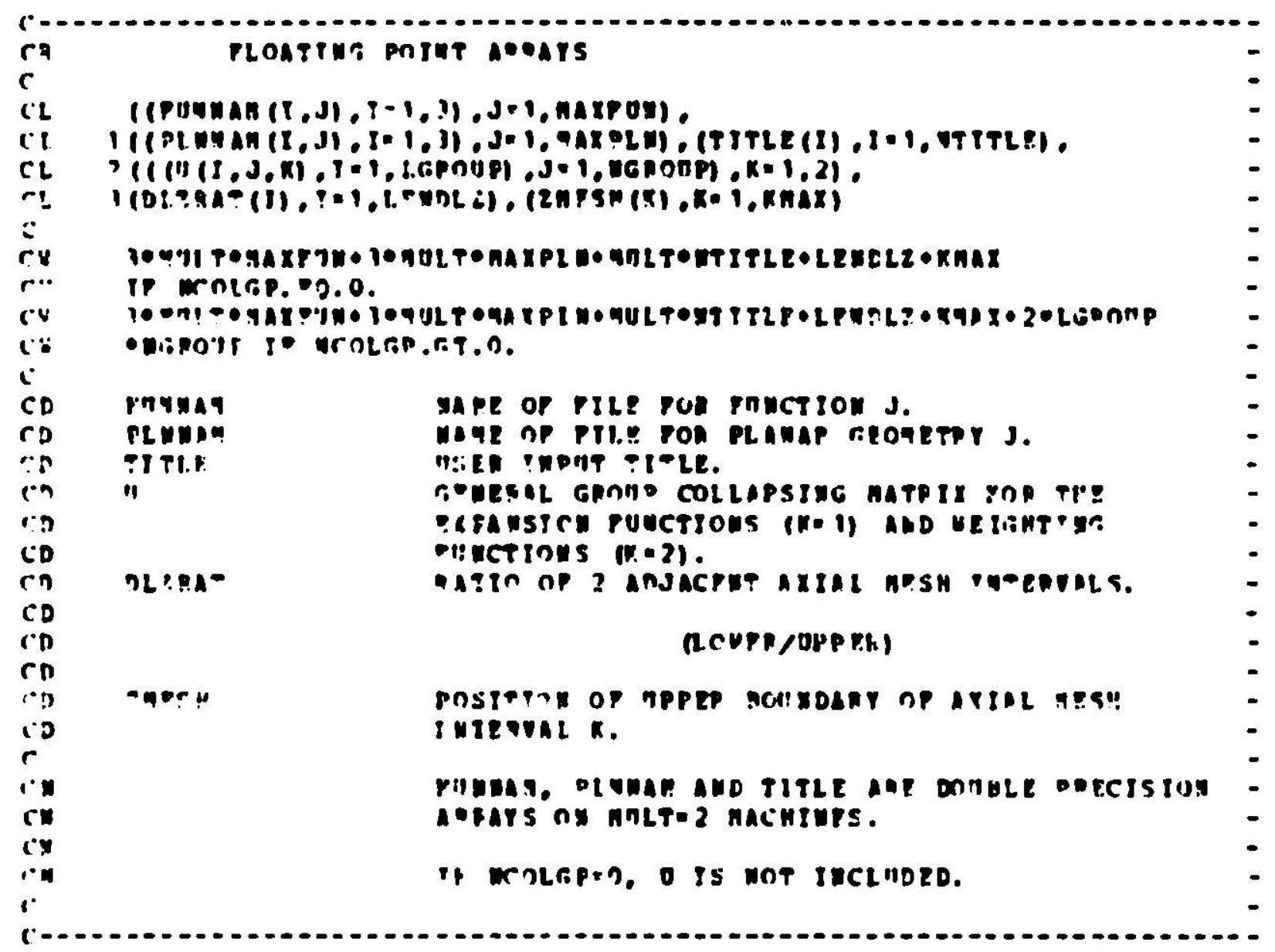


APDENATX 8. CODE-DEPENDENT BIMARY FILES (CONTD.). TNTTOC.

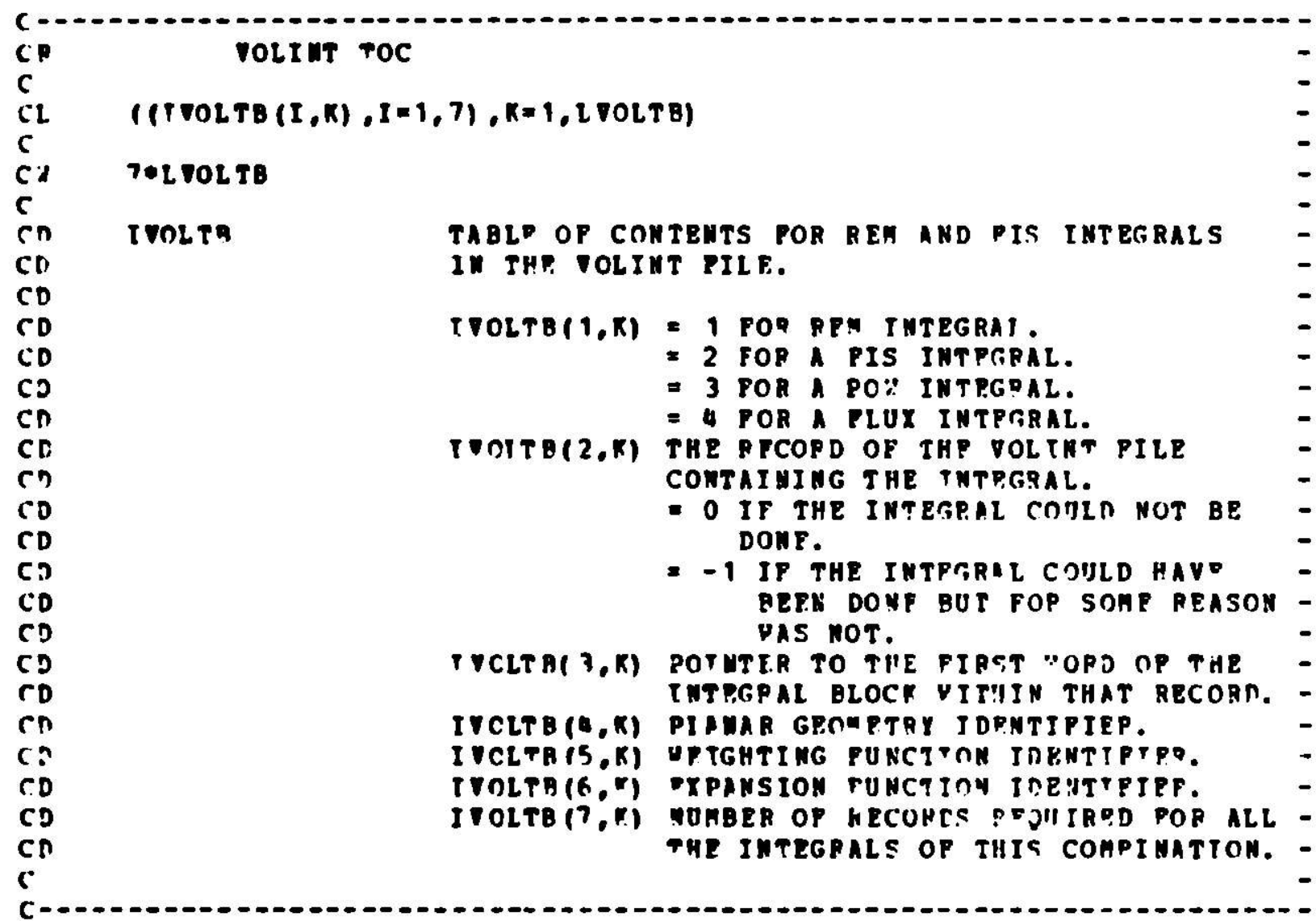


APPENTIX E. CODE-DEPENDENT BIMAPY FILES (CCNTD.). INTMOC.

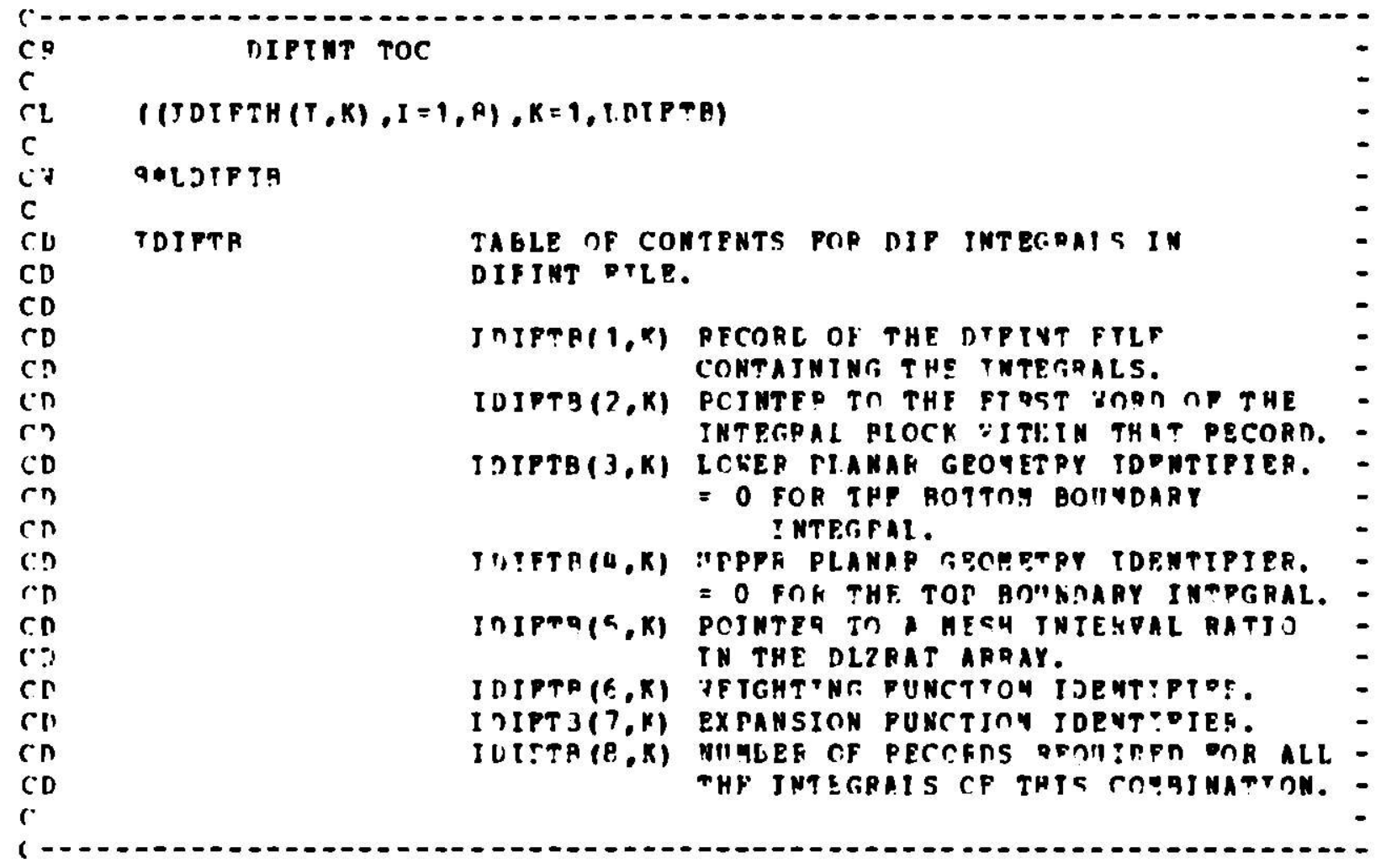

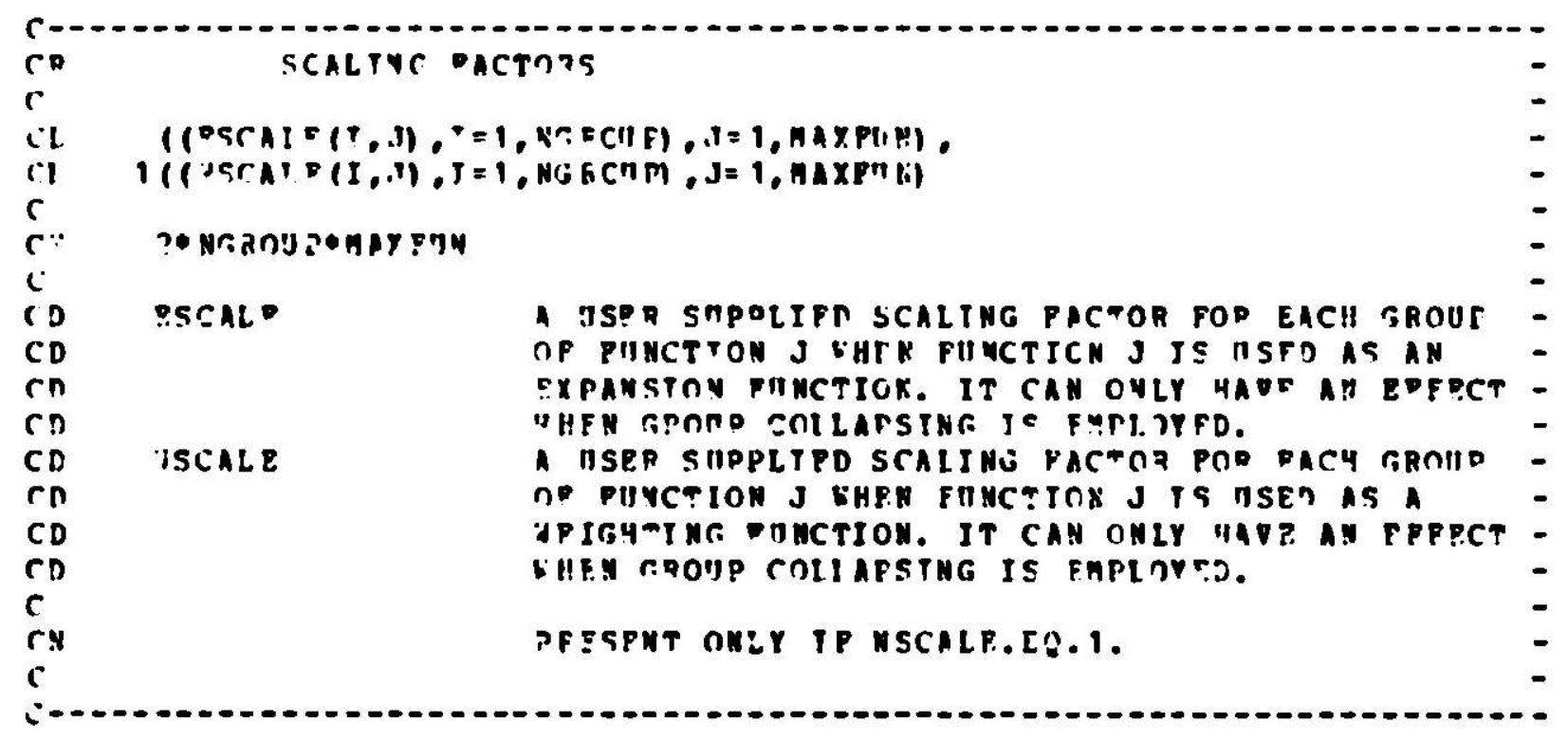


APPEADIX P. CODE-DEPENDENT PIMART PILS (CCWTD.). InT?OC.

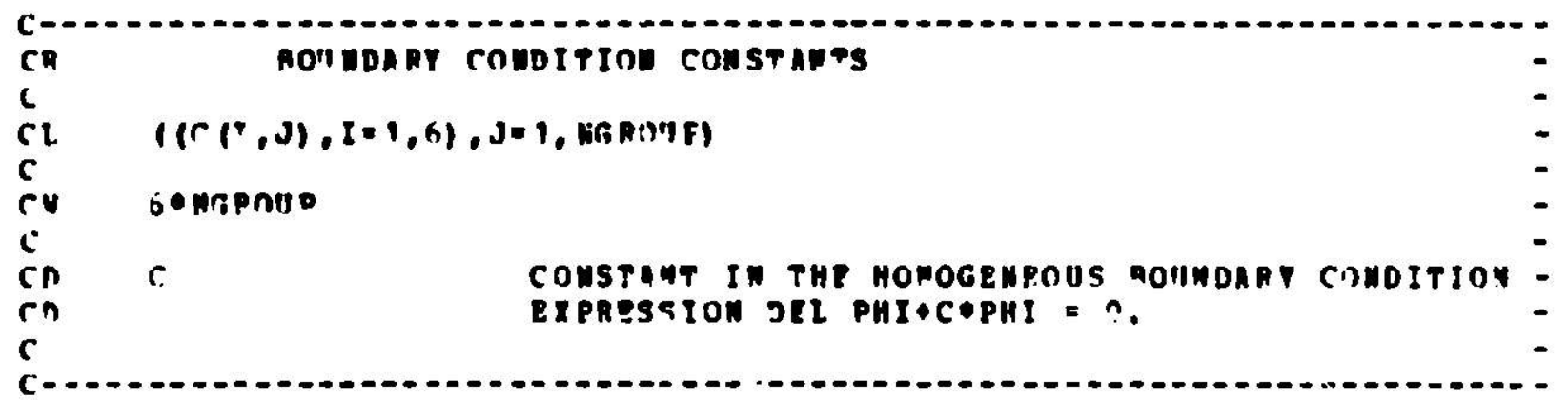

CPOP 


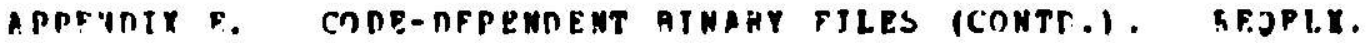

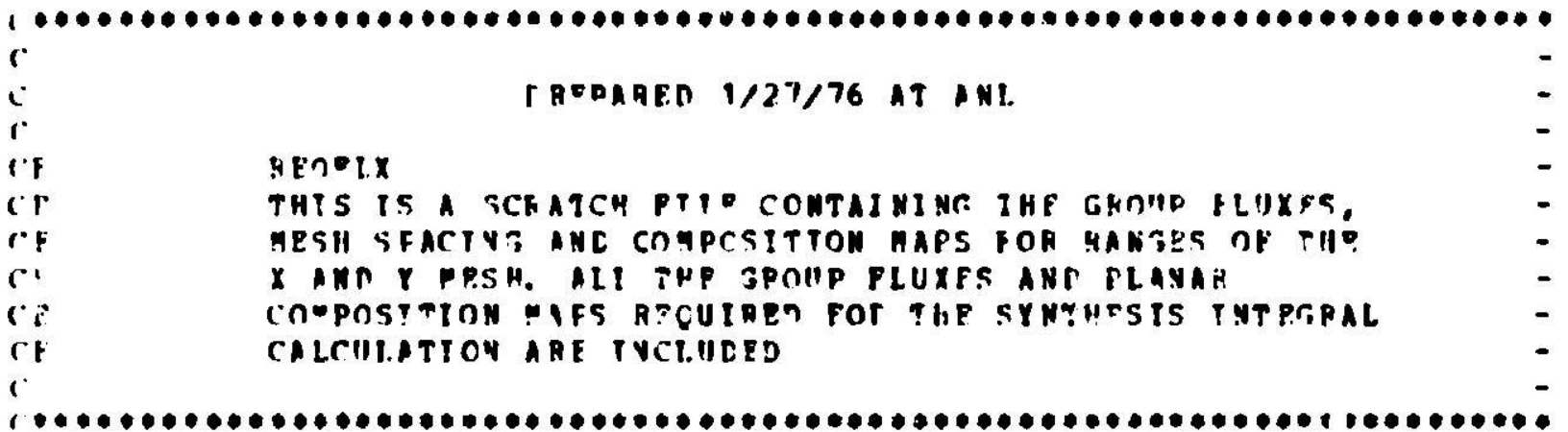

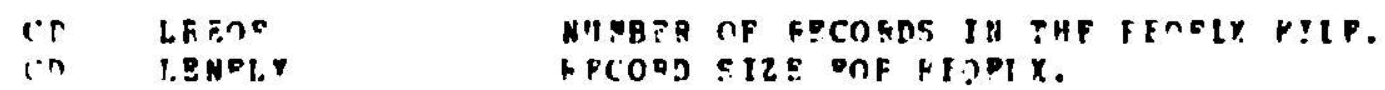

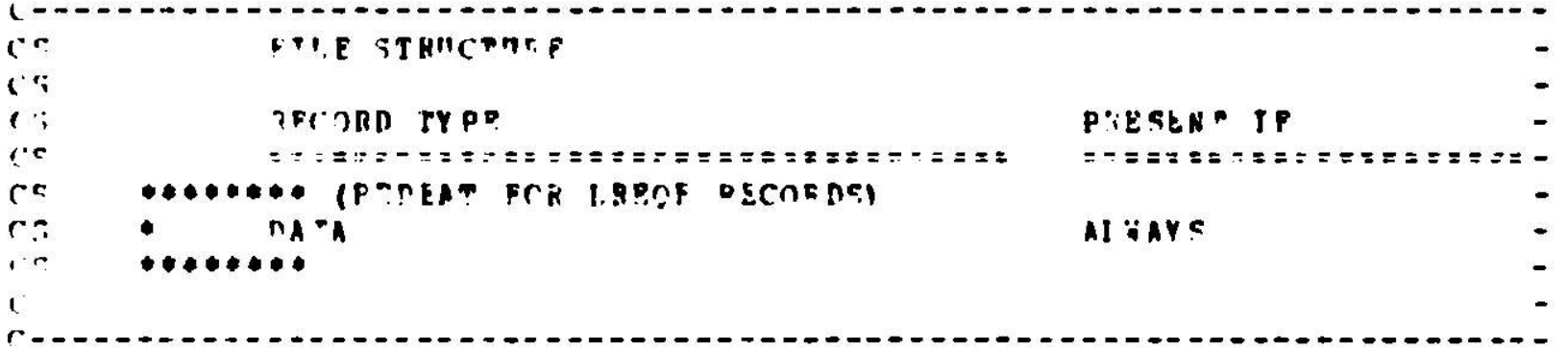

\begin{tabular}{|c|c|}
\hline$c_{n}^{n}$ & DATA \\
\hline $\begin{array}{l}\text { C: } \\
\text { Ci }\end{array}$ & 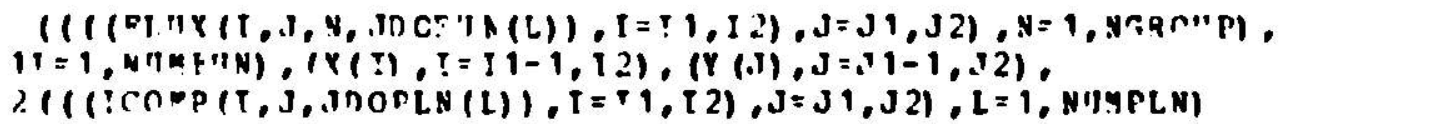 \\
\hline$c$ & \\
\hline$r d$ & 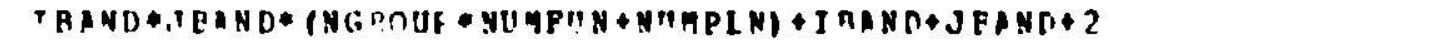 \\
\hline 6 & TНE PLIX FO० MFSH THTEPVAL $(I, J)$, (IRIIIP N, \\
\hline C & CF PURCTTON NUPEFF JOAFIN(L). JNTT DLUKDS \\
\hline Cn & ARE VAM INCLTDED IN IHE FIIF. \\
\hline C & THE Y POSITION OR TIE HFSH ITHE SFPAFATYY \\
\hline CD & I HTP.RVAI Q T ANT, I+1. \\
\hline cn & THE Y DOSTTION OF THE MESH ITHP SPPAOATING \\
\hline Cn & INIFDVALS IHT I+ 1 . \\
\hline C. D & 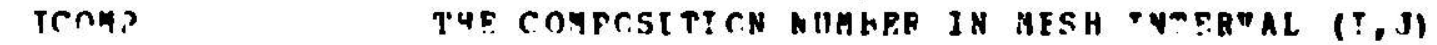 \\
\hline in & OF FLANAR CFJMPTPY NUMLER JMOPLN(l.). \\
\hline $\begin{array}{l}\text { CD } \\
\text { CD }\end{array}$ & 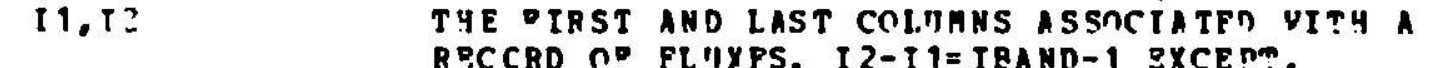 \\
\hline n & DORHPPE, DHEN T2 IS THE LAST COLMAN. FCR THP \\
\hline$n$ & FIPS: RFCAPD I I=0. \\
\hline$r . r$ & THE PTRST AND LAST POHS ASSOCTATEN VITH A \\
\hline $\operatorname{con}_{n}$ & 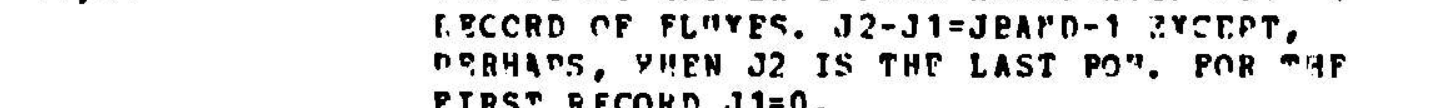 \\
\hline
\end{tabular}




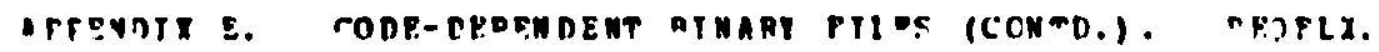

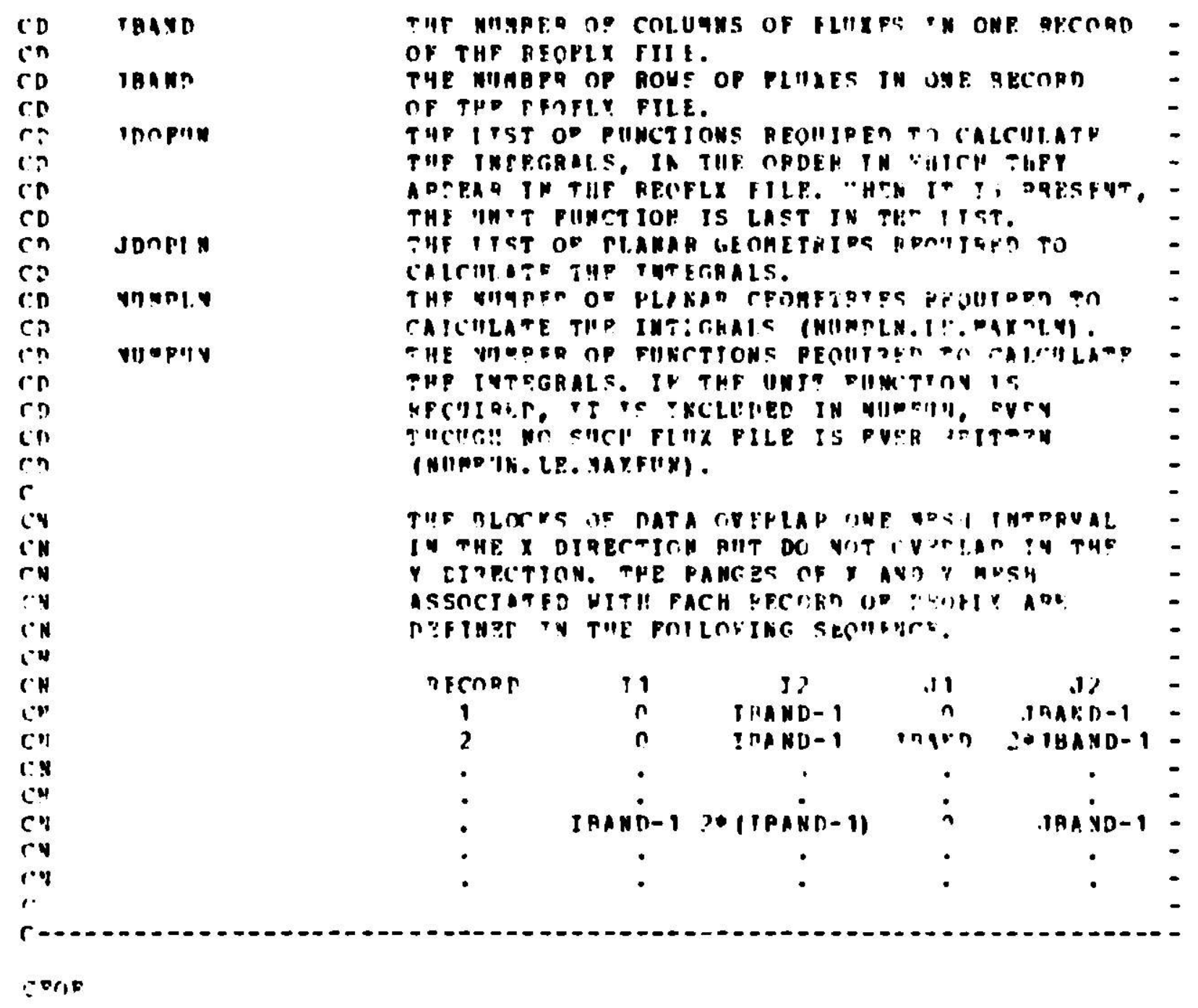


APPENDIY :. CODE-RERENDPRT BIWARY PIIES (CONTD.). RBOXST.

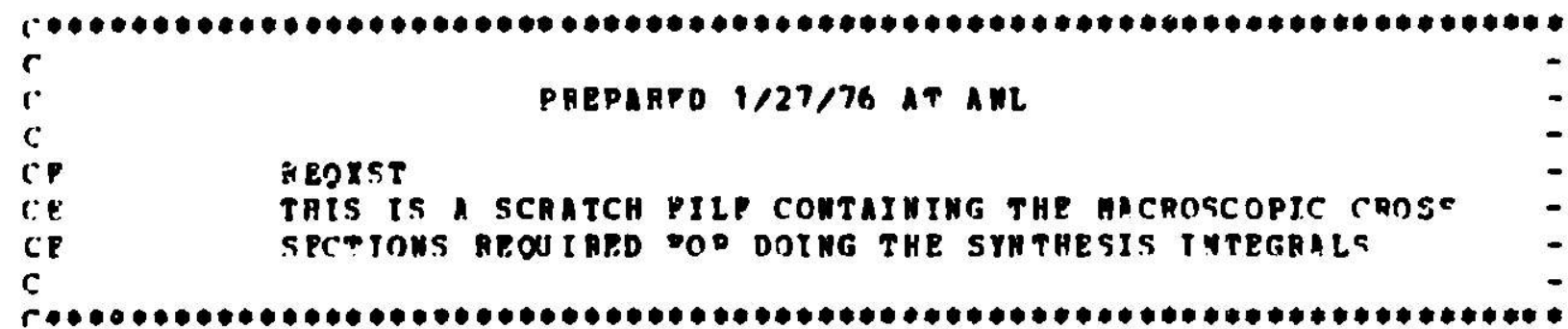

\begin{tabular}{|c|c|c|c|c|c|c|}
\hline $\begin{array}{l}10 \\
\text { ro }\end{array}$ & I RPOY 1 & $\begin{array}{l}\text { NHABER OP } \\
\text { DIFPTSTON }\end{array}$ & $\begin{array}{l}\text { AECORDS DP THE } \\
\text { CORPIC IENTS. }\end{array}$ & REQXST & PILE & EXCLNDING \\
\hline $\begin{array}{l}i v \\
r 5\end{array}$ & LREOY? & $\begin{array}{l}\text { NU FBEP OP } \\
\text { OULY DIFPI }\end{array}$ & $\begin{array}{l}\text { AECORNS OP THE } \\
\text { STON COPPPICIER }\end{array}$ & $\begin{array}{l}\text { REOXST } \\
\text { TE. }\end{array}$ & PILE & $\mathrm{COH}$ \\
\hline
\end{tabular}

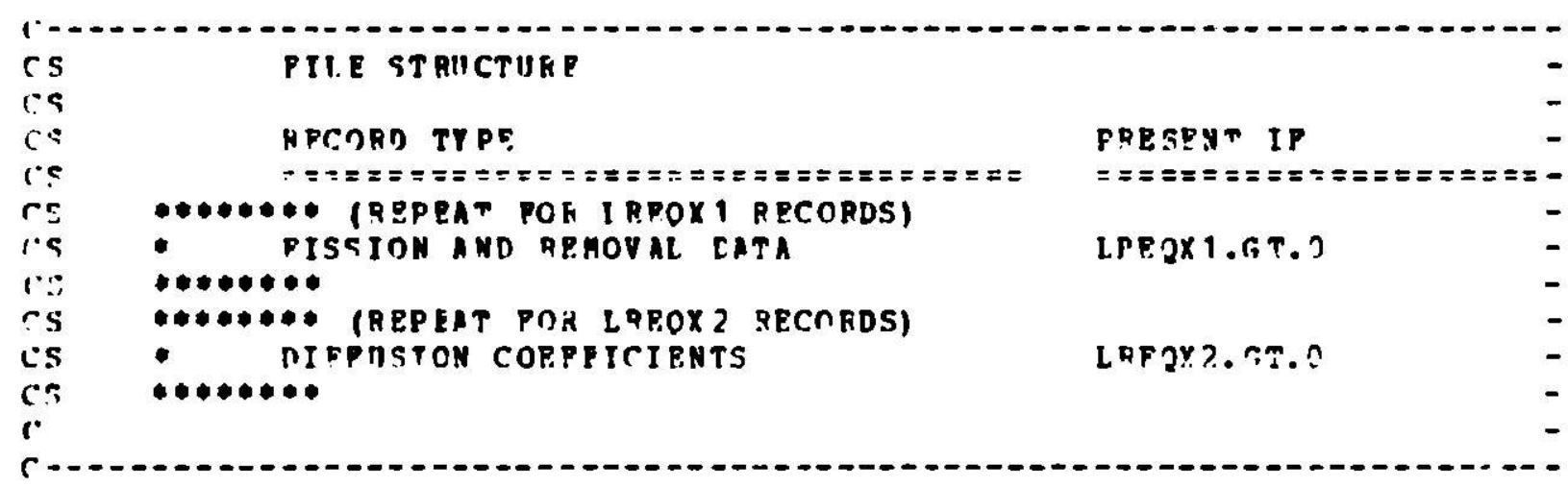

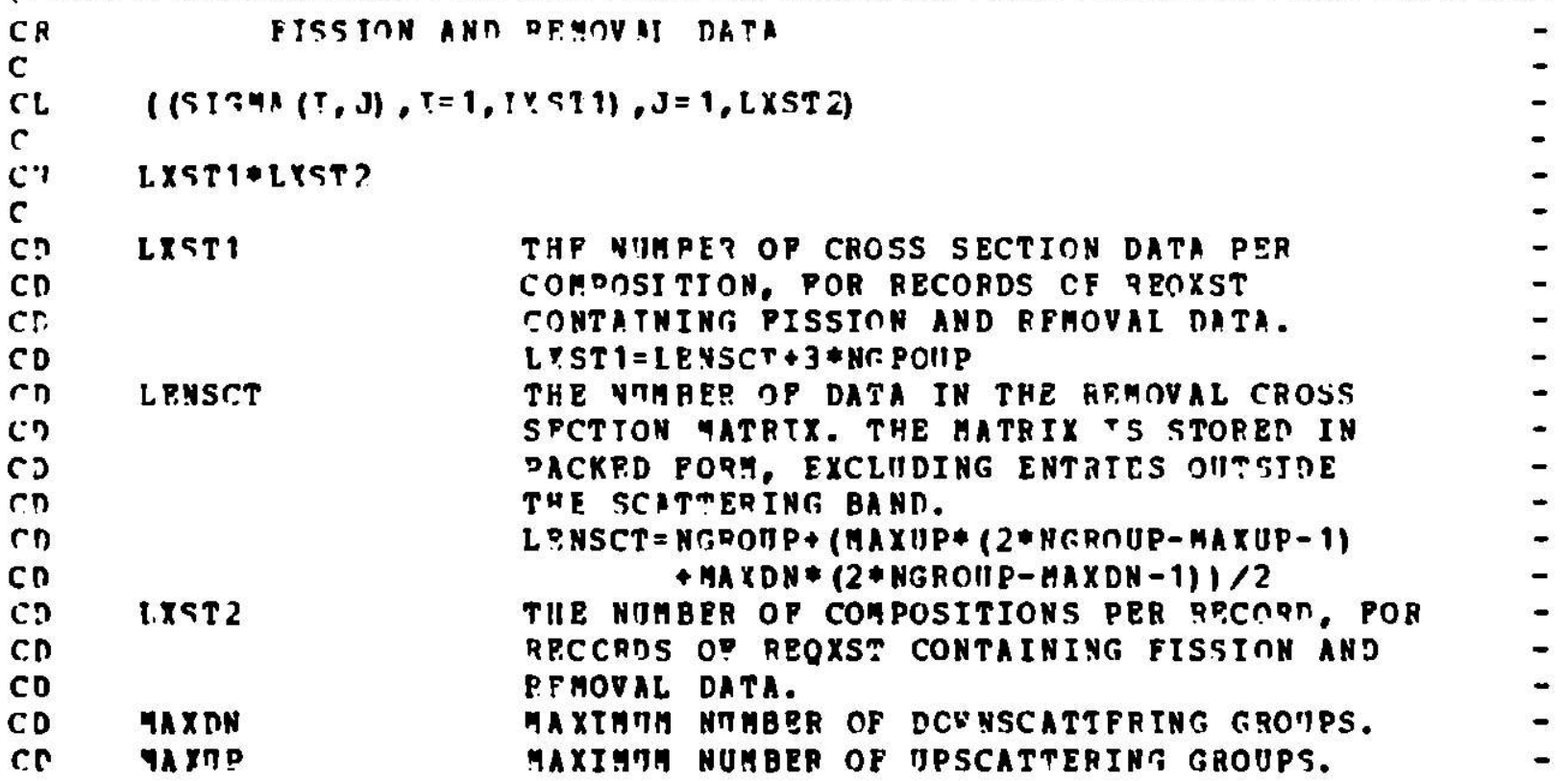


APPFVDTX R. CODE-DFPENDENT GINARY PIIES (CCNTT.). PEOXST.

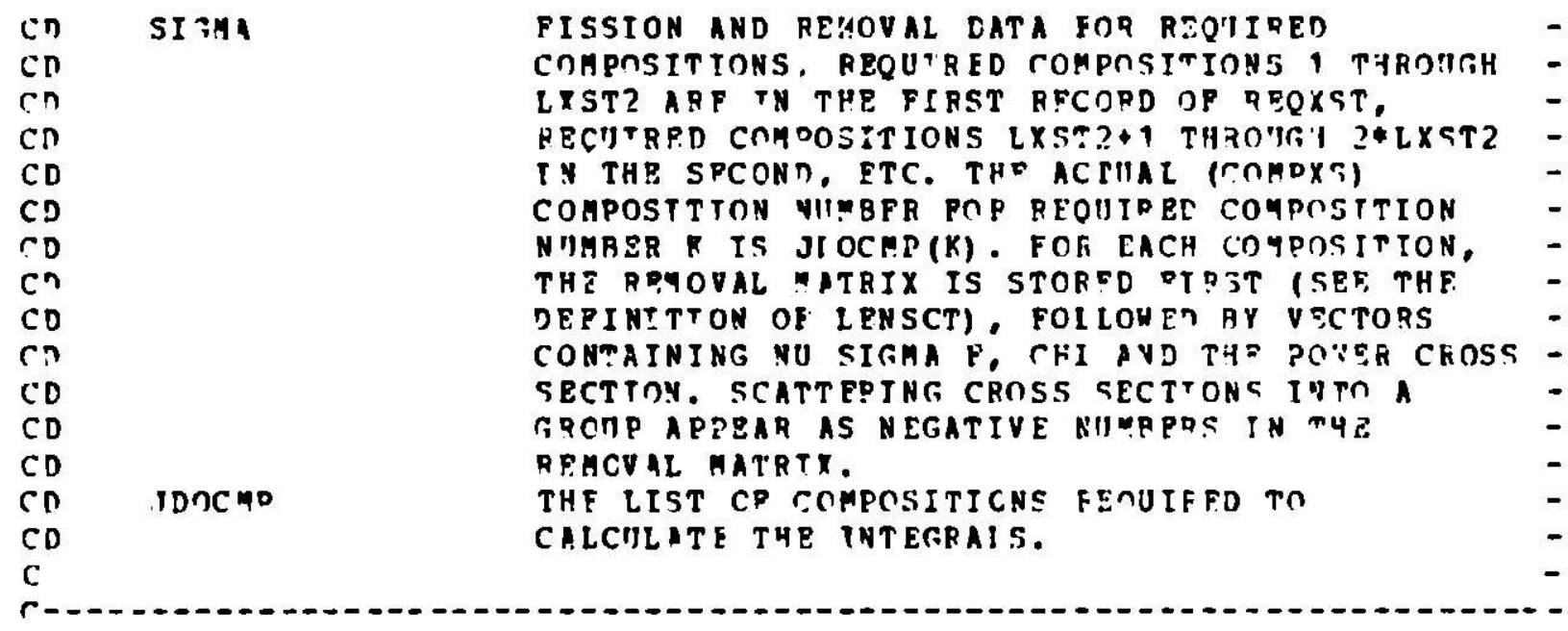

$C$
$C$


A??FYDIX D. CODE-DFEENDPNT BTMARY PTLES (CONTD.). GYMCON.
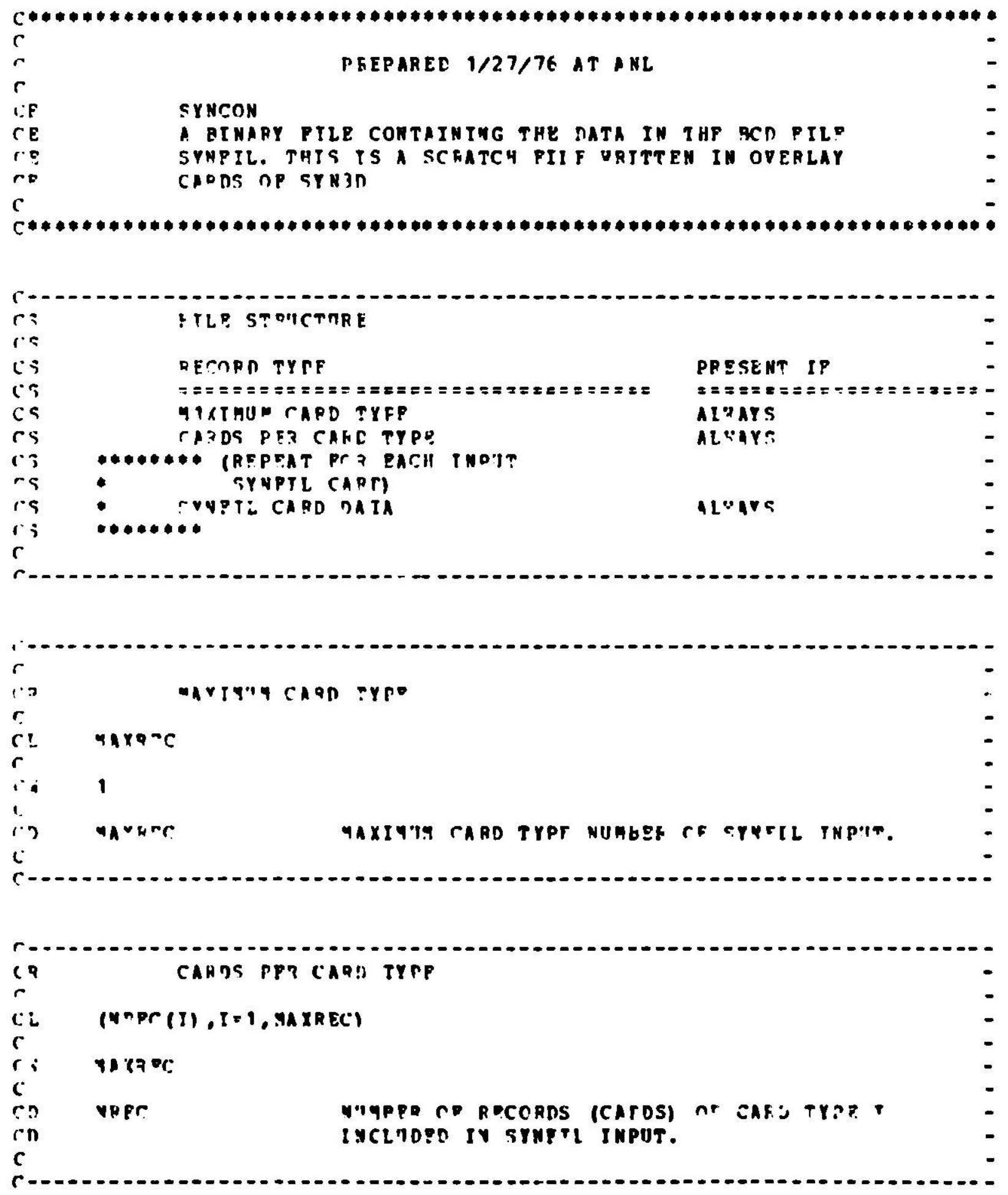
APPEYDIX E. COTE-OEPENDENT BINARY PITES (CONTD.). SYHCON.

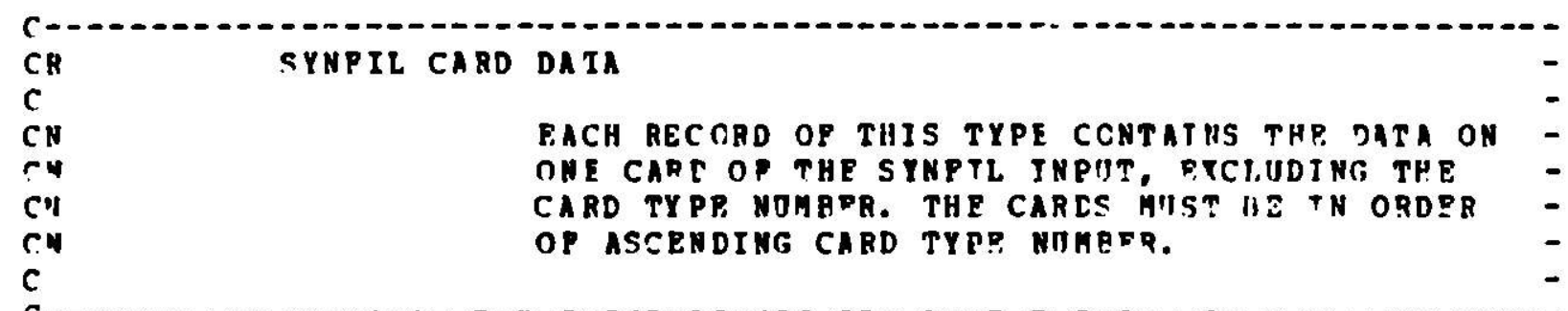

CFnp 
A PPENDIX F. CODE-DEPEUDENT GINARY PILES (CONTD.). VOLTNT.

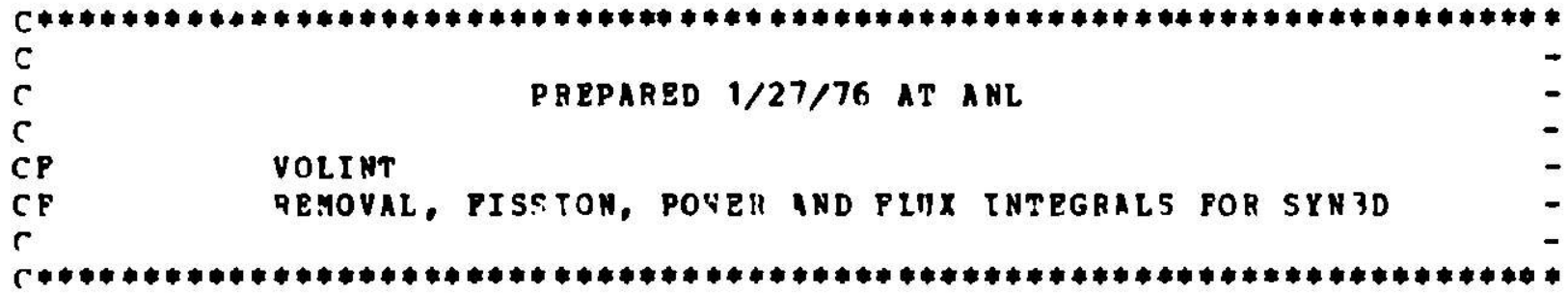

CD HRC"IL NMNPPR OP RECOROS IN VOLINT PILE. (SEP

CD SDECTPICATIONS RFCORD OF INTTOC PILF).
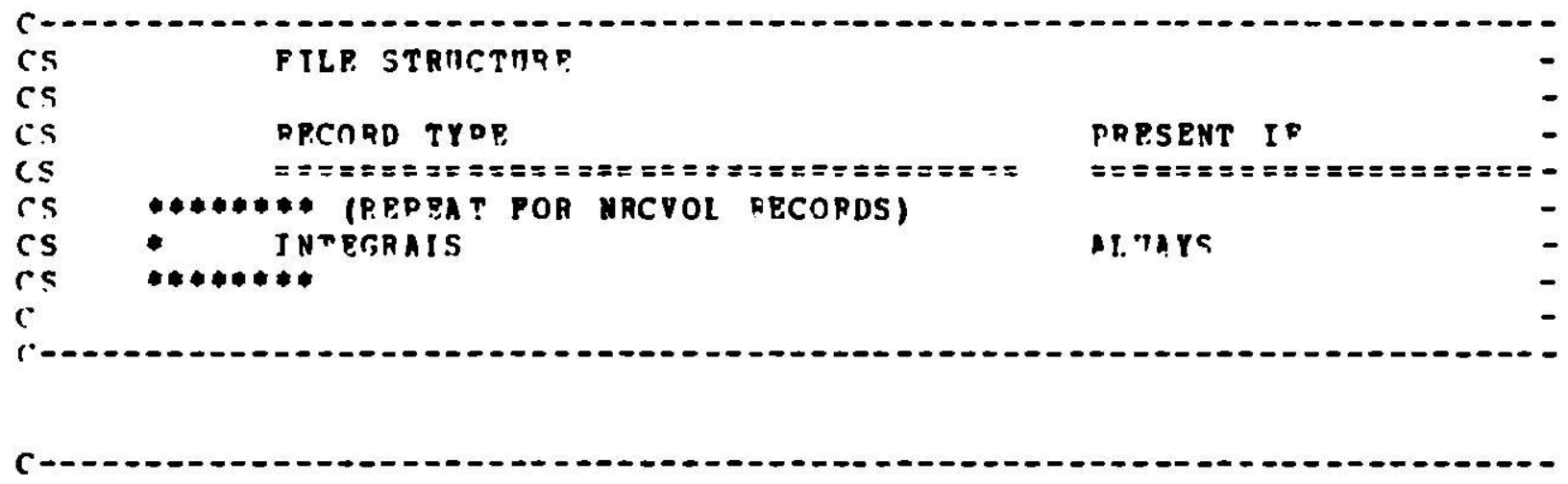

CQ INIPGQALC

C. $\quad(X(I), T=1, L P, N)$

(C) MOLTELF

$c$

CD

CD

CD

CD LEN

Cn LPNYOL

cn

$r$

$C D$

cn

Cr:

$r$

C?

Cn

cn

(6)

in

C:

CD

C?

(n)

A PTS, PFM, POA OE FLIIX INTEGRAL, SPD TDE INTFGAAI. TABLE OP CONTENTS IVOLTP IY THP T NTTR PILP. RPCOPD I PVGT'. I.ER:=LENVOL (T) POA KFCOAT T. GEE F:XTC POIST ARFAYS IN IVTTOC PTLE.

T"Y. PIS TNTPRAALS ARE STORFE ( ( ( (FIF (T, J,K,L), T = 1, NUMCHN (NCHAH $(J, I d))),-$

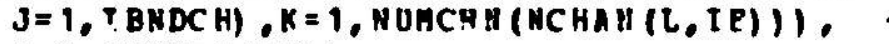
$I=1$, II NDF T $(T P))$

THE RPA INTEGPALS APF STORER

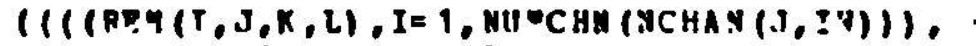
IX TRYDS $1(L)$, I BNAS? (L)). $K=1$, MTHCH N (MCHAN $(1, I D) i, L=1, L G R O U P)$ -

ThP ron thergats aro stcsich

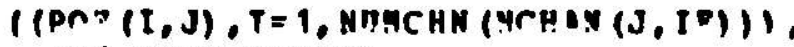
$J=1, T B \operatorname{srFI}(I P))$

THE FLIIX THEPGPALS ARE STORPD

( (EL"IX $(I, J), I=1$, NOACWU (NCHAN $(J, T E))$, $J=1$, (R Q Q⿱I) 
APPENDIX F. CODE-DEPENUENT BINATY FILES (CONTD.). VOITNT.

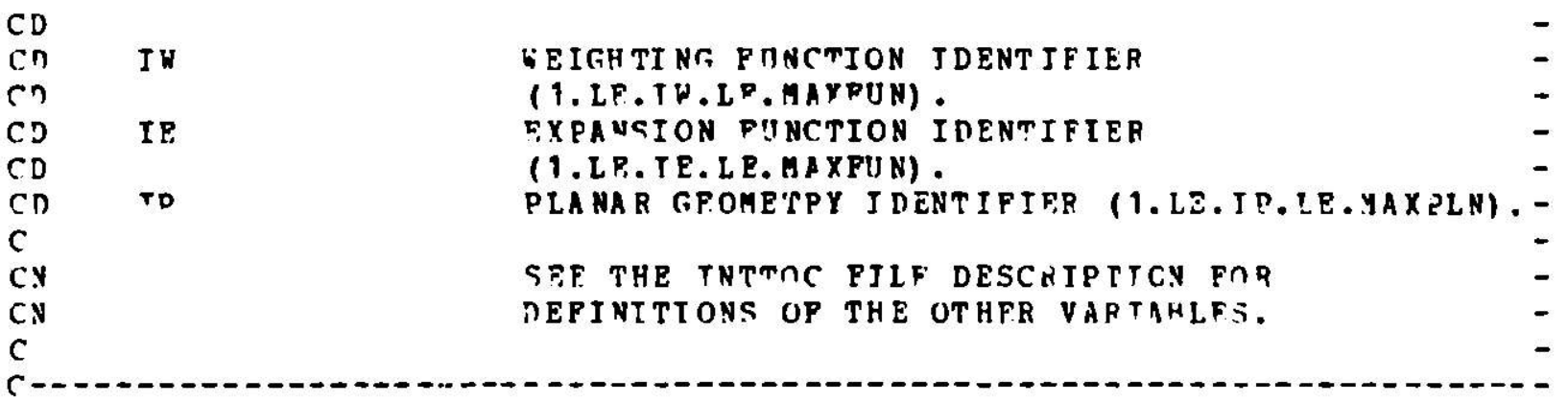

CEOF 
APPENDIX F. SYN3D ERROR MESSAGES. ERRORS ARE IDENTIFIED BY SUBROUTINE NAME AND ERROR NUMBER.

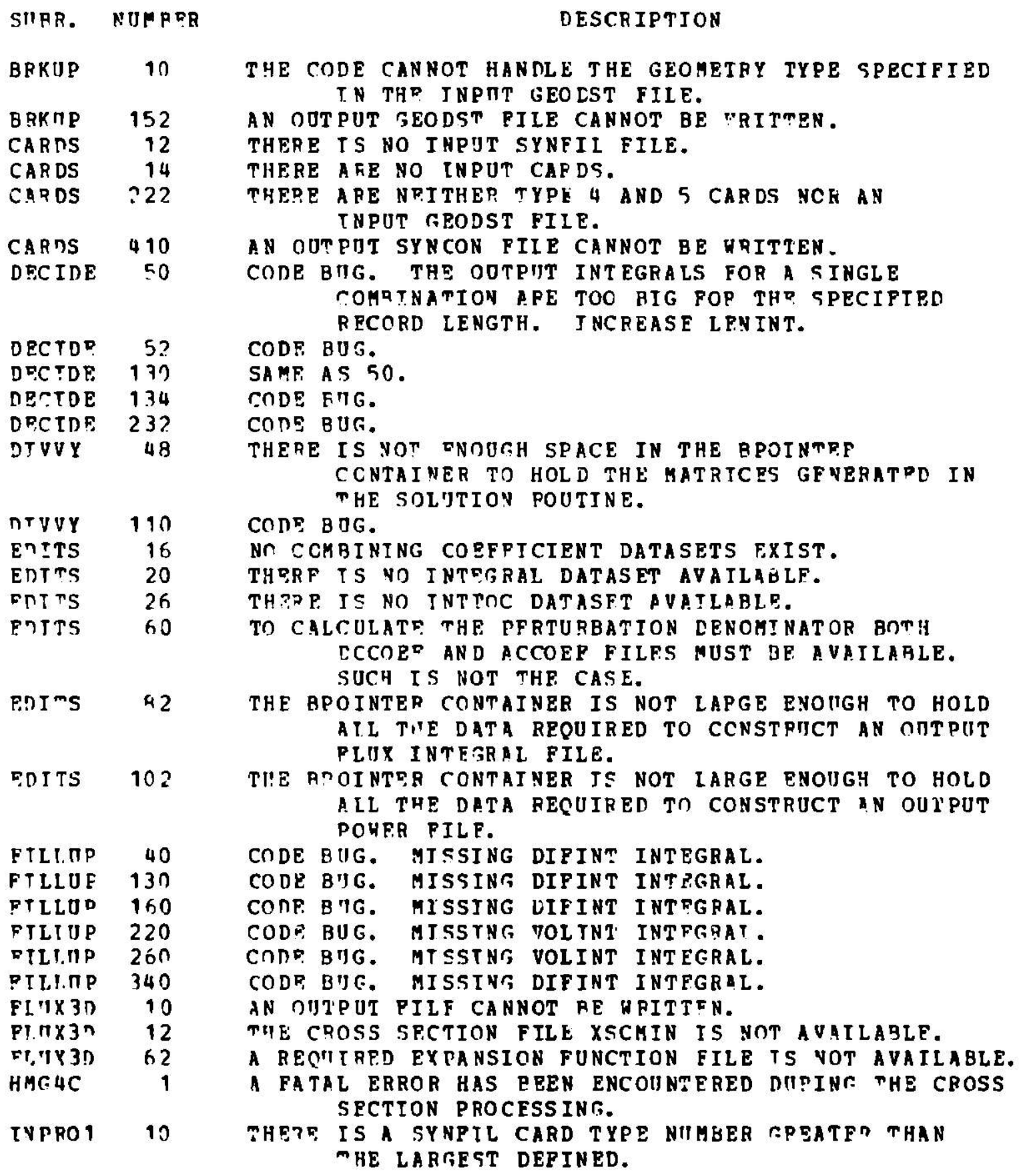


APPENDIX P. SYH3D ERROR MESSARES. CONTINOED.

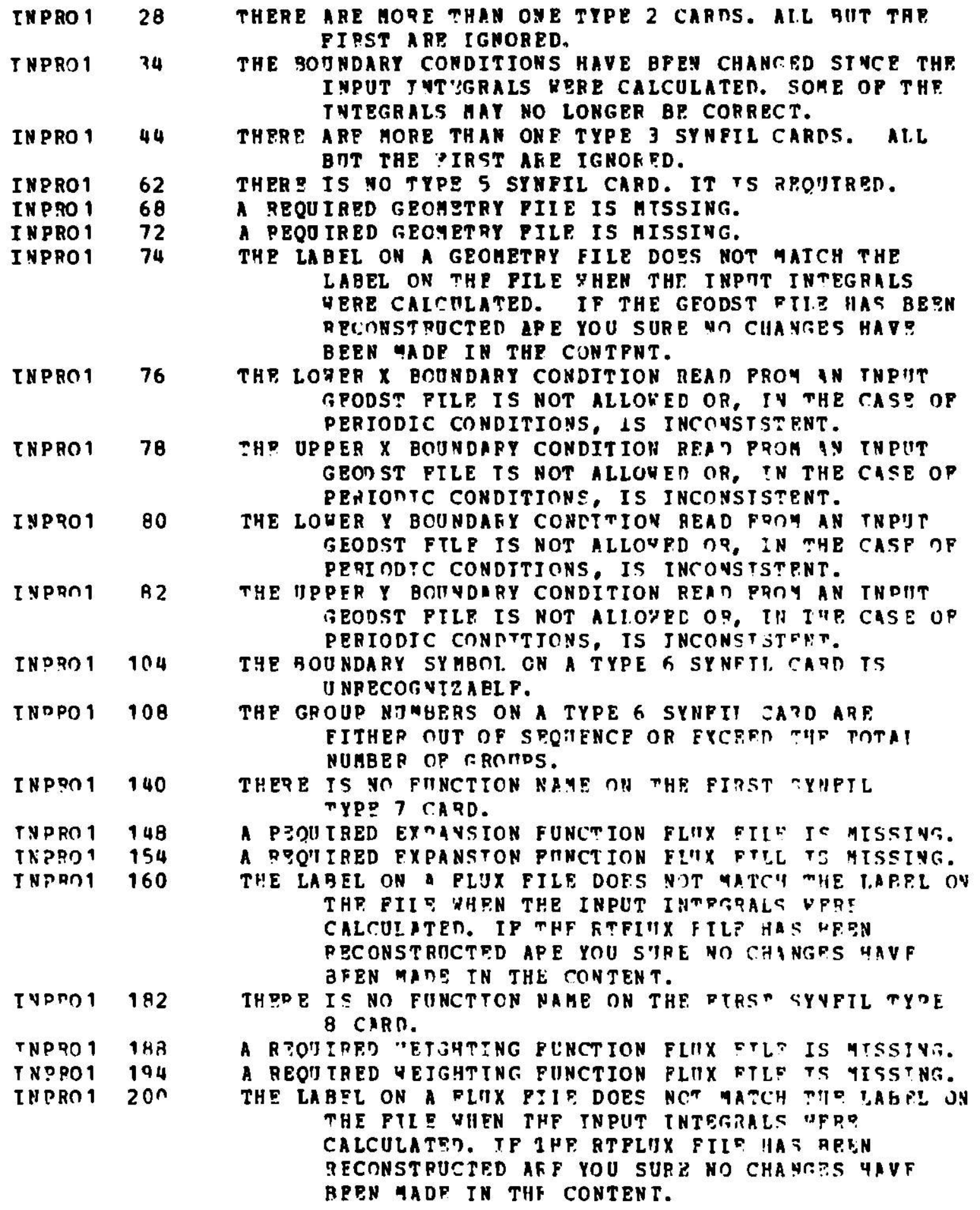




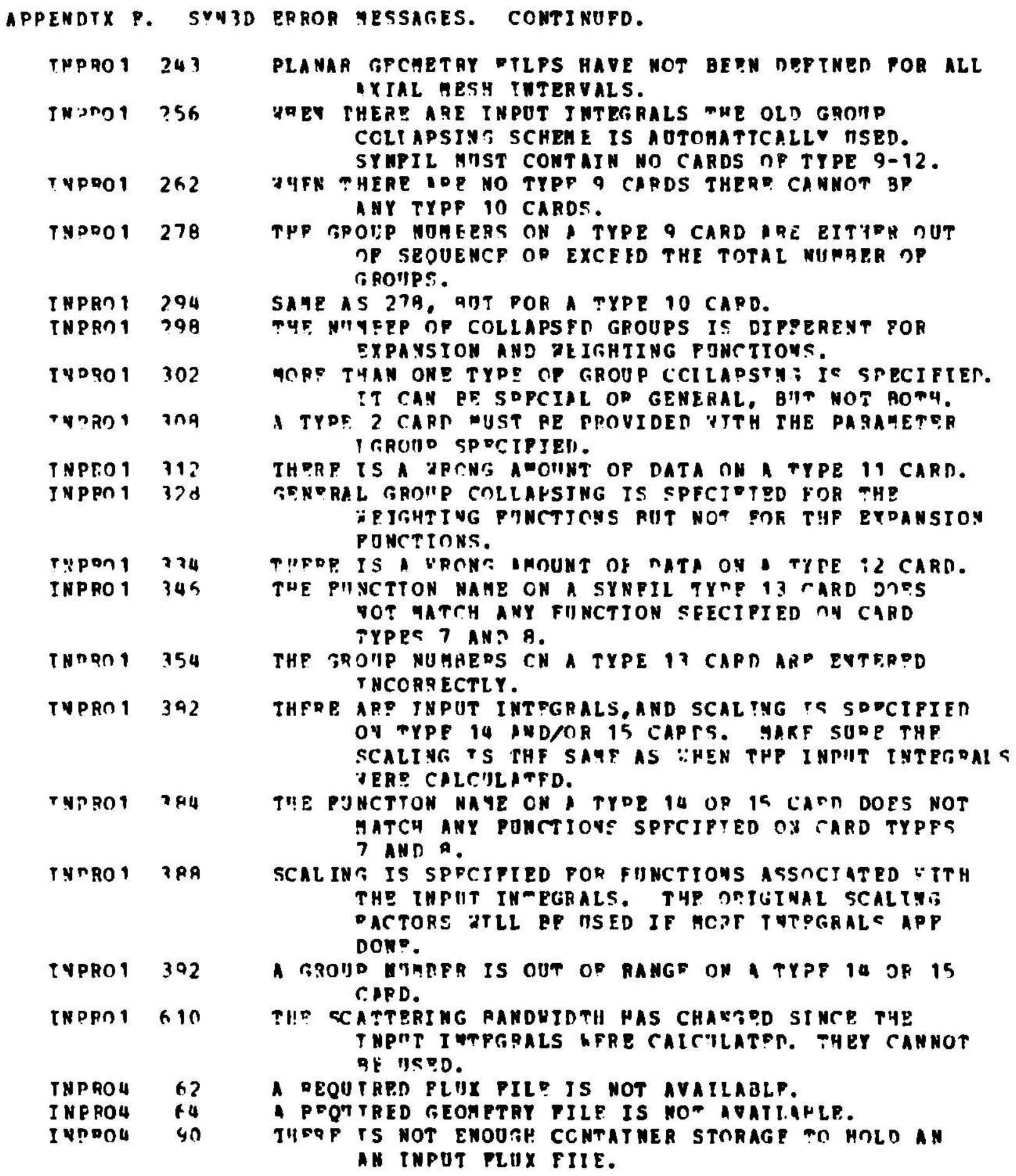




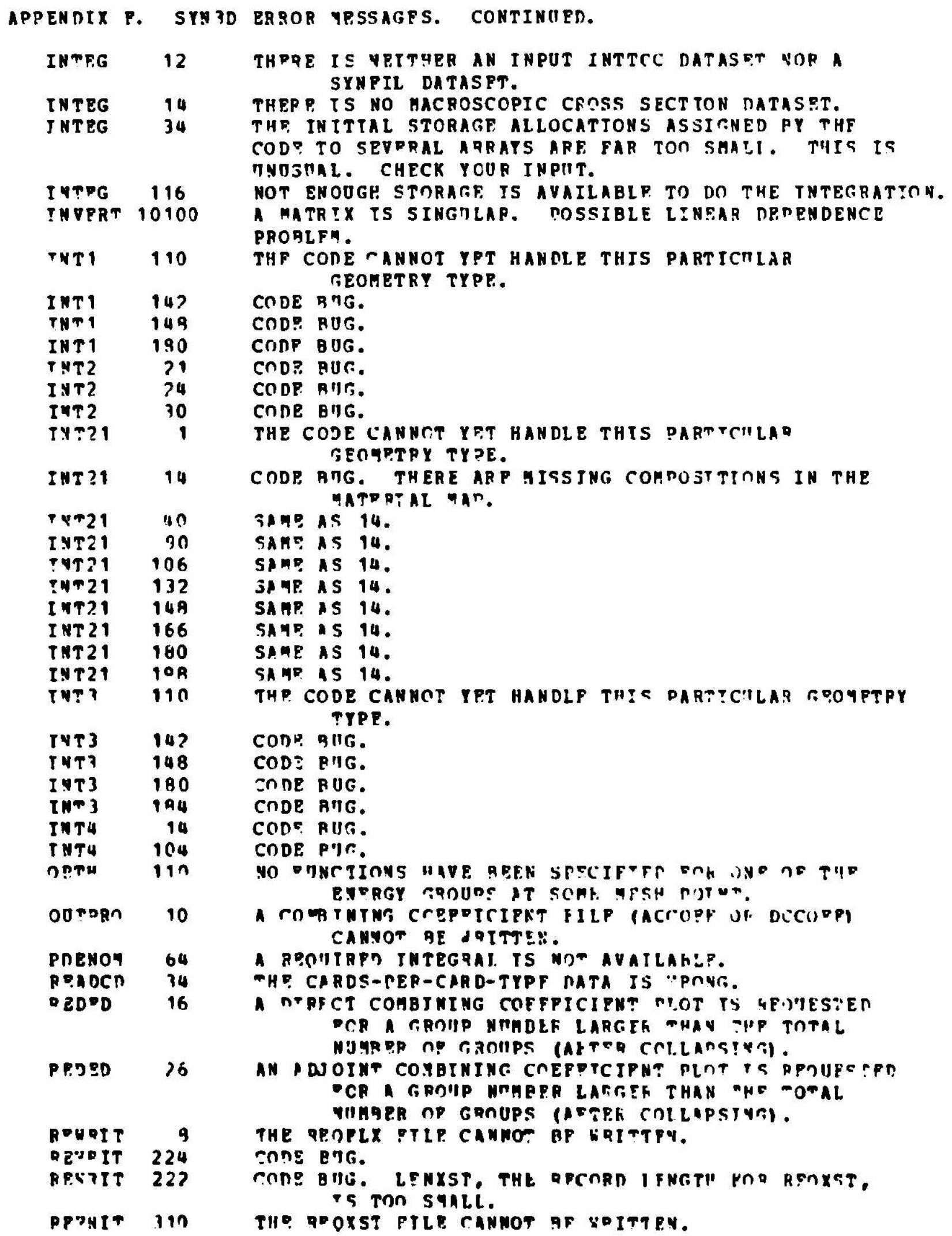




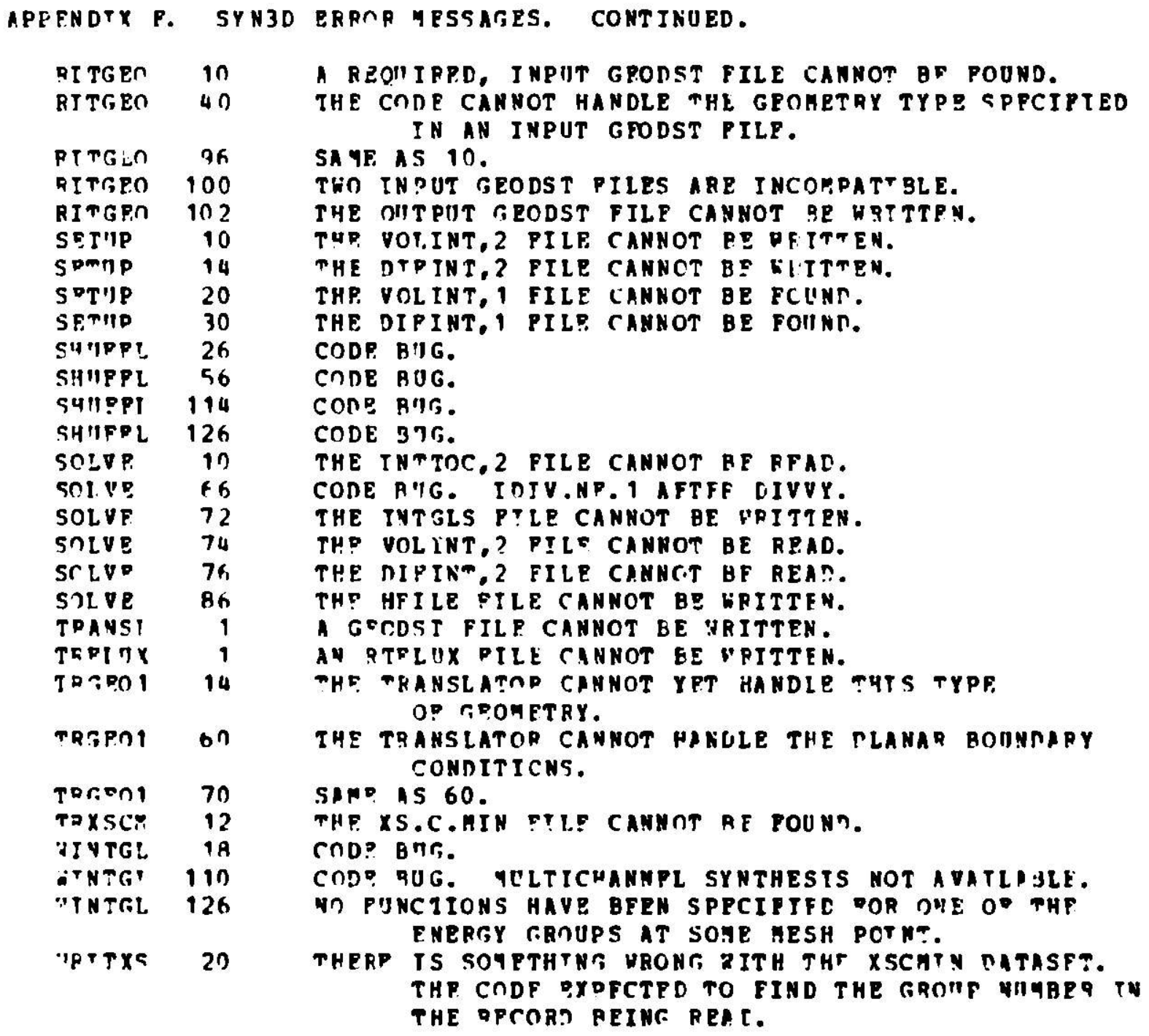


APPENDIX f. PORTRAN VARTARLE GLOSShRY.

$((A(T, K), I=1, K D I M(T ?)), R=1, K M A X)=$ IN OVERLAY SOLVE, FITHER THE DIRECT OR ADJOINT COHBINING COEPPICIENTS. IZ TS THE SYMTHESIS ZONF ASSOCIATED DTTH MESH INTPRVAL $K$.

$((A \operatorname{CCOEP}(I, K), I=1, \operatorname{KDIH}(I 2)), \pi=1, K \operatorname{KaX})=$ ADJCINT CONBININA CCEFFTCIENTS. IT, IS THP SYNTAESIS ZONE ASSOCTATED WITH MESH TYT QRVAL K.

( (AMTN'JS $(I, J), I=1, K D I M(I Z)), J=1, K D I H(I Z$ H)) = IHP. SI3ALOCK (POR THE CURRENT AXIAL MESH INTERVAL) BELON THE DIAGONAL OP TYP BLOCK-TRINIAGONAL SYSTEM OP SYNTHESIS EQUATIONS. IZ IS THE SYRTHESTS ZONE ASSOCIATPD HITH THE CORBENT MESH INTERVAL. TZY IS THE SYNTHESIS ZONE ASSOCIATFD HITH THP PREVIOULS AXIAL HESH T MTRARAL.

((IPLUS (I,J),I=1,RJIM(IZ)),J=1, KDIM(IZP)) = IMF SURRLOCK (POR THP CORRENT AXIAL MESH INTERVAL) ABOVE THE IIAGONAL OP THE BLOCK-TRIDIAGOVAL SYSTEM CF SYNTHESIS EQUATIOYS. IZ IS THP SYATHFSIS 2ONP ASSOCTATED WTT THE CURPENT HESH TNTFQVAL. IZP IS THE S YNTHESIS ZONE ASSCCTATED AITH THE NFXT AXIAL SESH INTORVAL.

(ADRAY (T), I = 1,36$)$ = THE LIST OD MAMES OP DIMENSTONED VARIPELES DEFT MT THRONGH BPOINTER.

$((A Z R R O(T,),. I=1, \operatorname{KDIM}(I 2)), J=1, K D T M(I Z))=$ THE SMBRLOCK (POR THE CURDENT AXIAL NESH I Y TPVAL) ON THE DIAGONAL OD THE SLOCK-TPIDIAGONAL STSTDY OF SYNTHESIS EQUATIONS. I? IS THP. SYWTHPSIS ZOME ASSOCTATED VITH THF C'JRBENT YESH TYTDOVAL.

(ALK, TI, T=1, MAXSIZ) = THE BPOI YTFR CONTAINER.

( $(C A P D(I, J), I=1,11), J=1$, MREC) = THF. CONTENTS OP EACH INPIT CAQD, EXCLTJING THE CARD TYPE NHMBFP. MREC = THE YMMAER CE DATA CARDS.

( ( (CAC $(I, J, K), T=1, N G$ ROOP) $, J=1,6), K=1,2)=$ THE BOUNDRY CONDITION COMSTANTS C1 ANE C2 FOR BACH GROIP ANC EACH OT THP 6 BOMMDARY PLANES.

CONVIG - EIGENVAI.TE CCNVERGP YCP CRITEhION.

$((n C C O B P(T, K), T=1, K D I H(T Z)), K=1, K M A X)=$ DIRECT CONATNTNG COEFPICIPHTS. IZ TS THE SYRTHESIS ZONE ASSOCIATFN "TTH MESH INTERNA $K$.

(DI.ZTAT(I),I=1,L?MLI?) = MATIO OP 2 ADJACENT AXJAL MECH TMTERVALS. (LOHER/UPPPR)

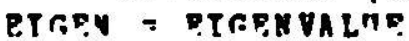

PDS = AMALL WIMBER USEO IN TPSTS FOP EQHALITY OF MES! TNTPRVALS.

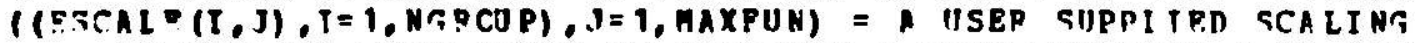
PACTOR POR EACH GROOP OE PRHCTION J ZHEN PIMCTION I TS "ISED AS A REPANSTON BUNCTION. TT CAN ONLY HAVP AN EPOFCT HHON GROTP COLLADSI VG IS FMOLOTED.

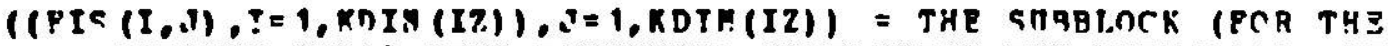
CORREYT AXIAL TFSH I WTERVALI CONTAINING THE INTERPALS OVPR THE PISSTON CAOSS SPCTTOSS. TZ IS THE STHTHEST S INNF. ASSOCIATED UTT'I THE CURPPNT AXTAI. MESH INTPPVAT.

(PIUX(I),I=1, GAYPNY LGROMP) = AN ABRAY CONTAININC FINCTINY TATDGRALS. THE IVIE':RALS ARE STORED TA TYP SAME UY AS TUE COARINING COEPPICIRNTS, WITH PLANKS CMITTDD. POJNOORS TO THE PIPST NOMZERC GPCIF ARP GTVEN IN THE APRAY IPLTOC. 
APQRNDIX G. FORTRAN VARIABLE GLOSSARY. (CONTD.)

(PLI) 1 (I),I=1,LENPLX) = THF ARRAY INTO WHICH A RECORD OP REQPLX IS READ. PLIIX 2 AN J FLTX? SERVF THE SAHF FORPOSE.

$(($ PTNNAM $(I, J), I=1,3), \operatorname{IVRPUN}(J)), J=1, \operatorname{MAXFON})=$ PTLL NAME OP FILE FOR PINCTICN J.

GUDSS = EISENVALIE ESTTHATE.

$((4(I, J), I=1, K D I M(I Z)), J=1, K D I M(I Z H))=$ THE HATRIX PORMED DIRING THE FORMARD ELIMINATION O THE SYNTHESIS EQOATIONS POR THE CURPFAT AESH INTERVAL. IT TS THE SYNTHESIS ZONE ACSOCTATET "IIH THE CIRRENT AXIAL MPSH INTERVAL, IZP TS THE ZONE FOR THE NEXT INTPRVAL.

TBAND = THF RUMPER OF COLMMNS OF FLUXES IN ONP RPCORD OP THE RFOFLX FTLF.

TBCS! = THF LOAFR $X$ EOINDARY CONDITION.

$1=$ TRRO FIUX

2 = REPT.ECTIVE

$3=\square X T R A P O L A T R D \quad C * D * D E L P H I+P H I=0$

4 = PERIODIC NITH OFPOSITE BOUNDARY

5 = PFRIODIC TITH NEXT BOIINDARY GCTNG CLOCKУISE

$G=$ FFRIODIC AITH NEXT BOUNDARY GOING COUNTERCLOCKÏISE

7 = PERIODTC, INVERTEO ALONG SAMF ECNNDARY.

TBCX') = TYF UPPEP X BCONDARY CONDITION.

IBCYL = THE LOUFA Y BCHNOADY CONDITION.

IBCY'J = THE UPPER Y FOINDARY CONDITION.

IACZI. = THE LOTPR Z BCTNOARY CONDITION.

TACZU = THF IDPFQ Z EOTNDARY CONDITION.

IAVDTH = LONEST FNERTY GRCUP (APTEP GROUP CCLLAPSING) FOR UHICH TIIFRE TS A YONZERO THI.

(TANORI (I), I = 1, MAXPIN) = LONEST FNSTRGY GROUP (AFTER GROI? COLLAPGING) FOR WHICH THERE IS A NONZFPO PISSION CROSS SECTION FOR PLANE I. A T: RO MEANS NO FISSTON.

(TRNAS1(T),T=1,LFRUTF) = THE POSITION IN COLUMN T JF THE GROTP COLLAFSEC SCATTERING MATRIX OF THF TOPMOST, NONZFRO PLEMENT. EQUTVALFNT TO LCCSCT WHEN THEPE IS NO GROMP COLLAPSING.

(IANRS? (I), I = 1, LSROIJE) = $T$ 4E POSITION IN COLUMN T OF THE GROIP COILAPSED SCAMTFRING MATRIX OF THF BOTTOM, NONZPRO PLFMFNT.

(IITPTR $(T, K), T=1, A), K=1$, IDIPTB) = TABLE OF CONTENTS FחR JTF INTRGRALS TN DIPINT FTLE.

TDIFTA $(1, K)=$ RFCCR! OP THE DIFINT PILE CONTATNING THE INTFCRALS.

IDTPTR $(?, K)$ = PCINTER TO THE FIRST KORD OF THF INTEGRAL BL DCK WTTHIN THAT RECORD.

TCTKMP $(?, K)=$ J.OURR PLANAR GEOMFTRY TDENTIETPR. $=\cap$ TOR THF BOTMOM BOINDAFY INTESPA:.

TIIFTB $(4, K)$ = UPPER PI.ANAR GEOHFTRY IDFNTTPTER. $=0$ FOR TH $=$ TOP POUNDARY INTEGRAL.

InIF⿻7 $(S, K)$ = TCINTEP TO A MESH INTPRVAL RATIO TN THE NLZ RA? ARPAY.

TITFTP $(6, K)=$ WaIG!ITING EUNCTION JDENTIPTEA.

TDIPTB $(7, K)=$ EYPANSION FUNCTION IRRNTIFIPK.

IDIFTA $(9, K)=$ N"MAPR OF KFCORDS REQNIRED DOR ILI THF TNTEGRALS OP THIS COMRINATION. 
APPENDIX G. PORTRAN VARIABLE GLOSSARY. (CONTD.)

(IRIM (T), I = 1, MAXFIN) = THE NIMBER OF COMBINING COPPFICIPNTS (OR EQUATIONS) ASSOCIITED ITH AN FXPASSION PUNCTION (NR PEIGHTING F(INCTION).

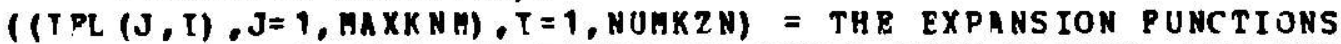
ISED IN ZONE I. IP TPERE AFP FFYER THAN HAXKHH, THE OMHER ENTRIPS POR A PARTICOLAR ZONE ARE ZERO.

(TFLTOC(I), I = 1, HAXPOH) = POINTERS TO THE FIPST GRONP PLOX TNTEGRAL FOR PUMCTION T IN THE ARRAY FLIIX. A ZRRO JEANS TYAT THERE. ARE NO INTERRALS POR A PUNCTION.

IGEOY = PLANAR GEUAETRY TYDE SENTINEL.

(ITOUSE (N,J),N=1,LGKCOP), J=1, MAXYUN) = A PPOJECTION MATRIX (EL SMENTS AQZ 0 OD 1 ) SHOYING WHTCH GROIP PLUXPC OP RACH PIJNCTTON ARF TO BP USFO (1) OR OAITTED(0).

THAX = THE NI HAFR OP HFSH INTERPALS IN THE X DIAFCTTON.

(TNTRL S (I), $T=1$, NCONRC MAXTNT) = STORAGE USED POR RTCORTS OP THE INTGLS FILE. DUR?NG THO SCLUT ION NCONRC=1.

(TTLACC(T), $T=1$, NPLACC) = THE GROUP FOR WIICH THE DIATNT COMRINING CNEPFICIENTS AQE TO BE PLOTTED.

(IRLDCC(I),I=1, NPLOCC) = THP GRONP POR WHICH THE DIPECT COABINING COEPFICIENTS ARP TO PE DLOTTPD.

((TPRATP (T,J), $T=1,2), J=1, N$ TAATY) = GROUP NUHEERS ( $I=1$ ) AND AXTAL -ESh INTERVALS $(?=2)$ POR YHTCH THE PLANAP ADJOINT IS m $B E$ EDITER. OOR TUO DTHFNSTONAT, HOTELS J=1 JILL EDTT ALL FLUXES. IPEIYT = BPOI YTER DEEIIT EITT SFNTINAL.

(IPRPAT(I) II = 1, HPRPUD) = AXIAL HESH TNTERVALS POP QYICH THE PLMNAR POYOR IS TO AP EDTTFD. PRE TKO DIMENSIONAL HODELS $I=1$ JTLL EDIT AII POUFRS.

$((T \cap P Q T=(I, I), T=1,2), J=1, N \cap R B T F)=$ GROUP NUMBFRS $(T=1)$ AND AXIAL MESH TVTERVALS $(I=2)$ FOS HAICH THE PLANAh PLUX IS TO BE EDTTE?. FOR $T$ HO TTAPNSIONAI MODELS $J=1$ KILL EDTT ALI, PLUYES.

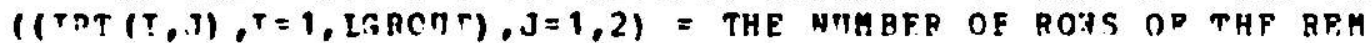
YATRIY STODPD IN THP OUTPTT INTFGPAL PILE POR THE COLIMNS ASSNCTATDD VITH COLLAPSTD GROUP I. IT IS THE SUM OP THF NHARFRS OF CHANNELS ASSOCTATFD NITH EACH COLIAPCFD GROIT BFTUPF TANDS1 (I) AND TBNDS2 (I). $J=1$ OK 2 DEPENTIVS ON EHFTHFR THE WEIGHTING/EXPANSION FLUX COMRTMATTON IDEING CONSITEPEN IS IN THF FKCPEP OBNEP FOR THE OUTPIIT INTPGRAL DESTRPA OD TS TAANSPOSPD.

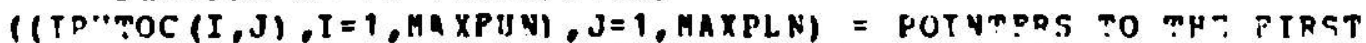
GPOUP ONAER INTERAAL FOR PUNCTION I ANL PIANE J IN THE ARPAY POI. A ZBPO MEANS THAT THEAE ARE NO TNTEGFAL.

TRCDIP = JIPINT PTLP PRCORD COINTEF.

IRTIVT = INTSLS PTLE BFCORC COINTER.

IRCITC = INTTOC PIID RECOPD COUNTEF.

TRCVOL = VOLTNT FILP RPCARD COUNTER.

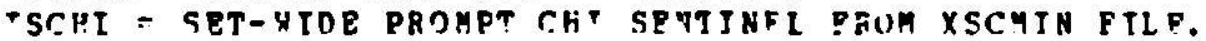


APPENDIX G. PORTRAN VARIABLE GLOSSARY. (CONTD.)

( ( I VOLTB $(I, K), T=1,7), K=1, I V O L T B)=$ TABLE OF CONTENTS FOR REH ANC PTS INTEGRALS IN THF VOLINT FILE.

$\operatorname{IVOLTA}(1, K)=1$ FOR REM INTPGRAL, 2 POR A PTS INTEGRAL, 3 POP A POW INTEGRAL, 4 FOR A PLIIX INTEGRAL .

IVOLTB $(2, K)=$ THE RECORD OP THF YCLINT PILE CONTAININA THF. INTEGRAL. =O IP THE INTEGRAL COILD NOT BE DONE AND - 1 ID THF INTPGRAL COULD HATE BEEN DONF BUT FOR SOME KEASON VAS NOT.

TVOLTR $(3, K)=$ PCTNTER TO THE FIRST YORD DF TH INTEGRAL BLOCK WITHIN THAT RECORD.

I VOITR $(4, K)$ = PLANAR GEOMETRY IDENTIFIER.

IVOLTB $(5, K)=$ WEISHTING FUNCTION INENTIFIFR.

TVOLTB $(6, K)=$ FYPANSION FU:TTION IDFNTIPIFR.

TVOLTA $(7, K)=$ NUHBEP OF FFCORDS REQUIPED POR ALL TTF TVTFGRA LS OF TUIS COMPINATION.

(I YRUN (J) ,J=1, MAXFUN) = VERSTCN NIMLEP GP FIIE POR FINCTION J. $S F E$ DINNAM.

(IVRPLN (J), J = 1, MAXPLN) = VERSIUN NBMBER OF PILE FOR PIANAR (B FONETRY J. SFE FJ. NW Y Y.

T:HERE = 1 IF THF INPUT NATA IS TO PF REAT DIRPCTIY FROM CARDS. $=2$ IF THF CARD TNPUT IS TO BE PRUCESSEN THPII THE AZC SYSTEM ROIITI NES.

( (I:N $(I, I), J=1$, MAXKNM), T = 1, N!IMK2N) = THE REIGH TTNG F"NCT'ONS USED TN ZNNF. I. TF I YFEE APE FE:TF THAN MAXKNY, THE OTHER FNMRIFS POR A PARTICULAP ZONE ARE ZFKC.

(TIAADP (I), T=1,50) = THE NORO LENGTH PARAMTTER FOR EACH DTMFNSTONED VARTABLF. DEFINFN THROIIFH BFOTNTFR. THIS ARPAY TS OP DTTFFOENT LFVTTH IN EACH OVERLAY.

JBANT = THF NMMAER OF RONS CP FLOXES IN ONF RECORD OP THF REOPLX FILE.

$(J) T$ TT $(I, K), I=1,7), K=1$, IDIPTB $)=$ TABLE OP CONTENTS FOD NTF TNMFGRAL.S IV THE INTCIS PILE. THF DEFINTTIONS ARE TIE SAME AS FOR IDTFTP, EXCEPT THAI THE LAST FNTRY IS OMTTTE.

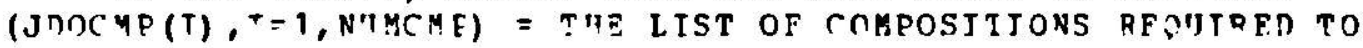
CALCTLATE THE INTEGRASS.

(.TMOFN (I) , T=1, NISMF"N) = THE LTST OF FIINCTTCNS REOUIRED TO CALCULATE THE ?NTEGRAIS, IN THF ORDER IN NHICH THFY ADP?AR TN THE FEOTIX EILE. RHEN IT TS PPESENT, THF JNTT FURCTTON JS IAST TN THF LTST.

(JIAPI.N (I), T= 1, N'IYPLN) = THE LTST OF FLANAR GFOMTTRIES RFOIIIRPD TO CALCIIATE THE INTEGRALS.

JMAY = THF, N'TRER OP MESH TNTERVALS IN THE Y DIRFCTIUN.

$(((J \cap T(I, J, K), I=1, T$ NDCH) $, K=1, M A X P I N), J=1,2)=A$ POJNTER IN A COLIMI DE THE GROIP CCLLAPSPD FIS INTEGRAL FOR PLANF $K$ TO THF FTRST FIEMENT ASSCCTATED WTTH YEIGHTTNG FUNCTTON TROID I. THE DIPPERTNCF. AETIEFN TPT $(I, J, K)$ AND JPT $(I+1, J, K)$ TS TI!T NYM PER OF CHANNELS ISSOCIATED VITH CROOP T OF THE WFIGHTING, PIINCTTON. J=1 OR 2 DEPENDTNG ON NHETHFE THE TE IGHTTNG/PY PANSION FI.UX COMBTNATION BFTNG CONSICERFD IS IN THE PROPFR ORDER POR THE OUTPIIT INTEGPAL DESTRED ND TS TRANSPRSFD. 
APPENDIX G. PORTRA VARTARLF GLOSSARY. (CONTD.)

(JVOL TB $(I, K), I=1,6), K=1,4$ YOLTB) = TABLE OP CONTENTS FOR REM S PIS INTEGRILS IN THE INTGLS FII.E. THE DEFINTTIONS ARF THE SAME AS FOR IVOLIB, FXCEOT THAT THE LAST ENTPY IS OMITTED.

(XCIIANG(I), I=1, NOMK $Z N$ ) = THE TOPMOST HPSH TNTERVAL ?N EACH ZONE. KC ४АNG ( NUNKZ $M$ ) = KHAX.

(KNTH (I), $I=1$, NUYKZN) = THF NIMBER OF UNKNOWN COMBININF COEFPICIENTS (AND THERFFORE BQUATIONS) ASSOCIATED WTTH ONE MESH INTERVAL IN ZONE I.

(KGEOH (I), I=1,NTMKZN) = THE (BEOHETRY FOR HFSH INTERVALS KCAANG(I-1) TO KCHANG(T). KCHANG(0) IS DPPINDD TO BE 1. KMAX = NMWBER C. AXIAL MESY TNTERVALS.

(KNIJYPI. (I), $T=1$, NU HKZ N) = THE NMMRER OF PLUX FTLEC REPFRENCFD AS EXOANSION PTNCTIONS FOR ZONE I.

(KNIITT (I), $T=1$, NU MK $2 \mathrm{~N}$ ) = TUE NIMBER OF PLUX FILES RFPERZNCED AS TEIGHTTNG FTHCTIONS POR ZONE I.

( ( $(K P T(I, J, K), I=1, L G R O J P), J=1, L G R O I P), K=1,2)=A P$ INTF, IN THE 1D ARAAT CONTAINING TYE 2D, GROUP-CCLLAPSET REM INT OGQAL TO THE FIDST STOREN FLEYFNT OP THE INTEGPALS ASCOCTATED

UITH HE JTHTINC PUNCTION GROUP I AND EXPANSION PIN $T$ TTON SROID J. THE DIFPERENCE BET'JEFN KPT $(I, J, Y)$ ANO KP! $(I+1, \therefore, K)$ IS THR. NIMBRR OP CHANNFLS FOR 'JEIGHTING FUNCTION ;RD"P $T$. $K=1$ nR 2 DEDPNDING ON WHETYEP THE NRIGHTING/FXPANSION PI"X COMRINATION BEING CONSIDERFD IS IN THF EROPER ORRFG POR THE OUTPOT INTPTRAL DESIRFD OR IS TFANSPOSPU.

I DTPTB = NIHRPR OF QNTQTFS TH THF IDTFTB TAGL.

LENA = THE STORATE RFOITRFD POR THE COMPTNTNG COEPPICISNTS.

(LENADP(I), T=1,5n) = THE IFNSTY OF EAC! DISENSTONE? "ARJABLF DEFTNED THPOUGH BOOTNTER. JHIS ADRAY IS OD RTDPEPP.NT LENGTH IV EACH OTEPLAY.

(LENCRD(T), T=1, NPEC) = TIIE LENGTY (IN R*4 VCRDS) TF SACH DATA RFCORD CF SY NCON. NRFC = THF NIHEEP OS DATA RZCOFOS.

(LENDIF(I), I = 1, NRCDTR) = IEVGTH OF PECORD I OF JIPINA FI:P. IENITZ = LEVTTY OF DIZPAT APAAY.

LENFLX = RECCPD SIEF POR BEOPLX.

T.ENFL" = LFNGTY OP THE ARFAY FLIX TN OVFRLAY SOLVE.

L.ENH = MAXTYHA PFCORC STZE FOS THE IIEILE FTLE.

LENIYT = TES MAXTMIM RFCORN LENCTH FCR VOLTNT AVD DIFIVT INT EGRAL. PILFS.

LPNIST = THE YAXTHIP LPNCTH OP THF LIST OF TNTPRQLLS, LTSTV.

LENROV = LENTTH OP THA APFAY PO: TN OVERLAY SOLVE.

(I. ENRCH(T), $?=1$, YRCH) = TUE LENGMH OF FACH "CRO OF TUF YETLE FTLE.

(LEVTCI (I), T=1, NBCTYT) = IHE LDVRTY OF EACH RECOPN OF THO TVTRLS FTLF.

(L FNVOL (T), I=1, NRCVOL) = LFNCTH OP FRCCRD T OP THIE VOI TVT FILF.

LEYY = RFCCRD SIZE POR CROSS SFCI JON PILE REOYST.

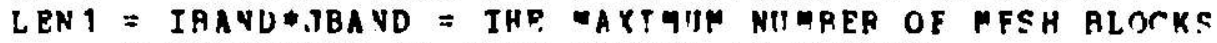

REPRESDNTER IN EACH FECCRD OP PFOFLX.

LEN2 = I. EN1* IT RATn

I.EN $3=$ I.YST 1 .

LGPOIIP = NTYAFO OP PNEPGY TROUTS AFTEP COLLAPSTHT.

(L'STV(I), I= 1,LENIST) = A LIST OP ENTPTES IN TVOLTH ANU/OR IOITTH DESTGNATING INTEGPALS TO AE DONF AND THF OSDFR TN NUTCH THEI ARE TO PE DONE. THE IVOLTA PRTFIES APF IISTEN FIDCT, THYN

THE TDTTTR ENTRIES. ALSO GFF NTDYV AHD NTRYN. 
APPENDTX r. PORTRA N VARTABLE GLOSSARY. (CONTD.)

(LACSCT (I), I= I, NGANIP) = THE POSITION IN COLJMN I O: THE SCATTERING MATQIX OP THP TOPHCST, NOHZERO ELPMENT. EO'JIVALDNT TO IBNDSI WHFN THEKE IS NO GROIIP COLLAPSING.

$(((L F T(T, J, K), I=1, L$ RORII $), K=1, \operatorname{MAXPLN}), J=1,2)=A$ POINTER IN THF ID APRAT CONTAIVINA THE 2D, GPOOP-COLLAPSEC PIS INTEGRAL POR PLANE K TO THF TOP OP THP FIPST COLUAN ASSOCTAT PN UTTH PXDINSTON FT MCTION RROU? T. THE DIFFEKENCE BET"EPY IOT $(\mathrm{I}, \mathrm{J}, K)$ AND LPT $(T+1, J, K)$ IS MOT $(J, R)$ TIMES THE NIMBPR OP CAANHELS ASSOCTATPD XTTH GROIIP I O? THE FXPAHSTON PUNCTION. $J=1$ OR ? DEPENTTN'; ON WHETUPA THE UFIGHT ING/EXPANSION FL!IX CONBINATION APING CONSIDERFD IS TN THE PROPER ORDER FOQ THE OUTONT INTERPAL JPSIRED OF TS TRAHSPOSEN.

LRE $O P=$ NITHFA OP RECODD IN THF REQFLX PILF.

LRFOY I = YISYAER OP OPCORD CP THE REQXST PILE EXCLNDTYG DIZYUSION COFFFICTENTS.

LRPAY 2 = VINAER OP RECORNS OP THF REQXST YIIE CONTAININA ONLY NIEPUSTCN COEETICIFYTS.

LVח ${ }^{-1}=$ NUMBEK OP ENTAISS TN THF IVOLTB TABLE.

LXCTI = TUP NIIMBFP OF CQOSS SFCTION DATA PRP COHDOSTTION, POR -OR RECOPAS OP TEOXST EXCIIDING DIDPUSICN COEPFTCIENTS.

LXCTy - -HF VIMAFO CF COMFOSTTIOYS PER RRCORD OP REQXST, FOK TFCOQDS FYCI'IDTNG DTFPUSION COEPPICIENTS.

IXST? = THF WIMRER OF GROIIPS OEP RECOAD POR PECORDS CONTATNTNG ONI Y DIF?ISTON COPPPICTENTS.

MARUN = THF MAYTMU MIYOOR OF CHANNELS IN ANY CHAYYEL STAUCTHRE SCHEYF. = THE LARGPST VOLIIF OP NJHCHN(I), $I=1$, NCHNST.

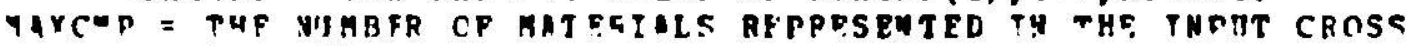
SECTION FTLP.

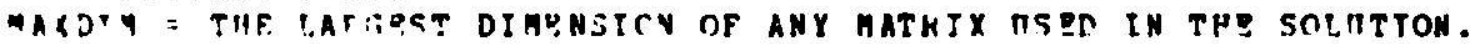
MAXNY = MAYTMIN Y"HBER OO OCRNGCATTERING GROHPS.

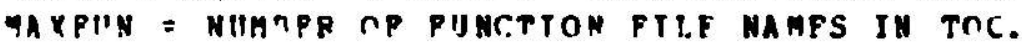

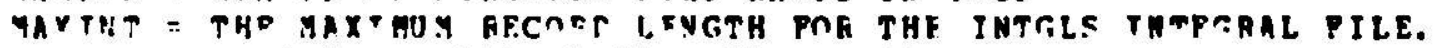

TAXITR - MAYTYUS NITAEA CP ITEPATIONS ALIOJED.

YAXYN. = THO MAXTMUA NIMRYP OF HPICHTING YINCTIOHS ISET IN A

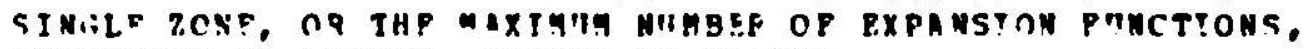
"HTC YEVEO Ir LAPIEQR. TAYKNP.LF. HAXUSE.

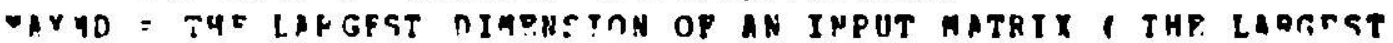
YUMAEP DD GROIID-CHANYFL CORBINATTONS FOA A STMGLE FINCTIOVI. YAXYDOU IS THE TTMTYIIY SPACE DEOUIAED FOR A RTCORD OF DEVRTTHF TVTFGBALS.

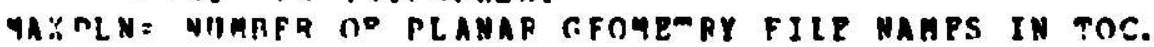

YAXR IG - THE. GAYTMIIM MIIMAPQ OP PPGJONS ASSOCIATRO D̈:TH AYY OP THE PLANAD TEUAETRTOS.

MAYSPZ = THE LENGT! CF TIF APOTHTEN CONTAINEQ ARRAY.

YAXTIT - MAYIAII ALLCEEN NIMBP? OP INPUT TITLF CAQNG.

MAXIP = UAYTMU VIMBEP OO URSCATTET ING GPOLPS.

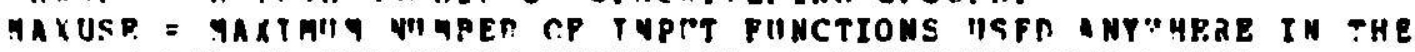
MCDEL IS DYDANSTON PINCTTONS OP REIGHTING FMNCTTOYS.

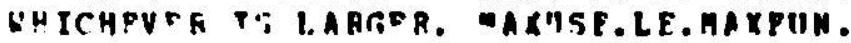

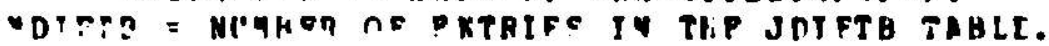

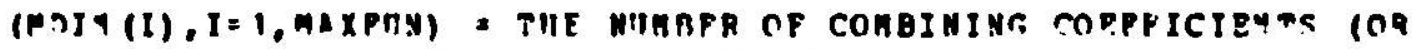

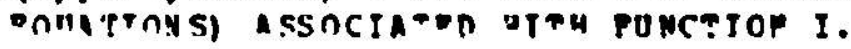


APTENDIX G. FCRTPAN VARTABLF RLOSSARY. (CONTR.)

( ( $P$ : $(T, J), I=1$, MAXPLN), J=1,2) = THE NUMBER OF ROYS TN THE GROMP CCLLAPSFT FIS INTEGPAL FOR PLANE I. IT IS THE STM O? THF. N"YBED OF CHANNEIS ASSOCIATFD KTTH EACH COLLADGED GROTD nO:V TO THF LAST NONZERO CHT. T=1 OR 2 DEPFNCING ON "METHF" THF NEIGHTING/DXPANSION FLITX COMEINITION EEING CONSTDEREN IS IN THF PRCPEE ORESR FOR THE OUTIIT INTEGRAL DESIRE T OR IS TRANSPOSFD.

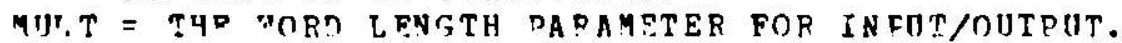
YVOLT = NTMREQ OP ENTAT TS TN TEF TVOLTB TABLE. गQ"FFH = 0 FCR NO RIFFERING, 1 FOR EIJFFERTNG TN HEED/RITF. NCATC - CAIC"T.ATION IYPE SENTTNEL. SFE TYPF 2 CARD OF SYNFII.

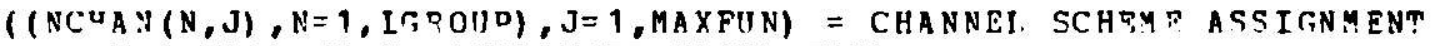
FOR EACH GROUP-CCLLAPSED BROUP FIIX.

HC"NCT = THF NIMEER CF CUANNEL STRUCT"RE SCHEMES.

NCOLG' $=$ COR GROMP DFPENDENT SYNTHFSIS, 1 FOR GFNERAT GROUP COITAPSIM, 2 FOF SPFCIAZ GPOUP COLLAPSING.

NCNIPC = THE NIMRPR CF CONCIRRENT TNTGLS PFCOFCS THAT CAY BE HFLD TN CORE NIRTNG THF. INTEGRAL RFVATTF.

NHFVOY = ?, IN NOT CALCIIIATE PERTORBATION DENCMINATOR. 1. CALCILATT PDRTIIRPATTON TENOMIUATOR.

VPI DIF - THF, FTIE NIMAFR FOR THF DTFINT FILF. NFLEI, $Y$ RFOFLT FILE NIYRFR.

(NFIFIJN (J), T=1, MAXFIN) = TIIF FJIF NIMBFR FCP FACH EL'TX FTLF. NEI

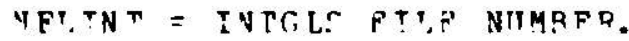
IFI TTC = THO ILO VUMAFP FOR TUE INITOC FIIE. (VFLOLN(I), I= 1, MAX!i,N) = THF FTIE HIMBFR FOR FACH TYAMAR TETYENTFY STLE.

\#PI SYN = SYNCOY FTLF NIMIER.

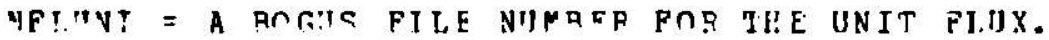

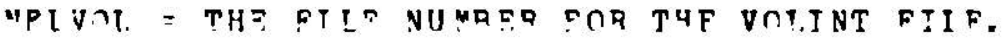

NEIXSC = XSCMTV FILE NIJMRF.R.

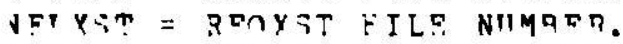

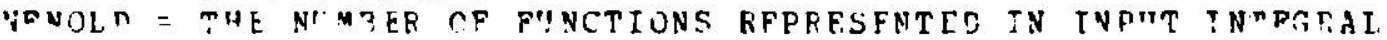
IT. TS.

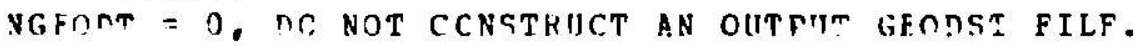

.r. D, TUE VF BSTCN NIIMJER FOF THE OUTDIT CFOCST FTIF.

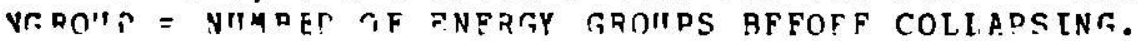

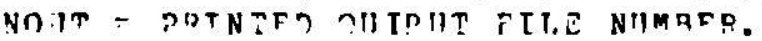

VP? ACC = THF NI:MNFD CF ANJOINT COMDINTNG COFFEICTFNT PLOTS.

VPI RTC = THF VI YGFR OE DIRTST COMBINING COFEFTCIONE PLDTS.

NPLOT = THE N"MEF OF NIANAD GEOMFTRIES RFETESENTEN IN TNEIT TNTEGKAI CTTES.

VPJATF = THF NIMBPF OF PIANAB ADIOINT GRCIP FLUXES TO BE F!TTED. NPPF ${ }^{*}$ = THF NIMREP CF DI.AVAR POWEF DISTRIPUT'ONS TC AP EDTTED.

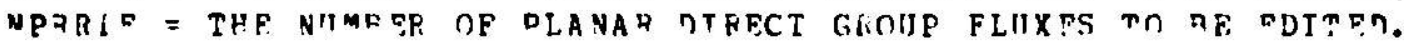
NPQQZF - 0, nO NOT EDIT THF AVIFAGF FLIXES ?Y $70 N F$.

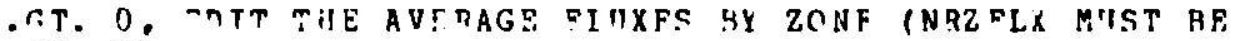
. r.t. ni.

(NPTARE (I), T=1,36) = THF POLNTER TC EACH ITAFNSTONFD VARTABLF nEFTE? THRAIGY REOTNTR. 
APPENDIY G. FORTRAN VARIABLE GLOSSARY. (CONTD.)

(NPTOIJT (I), I=1,2*LENLST) = A SCRPTCH ARRAY CONTATNING 2OINTERS VITHIN THE OUTPUT RECORDS FOR FACH ENTRY OF LISTV. NPTXMS = POTNTFE TO THE LOCATION JUST BEPORE THE START OF THE MESH TVTERVAL DATA IN A RPCCORD OP REQPIX.

(NPTXST (I), $I=1$, LENLST) = A SCRATCH ARRAY USED TO STORE POINTERS TO COMPOSITTONS FOR EACH ENTRY IN LISTV. NPWDNT $=0$, DO NOT CCNSTPUCT AN OUTPUT PWDINT FIIE. . ST. O, TUE VEPSION NUMBRA FOK THE GUTFUT PIUINT PILP. NPCDIF = NIMRER OP RFCORDS IN THE DIFINT FILE. NRCH = THE NMMAER OF RFCORLS IN THE HFILE FILF. NRCTVT = THE NIMRER CF RECCRDS TN THP INTGIS FTLF. NRCVOL = NIMPEP OF RECORDS TN THF VOLINT FILE.

NRECD = THE NUMBER OF RECORDS OF TLI DIFINT FTLF BEING CONSTFIICTED CN A PARTTCULAR PASS THRU THE INTESRATION LOOP. NRECV = MHE NIMBER OF RECORDS OF THF VOLINT FILE RETNG CONSTRICTED ON A FAPTICULAR PASS THRU THF INTERRATION LOCP. NRZFTX $=0$, NO NOT CCNSTRUCT AN OUTPUT RZFLUX PILF. . FT. 0, THE VERSION NUMAFR FOP THE OUTPUT RZFLUX PILE. NSCAL $=1$ IF TSER SUPPLIFD SCAIING FACTORS FSCALE AND "SCALE AFE TO RF ADPLTEN, 0 TF NOT.

NSTDTF = FODMAT SENTTNRL FOR DIFINT FIIE.

NTITIE = THE NIMAER CF AK WORDS ISED TO STORE THE TITIF.

NTRIAT = TRIANGULAP MESH SENTJNAL.

NTRIOT = SECCNIQRY "FIANGIIAR MESH SFNTINAL.

VTPYT = THE N'JMBPR OF ENTRIES IN LJSTV WHICH PERMAN TO THE I DIPTB TAPLE OF CONTENTS.

NOPY" = THE FIRST NTRYV FNTRTES IN LISTV PERTAIN TO THE TVOLTB TARIE OF CONTFNTS.

NTYOES = MAYIYUM ALLCHFD NTMRER OF INPUT CARD TYDES.

NUMREC = THF NMPER CF OUTPIIT INTEGPAL RECORDS THA? CAN RE CONTAINFD IN CORF.

(NIMLYN(I), I= 1, NRHNST) = NUMPEF OF CHANNELS TN CHAHNFL SIRUCTIPE SC.

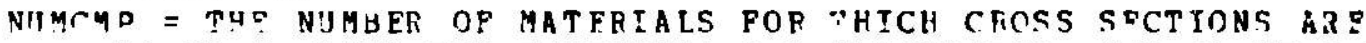
RTOITEET WHEN THE INTEGPALS ARE CALCULATED (NIMCMF.LR.MAYCMP) VIMFIN = THF NIMAER CD FINCTIONS REOUI?EN TO CALCILATF THZ TNTFIRAIS. TF THE TNIT FINCTION IS RFQUIRRD, IM IS INCLTDED IN "IMOUN, SVEN THOIGH NO SUCH FLUX PILE IS EVUR JDTTTFN (NITIIJN.TE YAXFUN) .

NHMKZN = THF NUMAFE CF AYIAL ZONFS IN THE MODFL. THER IS AN NES R.ONF WHEN FITHER THF PLANAD GECMETFY OF THE FINCTION SFMS CHANGF.

NTMPLN = THF NUMPER CF PI.ANAR GFOMETRIES REQUTRPR Tכ CALCULATE THE INTETRALG. (NUMPLN.LE.MAXPIN)

N3DANJ $=0$, RC NOT CCNSTRICT IN COTPHT ATFLUX FIIS. . GT. O, TIE VERSICN NIMBER FOF THE OUTPIJT ATFL"X PII. N3 J!LX = 0, DC NOT CCNSTRUCT AN CUTRUT RTPIUX FILF. .GT. $n$, TIIF VERSION NIMBEA FOR THF OUTPIIT RT DL'JX PTIE.

$((\cap D T H F C(I, J), T=1$, MAXOTY), $, I=1, N U P K 2 N)=$ THF FACIORS DOR EACF SYNTHFSTS ZNNE ISET TN THE NORMALIZATION/NIFPFRTNCINS, TRINSFORMAT ON APPLTOD TO THE SYHTHFSTS EOUATIONS. DOP PACII 2ONF THE FACTUFS AKF STORED IN THE SAME MANNPP AS THE CORRFSDONDINA COMRINTNG COFFFICIFNT. 
APPENDIX G. PORTRAN VARTABLF GLOSSARY. (CCNTD.)

$(($ PLNNAM $(T, J), I=1,3), \operatorname{IVDPLN}(J)), J=1, \operatorname{MAXPLN})=$ POLL NAME OP FILE FOR PLANAR GEOMFTRY J.

(POW(I),$\tau=1$, MAXFIN*LGROUP* YAXPLN) = AN ARRAY CONTAINIHS PONER INTRGRIIS POR EACH PUNCTION AND PLANF. THE TNTEGRALS ARE STORED IN TEE SAMP VAY AS THE COMBINING COEFFICJFNTS, WITH RLANKS OHITTED. POINTERS TO THE FIRST NCNZTRO GROIP ARE GIVEN TN THE ARRAY IPITOC.

PJHFTS = WATTS PER PISSION.

(PP (T), T=1,1.PN1) = A SCRATCH ARRAY USED TN CALCILATTNC THE INTEGRALS. FOR A MTLTICHANNEL CALCULATION 3*LEN 1 TS RESERVED.

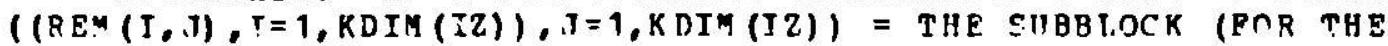
CURRENT AXIAL MESIT TNTERVAL) CONTAINING THE INTRGRALS OVER THF REMOVAL CROSS SFCTIONS. IZ IS THE SYNTHESTS ZONE ASSOCIATED WITH THE CURRENT AXIAL MESH INTERVAL.

( (?ESTLT $(\tau, J), J=1, L P N T N T), J=1, N$ IUMREC) = AKRAYS POR OTTPOT INTEG CAI.S.

(TT TP $(T), I=1,10)$ = THE ARRAY IN THF ARGJMENT OP SUBROITINE TTMER. (TITLE (T), I=1,NTTTLE) = USER TNPTT TITLE.

( ( (I) $(I, J, K), I=1, I, G R O(I P), J=1, N G R O U P), K=1,2)=$ GENERAL GQGO!D COLLAPSING YATRIX FOR ?HE FXPANSICN PINCTTONS $(K=1)$ AND AEIGHTING FUMCTIONS $(K=2)$.

(VOL (I), T=1,LPN1) = SCRATCR ARFAY FOR MFSH BLOCK VNLUMES. (' $\operatorname{SCALE}(I, J), I=1, N G R C U P), J=1, \operatorname{MAXFUN})=$ USEP SUROLIED SCALING FACTOR TOR EACD GROUP OD FUNCTION J WHEN FUNCTINN J TS IISED AS A HETGATTNG FUNCTION. TT CAN ONLY HAVE AN EPFFCT NUEN GROUN COLLAFSTNG IS EMPLOYFD.

YEOS = A SMALL NIMGER USED IN TESTS FOR ZERO CPOSS SECMIONS. (XSPCT1(T), I=1,LENXST) = THD ARRAY INTO HHICH A RECNRD OP REQXST TS PEAD. XSPCT 2 SEPVFS THE SAMP PURPOSF.

(ZMFSH (K) ,K=1,KMAX) = POSITION OF OPPER BOUNDARY OP AXYAT. MESH $I N T P R \nabla A L K$. 
APPENDIX H. Sample Problem Output. Problem 1 - Complete Output, with Cross Section Edits

STH 3D, OVERLAT CATSS

THOEE GROTD. FUNDAMENTAL MOTE CALCULATION

$1 / 20 /, 04.43 \ldots$ PAGE 1

IISTIMG OF SYIJ' I MPUT

ChPOS-PEF-CAPD-TFPE. THTA

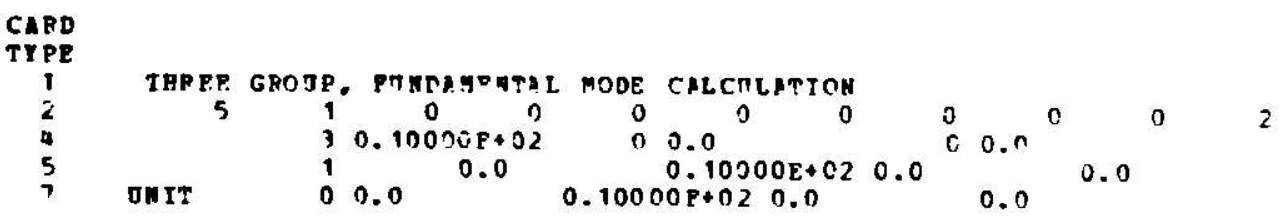


SYU30, OVERLAT HHGAC

* * hnsa - cccc to arc ststen cross section hohogenizarlon * * *

PILE WDXSBF IS LON 40 AHD COHTATNS THE JSER ID -3D,3GP NODFL-

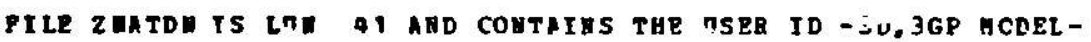

PILE ISOTXS IS LNT 39 ANO CONTAINS THE USER ID - 3D, 3GP NODEL-

PTLE COHPIS WILL NCD BE YRITTEH ON LON 50 


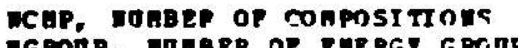

DGRONP. DOLBER OP FNEPGT GRGDPS

ISCET. PBOAPT FISSION SPECT RNA DLAG

ITIONS

COS OPSCATTERIMG

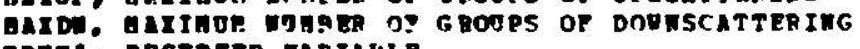

DOn1. RPseeved VanTable

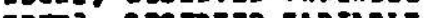

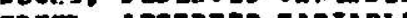

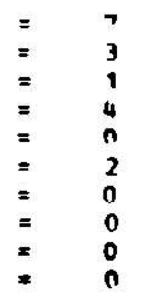

PHOAPT FISSION SPECThON (SET CHI VECTOR)

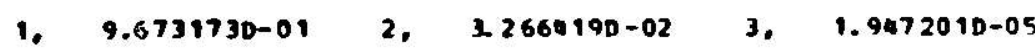


SYW3D, OTERLAT HEGHC

\begin{tabular}{|c|c|}
\hline G800P & ASSOAPTIOD \\
\hline $\begin{array}{l}1 \\
2 \\
3\end{array}$ & $\begin{array}{l}3.5232700-03 \\
5.7310640-03 \\
2.4204500-02\end{array}$ \\
\hline GrodP & $\begin{array}{l}\text { porea cciv } \\
\text { picto }\end{array}$ \\
\hline $\begin{array}{l}1 \\
2 \\
3\end{array}$ & $\begin{array}{l}0.008189 \\
6.349367 \\
2.496852\end{array}$ \\
\hline
\end{tabular}

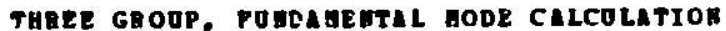

1/20\%. 04.03., PAGE

\section{PoIt of (PISSIOMABLE) CONPOSITION No. 1}

$$
\begin{aligned}
& \text { TOTAL REHOVL TRAMSPORT PISSTON MOPISSIOY CHI WOP WDE } \\
& \begin{array}{lllllllll}
1.4686340-01 & 1.2214770-02 & 1.6303430-01 & 2.5025600-03 & 7.4177060-03 & 9.6731730-01 & 0 & 0
\end{array}
\end{aligned}
$$

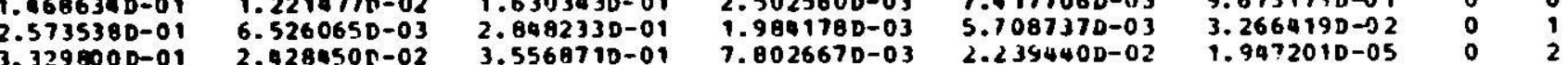

DIRECTIONAL DIPPOSION COEPP. ADDITIVE TEA

DIRE CTIORAL DIPYOSION COEPP. NOLTIPLIE oIREMSION 1 DIRESION 2 DTHEHSIOH

\section{$1.300000+00 \quad 1.000000+00 \quad 1.000000+00$}

$\begin{array}{lll}1.000000+00 & 1.000000+00 & 1.000000+00 \\ 1.000000+00 & 1.000000 \div 00 & 1.000000+1.00\end{array}$ DIGEASI OU

DIEEYSION 2

0.0

0.0

\section{0}

0.0

TOTAL SCATTERTh CROSS SECTION

IHTO GROOPANOA GROPP. CROSS SECTIOU
1 1. 1.4057340-01
1. $8.7249620-03 \quad 2.2 .5647390-01$
$3 \quad \because$ 3.404490-08
$2.2 .5647390-01$
$2.7 .9500150-04$
3. 3.0941550-01 
STO3D, OTEPLคT คMGEC

THPEE TROUP, FTEDATELTAL MONE CALCTLATION

$1 / 20 \%, 04.43 \ldots$ PAGE

EDIT OF (PISSIONALE) COMPOSITION No. 2

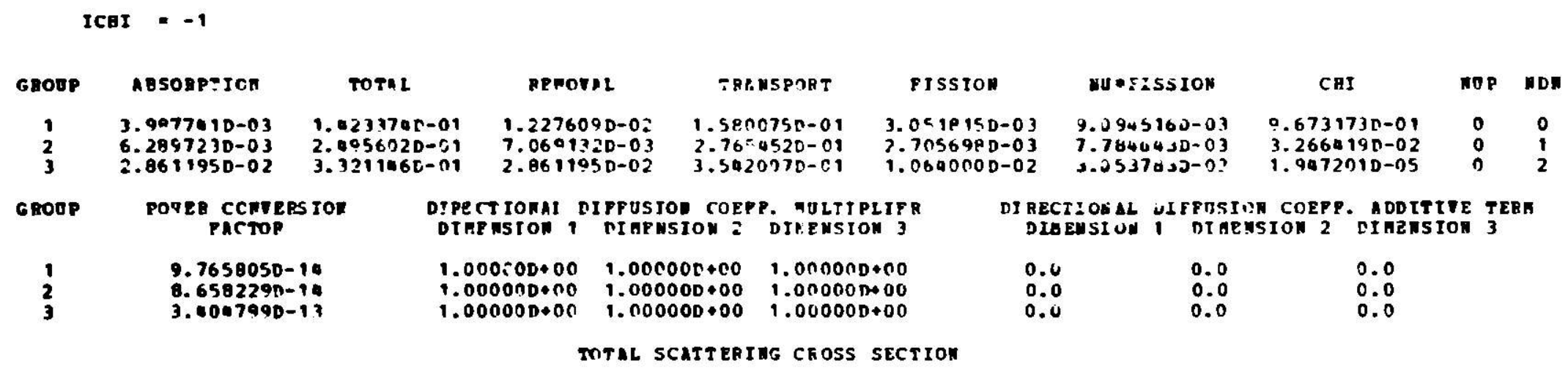

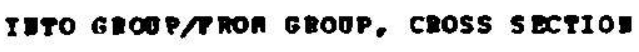

$\begin{array}{llllll}1 & 1.3954720-01 & & \\ 2 & 1.316980-03 & 20 & 2.4847810-01 & \\ 3 & 1.0139670-08 & 20 & 7.7940800-04 & 3 . & 3.0432860-01\end{array}$ 
STMzO, OTERLAT HMGAC

THREE jRCOP, POGDATFUTAL HODE CALCDLATION
1/20\%, 04.43.. PAGE 6

FitT of (FISSIOMABLE) COMPOSITION NO. 3

\begin{tabular}{|c|c|c|c|c|c|c|c|c|c|c|c|c|c|c|c|}
\hline GRODP & ABSORPTION & & & REFO & VAL & TRA & IASPORT & & & $W U * P I S$ & SS IOH & CEI & & MOP & IDE \\
\hline $\begin{array}{l}1 \\
2 \\
3\end{array}$ & $\begin{array}{l}2.0026150-03 \\
3.8027000-03 \\
1.1010540-02\end{array}$ & $\begin{array}{l}1.63 \\
2.91 \\
3.76\end{array}$ & $\begin{array}{l}-01 \\
-0 \\
0 \\
-01\end{array}$ & $\begin{array}{l}1.1437 \\
.6774 \\
1.1810\end{array}$ & $\begin{array}{l}020-02 \\
450-03 \\
5 \in 0-02\end{array}$ & $\begin{array}{l}1.602 \\
3.199 \\
4.020\end{array}$ & $\begin{array}{l}9690-01 \\
5270-01 \\
662 D-01\end{array}$ & $\begin{array}{l}8.67 \\
7.99 \\
7.99\end{array}$ & $\begin{array}{l}D-04 \\
D-53 \\
0-53\end{array}$ & $\begin{array}{l}2 .+5375 \\
0.0 \\
0.0\end{array}$ & $500-03$ & $\begin{array}{l}9.67317 \\
3.26641 \\
1.94720\end{array}$ & $\begin{array}{l}730-01 \\
190-02 \\
010-05\end{array}$ & $\begin{array}{l}0 \\
0 \\
0\end{array}$ & $\begin{array}{l}0 \\
1 \\
2\end{array}$ \\
\hline GROOP & $\begin{array}{r}\text { POJER CCIVE } \\
\text { PACTOE }\end{array}$ & stom & $\begin{array}{r}\text { Drae } \\
\text { Drn }\end{array}$ & $\begin{array}{l}\text { Trowhe } \\
\text { nsion }\end{array}$ & $\begin{array}{l}\text { DIProsI } \\
\text { DI GEI }\end{array}$ & $\begin{array}{l}\text { COEP } \\
\operatorname{ION} 2\end{array}$ & $\begin{array}{l}\text { P. HOLTI } \\
\text { DITEMSI }\end{array}$ & $\operatorname{ligR}_{3}^{2}$ & $\begin{array}{l}\text { DIRE } \\
\text { DI }\end{array}$ & $\begin{array}{l}\text { TIOHAL } \\
\text { IENSION }\end{array}$ & $\begin{array}{l}\text { DI PPOSI } \\
1 \text { DI HE }\end{array}$ & $\begin{array}{l}\text { CoEPP. } \\
\text { SIOS } 2\end{array}$ & $\begin{array}{r}\text { ADOTT } \\
\text { TIMENS }\end{array}$ & $\begin{array}{l}\text { V T } \\
\text { O: } \\
\text { T }\end{array}$ & \\
\hline $\begin{array}{l}1 \\
2 \\
3\end{array}$ & $\begin{array}{l}2.7757290 \\
2.5599990 \\
2.5599980\end{array}$ & & $\begin{array}{l}1.0 \\
1.0 \\
1.0\end{array}$ & $\begin{array}{l}000 \times 00 \\
000 D * 00 \\
000 D+00\end{array}$ & $\begin{array}{l}1.000 \\
1.000 \\
1.000\end{array}$ & $\begin{array}{l}O D \bullet 00 \\
O C+00 \\
O D+O D\end{array}$ & $\begin{array}{l}1.00000 \\
1.00000 \\
1.00000\end{array}$ & $\begin{array}{l}+00 \\
+00 \\
+00\end{array}$ & $\begin{array}{l}0 . \\
0 . \\
0 .\end{array}$ & & $\begin{array}{l}0.0 \\
0.0 \\
0.0\end{array}$ & & $\begin{array}{l}0.0 \\
0.0 \\
0.0\end{array}$ & & \\
\hline
\end{tabular}

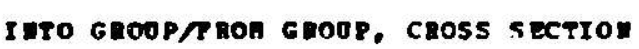

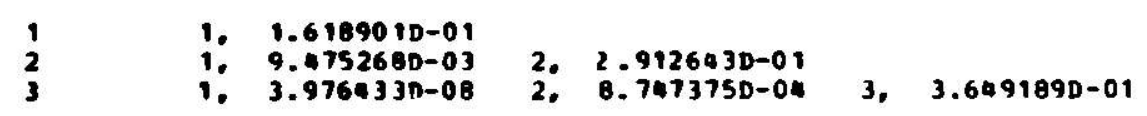


COMPOSITION No.

ICHI $=-1$

\begin{tabular}{|c|c|c|}
\hline GRODP & A ASORPT TON & TOTAL \\
\hline $\begin{array}{l}1 \\
2 \\
3\end{array}$ & $\begin{array}{l}3.5036150-03 \\
6.4546430-03 \\
1.8284760-02\end{array}$ & $\begin{array}{l}2.085707 \mathrm{D} \\
3.597723 \mathrm{D} \\
4.069050 \mathrm{D}\end{array}$ \\
\hline GRONP & $\begin{array}{l}\text { POFER CONVE } \\
\text { PACTOR }\end{array}$ & $S ? O N$ \\
\hline $\begin{array}{l}1 \\
2 \\
3\end{array}$ & $\begin{array}{l}5.0310090 \\
4.6399960 \\
0.6399960\end{array}$ & \\
\hline
\end{tabular}

IUTO GBOOP/PBOE GROEP. CROSS SECTIOI

\section{FISSION \\ 1. $5721910-03$ 1. $409099-52$}

HU * EISSIOH i. 0
CHI

ROP NDN

$9.673173 \mathrm{D} \cdots 01$ $3.2664190-02$ $1.9472010-05$

$0 \quad 0$

001

DYPETTONAL DIFFUSIOH COEPP. MULTIPLIF DIMENSTOF 1 DIAEHSION 2 DIMENSION ?

$1.000000+00 \quad 1.000000+00 \quad 1.00000 n+00$

$1.000000+00 \quad 1.000000+00 \quad 1.00000 D+00$

$.000000+00 \quad 1.00000 D+00 \quad 1.00000 D+00$

DTRECTIONAL DIPEUSION COEPP. ADDITIVE TERA DIAENSIOH 1 DIMENSIOH 2 กIRENSION

0.0

0.0

0.0

TOTAL SCATTERIAG, CROSS SECTION

0.0

$\begin{array}{lll}1 & 1.0767300-01 \\ 2 & 1.3601205-02\end{array}$

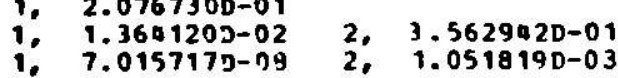

3. $3.8914840-01$ 
STU30, OTERLAT HHGAC

THREE GRCJP, PUNDAHFNTAL HCDE CALCJLATION

RDI" OP (MOMPISSIOBARLE) COHPOSITION NO. 5
$1 / 20 /, 04.43 \ldots$ PAGE 8

\begin{tabular}{|c|c|c|c|c|c|c|c|c|}
\hline GROUP & ABSUEPTIOU & TOTAL & REROVAL & TRANSPORT T & мпр & NDN & & \\
\hline $\begin{array}{l}1 \\
2 \\
3\end{array}$ & $\begin{array}{l}3.02879 \mathrm{DD}-0 \mathrm{Q} \\
7.077997 \mathrm{D}-03 \\
7.891622 \mathrm{D}-03\end{array}$ & $\begin{array}{l}1.7471520-01 \\
3.5772700-01 \\
6.4699460-01\end{array}$ & $\begin{array}{l}5.736323 \mathrm{D}-03 \\
2.075549 \mathrm{D}-03 \\
7.891622 \mathrm{D}-03\end{array}$ & $\begin{array}{l}1.8567620-01 \\
3.7930130-01 \\
6.7949240-01\end{array}$ & $\begin{array}{l}? \\
0 \\
0\end{array}$ & $\begin{array}{l}0 \\
1 \\
2\end{array}$ & & \\
\hline GROOP & $\begin{array}{l}\text { POEEP CONVE } \\
\text { PACTOR }\end{array}$ & $\begin{array}{l}\text { DI gec } \\
\text { DIn }\end{array}$ & $\begin{array}{l}\text { TIOHAL DIPPUSI } \\
\text { DSION }\end{array}$ & $\begin{array}{l}\text { COEFP. NOLTIPLIER } \\
\text { TOM } 2 \text { DITENSION } 3\end{array}$ & & $\begin{array}{l}\text { DIRECTION } \triangle L \\
\text { DIGBUSIOH }\end{array}$ & $\begin{array}{l}\text { DIPFUSION COEPP. } \\
1 \text { DIAERION } 2\end{array}$ & $\begin{array}{l}\text { ADDITIVE } \\
\text { DI IEESION }\end{array}$ \\
\hline $\begin{array}{l}1 \\
2 \\
3\end{array}$ & $\begin{array}{l}0.0 \\
0.0 \\
0.0\end{array}$ & $\begin{array}{l}1.0 \\
1.0 \\
1.5\end{array}$ & $\begin{array}{l}O 0 O D+00 \\
O O O D+C O \\
O O O D+0 O\end{array}$ & $\begin{array}{ll}O D+O C & 1.00000 D+00 \\
0 D+00 & 1.00000 D+00 \\
C D+00 & 1.00000 D+00\end{array}$ & & $\begin{array}{l}0.0 \\
0.0 \\
0.0\end{array}$ & $\begin{array}{l}0.0 \\
0.0 \\
0.0\end{array}$ & $\begin{array}{l}0.0 \\
0.0 \\
0.0\end{array}$ \\
\hline
\end{tabular}

ITTO GROOP/PRON GROTP. CHOSS SRCTIOI

$\begin{array}{lllll}1 & 1.7030310-01 & & \\ 2 & 1: 5.934390-03 & 2, & 3.5773060-01 \\ 3 & 1,9.9150000-09 & 2, & 9.9755140-04\end{array}$

3. 6.3978470-01 
EDIT OF (NONFISSIONABLE) COMPNSITTON NO. 6

ICAI $=0$

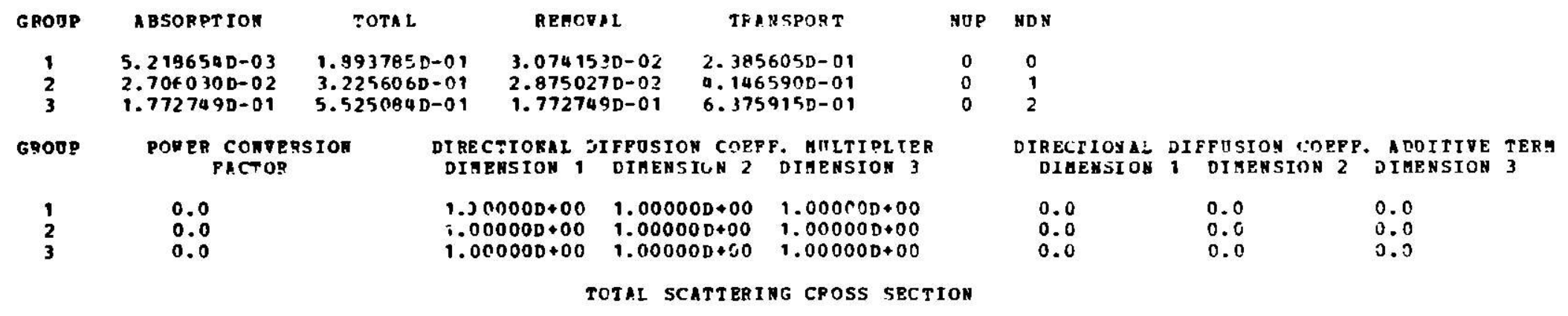

INTO GBOOP/FBOA GROTP, CROSS SECTION

$1 \quad 1,1.7473160-01$

$\begin{array}{llllll}2 & 1,2.552287 \mathrm{D}-02 & 2 . & 3.009916 \mathrm{D}-01 & \\ 3 & 1, & 1.2877980-09 & 2, & 1.6899640-03 & 3,3.7971700-01\end{array}$ 
EDIT OF (MONFISSIOMABLE) COHPOSITION NO. ?

ІСЯ $=0$

GROTP ABSORPTIOH

TOTn L

BEHOVAL

TAR KSPOST

HOP MD H

2. $3358100-05$

$5.5129300-02$

4. $1019860-03$

$4.6868270-0.04$

6. $3443910 \cdot 02$

$6.3443910 \cdots 02$
$1.0267330-01$
$7.4224770-02$

$\begin{array}{ll}0 & 0 \\ 0 & 1 \\ 0 & 1\end{array}$

GPOOP

POUEe COMTERSION

DTRS CTIOHAL DIFPOSION COEPP. MULTIPLIEA

PACTOR DIHEMSIOA, DIAENSION 2 DIMESSION 3

\section{1.) $00000 \times 00$}

0.0

$1.000000 \cdot 00$

$1.000000 \times 00 \quad 1.000000 \div 00$

$1.000000 \div 00 \quad 1.000005+00$

$1.000000+00 \quad 1.000000+00$

TOTML SCATTERIMG CROSS SECTIOH

DIRECTIOAAL DIPPOSIOR COEPP. ADDITIVE TERE OIAEUSIOA 1 DIUEASIOH 2 DIHEUSIOA 3

$\begin{array}{lll}0.0 & 0.0 & 0.0 \\ 0.0 & 0.0 & 0.0\end{array}$

0.0

0.0

0.0

0.0

ITYO GROUP/REON GDOUP, CROSS SECTIOI

1 1. 5.5878759-02

$\begin{array}{lll}\text { 1: } & 0786260-03 & 2, \\ \text { 2. } & .266800 D-02\end{array}$ 
SIZE OP COUTATYER ALLOCATEC POP AMGAC - SOOO

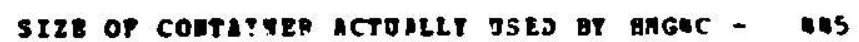

LAPSED CPO TIUE - $0.22 \mathrm{sEC}$

ELAPSE PP TITE $=0.00 \mathrm{sFC}$. 
GENTRAL PROEL EH DATA

WOABEB OP GROTPS $=3$ (HGROTP)
(HOT)

BPOIHTER COMTAIME? SIZE = 5000

WTHBER OP AYIAL HOSH INTERTALS =

THERE IS SO GROJP COLLAPSIHG

TERBE IS HO IO BOPPEPTNG
TAERE IS HO INPUT PDICTION SCAEIRG

THERE MERE HO INPOT ISTEGRALS

BOOUDARI CONDITIORS

LORE X BOU HDART COHDITICH = ZEAC CJP RERT

UPPEB Y BODRDABY CONDITION = 2ERO CTRPFHT

LOIER Y BOOHDARY CCYDITION = ZERO CURRENT

OPPER Y BOTHDARY CCHDITICY = ZERO COTREN

LOREB 2 BOTHDARY CONDTTION = ZERC COPREN

OPPER 2 BOTNDARY CONDITIOH = 2ERO CUBRENT 


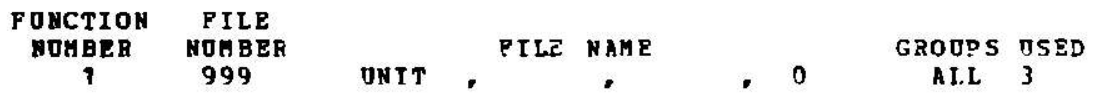

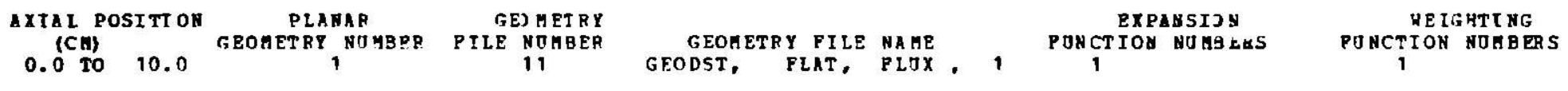

AXIAL GESH I HTERVALS
$3.3330+003.3330+39 \quad 3.3330+00$

DATA MANAGEHENT PARAMETERS FOR INTEGRAL CALC'TLATION SPACE AVAILABLE DगRIRG FLOX AND CROSS SECTION REARITE = 7998 REOPLX FILE, AOPDS/RECORD = 226 ROTS OP PLOXES/RPCORD $=14$
XST PILE, MORDS/RECORD $=15$

REQXST PILE, WORDS/RECORD $=$ T 15
COMPOSITIONS/RECORD FOR FISS TON-REMOVAL PECORDS =

COMPOSITIONS/RECORD FOR FISS ION-R EROV

SPACE AVATLALP DORIAG I NTEGRATION $=2120$
VOLINT

NUMBER OP CONCURBEAT BECURDJ DJRING RETRITE = 34

COLITNS OP PLOXES/RECJRD = 14

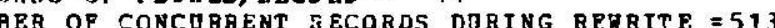

GROUPS/PECOBD FOR DIFPUSION COEPPICIENT RECORDS $=3$

NTMEEK OP CONCORRENT BECORDS DIRING INTEGRATION = 
PINAL INTEGRAL TOCS

\section{VOLIRT FILE}

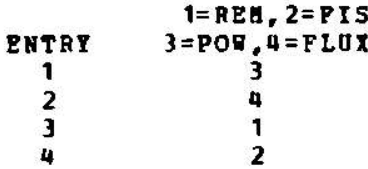

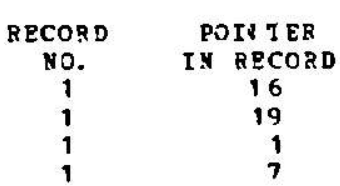
PIANAR WRIGHTING EROMPTRY NO. WOY,
0
1
1
o

0
0
1
1

16
19
1
7

DIPIRT FILE

HESA BATIO = (LOWER DELTA Z)/(IPPER UELTA Z)

LOEER PLANE = O POR LOHER BODNDARY INTEGAAL
RECORD
1
1
2
3
POINTER LOWER PLANAR OPPER PLANAB
RECORD GECMETRY NO GEOMETRY HO.

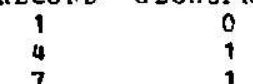
1
RATIO
1.00
1.00
1.00

FN. NO.

1

$\begin{array}{rc}\text { EXPANSION } & \text { NO. JP } \\ \text { FON. NO. } & \text { BECORDS } \\ 1 & 1 \\ 1 & 1 \\ 1 & 1\end{array}$

EXPAUSIOA

PU.

1
1
1
No. OP

TIME SPENT IN OVERLAY INTEG, $C P=0.4, P P=0.0$

SOPPOOTHE IPPBO1, $\mathrm{CP}=0.0, \mathrm{PP}=0.0$

SOBROOTIRE REDTOC, CP $=0.0$, PD $=0.0$

SUGROUTINE RERRIT, $C P=0.1, P P=0.0$

SUBROUTITE INT 1, CP $=0.0$, PP $=0.0$

SUBROOTI KE INT2 $: \mathrm{CP}=0.0, \mathrm{PP}=0.0$

SOBROUTIFE INT3:CP $=0.0, \mathrm{PP}=0.0$

SOBROUTIRE INTA: $\mathrm{CP}=0.0, \mathrm{DP}=0.0$

SUBROUTIHE RITTOC, CP =

$0.0, \mathrm{PP}=0.0$ 
SYHJD, OVERLAY SOLVE

THPES GROOP, FINDAMENTAI MODE CALCULATION

I XTTOC FILE LABEL $=1 / 20 / 0443.6$, VERSI CN NOHBER $=2$

DATA KANAGEEENT PARAHETERS FOR SOLUTION

IHTGLS PILE, RORDS/RECORD $=45$

MOH BER OF RECORDS =

NUNBER OF CONCURRENT RECORDS DURING GAUSS ELIGLNATTON = 1

E FILE, MORDS/RECORD = 19

NOHBER OF RECORDS $=1$

DIB ECT EIGEHVALUE CaLCOLATION

EIGENVALUE ESTIMATE $=0.0$, AA XIMTR NOHBER OF ITERATIONS $=10$, CONVERGENCE CRITERION $=0.10000$ E-04

EIGENTALUD

$\begin{array}{ll}1 & 0.12906 \mathrm{E}+01 \\ 2 & 0.13017 \Xi+01\end{array}$

$0.13017 \mathrm{E}+01$

$0.130178+01$

THE CALCULATIOH HAS CONVRRGD ON AN ETGRVALOB

ROREALIZATION, FLTX * SIGHA-P * POY YER/PISSION $=0.10000 \mathrm{E}+01$ WATTS. 
COHAIHIRG COEPPICIENTS FOR OIRECT CALCJLATION

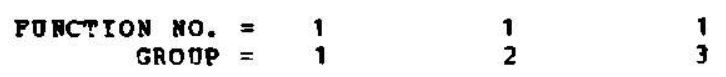

\section{AXIAL AXIAL}

\begin{tabular}{|c|c|c|c|c|}
\hline $\begin{array}{l}1.67 \\
5.00 \\
8.33\end{array}$ & 1 & $\begin{array}{l}4.191 E+07 \\
4.191 E+07 \\
4.191 E+07\end{array}$ & $\begin{array}{l}5.868 F+07 \\
5.868 E+07 \\
5.868 E+07\end{array}$ & $\begin{array}{l}1.921 \mathrm{E}+06 \\
1.921 \mathrm{0}+06 \\
1.921 \mathrm{Q}+06\end{array}$ \\
\hline
\end{tabular}

TIAE SPEHT IM OVPRLAT SOLVE $, C P=0.2, P P=0.0$
SUBROOTJHE REDTOC, CP
$C P=0.0, P P=0.0$
SOBRT $\mathrm{CP}=0.0 \mathrm{PP}=0.0$
SUBROUTINE SPROB, CP $=0.1, \mathrm{PP}=0.0$

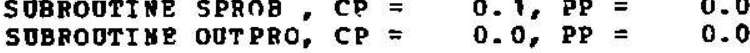


APPENDIX H. Sample Problem Output. Problem 2 - Complete Output

STA3D, OVERLAY CARDS

20 GOCKLED PLANE (THE UNRODDED CORE PLANE FROA THE 3 D SODEL) HALP CORE ALIAL SYBHETRY

LISTIBS OP STH JD IEPOT

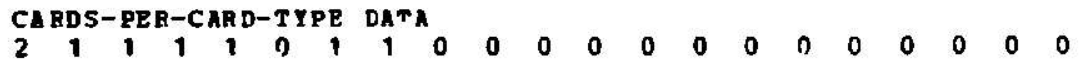

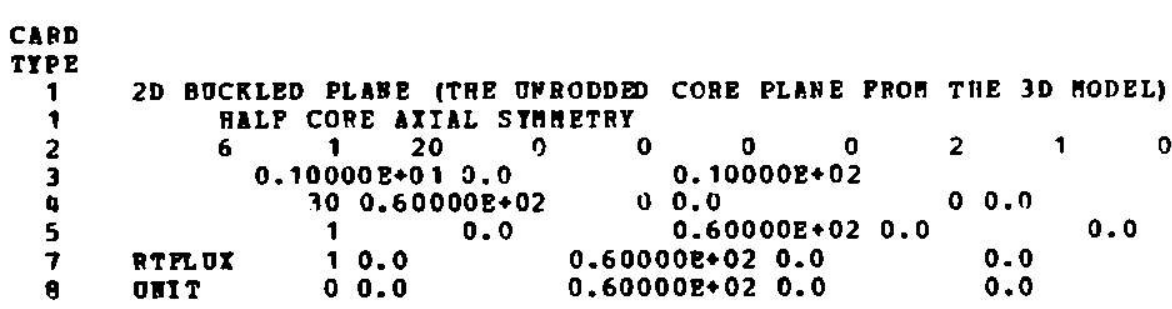


Gengal PBoblen DATA

MOABER OP GROOPS = ? (NGROUP)

B POI UTER CONTAINEA SIZP = 6000

MOABER OP AXTAL HESH I WT PRVALS = 30

THEAE IS TO GROOP COLLATSIMG

THERE IS 10 TO BOPFERIMG

THRBE IS MO TUPOT POTCTIOE SCALI HG

THEBE DERE WO IAPOT INTEGRALS

BOONDARY COEDITIONS

LOUEB I BOO WDART CONDIT TOW = 28 RO CTR REAT

TPPEB X BODWDARI CONDITIOH = ZERO PLUY

LORER Y BODNDARY CORDTTIOA = 2ERC CURREM

OPPEB I BOOGDABY COBDITION = 2RRO PLOX

LONER 2 GOOMDARY COUDITIOA = 2ERO CORREW

OPPEA 2 BOULDAT COADITIOA = ZERO PLOX 


$\begin{array}{cc}\text { POECTIOR } & \text { PILE } \\ \text { IOHBEB } & \text { MTHER } \\ 1 & 22 \\ 2 & 999\end{array}$
HALP CORE AXIAL SYHEETRY

AXIAI POSITIOR OBT

(Ch)

GEOTRTBMA

GEOHETRT

E, $\begin{array}{lll}1 & \text { ALI } & 3 \\ 0 & \text { ALL } & 3\end{array}$

0.0 To

1

PILE NO

11

GEOHETRY FILE NAHE

GECDST, CORE, THROD,
EXPAHSIJ N
PONCT ION HIJ

1
WE IGHTI RG

PUNCT IOY NOR BERS

AIIAL GESB INTERVALS

$2.000 D+002.000 D+002.000 D+002.000 D+00 \quad 2.000 D+00 \quad 2.000 D+002.000 D+002.000 D+00 \quad 2.000 D+00 \quad 2.000 D+002.000 D+002.000 D+00$ $2.000 D+00 \quad 2.000 D+002.000 \pi+00 \quad 2.000 D+00 \quad 2.000 D+002.000 D+00 \quad 2.000 D+00 \quad 2.000 D+002.000 D+00 \quad 2.000 D+00 \quad 2.000 D+00 \quad 2.000 D+00$ $2.000 D+00 \quad 2.0000+002.0000+002.000 D+002.000 D+002.000 D+00$

DATA MAUGEUET PABAGETERS FOR IRTEgRAL CALCULATIOH

SPACE ATATABLE DURIMG ILIY AT CROSS SBCTIOA REHAITE = 985 BEQPLI PILE, DORDS/RBCORD = 810

$\begin{aligned} \text { BEQPLI PILE, BORDS/RECORD }= & 814 \\ \text { RORS OP PLOXES/RECORD } & =14 \\ \text { REQTST PILE, DORDS/BECORD } & =75\end{aligned}$

CORPOSITIORS, RECOQD FOR PISS IOH-REHOVBL RECORDS $=5$

SPACE ATATABLE DORIMG IBTEGRATIOH $=2416$

MOHBER OP CONCORBEHT BECOBDS DIRING REMRITE $=11$ COLOHRS OF PLUYES/BECORD = 14

COLOB GROOPS $/$ AECORD FOR DIPP USION COEPPICIENT RECORDS = 3

MOHBER OP COMCERBEAT BBCOHDS DERIMG INTEGRATION $=$, 
STH3D, CVERLAT INTEG

2C AICKLPD PLANE (T AE ONRODDED CORE PLAME PRON THE 30 MODEL) HALP CORP BXIAL SYHAETRY

PIRAL IHTEGRAL TOCS

VOLIET PILE

\begin{tabular}{|c|c|c|}
\hline EETAT & $\begin{array}{r}1=8 \mathrm{BEH}, 2=\mathrm{PIS} \\
3=\mathrm{POV}, 4=\mathrm{PLOX}\end{array}$ & $\begin{array}{l}\text { BECORD } \\
\text { MO. }\end{array}$ \\
\hline 1 & 3 & 1 \\
\hline 2 & 4 & 1 \\
\hline 3 & 3 & 1 \\
\hline 4 & 4 & 1 \\
\hline $\mathbf{5}$ & 1 & 1 \\
\hline 6 & 2 & 1 \\
\hline
\end{tabular}

$\begin{array}{cc}\text { PLAMA } & \text { TEIGRTIMG } \\ \text { GEOSETRY HO. PUN. MO. } \\ 1 & 0 \\ 0 & 0 \\ 1 & 0 \\ 0 & 0 \\ 1 & 2 \\ 1 & 2\end{array}$

DIPIWT PILE

MESG BATIO = (LOUER DELTA Z)/(UPPRR DRLTA 2)

LOMEE PLANE = O POR LOMER SOOHDAAY THTEGRAL

UPPER PLAME = 0 POR TPPEB BOONDARY IHTEGRAL

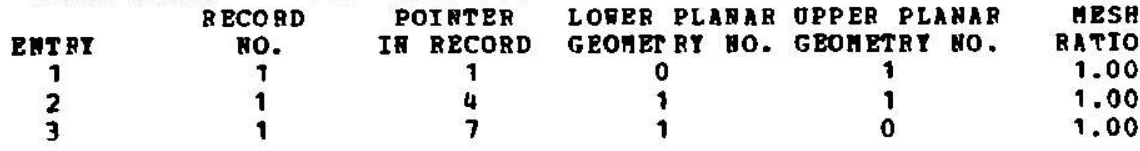

1.00
1.00
1.00

0.0

TIAE SPEHT IY OVERLAY INT BG

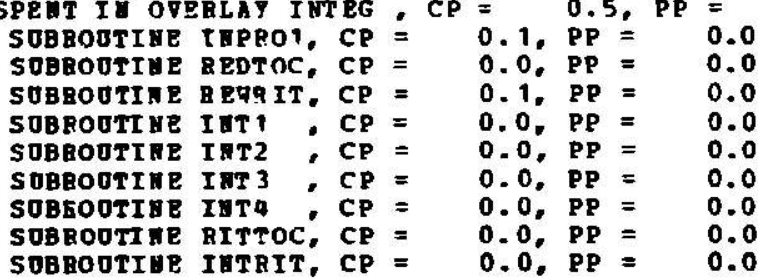

$\begin{array}{cc}\text { EXPAHSION } & \text { NO. OF } \\ \text { POH. NO. } & \text { RECOBDS } \\ 1 & 1 \\ 1 & 1 \\ 2 & 1 \\ 1 & 1 \\ 1 & 1\end{array}$

UEIGHTING PON. NO.

$$
2
$$

EXPANS IOH

Expas 10.

No. OF$$
\text { ; }
$$

1 
SYHJD, OTRRLAY SOLVE

IHTTOC FILE LABEL $=1 / 20 / 0507.8$. VERSION NOMBER $=2$

DATA MAHAGEGERT PARAHETERS PCR SOLOTIOH I ATGLS PILE, NORDS/RECORD $=45$ TOHBEF OP PECORDS $=1$

NURBER OF CONCISRENT RECORDS DJRING GAJSS ELIMIMATION =

PIIE, YOPDS/RECORD $=261$

NOMBER OP RECORDS $=1$

DIRECT EIGEHVALIE CALCOLATTOA

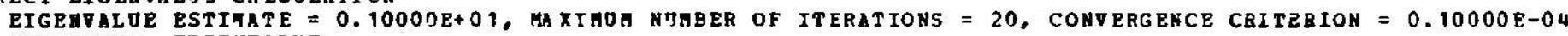

ITPRATIOU EIGEYPALUE

$\begin{array}{lll}1 & 0.99508 \mathrm{E}+00 \\ 2 & 0.99600 \mathrm{Q}+00\end{array}$

$0.99600 \mathrm{E} \div 00$

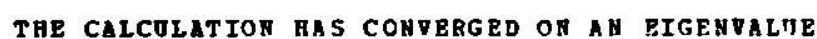

MORHALIZRTION, PLJX * SIGHA-P * PONER/PISSION $=0.10000 E+02$ HATTS. 
CONBIAIAG COEPPTCIERTS POR DIBECT CALCULATIOH

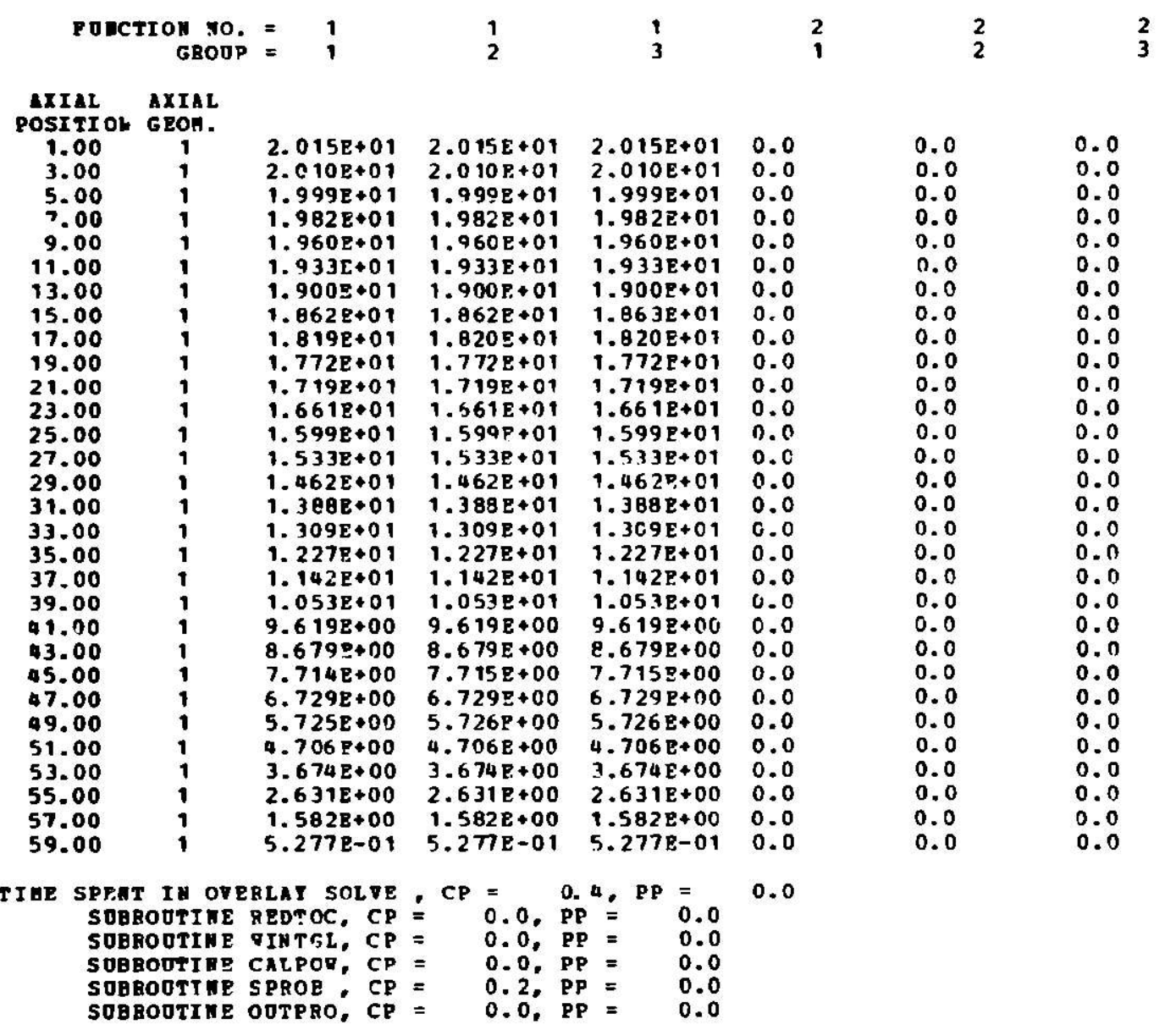


APPENDIX H. Sample Problem Output. Problem 3 - Partial Output

STH3D, OVERLAT CARDS 3 GROJP, 3-DIMERSIOHAL HODEL, FLUX MEIGHTED SYNTHESIS GLAHRET PONCTIONS (3 AND 4) NOT OSED PVERYWHERE

LISTING OF STH 3D IHPOT

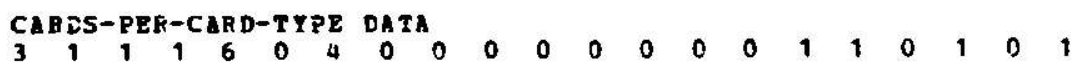

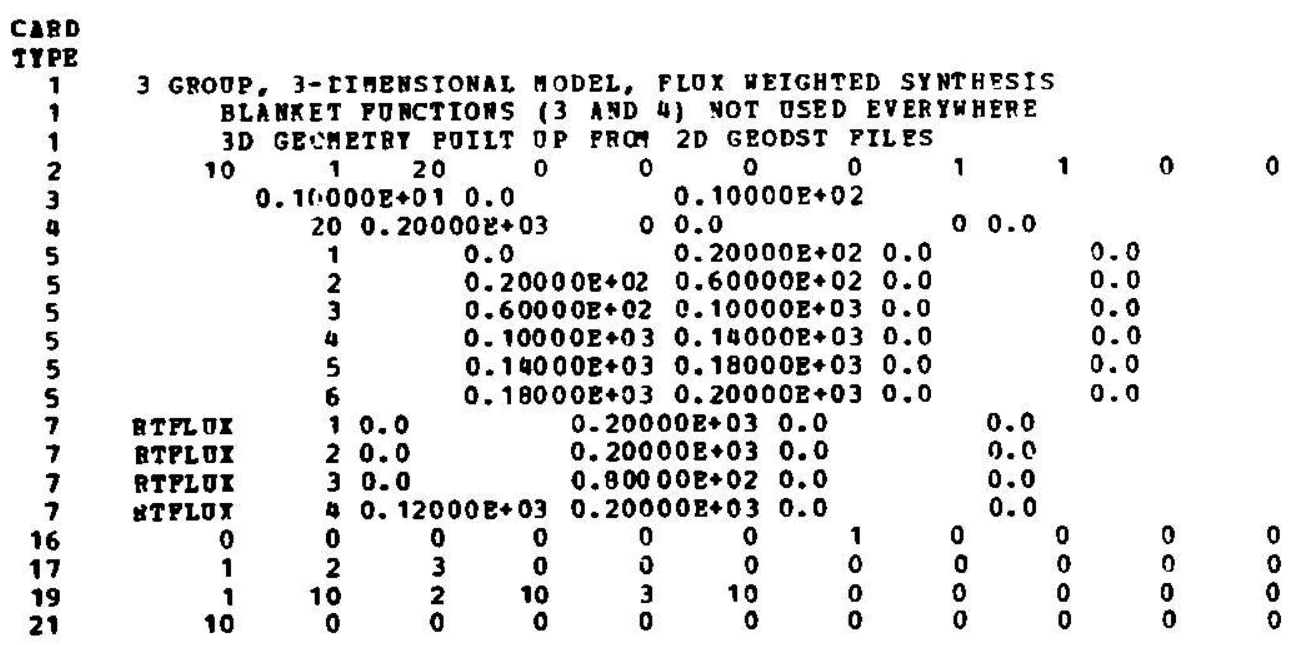



BLAETET POHCTIOHS (3 AHD 4) NOT OSED EVERYRHERF

GEMERAL PROBLEH DATA

MOHEER OP GROODS $=3$ (MG8OUP)

BPoI ITER CONTAINER SIZE $=10000$

OOEBE OF ATILL MESB IATERVALS $=20$

THERE IS MO GRONP COLLAPS ING

TAERE IS NO IO DUPPERING

TCTCB SCAL IRG

THERE TERE

BOONDABI CCMDITIOAS

LORRE I BOONDARY COWDITIOA = ZEBO CDA RENT

OPPB X X BOOWDABY CONDITICE = ZEBO PLOX

LORER Y BOHSOARY COBDYTION = ZEFO CORRENT

OPPEB I BCOMDARY CONDITYGH = ZEPO PLUX

OPPEQ $z$ BOTRDART COMDITIOA = ZEBO PLIX 

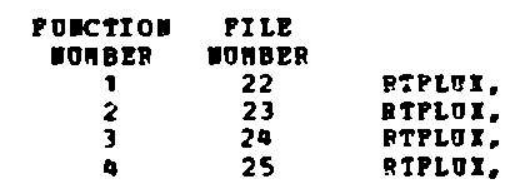

PILE TATE

OHROD.

AROD, CORE,

GROUPS OSED

CORE, 2 ALL 3

$3 \quad 25$

POD: BLAMRT.

ALI 3

ALL 3

ArIAL position

(C)

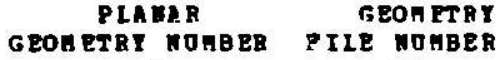

$\begin{array}{rrr}0.0 & \text { To } & 20.0 \\ 20.0 & \text { T0 } & 60.0 \\ 60.0 & 10 & 80.0 \\ 80.0 & \text { T0 } & 100.0 \\ 100.0 & \text { T0 } & 120.0 \\ 20.0 & \text { To } & 140.0 \\ 40.0 & 10 & 180.0\end{array}$

11

$\begin{array}{ll}1 & 11 \\ 2 & 12 \\ 3 & 13 \\ 3 & 13 \\ 4 & 14 \\ 4 & 14 \\ 5 & 15 \\ 6 & 16\end{array}$

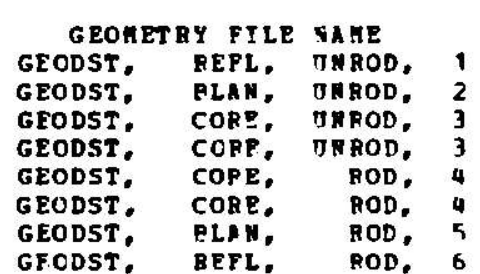

\begin{tabular}{|c|c|c|}
\hline & $2 \times P$ & HSIO A \\
\hline PONCT & Ing & NUGB FRS \\
\hline 1 & 2 & 3 \\
\hline 1 & 2 & 3 \\
\hline 1 & 2 & 3 \\
\hline 1 & 2 & \\
\hline 1 & 2 & \\
\hline 1 & 2 & 4 \\
\hline 1 & 2 & 4 \\
\hline 1 & 2 & 4 \\
\hline
\end{tabular}

\begin{tabular}{ccc}
\multicolumn{4}{c}{ MEIGHTIMG } \\
POMCTI ON & ROMBFRS \\
1 & 2 & 3 \\
1 & 2 & 3 \\
1 & 2 & 3 \\
1 & 2 & \\
1 & 2 & \\
1 & 2 & 4 \\
1 & 2 & 4 \\
1 & 2 & 4
\end{tabular}

IXIAL GESB I TTERTAS

$1.0000+011.0000+011.0000+011.000 D+011.00 J 0+011.0000+011.0000+011.0000+011.0000+011.0000+011.0000+011.000 D+01$ $\therefore .0000+011.0000+011.0000+011.0000+011.0000+011.0000+011.0000+011.0000+01$

DATA MALAgEST PARAHETERS FOR ITTEGRAL CALCOLATION

SPACE ATITAGLE DOBIMG FLOX AYD CROSS SECTION RERRITE = 16132 BROPLI PILE, MOBDS/RECORD = 2793

BORS OF RLOXES/RECORD = 1!

BEOTST PILE, MOBDS RECORD = 105

COYPOSTTTOIS/RECOBD FOR PISSIOH-REHOVAL RECORDS =

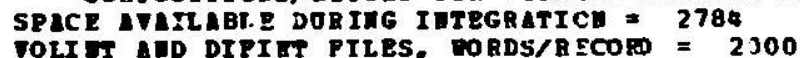

MUHBER OP CONCURAEHT $\triangle E C O R D S$ DURING REHRITE = 5

COLTHSS OP PLOTES/RECORD = 14

GROER OF COHCORBENT BECORDS DORIHG RERRITE $=150$

WOHEER OP CONCOABEHT BECORDS DURIAG I MTEGRATION = 
STE3D, OTEBLAT SOLV

IUTTOC PILE LABEL $=1 / 20$, OS13.0, VEBSION NDABPR $=2$

DATA haAAGEGET PARAHETERS FOR SOLUTIOH

IMTGIS PILE, DORDS/BECORD $=2655$

DOHBER OP RECOROS $=1$

NOHBER OP CONCURBENT RECORDS DURI GG GAUSS ELIAINATION $=1$

H FILE, UORDS/RPCOPD $=1350$

NUHBER OF RECORDS $=$

DIREC EIGEMVIUE CALCULATIOA

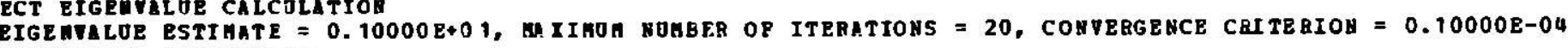

ITEBATION EIGENVALOE

$$
\begin{array}{ll}
1 & 0.96700 \mathrm{E}+00 \\
2 & 0.97495 \mathrm{E}+00 \\
3 & 0.97505 \mathrm{E}+00 \\
4 & 0.97506 \mathrm{E}+00 \\
5 & 0.97506 \mathrm{R}+00
\end{array}
$$

The Calcolation has COHUEGed on a eigentalue

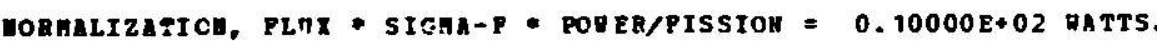


COABINIMG COEPPICIENTS POR DIRECT CALCULATION

\begin{tabular}{|c|c|c|c|c|c|c|c|c|c|c|c|}
\hline POECT & $\begin{array}{l}\text { IIOH NO. } \\
\text { GROUP }\end{array}$ & $\begin{array}{l}=1 \\
p=1\end{array}$ & $\begin{array}{l}1 \\
2\end{array}$ & $\begin{array}{l}1 \\
3\end{array}$ & $\begin{array}{l}2 \\
1\end{array}$ & $\begin{array}{l}2 \\
2\end{array}$ & $\begin{array}{l}2 \\
3\end{array}$ & 1 & $\begin{array}{l}3 \\
2\end{array}$ & $\begin{array}{l}3 \\
3\end{array}$ & $\begin{array}{l}4 \\
1\end{array}$ \\
\hline $\begin{array}{c}\text { AXIAL } \\
\text { POSITIOH } \\
5.00 \\
15.00 \\
25.00 \\
35.00 \\
45.00 \\
55.00 \\
65.06 \\
75.00 \\
95.00 \\
95.00 \\
105.00 \\
115.00 \\
125.00 \\
135.00 \\
145.00 \\
155.00 \\
165.00 \\
175.00 \\
185.00 \\
195.00\end{array}$ & $\begin{array}{c}\text { AXIAL } \\
\text { GEGH. } \\
1 \\
1 \\
2 \\
2 \\
2 \\
2 \\
3 \\
3 \\
3 \\
3 \\
4 \\
4 \\
4 \\
4 \\
5 \\
5 \\
5 \\
5 \\
6 \\
6\end{array}$ & $\begin{array}{r}-4.011 \mathrm{E}-02 \\
-1.140 \mathrm{E}-01 \\
-1.336 \mathrm{E}-01 \\
-1.084 \mathrm{E}-01 \\
2.150 \%-01 \\
1.755 \mathrm{E}+00 \\
6.756 \mathrm{P}+00 \\
9.014 \mathrm{E}+00 \\
9.909 \mathrm{E}+00 \\
9.286 \mathrm{E}+00 \\
2.670 \mathrm{E}+00 \\
6.270 \mathrm{E}-01 \\
1.029 \mathrm{E}-01 \\
-7.924 \mathrm{E}-02 \\
-2.617 \mathrm{E}-02 \\
-4.339 \mathrm{E}-03 \\
-3.609 \mathrm{E}-03 \\
-4.999 \mathrm{E}-03 \\
-9.930 \mathrm{E}-03 \\
-3.628 \mathrm{E}-03\end{array}$ & $\begin{array}{r}-6.790 \mathrm{E}-02 \\
-2.015 \mathrm{E}-01 \\
-1.373 \mathrm{E}-01 \\
2.187 \mathrm{E}-01 \\
1.197 \mathrm{E}+00 \\
3.531 \mathrm{E}+00 \\
7.527 \mathrm{E}+00 \\
9.430 \mathrm{E}+00 \\
1.001 \mathrm{E}+01 \\
9.171 \mathrm{E}+00 \\
3.224 \mathrm{E}+00 \\
9.224 \mathrm{E}-01 \\
1.566 \mathrm{E}-01 \\
-2.036 \mathrm{E}-01 \\
-6.264 \mathrm{E}-01 \\
-3.208 \mathrm{E}-01 \\
-1.178 \mathrm{E}-01 \\
-4.665 \mathrm{E}-02 \\
-6.423 \mathrm{E}-02 \\
-2.155 \mathrm{E}-02\end{array}$ & $\begin{array}{r}-3.858 \mathrm{E}-01 \\
-1.101 \mathrm{E}+00 \\
-4.234 \mathrm{E}-01 \\
-7.839 \mathrm{E}-01 \\
-1.835 \mathrm{E}+00 \\
-1.828 \mathrm{E}+00 \\
9.237 \mathrm{E}+00 \\
1.008 \mathrm{E}+01 \\
1.061 \mathrm{E}+01 \\
9.971 \mathrm{E}+00 \\
9.039 \mathrm{E}-01 \\
1.263 \mathrm{E}-01 \\
-1.331 \mathrm{E}-02 \\
-6.129 \mathrm{E}-02 \\
2.831 \mathrm{E}-01 \\
1.429 \mathrm{E}-01 \\
2.961 \mathrm{E}-02 \\
-2.023 \mathrm{E}-02 \\
-8.034 \mathrm{E}-02 \\
-2.923 \mathrm{E}-02\end{array}$ & $\begin{array}{r}1.939 E-02 \\
4.963 E-02 \\
2.138 E-02 \\
2.074 E-02 \\
4.994 E-02 \\
9.521 E-02 \\
1.678 E-01 \\
4.874 E-01 \\
1.159 E+00 \\
2.677 E+00 \\
1.047 E+01 \\
1.174 E+01 \\
1.040 E+01 \\
7.609 E+00 \\
2.018 E+00 \\
2.671 E-01 \\
-1.026 E-01 \\
-1.220 E-01 \\
-6.927 E-02 \\
-2.239 E-02\end{array}$ & $\begin{array}{r}4.160 E-02 \\
1.433 E-01 \\
9.618 E-02 \\
1.178 E-01 \\
3.294 E-01 \\
5.2608-01 \\
-2.078 E-01 \\
1.275 E-01 \\
1.013 E+00 \\
2.687 E+00 \\
9.597 E+00 \\
1.124 E+01 \\
1.017 E+01 \\
8.149 F+00 \\
4.849 E+00 \\
1.757 E+00 \\
3.453 E-01 \\
-9.064 E-02 \\
-7.638 E-02 \\
-3.399 E-02\end{array}$ & $\begin{array}{r}3.283 E-01 \\
9.705 E-01 \\
3.904 E-01 \\
8.638 E-01 \\
2.303 E+00 \\
3.591 E+00 \\
-8.9518-01 \\
-5.675 E-01 \\
3.418 E-01 \\
1.6398+00 \\
1.244 E+01 \\
1.226 E+01 \\
1.066 E+01 \\
7.685 E+00 \\
-5.096 E-01 \\
-9.739 E-01 \\
-4.490 E-01 \\
-1.979 E-01 \\
-3.406 E-01 \\
-1.242 E-01\end{array}$ & $\begin{array}{l}4.569 E-04 \\
1.485 E-03 \\
2.831 E-01 \\
4.929 E-03 \\
7.6<5 E-03 \\
8.641 E-03 \\
5.692 E-04 \\
-2.723 E-04 \\
0.0 \\
0.0 \\
0.0 \\
0.0 \\
0.0 \\
0.0 \\
0.0 \\
0.0 \\
0.0 \\
0.0 \\
0.0 \\
0.0\end{array}$ & $\begin{array}{l}5.733 E-04 \\
1.760 \mathrm{E}-03 \\
2.923 \mathrm{E}-03 \\
3.992 \mathrm{E}-03 \\
4.549 \mathrm{E}-03 \\
3.516 \mathrm{E}-03 \\
8.050 \mathrm{E}-04 \\
7.937 \mathrm{E}-05 \\
0.0 \\
0.0 \\
0.0 \\
0.0 \\
0.0 \\
0.0 \\
0.0 \\
0.0 \\
0.0 \\
0.0 \\
0.0 \\
0.0\end{array}$ & $\begin{array}{l}8.672 E-04 \\
2.523 E-03 \\
3.250 E-03 \\
4.663 E-03 \\
6.462 E-03 \\
7.214 E-03 \\
1.083 E-03 \\
1.892 E-04 \\
0.0 \\
0.0 \\
0.0 \\
0.0 \\
0.0 \\
0.0 \\
0.0 \\
0.0 \\
0.0 \\
0.0 \\
0.0 \\
0.0\end{array}$ & $\begin{array}{l}0.0 \\
0.0 \\
0.0 \\
0.0 \\
0.0 \\
0.0 \\
0.0 \\
0.0 \\
0.0 \\
0.0 \\
0.0 \\
0.0 \\
-4.728 E-04 \\
5.586 E-04 \\
9.911 E-03 \\
8.670 E-03 \\
5.491 E-03 \\
3.084 E-03 \\
1.594 E-03 \\
4.861 E-04\end{array}$ \\
\hline
\end{tabular}


SYHOD, OVERLAT SOLVF.

COHBI MI G COEPICIENTS POB DIRECT CALCULATION
$\begin{aligned} \text { PONCTION WO. } & =4 \\ \text { GROTP } & =2\end{aligned}$

\section{MXIAI AXIAI
POSITIOH GEOH.}

$\begin{array}{ccll}\text { POSITIOI } & \text { GEOH. } & & \\ 5.00 & 1 & 0.0 & 0.0 \\ 15.00 & 1 & 0.0 & 0.0 \\ 25.00 & 2 & 0.0 & 0.0 \\ 35.00 & 2 & 0.0 & 0.0 \\ 45.00 & 2 & 0.0 & 0.0 \\ 55.00 & 2 & 0.0 & 0.0 \\ 65.00 & 3 & 0.0 & 0.0 \\ 75.00 & 3 & 0.0 & 0.0 \\ 85.00 & 3 & 0.0 & 0.0 \\ 95.00 & 3 & 0.0 & 0.0 \\ 105.00 & 4 & 0.0 & 0.0 \\ 115.00 & 4 & 0.0 & 0.0 \\ 125.00 & 4 & 4.128 \mathrm{E}-04 & 1.459 \mathrm{E}-04 \\ 135.00 & 4 & 1.122 \mathrm{E}-03 & 1.496 \mathrm{E}-03 \\ 145.00 & 5 & 4.308 \mathrm{E}-03 & 1.017 \mathrm{E}-02 \\ 155.00 & 5 & 5.536 \mathrm{E}-03 & 8.542 \mathrm{E}-03 \\ 165.00 & 5 & 4.736 \mathrm{E}-03 & 5.697 \mathrm{E}-03 \\ 175.00 & 5 & 3.376 \mathrm{E}-03 & 3.735 \mathrm{E}-03 \\ 185.00 & 6 & 2.035 \mathrm{E}-03 & 2.896 \mathrm{E}-03 \\ 195.00 & 6 & 6.639 \mathrm{E}-04 & 9.032 \mathrm{E}-04\end{array}$
SUBBOUTINE REDTOC,
$0.0 .09=0.0$
SOBROOTIB CALPOR, $C D=0.0$, $P P=0.0$
SOBROOTI HE SPROE, CP $=0.8$, PP $=0.0$
SOBROOTIVE OUTPBO, CP $=0.1$, PP $=0.0$

$=$

1.2, $P P=0.0$ 
3 GROTP, 3-DIY ENSIONAL MODEL, FLOX WEIGHTED SYNTHES IS BLANKET FONCTIONS (3 AND 4) NOT USED EVERY THERE BL ANR ET FONCTIONS (3 AND 4) NOT USED EVERY
$z=95.00$.
GROUP $=1$

PLAaAR PLOT DISTRIBUTION,

$\begin{array}{ll}1.9046 D+08 & 2.08970+09 \\ 2.08970+08 & 2.12770+08 \\ 2.12330+08 & 2.1206 D+08 \\ 2.05650+08 & 2.0448 D+08 \\ 1.92340+08 & 1.91120+08 \\ 1.73810+08 & 1.7346 D+08 \\ 1.5026 D+08 & 1.5419 D+08 \\ 9.8743 D+07 & 1.12140+08 \\ 4.83020+07 & 4.84590+07 \\ 1.8800 D+07 & 1.87980+07 \\ 8.4087 D+06 & 8.3831 D+06 \\ 2.4764 D+06 & 2.4656 D+06\end{array}$

\section{2. $12330+08$} 2. $12060+08$ 2. $0806 \mathrm{D}+0 \mathrm{~B}$ 1.954008

\section{$2.0565 D+08$}

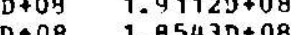
$40+0$ $1.58140+08$ $20+08$ 1. $1007 \mathrm{D}+08$ 1. $66090+07$ $4.87470+07$ 1. $86500+07$ 2. $4115 D+06 \quad 2.2834 D+06$ $7.8146[+06$

$1.73810+08$ $1.73460+08$ $1.6981 D+08$ 1. $5814 D+00$ $1.3530+08$ $1.11860+v 8$ $1.19840+08$ $8.47470+07$ $3.5923 D+07$ $1.37230+07$ $1.7676 \mathrm{D}+06$ $1.54190+08$ 1. $5<7<0+08$ 1. $4432 D+0 B$ $1.2904 D+08$ $1.10040+08$ $9.25700+07$ $63840+07$ 2.79820+07 $1.477 \leq 0+07$ $4.7848 D+06$ $\begin{array}{ll}1.6103 D+07 & 1.37230\end{array}$ $7.0760 \mathrm{D}+06$ cotong 0.0
10 11$$
\begin{array}{r}
020 \\
12
\end{array}
$$

1. $80000+07$

$1.8798 D+07$

$1.86500+07$

1. 7777D+07

$1.61030+07$

$1.3723 D+07$

1. $0773 D+07$

$7.55290+06$

$4.26730+06$

$2.1540 D+06$

1. $1782 D+0 E$

8. $40870+06$

8. $38310+06$

$8.23390+06$

$7.8146 \mathrm{D}+06$

$7.07600+06$

$6.04330+06$

4. $7848 D+06$

3. $42360+06$

2. $1167 D+06$

1. $1782 \mathrm{D}+06$

$6.2775 n+05$

1. $98060+05$

$2.4764 D+06$

$2.4656 D+06$

$2.41150+06$

$2.28340+06$

$2.06680+06$

1. $7676 D+06$

$1.4061 D+06$

$1.01810+06$

$6.52140+05$

3. $7670 \mathrm{D}+05$

$1.9806 D+05$

$6.2043 D+04$
9. $87430+07$

1. $1214 \mathrm{D}+08$

1. $1512 \mathrm{D}+0 \mathrm{\theta}$

1. $10070+00$

$9.95270+07$

$8.4747 n+07$

$6.5384 \mathrm{D}+07$

4. $0483 \mathrm{D}+07$

$1.9421 \mathrm{D}+07$

$7.5529 D+06$

$4236 \mathrm{D}+06$

$1.0181 \mathrm{D}+06$
4. $8302 D+07$

$4.8459 D+07$

4. $8747 D+07$

$4.6609 \mathrm{D}+07$

3. $5923 \mathrm{D}+07$

2. $7982 \mathrm{D}+07$

9. $56110+06$

4. $2673 D+06$

2. $11670+06$

$6.5214 D+05$ 
BLANKET PONCTIONS (3 AND 4) NOT USED EVERYHHERE
3D GZOHETRY BOILT OP FROM 2D GEODST FILES

PLABA POÝR DENSITY (HATTS/CC), $z=95.00$

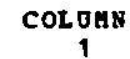

colun

COLTan

1

3

COLOHN

4

COLUHN

5

COLOHA

6

COLU日

COLOH N

B

3. 1213E-05

$2.7897 E-05$
$2.7796 E-05$

2.7004E-05

$2.5307 \mathrm{E}-05$

2. $2482 \mathrm{E}-05$

2.248

$3.4801 \mathrm{E}-05 \quad 3.4698 \mathrm{E}-05$

3. $4698 E-05$ $3.3331 \mathrm{E}-05$

$3.0739 \mathrm{E}-05$

.2415E-05

$3.0060 \mathrm{E}-05$

3. $1213 \mathrm{E}-05$

3. $1004 \mathrm{E}-05$

$3.0186 \mathrm{E}-05$

0.0

3. $0652 \mathrm{E}-05$

2. $3299 \mathrm{E}-05$

2. $7004 \mathrm{E}-0 \mathrm{~S}$

$3.0153 \mathrm{E}-05$

9.4583 E-07

0.0

$9.4573 \mathrm{~B}-07$

0.0

2. $4525 \mathrm{E}-06$

9. $3829 \mathrm{E}-07$

0.0

(2.

2.00978-05

2. $2204 \mathrm{E}-05$

1. $7248 \mathrm{E}-05$

$6.8073 \mathrm{E}-06$

. $1014 \mathrm{~B}-07$

0.0

0.0

CoL U: N

10

colonn

12

y. $7583 \mathrm{E}-07$

$9.4573 E-07$

9. $38298-07$

0.9435E-07

8. $1014 \mathrm{E}-07$

$6.9040 E-07$

$3.41998-07$

2.1469E-07

$1.08378-07$

0.0

11

0. 0

0.0

0.0

0.0

0.0

0.0

0.0

0.0

0.0

0.0

$\begin{array}{ll}0.0 & 0.0 \\ 0.0 & 0.0 \\ 0.0 & 0.0 \\ 0.0 & 0.0 \\ 0.0 & 0.0 \\ 0.0 & 0.0 \\ 0.0 & 0.0 \\ 0.0 & 0.0 \\ 0.0 & 0.0 \\ 0.0 & 0.0 \\ 0.0 & 0.0 \\ 0.0 & 0.0\end{array}$


STEJD, OVERLAY RDITS

\section{ZOSE AVEPAGE PLTX}

2OSE

GROIP$$
1
$$

$1.51828+08$

$9.3248 E+07$

$1.41332+07$

$1.91148+07$

1. $3912 E+06$

2. 4 ROBE +07

$3.9452 \mathrm{P}+07$
3 GROTR, 3-כIMENSTONAL MODEL, FLUX NEIGHTER SYNTHFSIC 9LANKET FUNCTIONS $(3$ ANL 4$)$ NOT ISFE EVERYWHERE TDEOFTY BUILT UF FROM 20 GEODST FILES $\operatorname{cosin}$

$1.99240+99 \quad 5.79730+06$

5. $79739+06$

$0606072.39658+06$

2.2298.06

. 


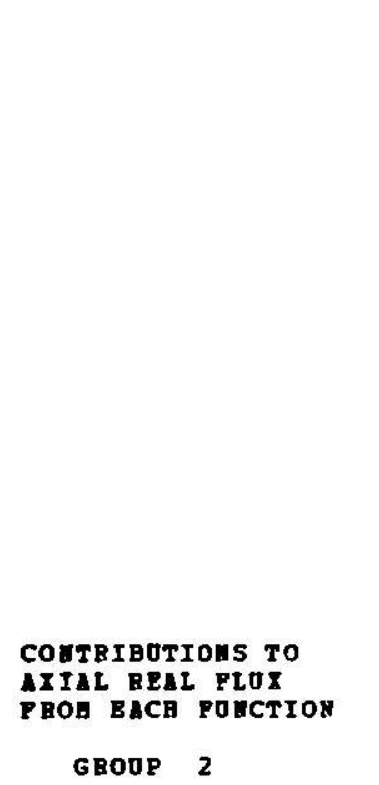

$A x=1.175 E+12$ II $=-6.523 \mathrm{E}+10$ BL ARR E' PONCTIONS (3 AND 4) NOT USED EVERYAHERE

BLAKRE' PONCTIONS (3 AND 4) NOT OSED ENER
30 GEOIETRY BOILT UP FROH 2D GEODST FILES

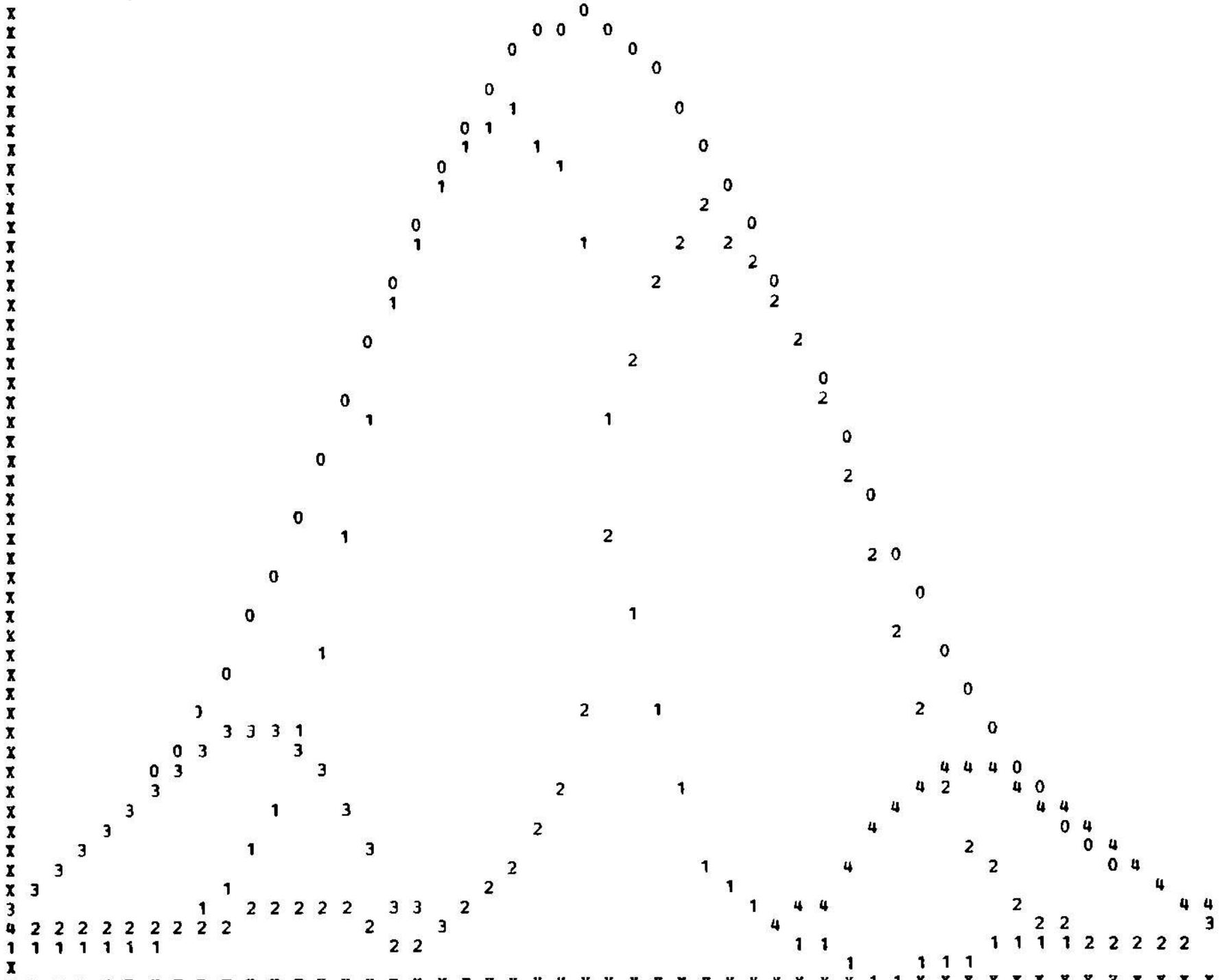

\section{AXIAL POSITION}


APPENDIX H. Sample Problem Output. Problem 4 - Partial Output

STA3D, OVERLAY CARDS

3 GRODP, 3-DIRENSIONAL MODEL, HIXED FLUX AND ADJOINT TEIGHTING BLANKET FONCTIONS (3 AND 4) NOT OSED EVERYY्रHERE

GROTP 3 OP BLANKET FUNCTIONS NOT OSED AT AIL

INPDT 30 GEODST FILE

LISTIRG OF SYRJD INPOT

CARDS-EER-CARD-TYPE TATA

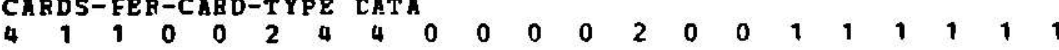

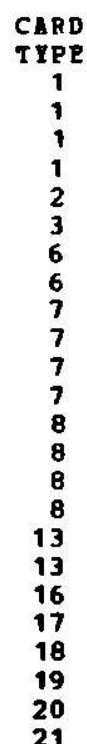

3 GROUP, 3-CIMENS TOHAL HODEL, MIXED PLOX AND ADJCINT HEIGATING BL A UK ET POHCT IONS ( 3 AND 4) NOT USED EVERYHAERE GROJP 3 OP BLANRET FONCTI ONS NOT USED AT ALI IRPOT 3D GEODST PILE

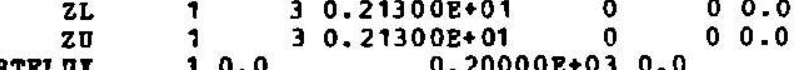

ATPL IX $10.0 \quad 0.20000 \mathrm{E}+030.0$

$\begin{array}{lll}\text { BTPLOT } & 20.0 & 0.20900 \mathrm{E}+030.0 \\ \text { BTEX } & 30.0 & 0.100008+030.0\end{array}$

BTFLX $0.10000 \mathrm{E}+030.20000 \mathrm{E}+030.0$

$\begin{array}{lll}\triangle \text { TPL OI } & 10.0 & 0.20000 \mathrm{E}+030.0\end{array}$

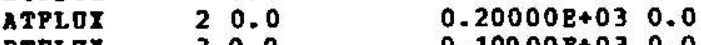

BTPLOX $30.0 \quad 0.10000 \mathrm{E}+030.0$

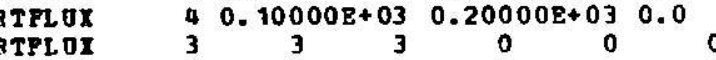

RTPLOI

$\begin{array}{ll}3 & 3 \\ 4 & 3\end{array}$

3

$\begin{array}{lll}0 & 0 \\ 0 & 0\end{array}$

0.0

0.0

0.0
0.0

0.0

0.0

0.0

0.0

$\begin{array}{ll}5 & 3 \\ 2 & 3\end{array}$

$\begin{array}{lll}1 & 1 & 0 \\ 0 & 0 & 0 \\ 0 & 0 & 0\end{array}$

000

$\begin{array}{lll}0 & 0 & 0 \\ 1 & 0 & 0\end{array}$

1

5

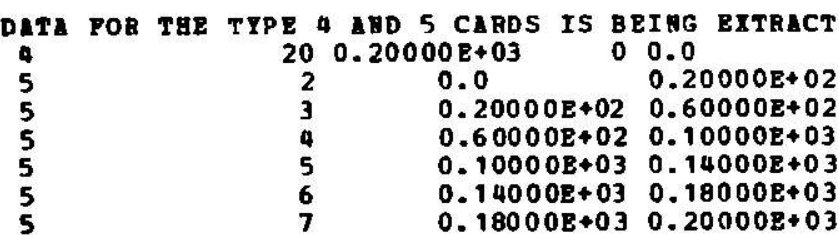


INFUT 3D GEODST FILE

GEEERAL PROBLEH DATA

TOABER OP GBOUPS $=3$ (NGROOP)

BOIATEB CONTIIEER SIZE $=15000$

MOABER OF AXIAL HESH IMTERVALS $=20$

THERE IS NO GROOP COLLAPSIHG

TABEE IS HO IO BOPFERIFG

TEREE IS HO ITPUT PUNCTION SCAL I MG

THEBE UERE SO IHPUT IHTEGRALS

BOU TDABT COBDITIONS

LORER Y BOU HDARY CONDTTION = ZERO CUS RENT

OPPER I BOTHDARY CCHDITION = ZERO PLJX

LODER I BOUHDABY CONDITION = ZEBC CORRENT

OPPEB Y BOUNDARY CCNDITION = 2ERO PLOX

IOREB 2 BOJHDARY CONDITION = LOGABITAMIC

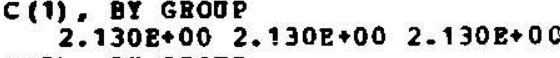

C(2). BY GROOP

$.0008+001.000 E+001.000 E+00$

OPPE $\mathrm{Z}$ BOUUDABY CONDITIOU = LOGARITHIC

C(1). BI GROOP

$2.130 \mathrm{E}+002.130 \mathrm{E}+00 \quad 2.130 \mathrm{E}+00$

C(2), BY GROU?

$1.000 \mathrm{E}+00 \quad 1.000 \mathrm{E}+00 \quad 1.000 \mathrm{E}+00$ 


$\begin{array}{cc}\text { POHCTION } & \text { FILE } \\ \text { BOHBEP } & \text { ROMBEP } \\ 1 & 22 \\ 2 & 23 \\ 3 & 24 \\ 4 & 25 \\ 5 & 32 \\ 6 & 33\end{array}$

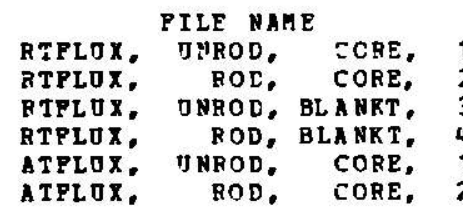

$$
\begin{array}{rl}
\text { GROUPS } & \text { OSED } \\
\text { ALL } & 3 \\
\text { ALL } & 3 \\
1 & 2 \\
1 & 2 \\
\text { ALL } & 3 \\
\text { ALL } & 3
\end{array}
$$

AxIal positron

\section{PIANAR}

ROD. CORE,

GEOHETRY
NTEBER PILE NOHBER

0.0 To 20.0

20.0 To 60.0

60.0 To 100.0

\begin{tabular}{|c|c|c|}
\hline \multicolumn{3}{|c|}{ EXPANSION } \\
\hline & ION & NUBA ESS \\
\hline 1 & 2 & 3 \\
\hline 1 & 2 & 3 \\
\hline 1 & 2 & 3 \\
\hline 1 & 2 & 4 \\
\hline 1 & 2 & 4 \\
\hline 1 & 2 & 4 \\
\hline
\end{tabular}

100.0 TO 140.0

\begin{tabular}{|c|c|c|}
\hline \multicolumn{3}{|c|}{ YEIGHTING } \\
\hline NCTI & an & NUMBES \\
\hline 3 & 5 & 6 \\
\hline 3 & 5 & 6 \\
\hline 5 & 6 & 4 \\
\hline 5 & 6 & 4 \\
\hline 5 & 6 & 4 \\
\hline
\end{tabular}

140.0 10 180.0

1
2
3
4
5
6

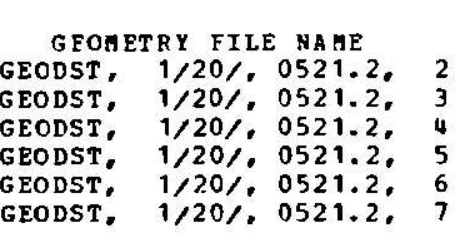

IIAL HESG INTERVALS

$1.000 D+011.000 D+011.000 D+011.000 D+011.000 D+011.000 D+011.000 D+011.000 D+011.000 D+011.000 D+011.000 D+011.000 D+09$ $1.0000+011.000 D+011.000 D+011.000 D+011.000 D+011.000 D+011.0000+011.000 D+01$

DATA HAKAGEHETT PARAERTERS FOR INTEGRAL CALCOLATION

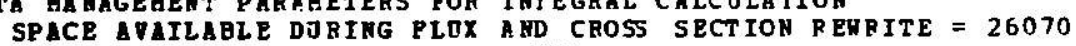
REQFI.X PILE, DORDS RORS OP PLOXES/BECORD $=14$

NTHARA OP CONCURBENT BECORDS DURING REHRITE = 5

IBITIAL ESTIHATES OP STORAGE REQUTREAETS S POR FLOX, GEONETRY ANO/OR CROSS SECTIOT REHATE MAS WRONG. SYHJD WILL START THE BEDBTTE AGATH MITA BETTEB ESTI

DATI GAMAGEAENT PABATETERS POR INT RGRAL CALCOLATIO

SPACE AVAILABLE DORIHG PLUX AND CROSS SRCTION REHRITE = 25846

REQPLX FILE, MORDS/BECORD $=4734$

BORS OP FLOTES/RECORD $=14$

REQXST FILE, DORDS/BECORD $=105$

COHPOSI TIOAS/RRCORD FOR PISSION $\rightarrow$ REHOV AL RECORDS $=$

SPACE AVAILALE DURIAG IATEGRATION = 5561

VOLINT IUD DIFINT PILES, MORDS/RECS,

NUHBER OP CONCORRENT BECORDS DURING REHRITE = 5

COLOHNS OF PLUXES/RECORD $=14$

BCOBDS DERING REHRTTE $=240$

GROIPS/RECORD FOR DIPPUSION CORPPICIENT RECORDS $=3$

NTHEER OP CONCURRENT RECORDS DJRING INTEGRATION $=2$ 
STU3D, OVERLAT SOLVE

3 GROUP, 3-DIMFMS IONAL MODEL, MIXED FLOX AND ADJOINT WEIGHTIYG

BLARXET FONCTIONS (3 AND 4) NOT OSED EVERYWHERE
GROUP 3 OP BLANKET FUNCTIONS NOT USED T ALL

INEOT 3D GEODST FILE

IUTTOC FILE LEBEL $=1 / 20 / 0521.7$, VERSICN AOHBER $=2$

DAT MAMAEGET PARAHETERS FOR SOLUTION

ITTGLS PILE, DOBDS/RECORD $=2214$

NOMBER OF CONCURRENT RECORDS DORING GAUSS EL IHIHATION = 1

MOABER OP RECORDS $=1$

P PILE

NOMBER OF RECORDS $=1$

DIRECT EIGETELIJE CalCULATIO

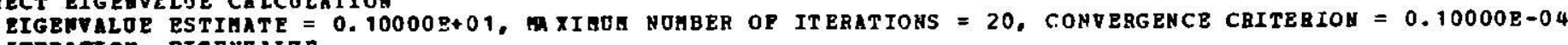

ETGENILO

$\begin{array}{ll}1 & 0.97289 \mathrm{E}+00 \\ 2 & 0.97518 \mathrm{O}+00 \\ 3 & 0.97520 \mathrm{O}+00 \\ 4 & 0.97520 \mathrm{E}+00 \\ 5 & 9.97520 \mathrm{E}+00\end{array}$

THE CALCOLATION BAS COHVEBgE ON AN EIGENVALUE

morgalization, PLOX * SIGHa-F * PORER/PISSION $=0.10000 E+02$ MatTS. 

BLANKET PINCTIONS ( 3 AND 4) NOT USED EVERYYHERE GROUP 3 OP BLANKET PUNCTIONS NOT USED AT $A L L$ INPOT 3D GEODST FILE

COBAIAIAG COEPEICIENTS POR DIRECT CALCULATION

\begin{tabular}{|c|c|c|c|c|c|c|c|c|c|c|c|c|}
\hline POHC & $\begin{array}{r}\text { TIOH No } \\
\text { GROJ }\end{array}$ & $\begin{array}{l}\dot{P}= \\
=\end{array}$ & 1 & $\begin{array}{l}1 \\
2\end{array}$ & $\begin{array}{l}1 \\
3\end{array}$ & $\begin{array}{l}2 \\
1\end{array}$ & $\begin{array}{l}2 \\
2\end{array}$ & $\begin{array}{l}2 \\
3\end{array}$ & $\begin{array}{l}3 \\
1\end{array}$ & $\begin{array}{l}3 \\
2\end{array}$ & $\begin{array}{l}4 \\
1 .\end{array}$ & $\begin{array}{l}4 \\
2\end{array}$ \\
\hline $\begin{array}{l}\text { TAI } \\
\text { ITIOA } \\
.00 \\
.00 \\
.00 \\
.00 \\
.00 \\
.00 \\
.00 \\
.00 \\
.00 \\
.00 \\
.00 \\
.00 \\
.00 \\
.00 \\
.00 \\
.00 \\
.00 \\
.00 \\
.00 \\
.00\end{array}$ & $\begin{array}{c}\text { AXThL } \\
\text { Gron. } \\
1 \\
1 \\
2 \\
2 \\
2 \\
2 \\
2 \\
3 \\
3 \\
3 \\
3 \\
4 \\
4 \\
4 \\
4 \\
5 \\
5 \\
5 \\
5 \\
6 \\
6\end{array}$ & $\begin{array}{r}-2 \\
-3 \\
-8 \\
-1 \\
-6 \\
1 \\
6 \\
8 \\
9 \\
7 \\
2 \\
7 \\
1 \\
-8 \\
-5 \\
-1 \\
-4 \\
-3 \\
-9 \\
-5\end{array}$ & $\begin{array}{l}.205 \mathrm{E}-03 \\
.573 \mathrm{E}-02 \\
.764 \mathrm{E}-02 \\
.489 \mathrm{E}-01 \\
.116 \mathrm{E}-02 \\
.097 \mathrm{E}+00 \\
.707 \mathrm{E}+00 \\
.851 \mathrm{E}+00 \\
.304 \mathrm{E}+00 \\
.632 \mathrm{E}+00 \\
.750 \mathrm{E}+00 \\
.082 \mathrm{E}-01 \\
.316 \mathrm{E}-01 \\
.474 \mathrm{E}-02 \\
.773 \mathrm{E}-02 \\
.486 \mathrm{E}-02 \\
.595 \mathrm{E}-03 \\
.712 \mathrm{E}-03 \\
.074 \mathrm{E}-03 \\
.959 \mathrm{E}-03\end{array}$ & $\begin{array}{r}3.212 \mathrm{E}-01 \\
-1.853 \mathrm{E}-01 \\
-1.261 \mathrm{E}-01 \\
3.669 \mathrm{E}-01 \\
1.676 \mathrm{E}+00 \\
4.715 \mathrm{E}+00 \\
8.495 \mathrm{E}+00 \\
9.824 \mathrm{E}+00 \\
1.023 \mathrm{E}+01 \\
9.666 \mathrm{E}+00 \\
3.285 \mathrm{E}+00 \\
9.588 \mathrm{E}-01 \\
1.289 \mathrm{E}-01 \\
-4.222 \mathrm{E}-01 \\
-9.160 \mathrm{E}-01 \\
-4.825 \mathrm{E}-01 \\
-1.757 \mathrm{E}-01 \\
-5.592 \mathrm{E}-02 \\
-6.586 \mathrm{E}-02 \\
-2.290 \mathrm{E}-02\end{array}$ & 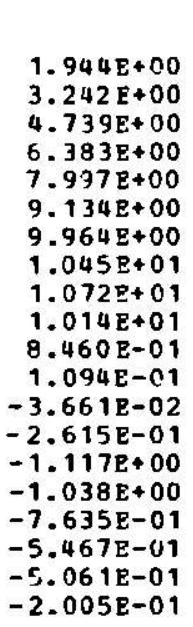 & $\begin{array}{r}-4.265 \mathrm{E}-02 \\
-1.966 \mathrm{E}-02 \\
-1.785 \mathrm{E}-02 \\
4.707 \mathrm{E}-02 \\
2.480 \mathrm{E}-01 \\
5.667 \mathrm{E}-01 \\
2.046 \mathrm{E}-01 \\
6.109 \mathrm{E}-01 \\
1.599 \mathrm{E}+00 \\
3.828 \mathrm{E}+00 \\
1.004 \mathrm{E}+01 \\
1.156 \mathrm{E}+01 \\
1.028 \mathrm{E}+01 \\
7.538 \mathrm{E}+00 \\
2.108 \mathrm{E}+00 \\
3.104 \mathrm{E}-01 \\
-1.002 \mathrm{E}-01 \\
-1.347 \mathrm{E}-01 \\
-8.581 \mathrm{E}-02 \\
-3.724 \mathrm{E}-02\end{array}$ & $\begin{array}{r}-3.450 \mathrm{E}-01 \\
6.313 \mathrm{E}-02 \\
4.543 \mathrm{E}-02 \\
2.298 \mathrm{E}-02 \\
7.690 \mathrm{E}-02 \\
-5.315 \mathrm{E}-02 \\
-7.160 \mathrm{E}-01 \\
-1.116 \mathrm{E}-01 \\
8.199 \mathrm{E}-01 \\
2.266 \mathrm{E}+00 \\
9.015 \mathrm{E}+00 \\
1.086 \mathrm{E}+01 \\
1.026 \mathrm{E}+01 \\
8.768 \mathrm{E}+00 \\
6.125 \mathrm{E}+00 \\
2.416 \mathrm{E}+00 \\
5.644 \mathrm{E}-01 \\
-. .333 \mathrm{E}-02 \\
-5.071 \mathrm{E}-01 \\
-6.697 \mathrm{E}-02\end{array}$ & $\begin{array}{r}-7.119 E-01 \\
1.7 C 0 E-0 \\
-3.025 E-01 \\
3.901 E-02 \\
1.201 E+00 \\
2.323 E+00 \\
-1.133 E+00 \\
-6.752 E-01 \\
2.259 E-01 \\
1.443 E+00 \\
1.248 E+01 \\
1.226 E+01 \\
1.085 E+01 \\
9.809 E+00 \\
1.251 E+01 \\
9.991 E+00 \\
6.900 E+00 \\
4.673 E+00 \\
3.541 E+00 \\
1.387 E+00\end{array}$ & $\begin{array}{l}6.790 E-04 \\
1.462 E-03 \\
2.806 E-03 \\
5.052 E-03 \\
8.230 E-03 \\
1.006 E-02 \\
6.387 E-04 \\
4.960 E-05 \\
1.246 E-03 \\
3.626 E-03 \\
0.0 \\
0.0 \\
0.0 \\
0.0 \\
0.0 \\
0.0 \\
0.0 \\
0.0 \\
0.0 \\
0.0\end{array}$ & $\begin{array}{l}6.021 \mathrm{E}-04 \\
1.958 \mathrm{E}-03 \\
3.030 \mathrm{E}-03 \\
3.904 \mathrm{E}-03 \\
4.059 \mathrm{E}-03 \\
2.247 \mathrm{E}-03 \\
-1.974 \mathrm{E}-04 \\
-2.784 \mathrm{E}-04 \\
-1.005 \mathrm{E}-04 \\
-2.828 \mathrm{E}-04 \\
0.0 \\
0.0 \\
0.0 \\
0.0 \\
0.0 \\
0.0 \\
0.0 \\
0.0 \\
0.0 \\
0.0\end{array}$ & $\begin{array}{l}0 . c \\
0.0 \\
0.0 \\
0.0 \\
0.0 \\
0.0 \\
0.0 \\
0.0 \\
0.0 \\
0.0 \\
1.829 E-03 \\
3.830 E-04 \\
-2.793 E-05 \\
9.650 E-04 \\
9.613 E-03 \\
8.501 E-03 \\
5.498 E-03 \\
3.181 E-03 \\
1.756 E-03 \\
7.301 E-04\end{array}$ & $\begin{array}{l}0.0 \\
0.0 \\
0.0 \\
0.0 \\
0.0 \\
0.0 \\
0.0 \\
0.0 \\
0.0 \\
0.0 \\
1.101 \mathrm{E}-03 \\
7.380 \mathrm{E}-04 \\
2.825 \mathrm{E}-04 \\
1.371 \mathrm{E}-04 \\
2.302 \mathrm{E}-03 \\
4.542 \mathrm{E}-03 \\
4.436 \mathrm{~B}-03 \\
3.410 \mathrm{E}-03 \\
2.196 \mathrm{E}-03 \\
8.869 \mathrm{E}-04\end{array}$ \\
\hline
\end{tabular}


SYM 3D, OVERLAY SOLVE

3 GROOF, 3-DIMENSIONAL HODEL, HIXED PLOX AND ADJOINT WEIGHTIAG BLAKRET FONCTIONS ( 3 AND 4) NOT USED EVERYTHERE

GROD́́ 3 OF BLANKET FUNCTIONS NOT USED AT ALL

IHPOT 3D GEODST FILE

COHBIHIgG COEPYICIENTS POR DTRECT CALCULATION

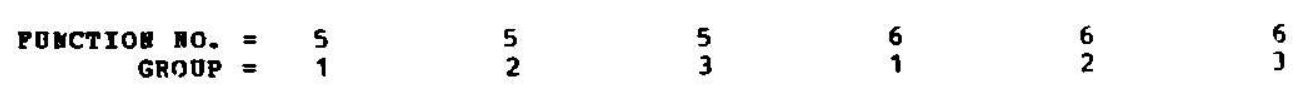

\section{AIIAL AXIAL}

$\begin{array}{rccc}5.00 & 1 & 0.0 & 0.0 \\ 15.00 & 1 & 0.0 & 0.0 \\ 25.00 & 2 & 0.0 & 0.0 \\ 35.00 & 2 & 0.0 & 0.0 \\ 45.00 & 2 & 0.0 & 0.0 \\ 55.00 & 2 & 0.0 & 0.0 \\ 65.00 & 3 & 0.0 & 0.0 \\ 75.00 & 3 & 0.0 & 0.0 \\ 85.00 & 3 & 0.0 & 0.0 \\ 95.00 & 3 & 0.0 & 0.0 \\ 105.00 & 4 & 0.0 & 0.0 \\ 115.00 & 4 & 0.0 & 0.0 \\ 125.00 & 4 & 0.0 & 0.0 \\ 135.00 & 4 & 0.0 & 0.0 \\ 145.00 & 5 & 0.0 & 0.0 \\ 155.00 & 5 & 0.0 & 0.0 \\ 165.00 & 5 & 0.0 & 0.0 \\ 175.00 & 5 & 0.0 & 0.0 \\ 185.00 & 6 & 0.0 & 0.0 \\ 195.00 & 6 & 0.0 & 0.0\end{array}$

0.0
0.0
0.0
0.0
0.0
0.0
0.0
0.0
0.0
0.0
0.0
0.0
0.0
0.0
0.0
0.0
0.0
0.0
0.0
0.0

$\begin{array}{ll}0.0 & 0.0 \\ 0.0 & 0.0 \\ 0.0 & 0.0 \\ 0.0 & 0.0 \\ 0.0 & 0.0 \\ 0.0 & 0.0 \\ 0.0 & 0.0 \\ 0.0 & 0.0 \\ 0.0 & 0.0 \\ 0.0 & 0.0 \\ 0.0 & 0.0 \\ 0.0 & 0.0 \\ 0.0 & 0.0 \\ 0.0 & 0.0 \\ 0.0 & 0.0 \\ 0.0 & 0.0 \\ 2.0 & 0.0 \\ 0.0 & 0.0 \\ 0.0 & 0.0 \\ 0.0 & 0.0\end{array}$

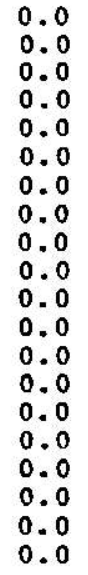

0.0 
SYH 3D, OVERLAT SOLVE

3 GROOP, 3-DIA ENSIONAL MODEL, MIXED PLUX AND ADJOINT WEIGHTIHG BLANKET FONCTIONS ( 3 AND 4) NOT OSED EVERYUHERE

G ROOP 3 OP BLANKET FUNCTIONS NOT JSED AT ALI

IN FUT 3D GEODST FILE

DATA HANAGEHENT PARAHETERS FOR SOLTTION

INTGLS FILE, TORDS/RECORD = 2211

NOK BER OP R ECORDS $=1$

PILE, YORDS BRCORD $=1216$

NOHREP OF CONCURRENT RECORDS DURING GAUSS ELIUIHATION = 1

DJOIHT EIGEBVALUE CALCULATION

EIGENVALUR ESTIMATE $=0.976208400$, HAXIMOH NUABER OF ITERATIONS $=20$, CONVERGENCE CRITEBIOA $=0.10000$-O 4

ITESATI OA EIGENVALOE

$\begin{array}{ll}1 & 0.97541 \mathrm{E}+00 \\ 2 & 0.97520 \mathrm{E}+00\end{array}$

$\begin{array}{ll}2 & 0.97520 \mathrm{E}+00 \\ 3 & 0.97520 \mathrm{E}+00\end{array}$

$0.97520 \mathrm{R}+00$
$0.97520 \mathrm{E}+00$

THE CALCOLATION RAS CONPERGED OY AN EIGENVALOE

MORMALIZATION, ADJOIGT * SIGHA * PORER/FISSION $=0.10000 \mathrm{E}+02$ HATTS. 
STE30, OTELAY sotve

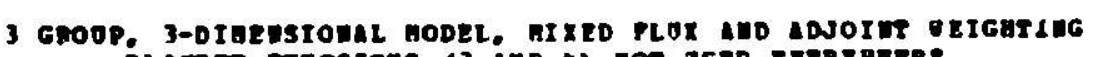

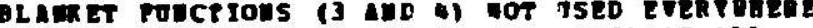
GECOP OP OLATET PJECTIOAS NOT OSED AT ALL IDPT 30 GEODST FILE

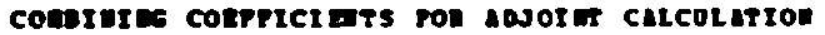

ronctron $10 .:-1$

Asral

Position Geom.

5.00

$\begin{array}{rrr}5.00 & 1 & 0.0 \\ 15.00 & 1 & 0.0 \\ 25.00 & 2 & 0.0 \\ 35.00 & 2 & 0.0 \\ 15.00 & 2 & 0.0 \\ 55.00 & 2 & 0.0 \\ 65.00 & 3 & 0.0 \\ 75.00 & 3 & 0.0 \\ 75.00 & 3 & 0.0 \\ 15.00 & 3 & 0.0 \\ 105.00 & : & 0.0 \\ 115.00 & 3 & 0.0 \\ 125.00 & 3 & 0.0 \\ 135.00 & 5 & 1.0 \\ 155.00 & 5 & 0.0 \\ 155.00 & 5 & 0.0 \\ 155.00 & 5 & 0.0 \\ 175.00 & 5 & 0.0 \\ 195.00 & 6 & 0.0 \\ 195.00 & 6 & 0.0\end{array}$

i i

0.0
0.0
0.0
0.0
0.0
0.0
0.0
0.0
0.0
0.0
6.0
0.0
0.0
0.0
0.0
0.0
0.0
0.0
0.0
0.0

0.00
0.0
0.0
0.0
0.0
0.0
0.0
0.0
0.0
0.0
0.0
0.0
0.0
0.0
0.00
0.0
0.0
0.0
0.0
0.0

$\begin{array}{ll} & 2 \\ & 1 \\ & \\ & \\ 0.0 & \\ 0.0 & 0.0 \\ 0.0 & 0.0 \\ 0.0 & 0.0 \\ 0.0 & 0.0 \\ 0.0 & 0.0 \\ 0.0 & 0.0 \\ 0.0 & 0.0 \\ 0.0 & 0.0 \\ 0.0 & 0.0 \\ 0.0 & 0.0 \\ 0.0 & 0.0 \\ 0.0 & 0.0 \\ 0.0 & 0.0 \\ 0.0 & 0.0 \\ 0.0 & 0.0 \\ 0.0 & 0.0 \\ 0.0 & 0.0 \\ 0.0 & 0.0 \\ 0.0 & 0.0 \\ & 0.0\end{array}$

$\begin{array}{ll} & 2 \\ & 1 \\ & \\ & \\ 0.0 & \\ 0.0 & 0.0 \\ 0.0 & 0.0 \\ 0.0 & 0.0 \\ 0.0 & 0.0 \\ 0.0 & 0.0 \\ 0.0 & 0.0 \\ 0.0 & 0.0 \\ 0.0 & 0.0 \\ 0.0 & 0.0 \\ 0.0 & 0.0 \\ 0.0 & 0.0 \\ 0.0 & 0.0 \\ 0.0 & 0.0 \\ 0.0 & 0.0 \\ 0.0 & 0.0 \\ 0.0 & 0.0 \\ 0.0 & 0.0 \\ 0.0 & 0.0 \\ 0.0 & 0.0 \\ & 0.0\end{array}$

0.0
0.0
0.0
0.0
0.0
0.0
0.0
0.0
0.0
0.0
0.0
0.0
0.0
0.0
0.0
0.0
0.0
0.0
0.0
0.0

3

$\sqrt{3}$

i.

3

\begin{tabular}{|c|c|c|c|}
\hline $\begin{array}{l}1.2658-03 \\
2.0038-03 \\
4.7098-03 \\
7.0888-03 \\
9.1978-03 \\
.4578-03 \\
1.3208-03 \\
.9398-05 \\
6.0628-04 \\
8.0718-04\end{array}$ & 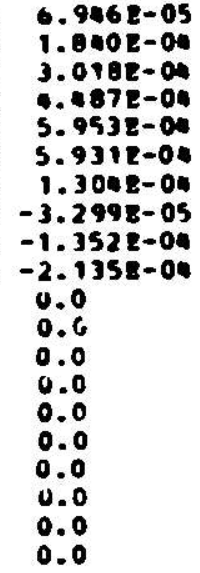 & $\begin{array}{l}0.0 \\
0.0 \\
0.0 \\
0.0 \\
0.0 \\
0.0 \\
0.0 \\
0.0 \\
0.0 \\
0.0 \\
-3.0238-00 \\
1.0418-04 \\
5.1368-04 \\
1.6028-03 \\
9.5618-03 \\
1.0278-02 \\
7.8118-03 \\
5.1668-03 \\
3.0758-03 \\
1.3398-03\end{array}$ & $\begin{array}{l}0.0 \\
0.0 \\
0.0 \\
0.0 \\
0.0 \\
0.0 \\
0.0 \\
0.0 \\
0.0 \\
0.0 \\
2.0408-04 \\
2.032 E-04 \\
1.0428-04 \\
1.5198-04 \\
6.9728-04 \\
6.5598-00 \\
1.6098-04 \\
2.9108-04 \\
1.7018-04 \\
6.0818-05\end{array}$ \\
\hline
\end{tabular}




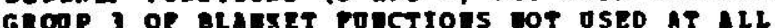

IJPOP 10 GejoST PILP

comrares coeptrcietrs ron sovort calcolation

\begin{tabular}{|c|c|c|c|c|c|c|c|}
\hline & cmor. & 1 & $\begin{array}{l}5 \\
2\end{array}$ & 3 & ; & 2 & $\begin{array}{l}6 \\
3\end{array}$ \\
\hline 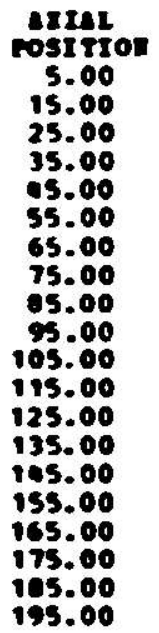 & $\begin{array}{c}\text { Arrat } \\
\text { Geon. } \\
1 \\
1 \\
2 \\
2 \\
2 \\
2 \\
3 \\
3 \\
3 \\
3 \\
\vdots \\
\vdots \\
5 \\
5 \\
5 \\
5 \\
5 \\
6 \\
6\end{array}$ & 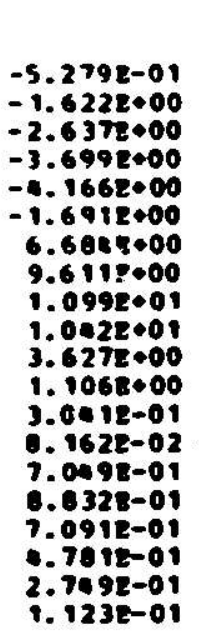 & 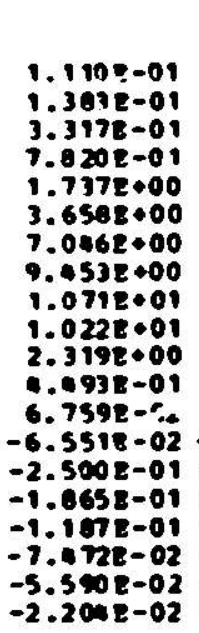 & 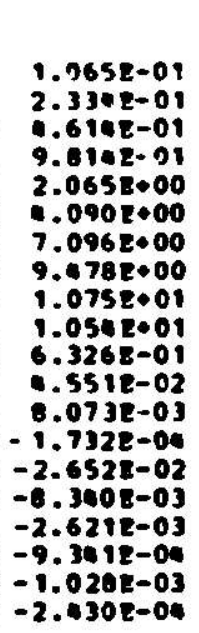 & 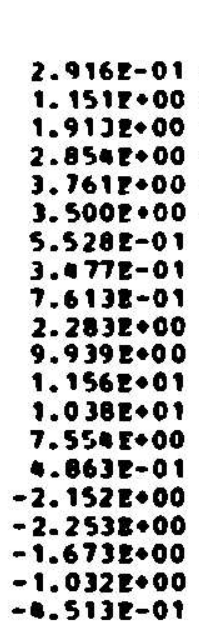 & 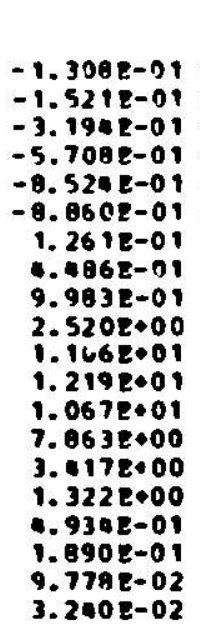 & 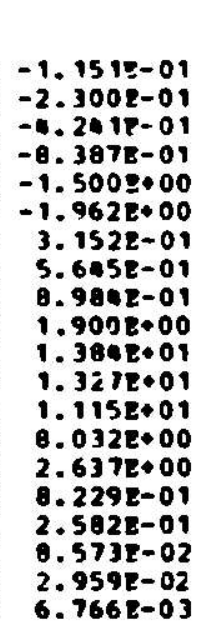 \\
\hline
\end{tabular}

$$
\begin{aligned}
& \text { 0.0. PP } 1 . P P= \\
& 0.0 \\
& 0.0 . \mathrm{PP}=0.0 \\
& \begin{array}{ll}
1.2 . & P P=0 \\
0.1 . P P & 0.0
\end{array}
\end{aligned}
$$




\section{APPENDIX I}

\section{CCCC Version III Standard Interface Files}

The CCCC Standard Interface FIles used in SYN3D are defined by the specifications in Ref. 24 with the following two additions:

(1) In the File Specification record of GEODST. The 23rd entry (one of the "Reserved" In Ref. 24) 18 used to specify the orientation of the $(1,1)$ mesh triangle for triangular mesh geowetries (IGOM-9 or 17) bounded, in the $x-y$ plane, by rectangles (NTRIAG $=2$ ). In SYN3D that entry 18 designated "NTRIPT" and has the following definteion.

$$
\begin{aligned}
& \text { NTRIPT = } 1 \text { - Triangle }(1,1) \text { polnts away from the } \\
& \text { first dimensions axds, 1.e., no } \\
& \text { internal mesh line incersects the origin. } \\
& 2 \text { - Triangle }(1,1) \text { points touards the first } \\
& \text { dimension axis. 1.e., an internal mesh } \\
& \text { ilne intersects the origin. }
\end{aligned}
$$

(2) In the Mesh Interval Boundary record of GEODST. For triangular mesh geometries (ICOYs or 17) the length (L) of a side of a triangle 18 calculated from

$$
\text { L - } 2 \frac{\operatorname{XXSH}(2)-\operatorname{XgESH}(1)}{\operatorname{IFINTS}(1)}
$$

Thc other entries In XIESH and MESH are never used.

The rest of this appendix consists of listings of the following CCCC Standard Interface F1les from Reference 24:

$$
\begin{aligned}
& \text { GEODST } \\
& \text { ISOTXS } \\
& \text { NDXSRP } \\
& \text { ZNATDN } \\
& \text { RTPLUX } \\
& \text { ATPLUX } \\
& \text { PWDLNT } \\
& \text { REFUR }
\end{aligned}
$$


APlELIIX 1. CCCC Version III Standard Interface Files. GLOLST

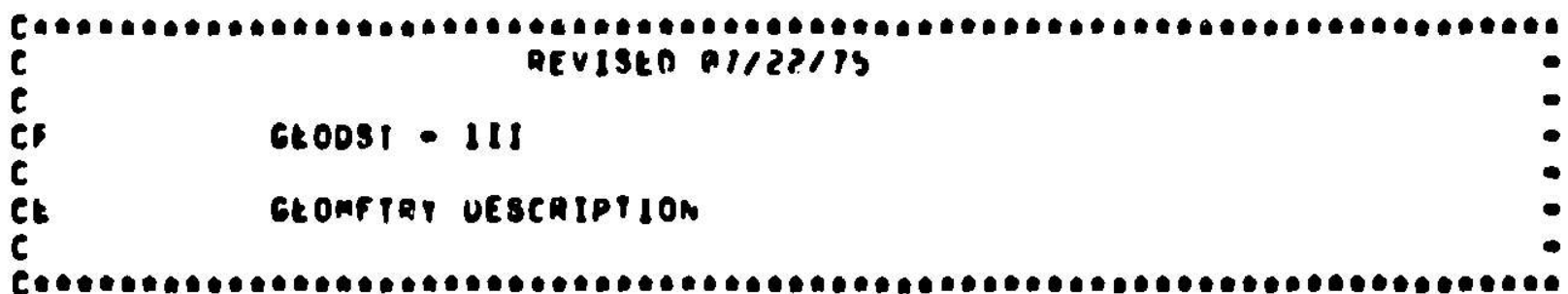

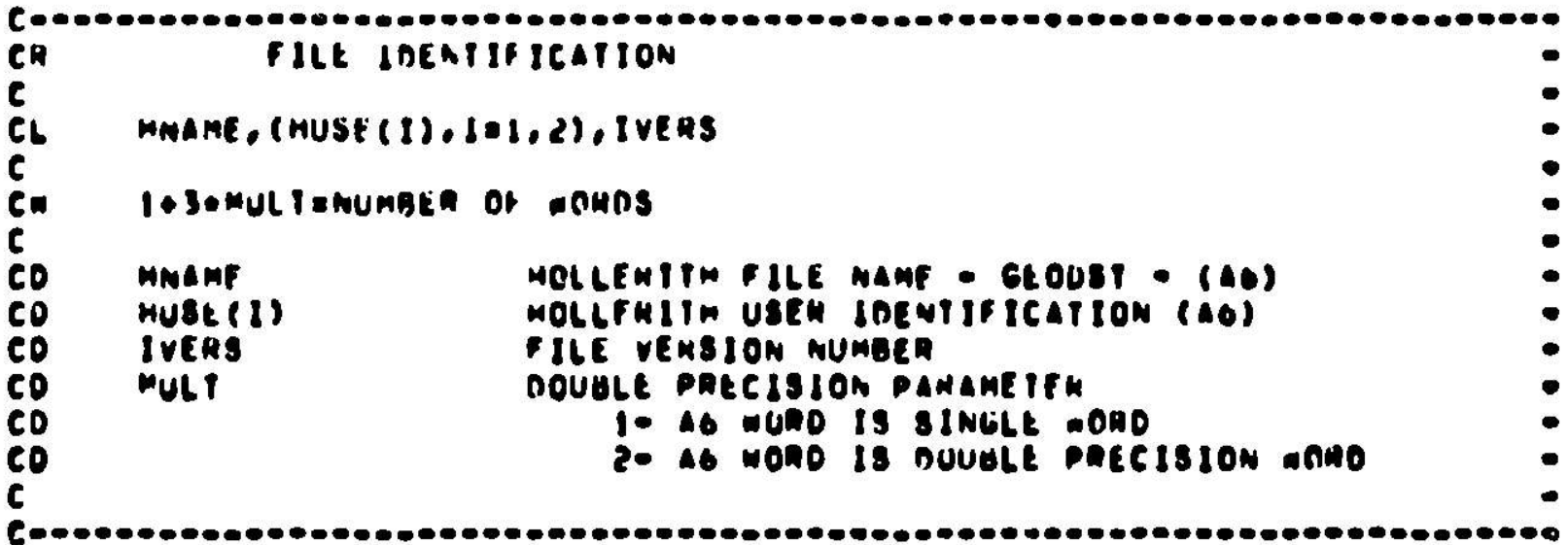

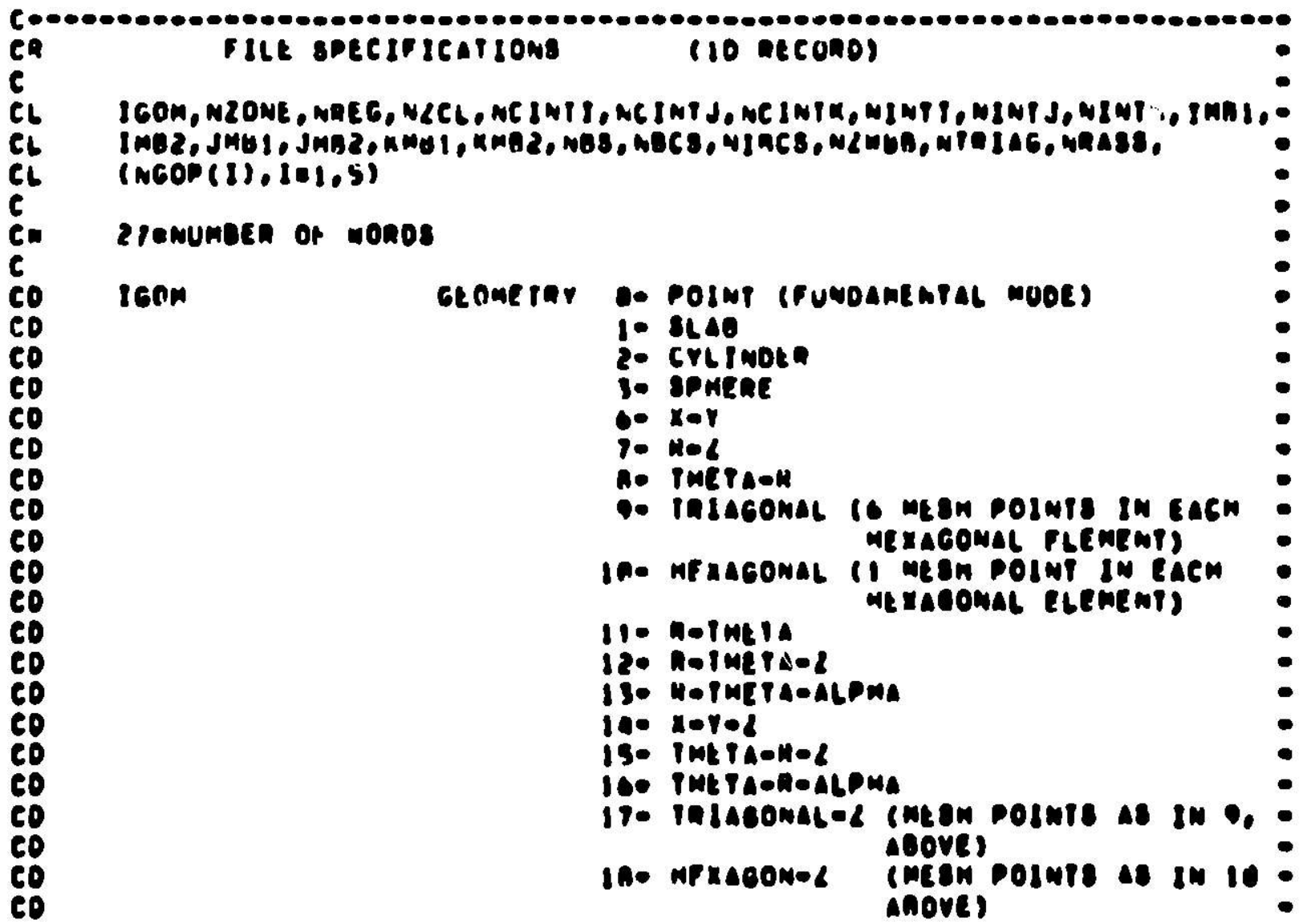




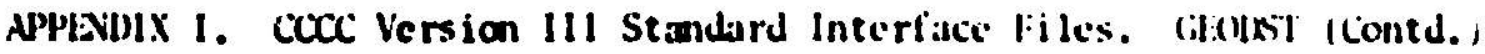

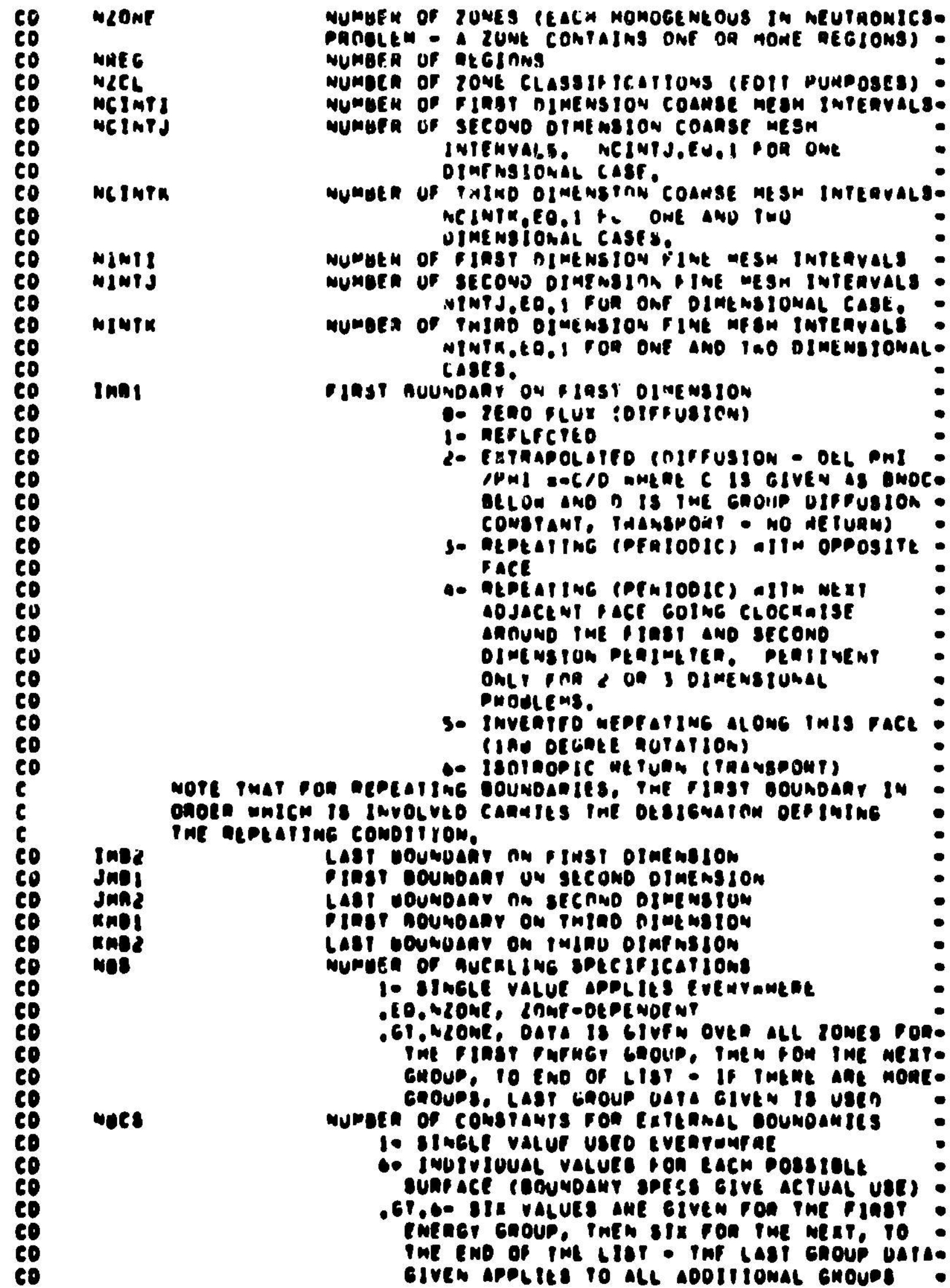




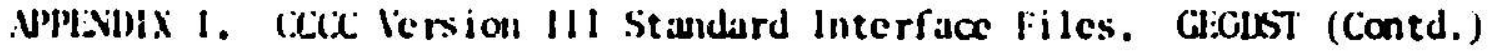

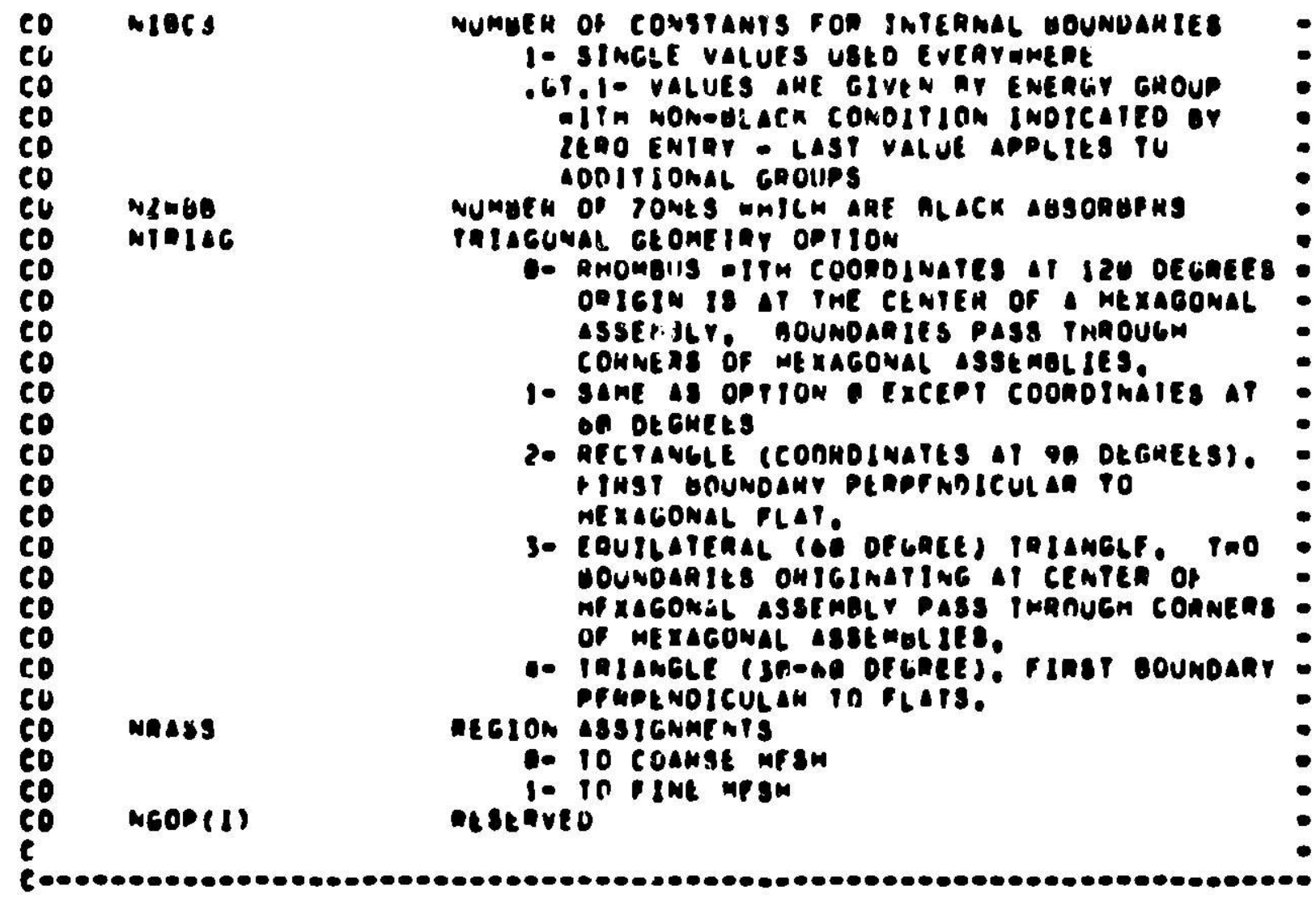

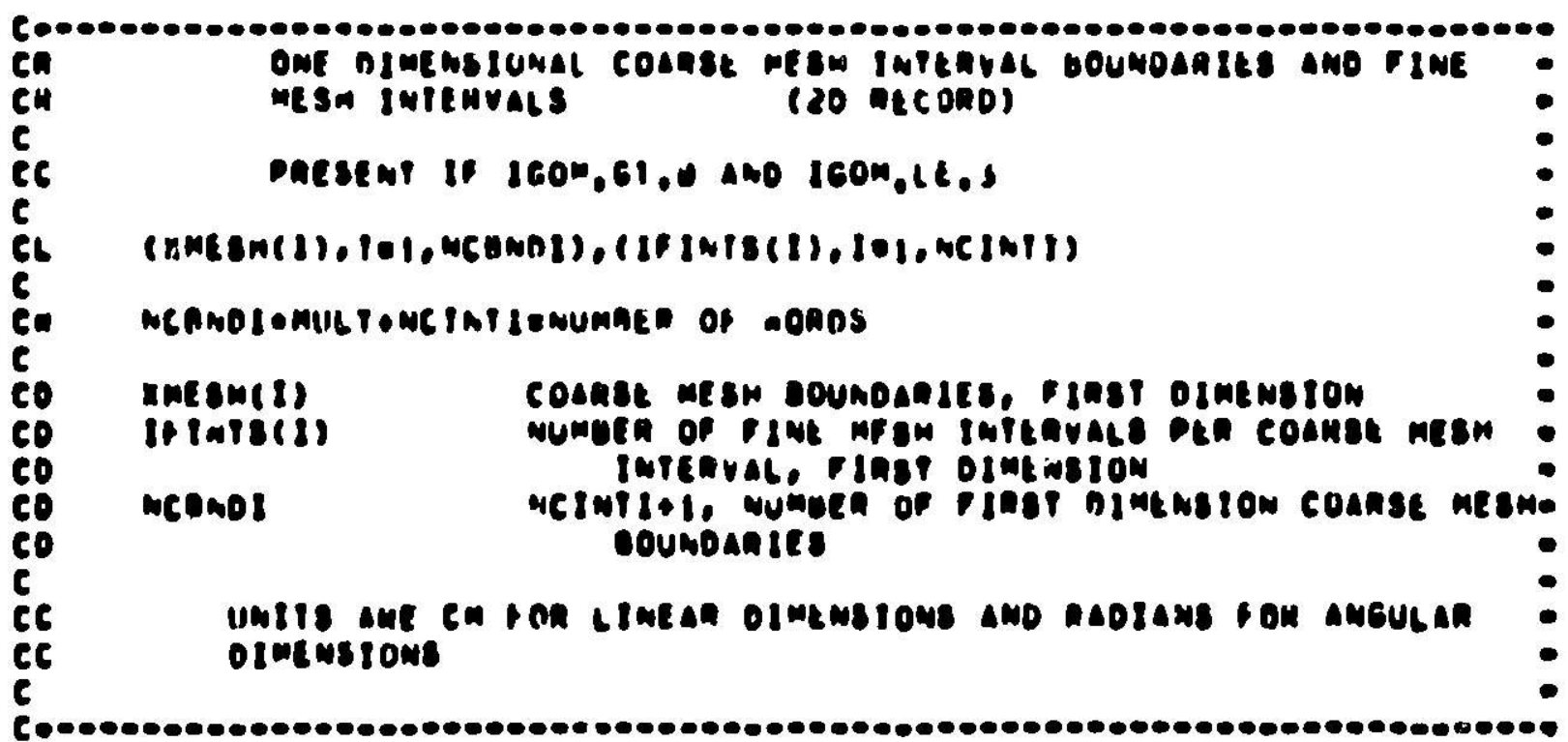


APIENDIX 1. CCCC Version III Standard Interface liles. (itiolsi (Contd.)

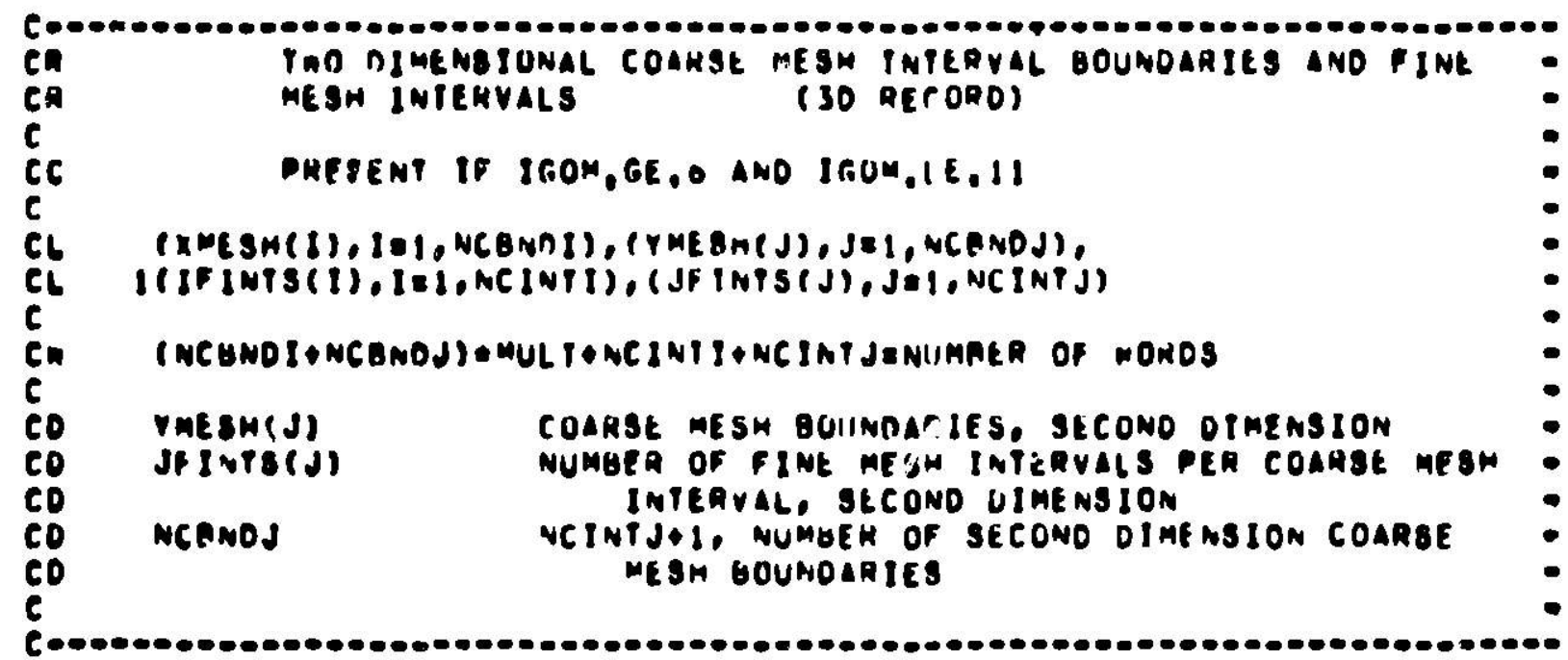

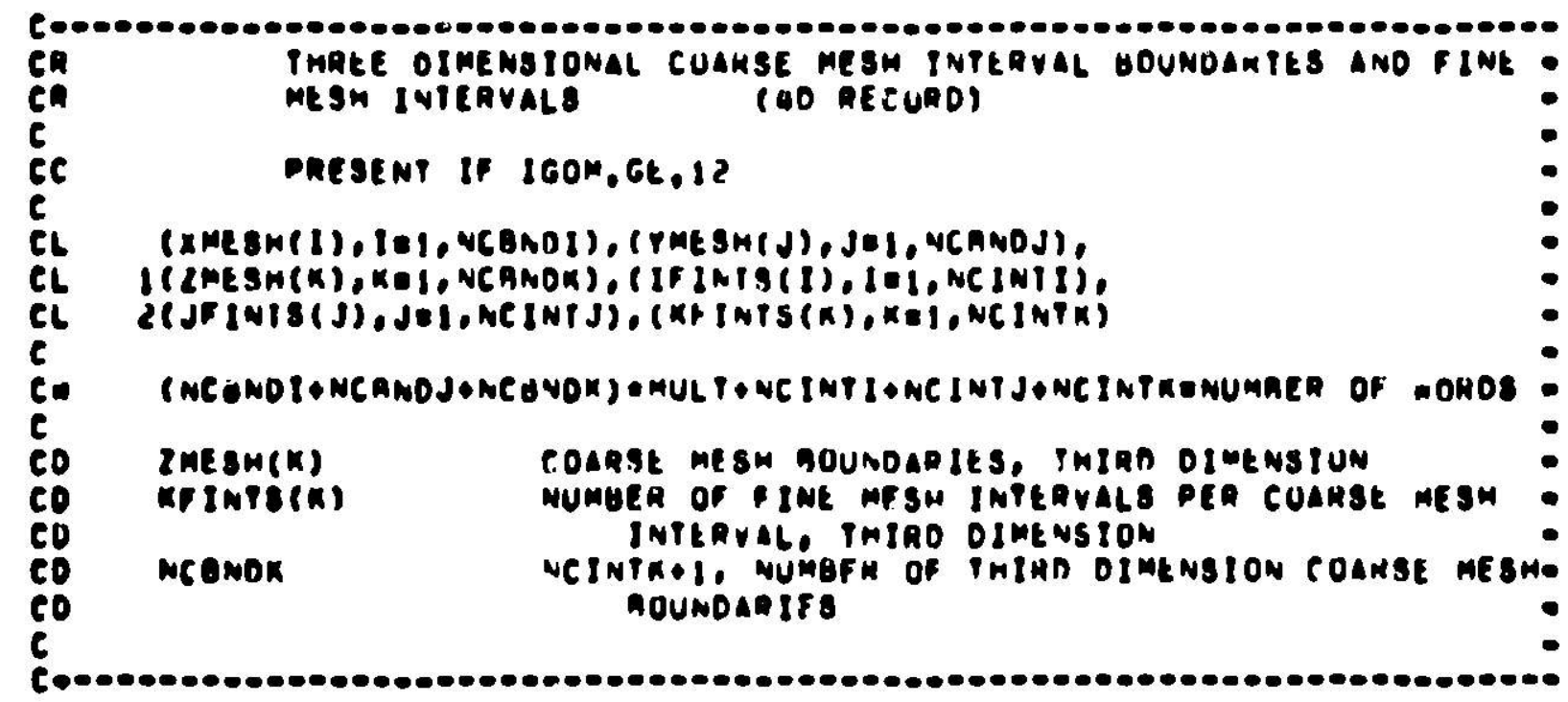

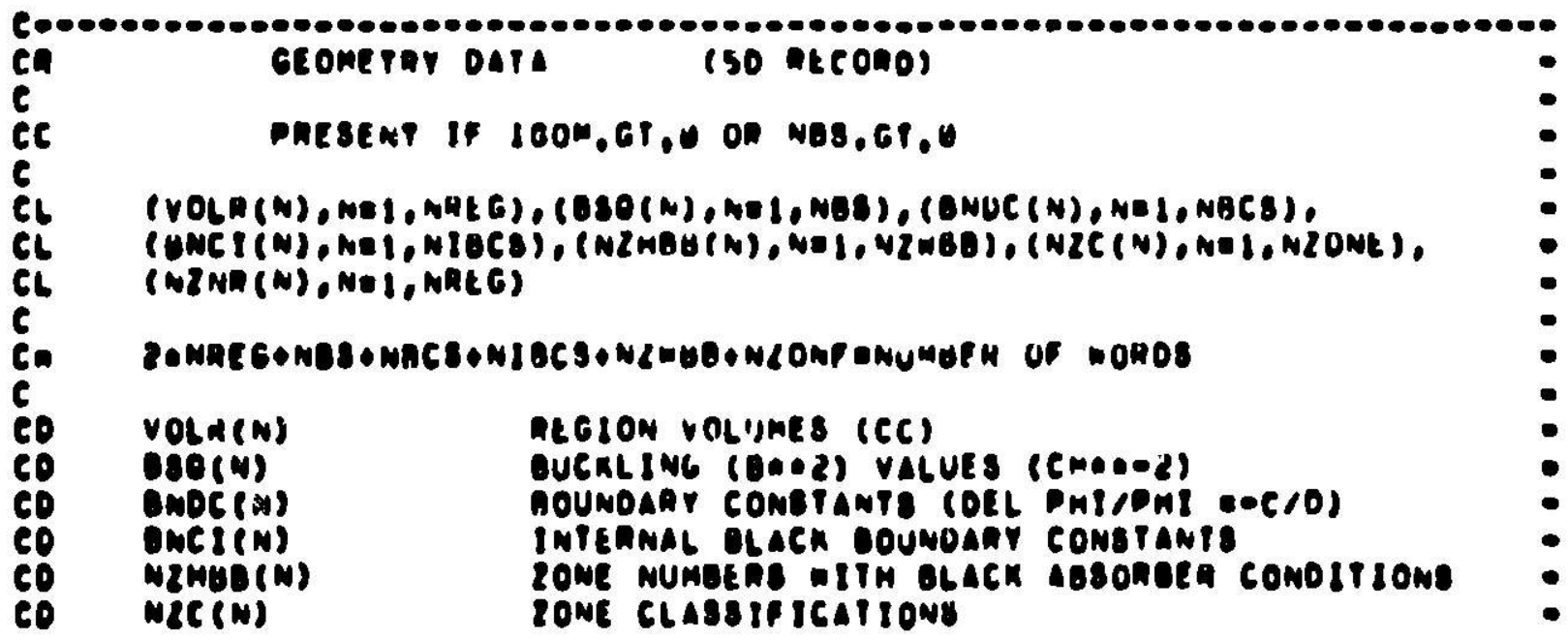


NPINIIIX I. (CCC Version III Stardard Interface Files. GEODST (Contd.) CO NZNH(N) ZONE NUMAEA ISSIGNED IO EACN REGION C

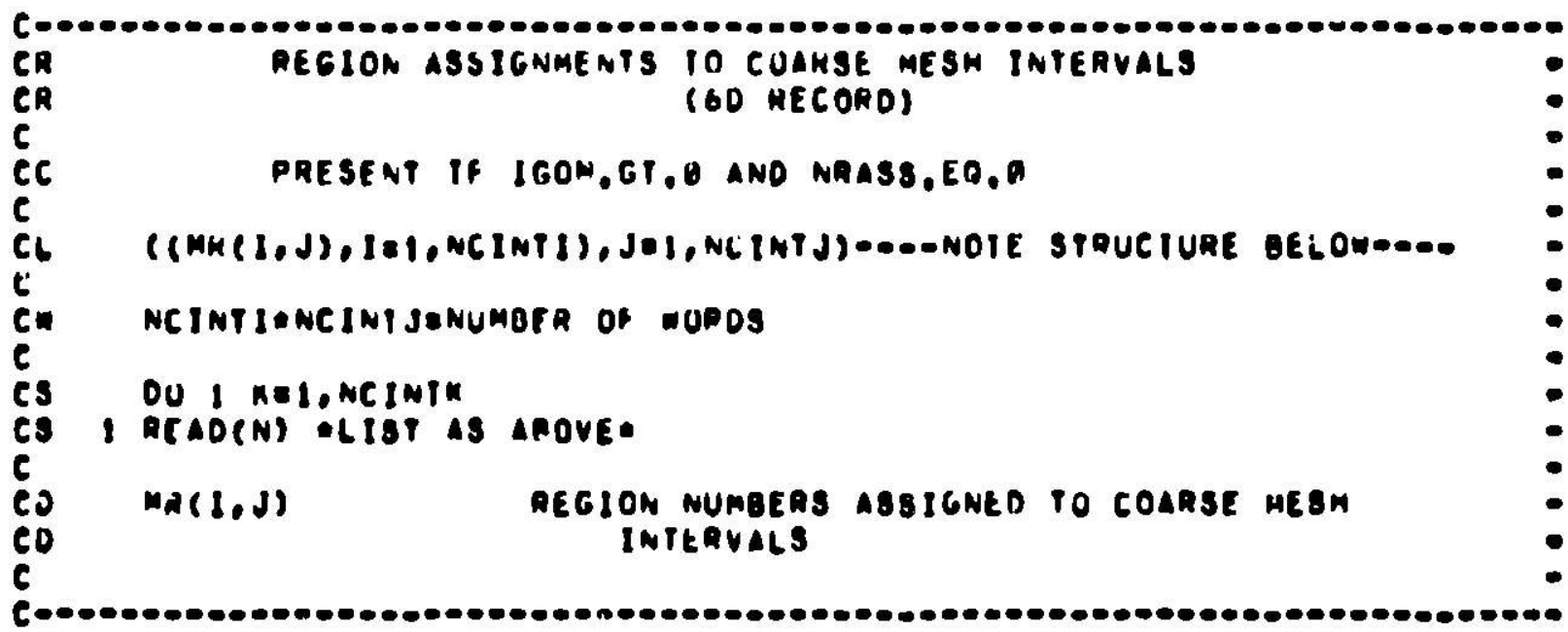


APPLNIIX I. CCCC Version III Standard Interface files. ISOYXS

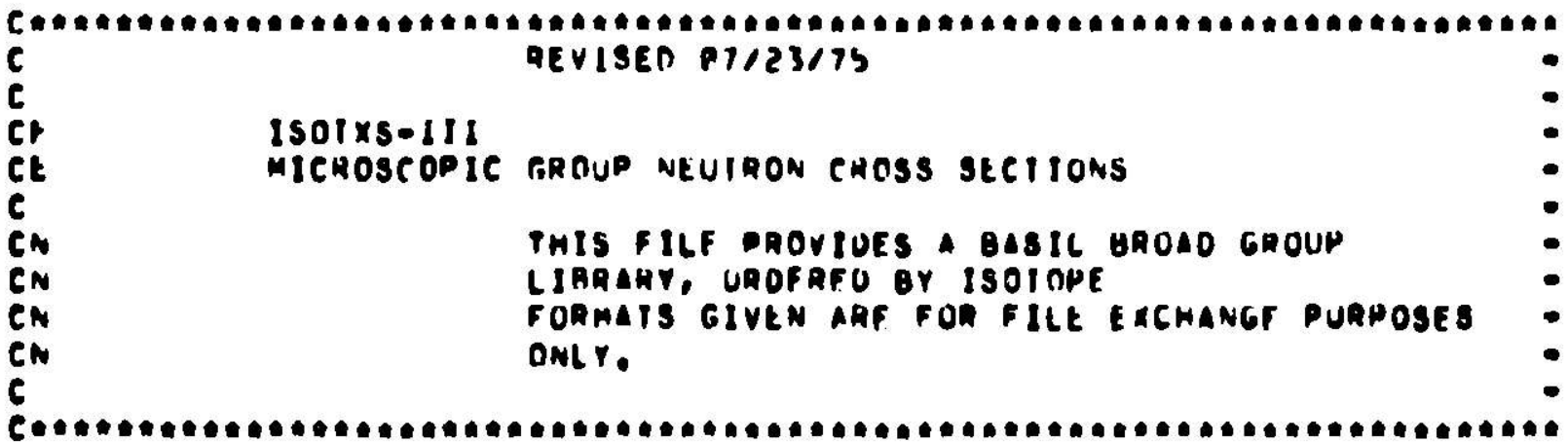

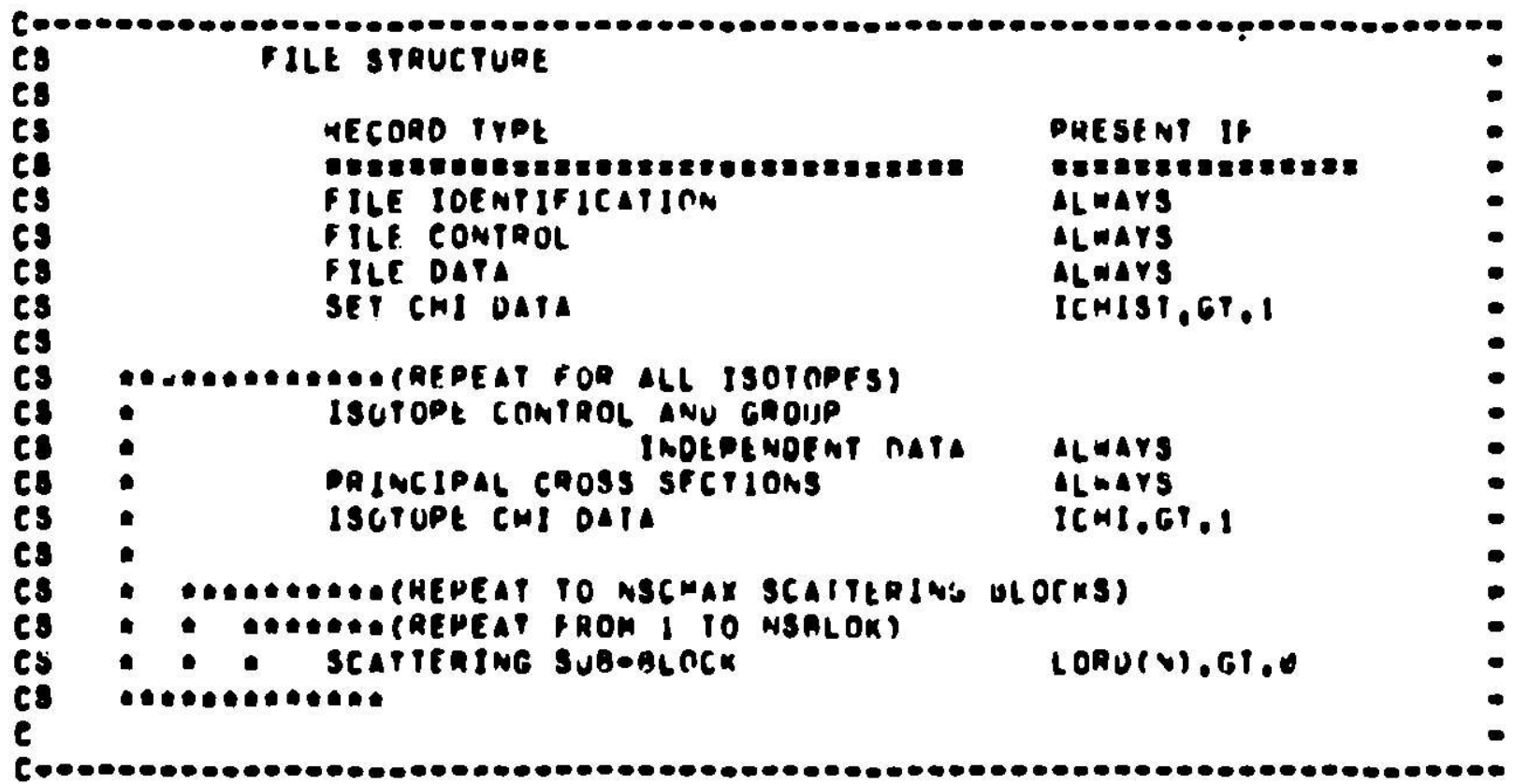

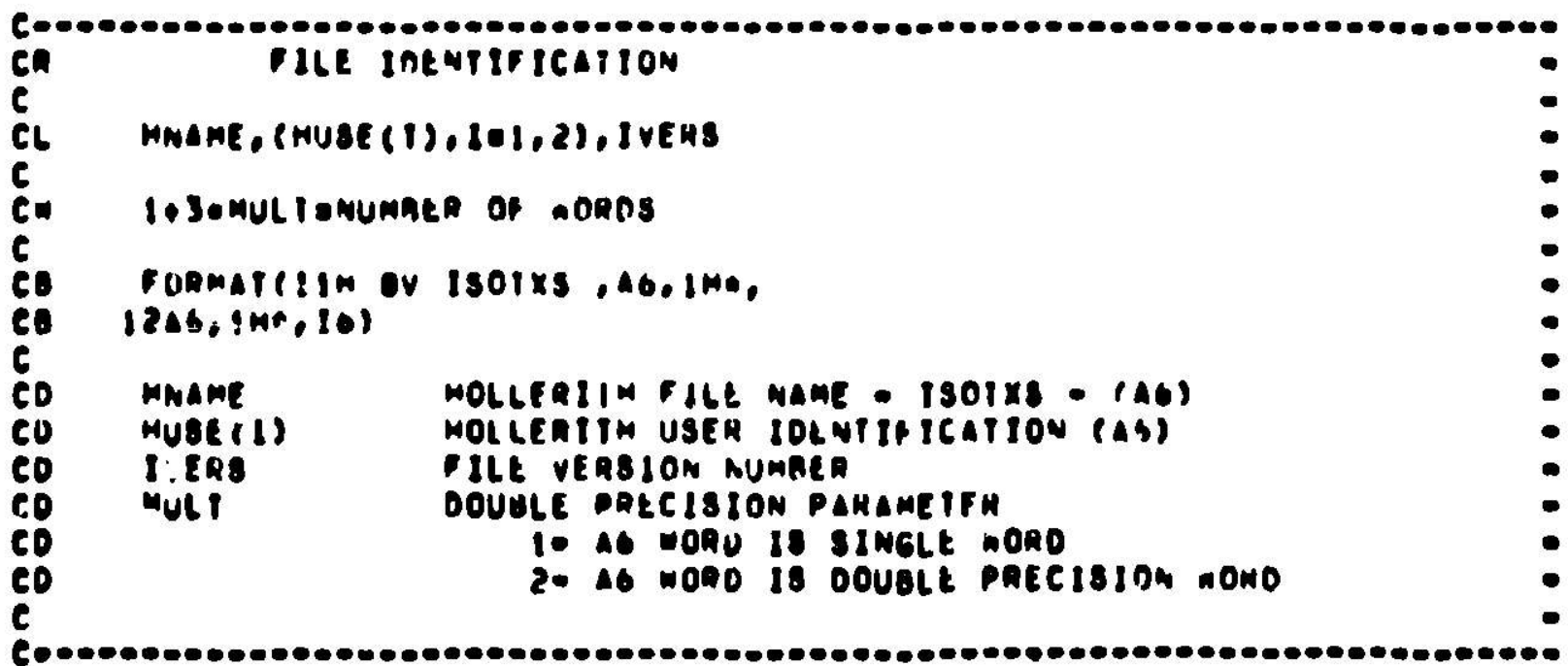


NPLEIIIX 1. CCCC Version III Standard Interface Files. ISOTXS (Conti.)

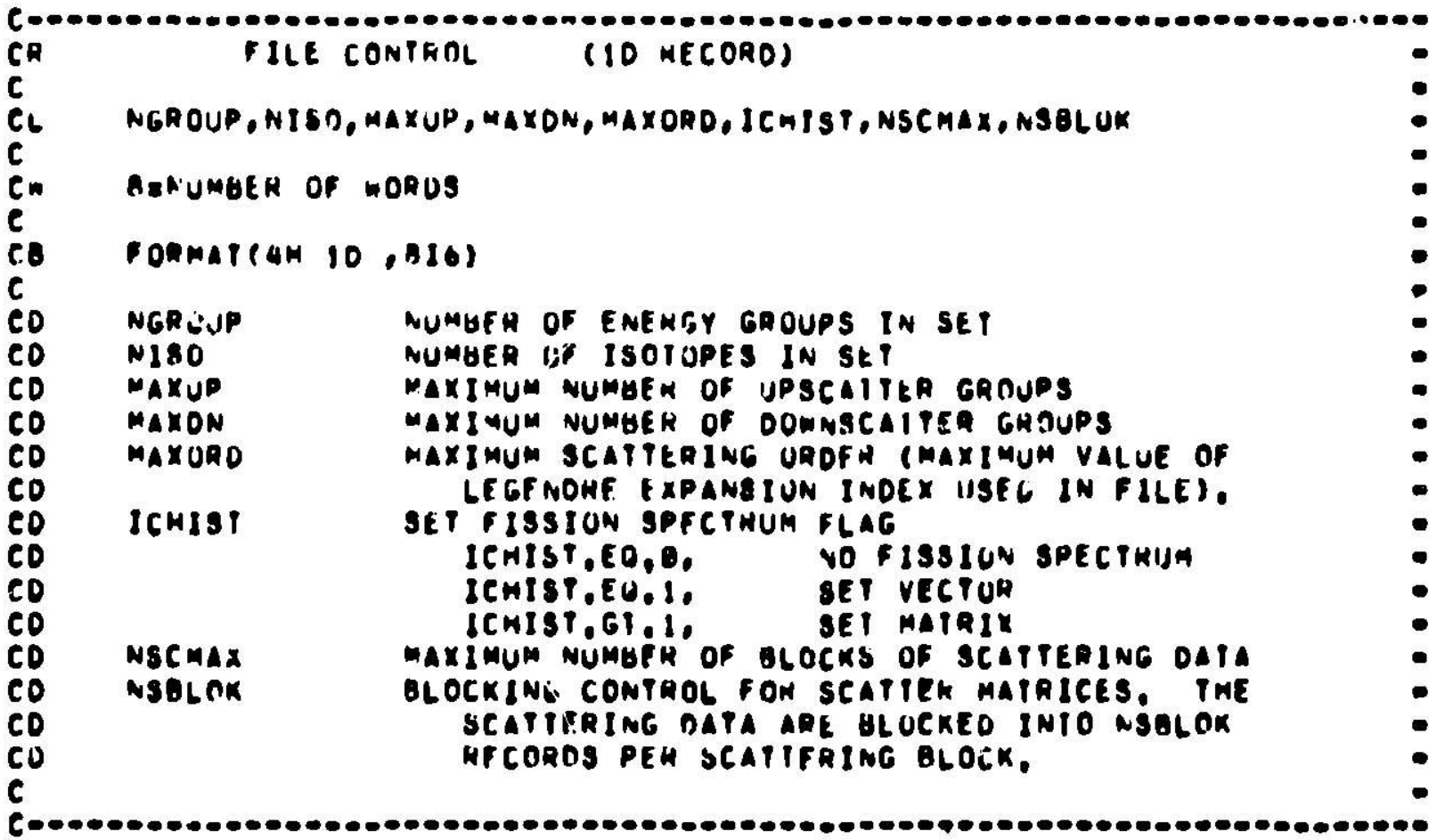

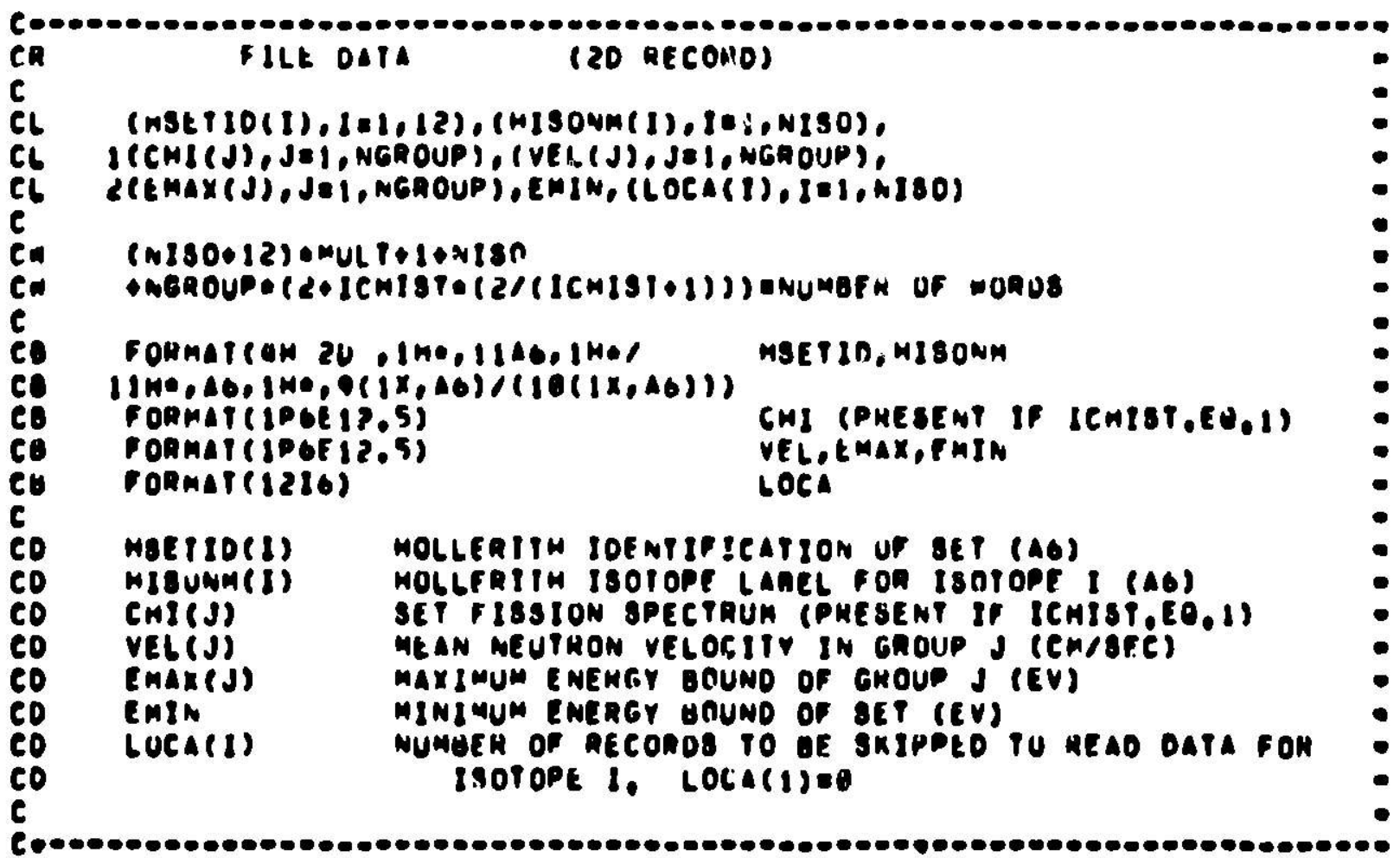


APPENDIX 1. CCCC Version III Standard Interface Files. 1.xylXs (Contu.)

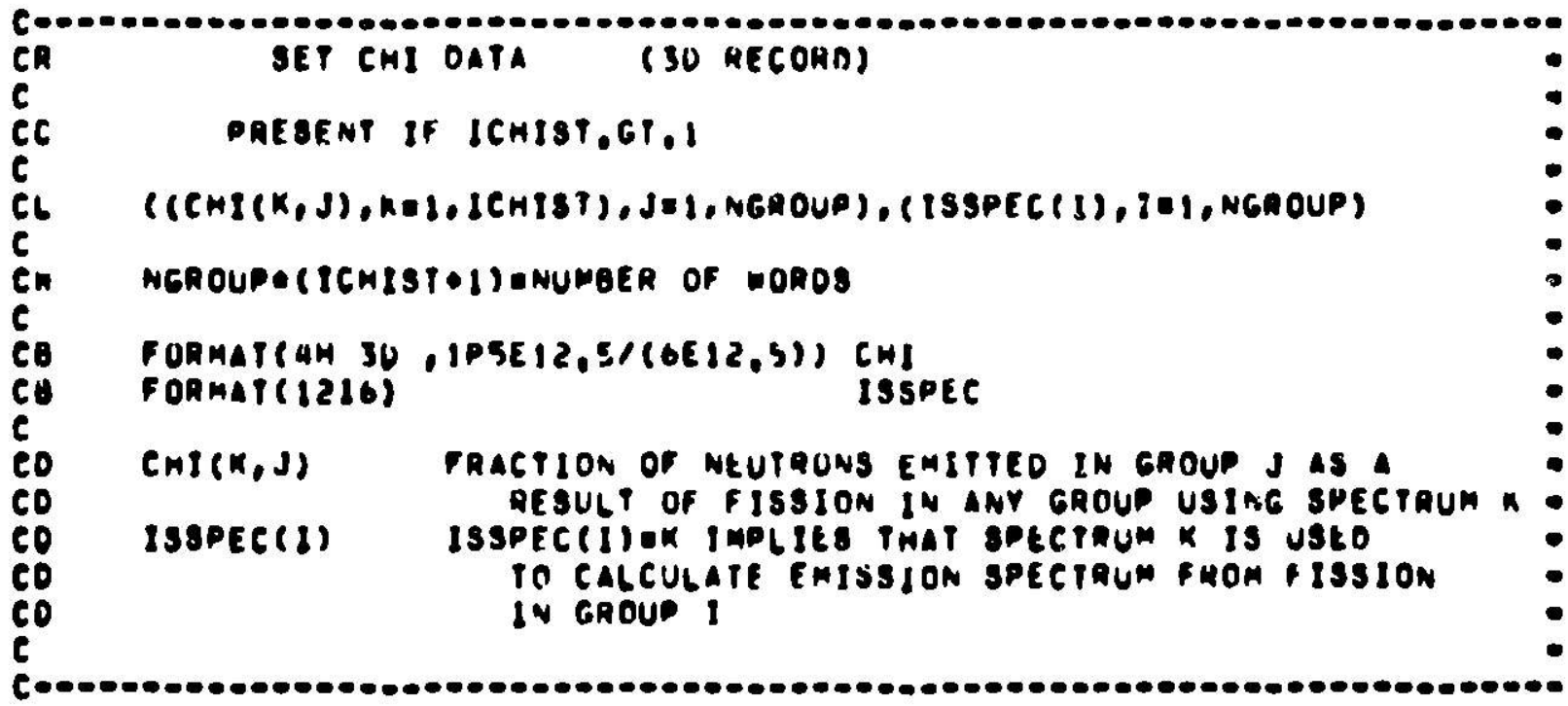

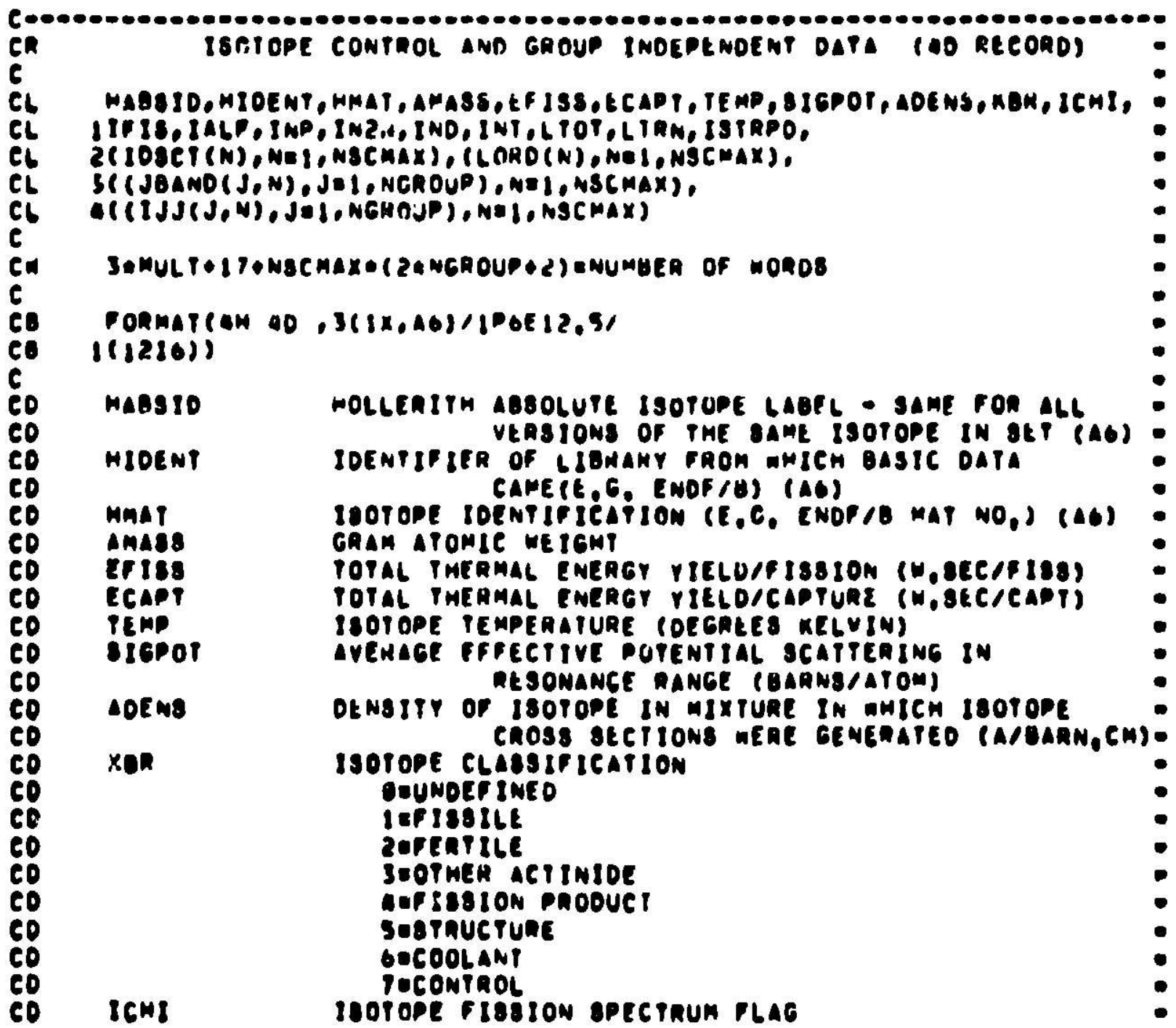




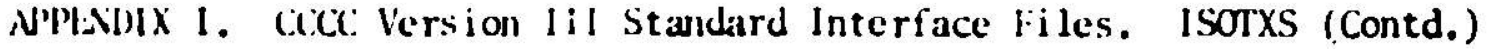

CD

CO

CO

CD

CO

CD

CD

CO

CD

Co

CO

co

Co

CD

Co

Co

CO

Co

Co

CO

CO

Co

CO

60

Co

CO

CO

Co

CO

CD

CO

CD

CD

CO

Co

CD

Co

cu

CO

60

co

CO

Co

Co

CD

CO

Co

CO
If 15

Iat?

INP

IN2N

INO

IN

t101

LPA

ISTAPO

IOSCP(N)

LORO(N)

JOANO(J,N)

IJJ $(J, N)$
ICNI,EO,G, USE SET CHI

ICMI.EO.1, ISOTOPE CHI VECPOQ

ICNI.GT.I. ISOTOPE CMI MAIRIX

(N,F) CROSS SECTIUN LAG

IF ISEA. NO FISSION DATA IN PHINCIPAL CROSS SECTION RECORD

-1. HISSION DATA PRESENT IN PAINCIPAL CROSS SFETION RECORD

IN, ALDA: : CROSS SECTION FLAG

IME COPIONS AS IFIS

(N,P) inOSS SECTION FLAG SAME OPII' MS IS IFI3

(N.ZN) CAJBS SELTION FLAG

SAME OPTIONS AS IF IS

$(N, 0)$ CAOSS SECTION FLAG SAME OPIIONS AS IF IS

(N.I) CROSS SECTION RLAG SAME OPIIONS AS IFIS

WUMBER OF MOMENTS OF IRIAL CROSS SECTION PAOVIDEO IN PAINCIPAL CROSS SECTIONS AECORO

NUMAEA OF HOMENTS OF PAANSPUAT CROSS SECTION PROVIOZO IN DAINCIPAL CAOSS SECTIONS RECORO

NUMGER OF COCRDINATE DINECTIONS FOR WHICH COOROINATE DEPENDE VT PRAMSPORT CROSS BECTIONS IRE GIVEN. IF ISTRPABE, NO COOROINATE DEPENDENT TAAMSPORI CAUSS SECTIONS ARE GIVEN.

SCATTERING MATRIX TYPE IDENIIHICABION FOR

SCATIEKING BLOCK N. SIGNIPICANT ONLY IF LORO(N), GI,

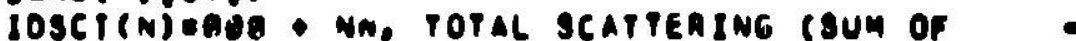
CLASIIC, INELASTIC, ANO No 2N SCATIERING) - IU0 - NN. ELASTIC SCAITERING -zUP - NA, INELASTIC SChTTERING -3Ua - NN, (N.2N) SCATIERING PER EAITTEDo nEUTRON, MHERE NM IS THE LEGENOAE EXPANBION INDEX OF THE Piasi mataix in block n

NUMUER OF SCAITEAING OADERS IN BLOEN $N$. IF

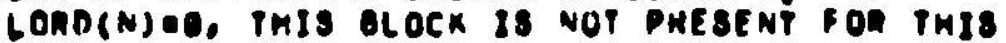
I8OTOPE, IF NN 18 THE VALUE TAKEN FROM IOSETPN). THEN TME MATRICES IN THIS BLOCK MAYE LEGENOAE EXPANSION INOICFS OF NM, NWHI, NY $2, \ldots . . N N A L O R D(N)-1$

sCATPERING BANOWIOTH FOR GROUP J. BCATPEAINE olock N

posifion of inoghoup seatienine cross section in SCATIERING DATA GOR GROUP J. BCAPTEAIMG BLOCK n. COUNTEO FRON THE FIRST WORO OF GROUP J OATA. 
APPENDIX I. CCCC Version III Standard Interface liiles. ISOIXS (Contd.)

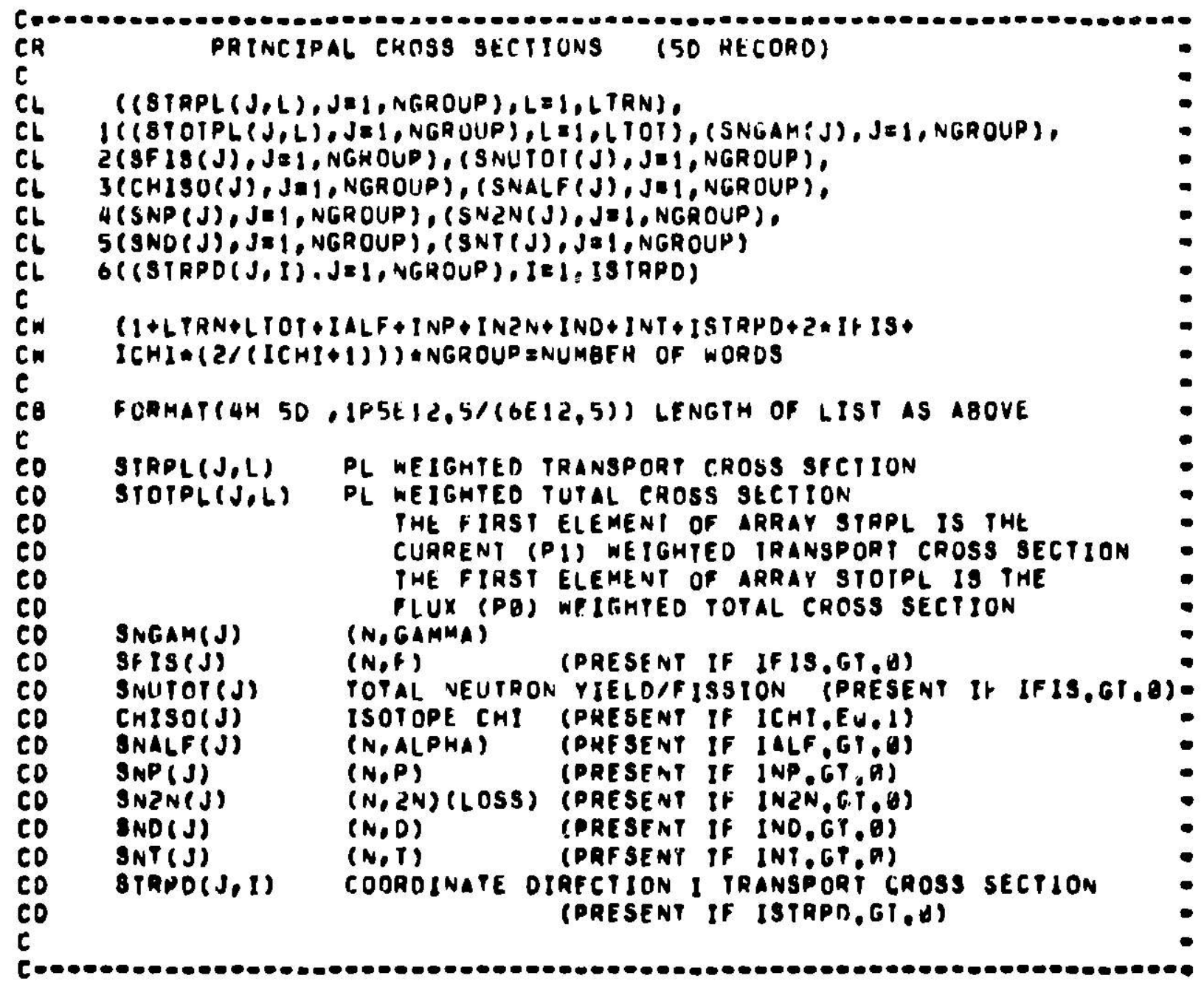

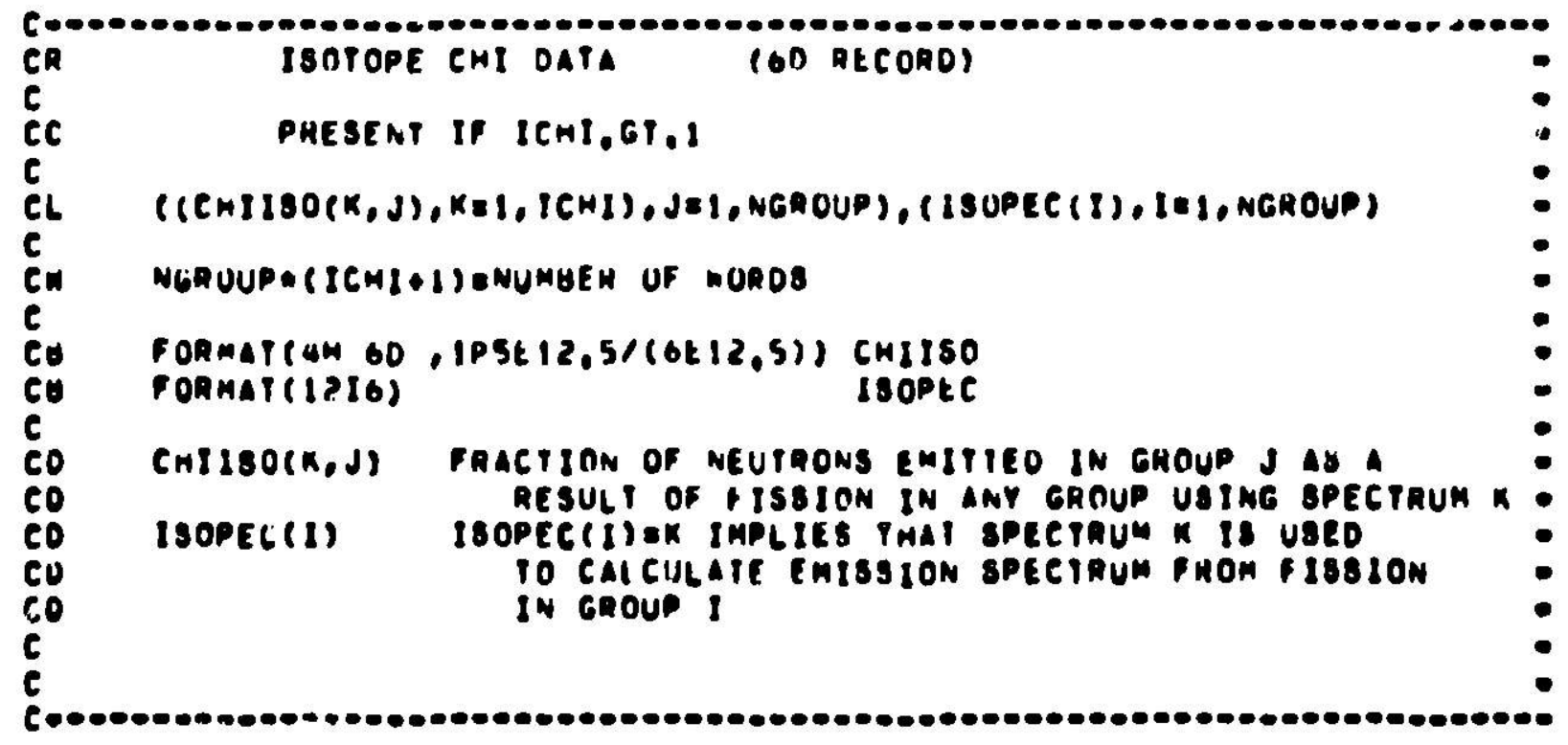


APPENDIX I. CCCC Version III Standard Interface Files. ISOTXS (Contd.)

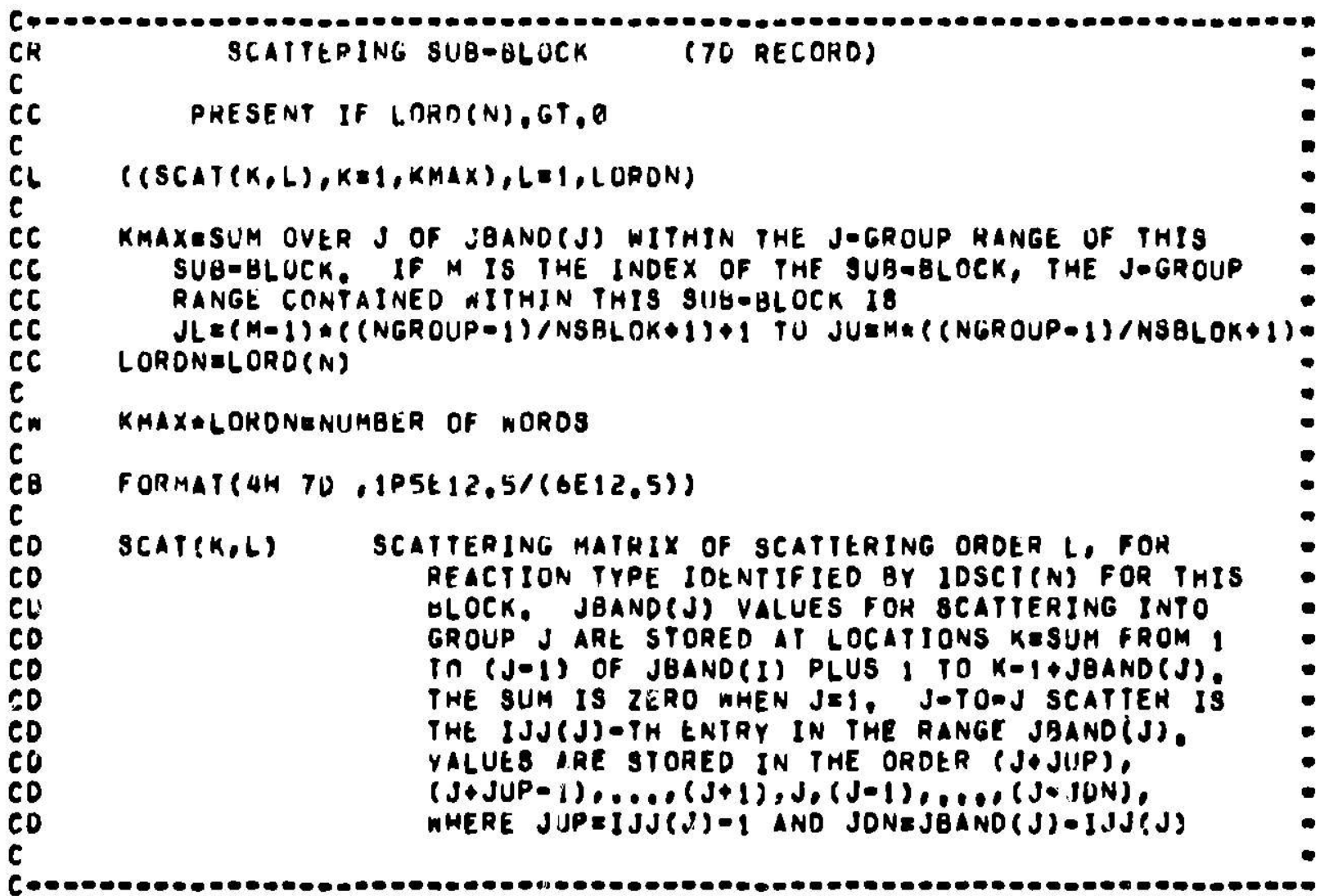


APPENDIX I. CCCC Version III Standard Interface Files. :JDXSRF

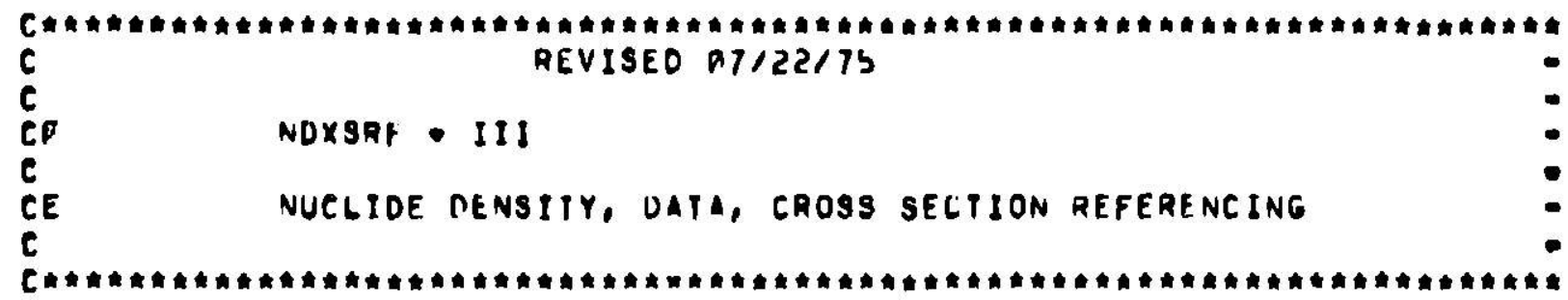

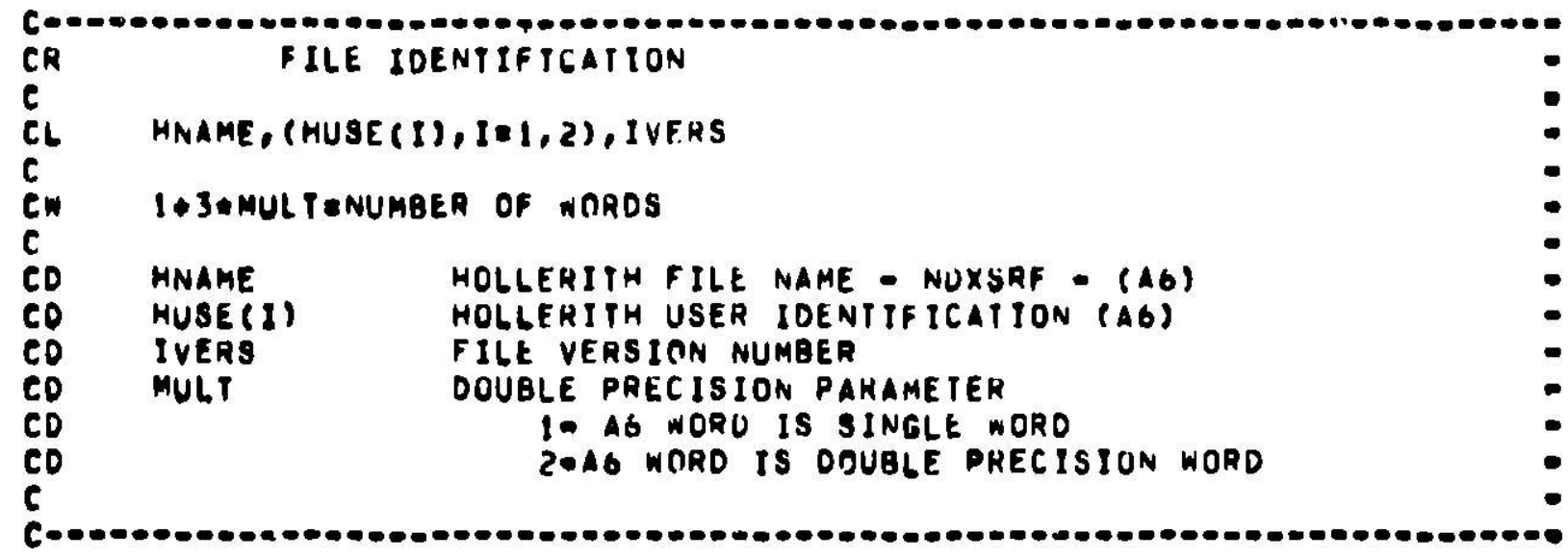

CR
$C L$
$C$ NON,NSN,NNS, NAN, NZONF,NSZ

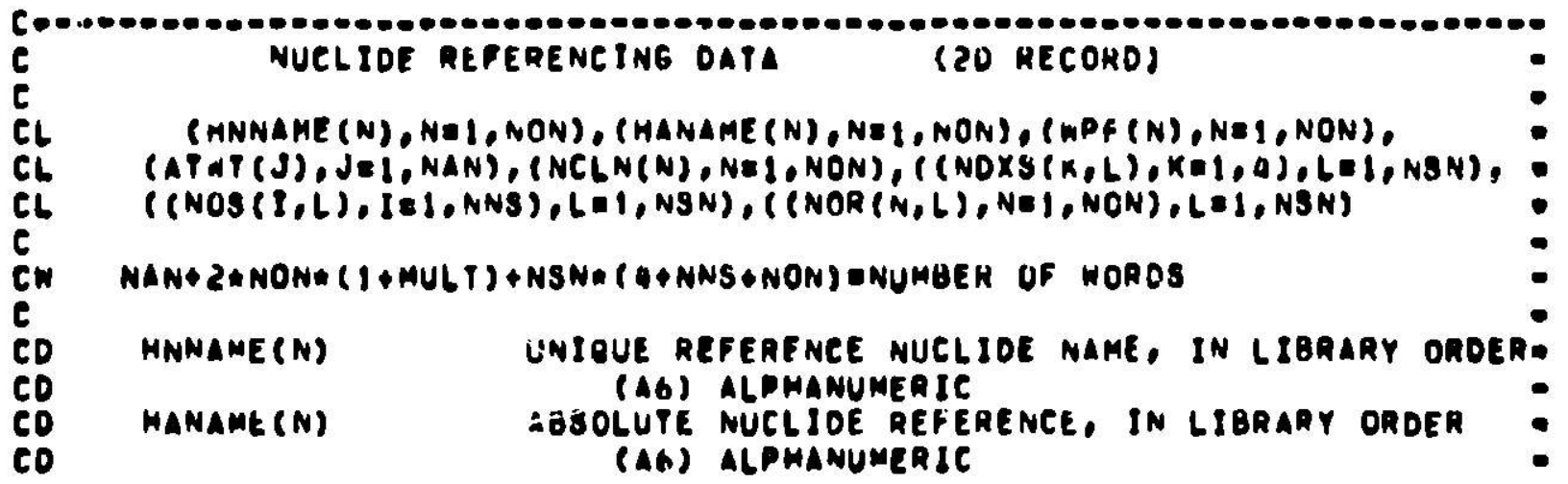


APPENiIX I. CCCC Version III Standard Interface Files. NDXSRF (Contd.)

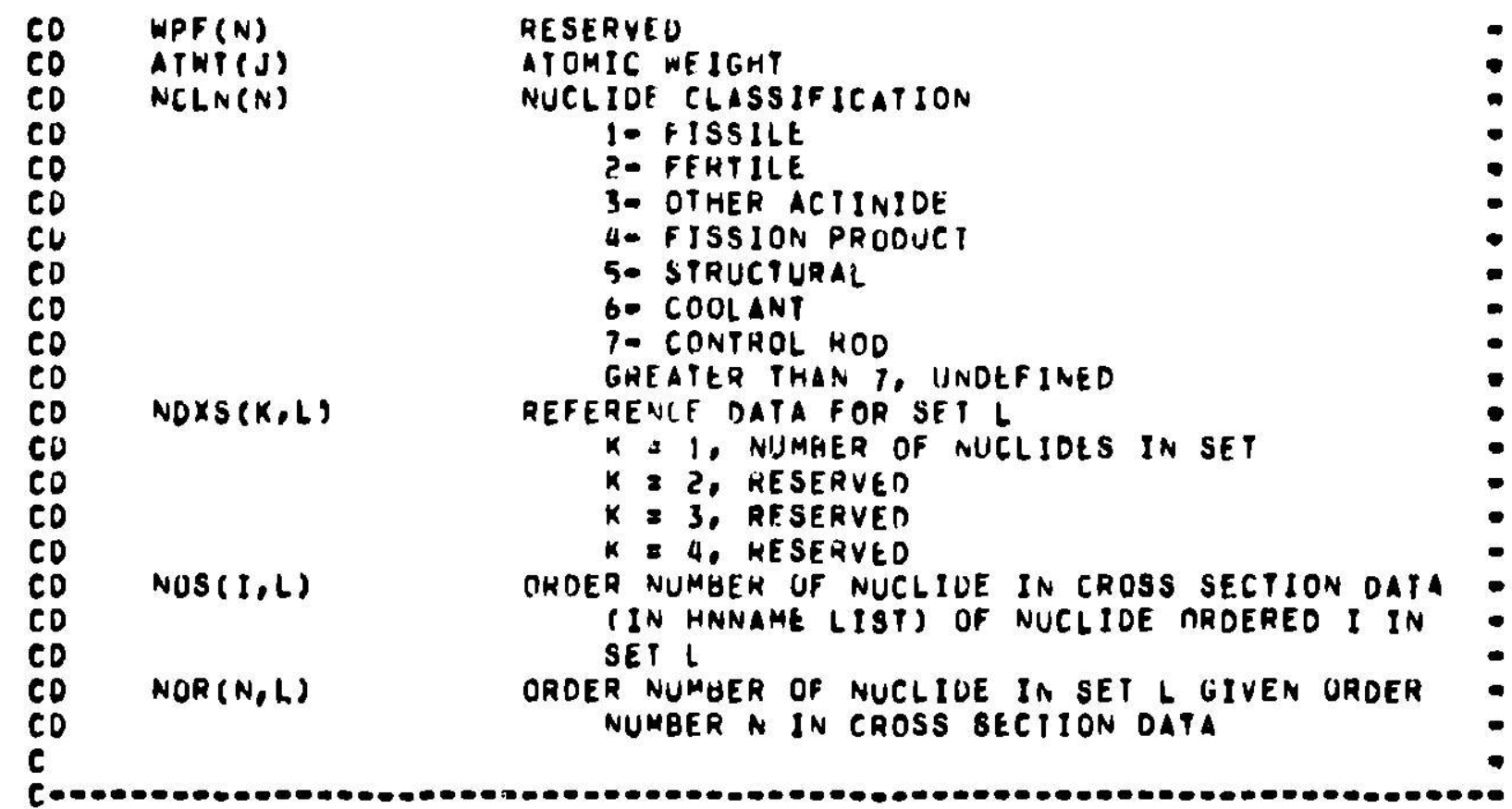

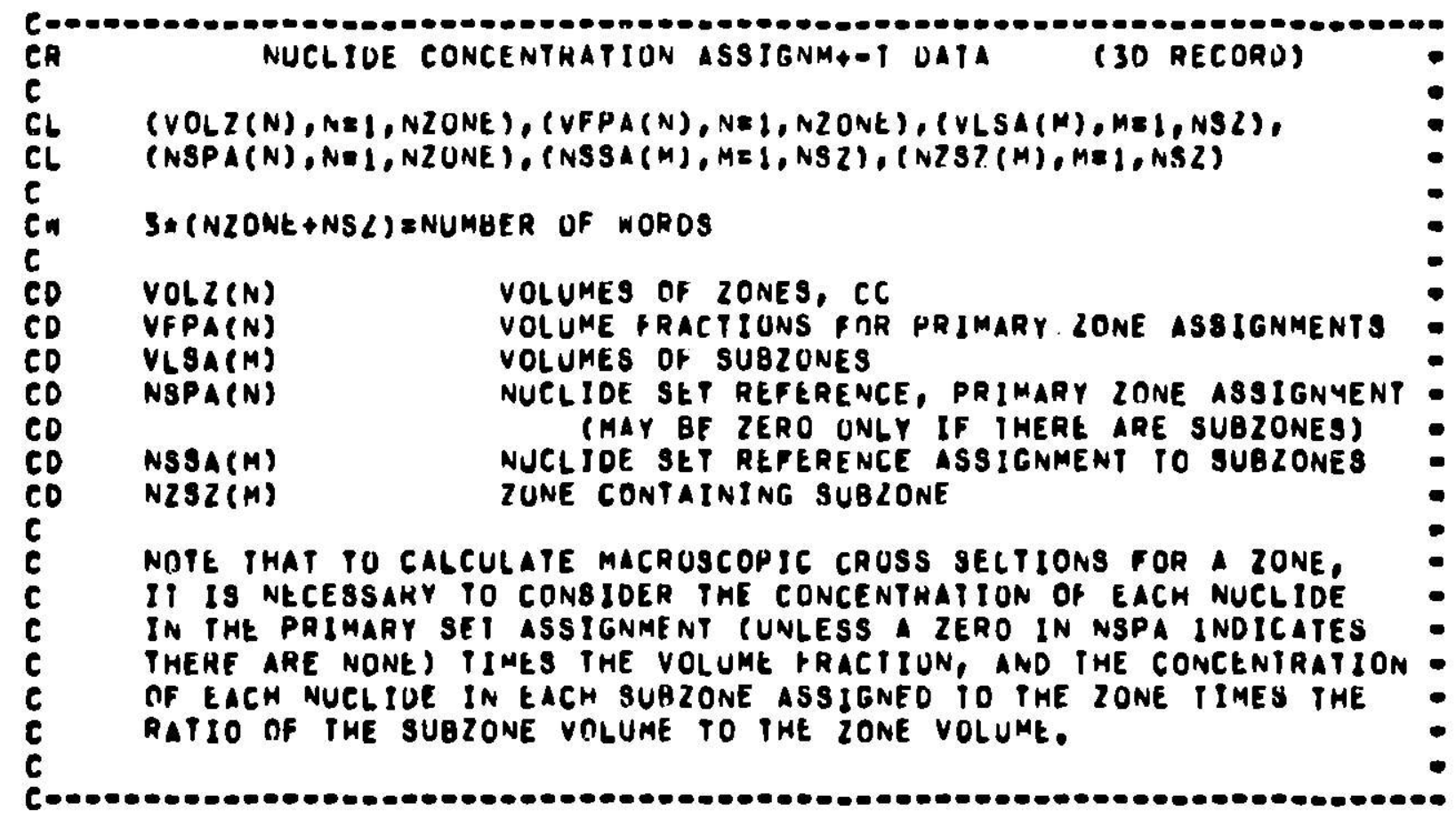


APPENDIX 1. CCCC Version III Standard Interface Files. ZNATDN

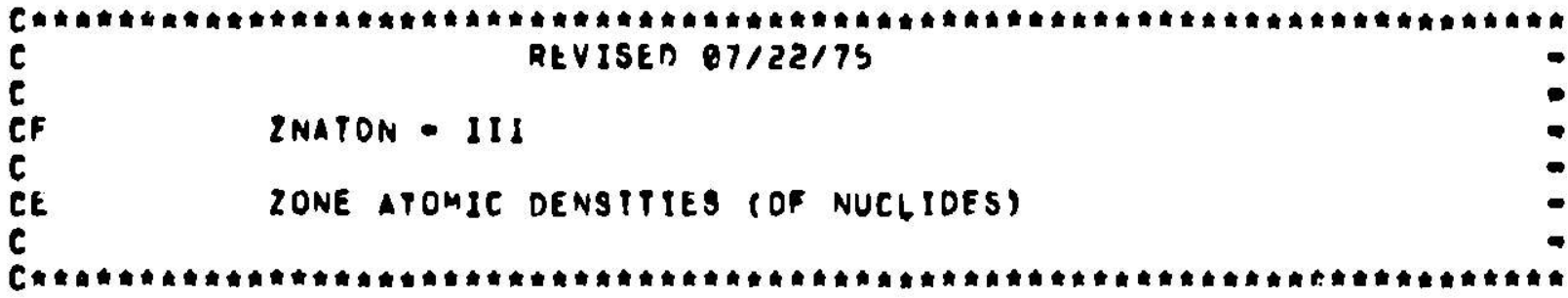

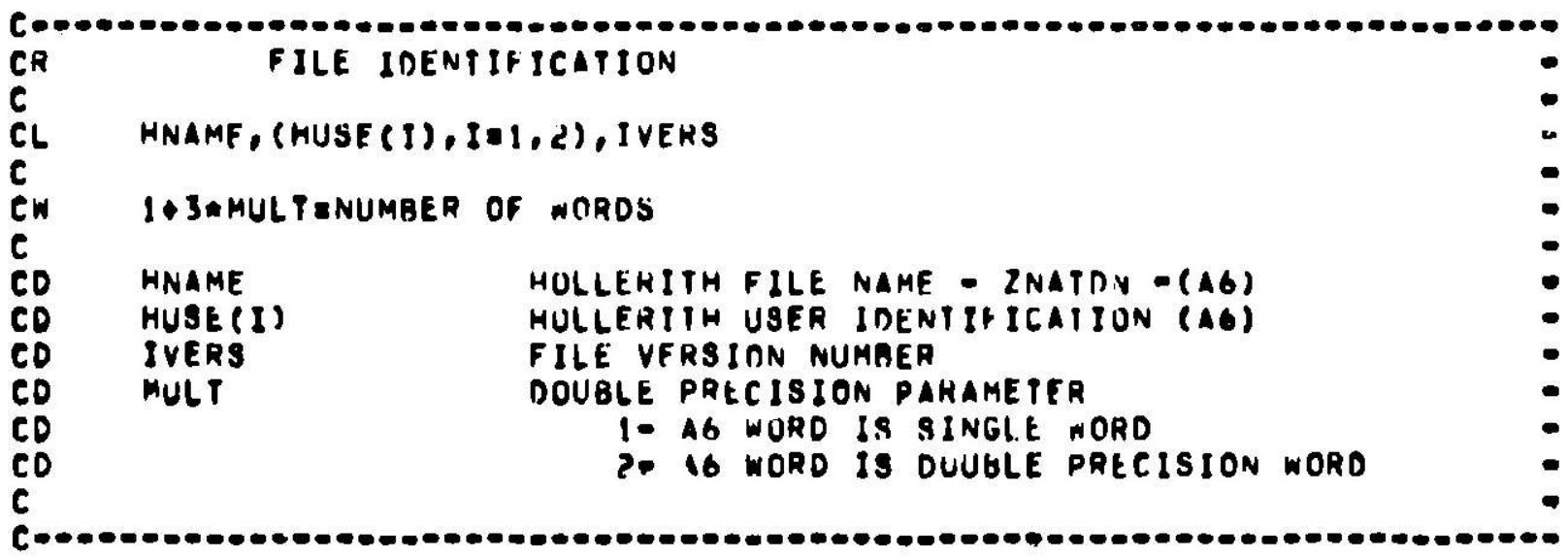

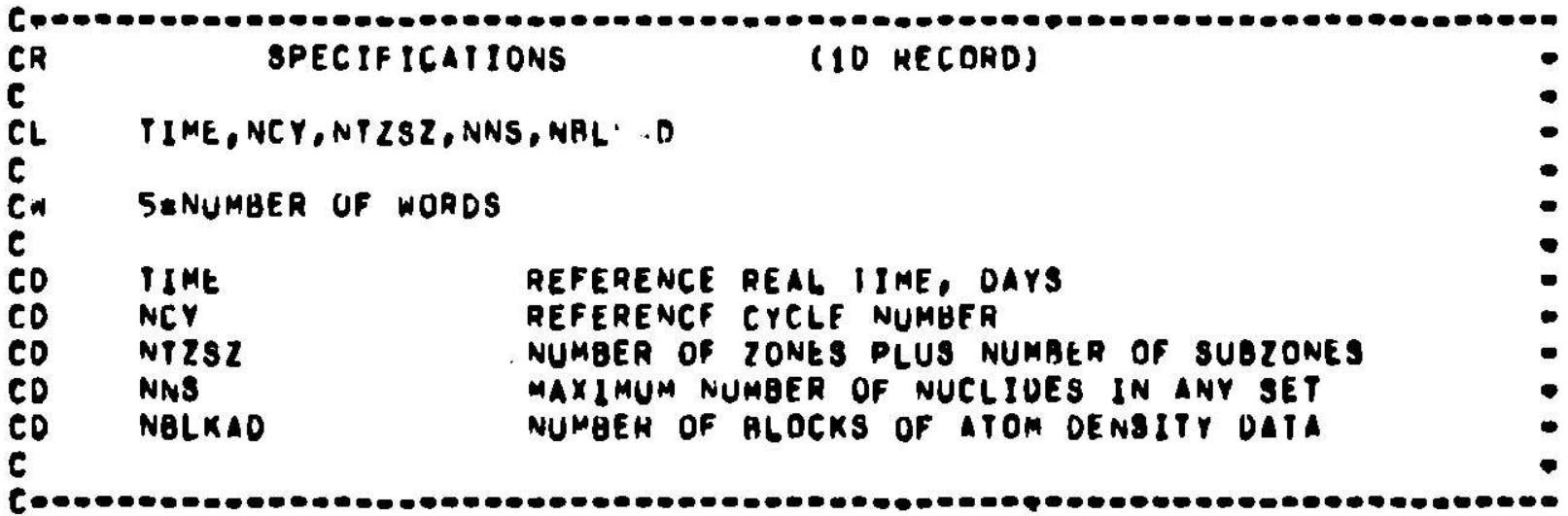

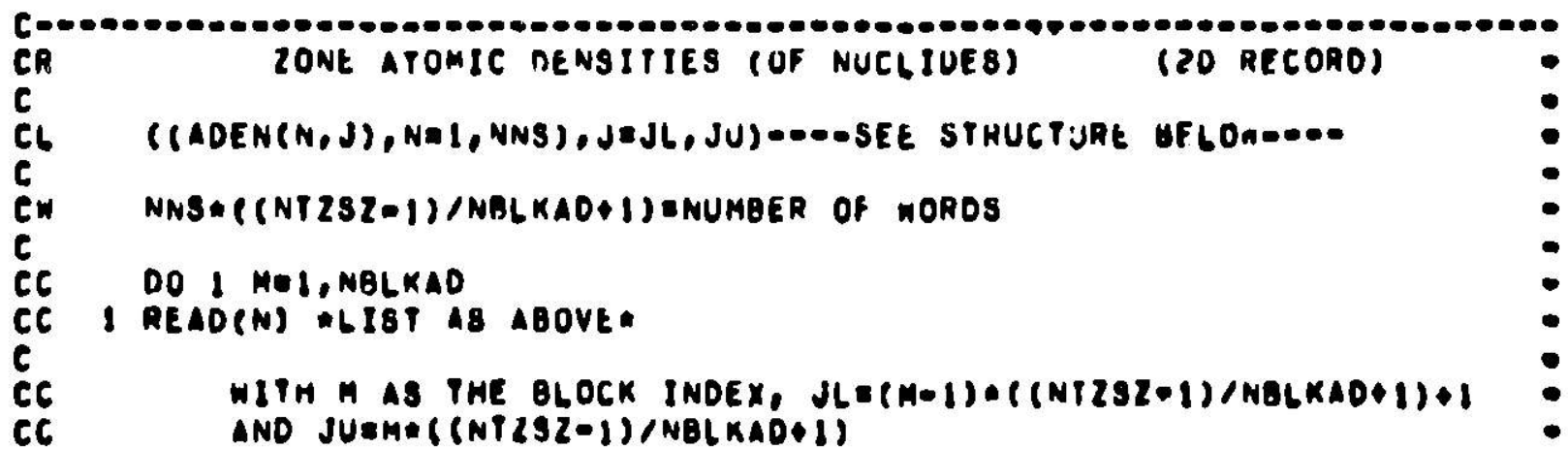


APPLNDIX I. CCCC Version III Standard Interface Files. ZNATDN (Contd.)

C

CO $A D E N(N, J)$

CD

CD

TOMIC DFNSITY OF NUCLIDE ORDEAED N IN THE ISSOCIATEO SFT GIVEN IN ORDER FUR FACN LONE FOLLONEU IN ONDEA FOR FACM SUBzONE 
APPENDIX I. CCCC Version III Standard Interface Files. RTFLUX

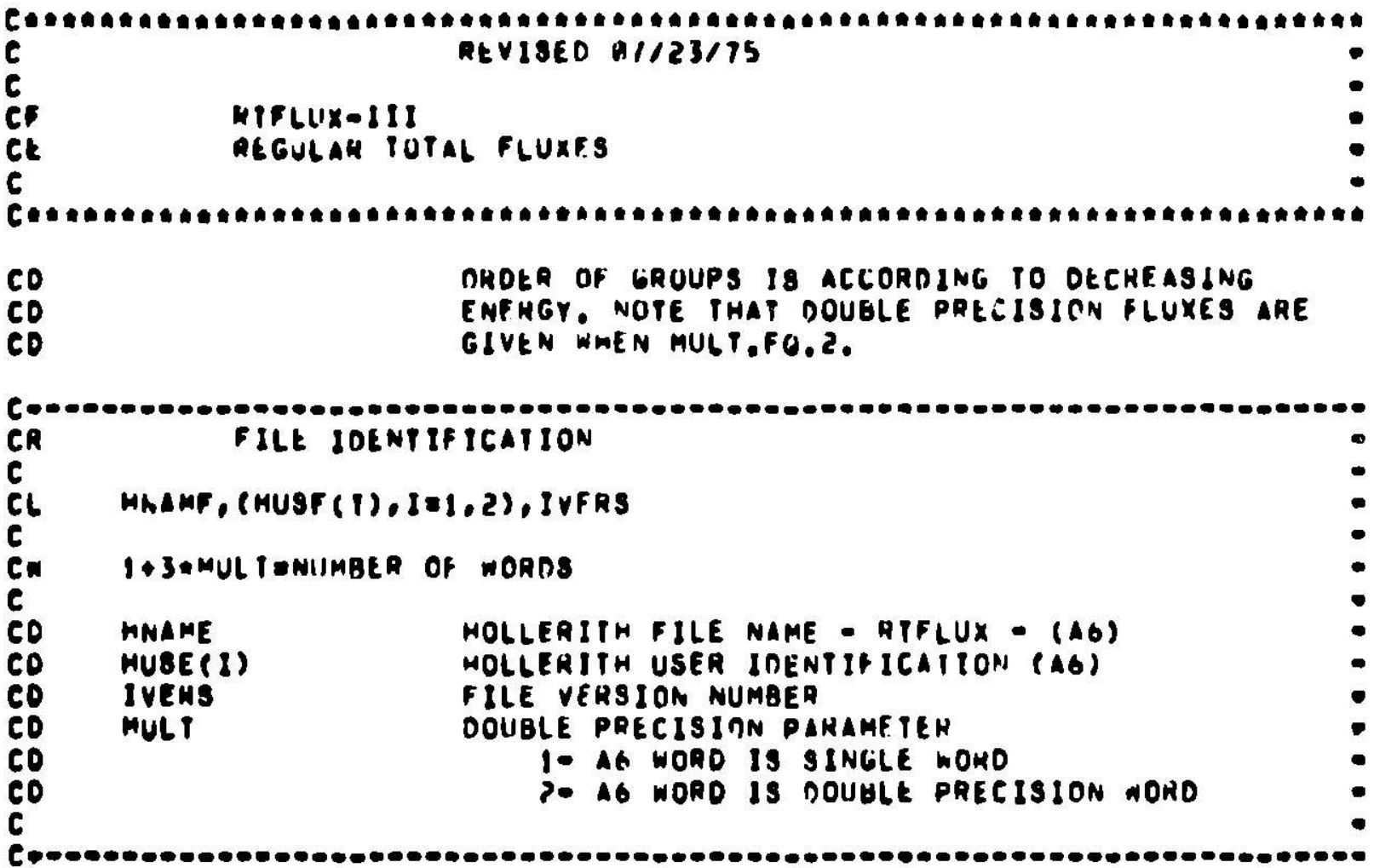

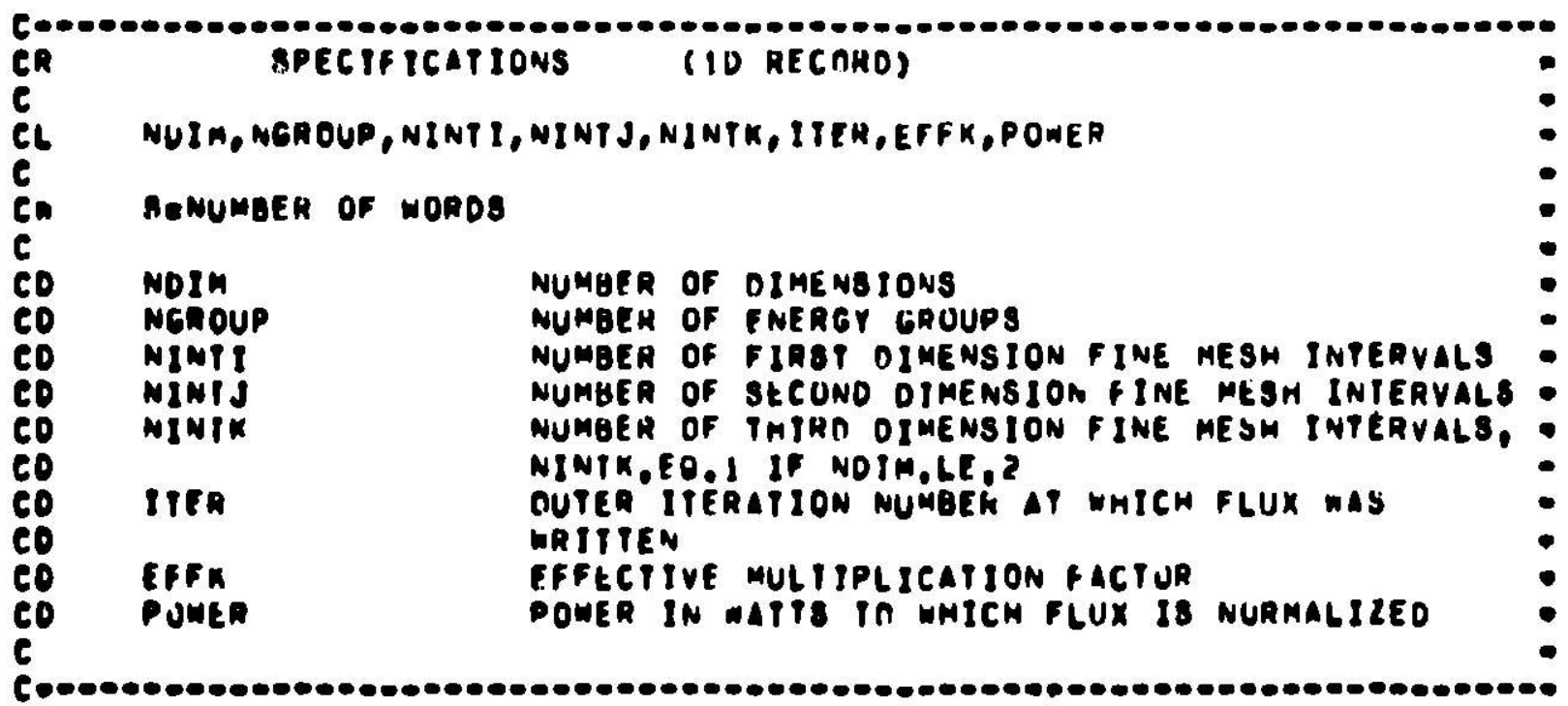

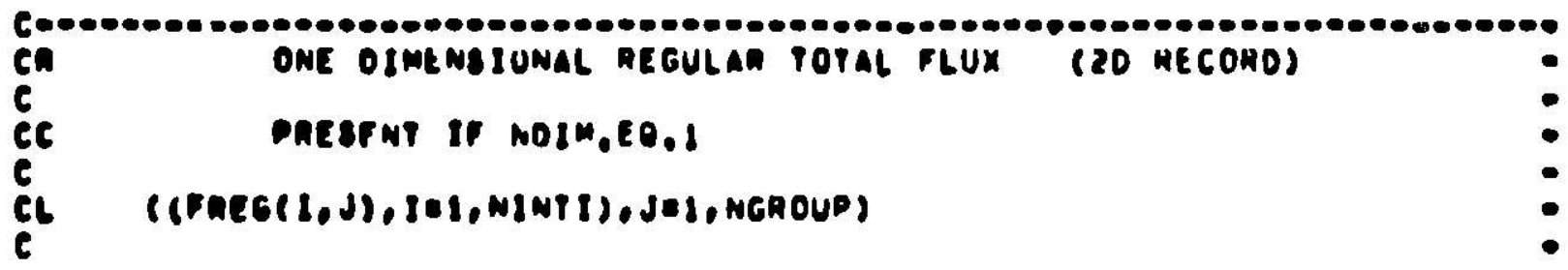


APPENDIX I. CCCC Version III Standard Interface Files. RTFLLX (Contd.)
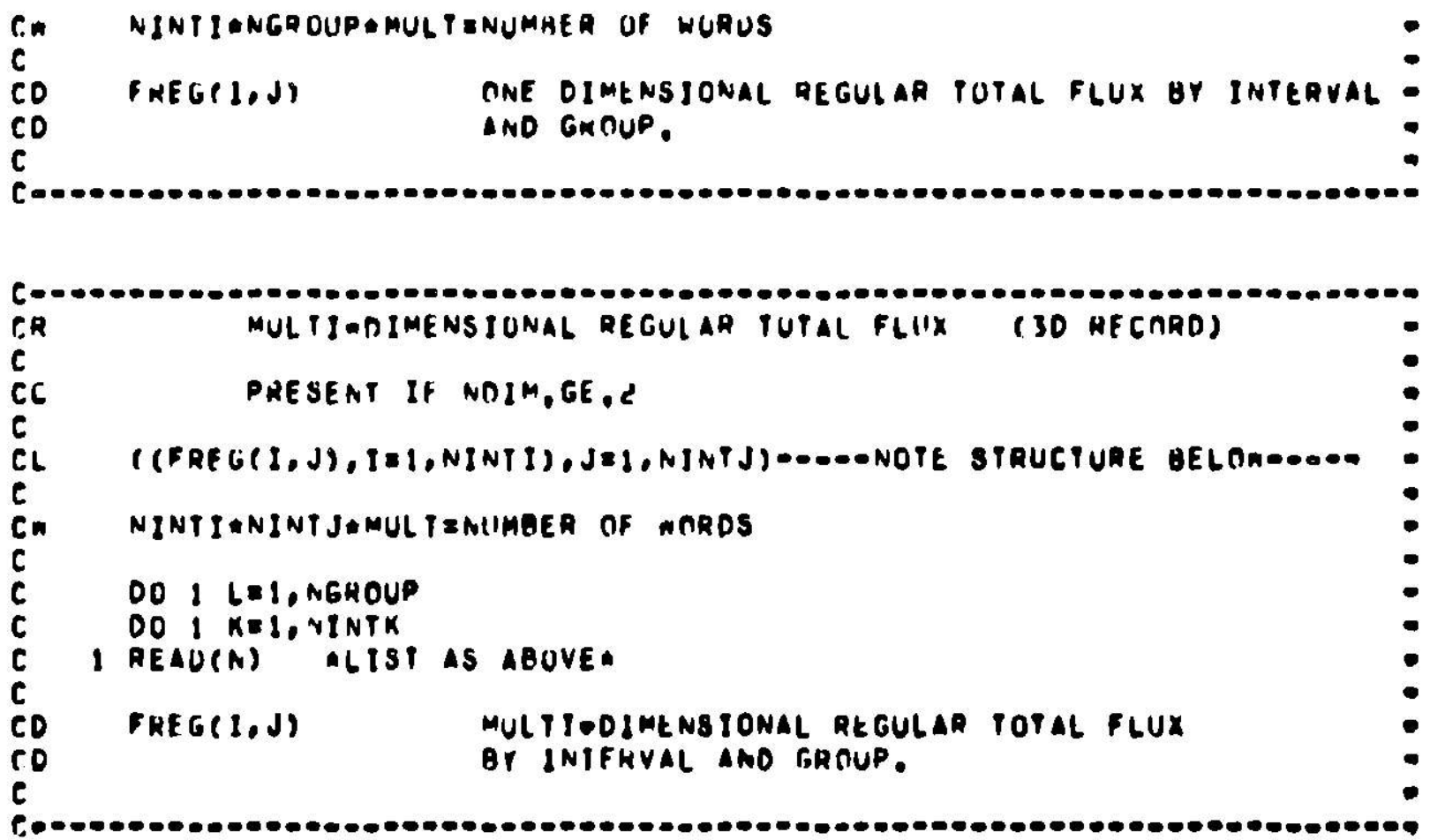
APPENDIX I. CCCC Version III Standard Interface Files. ATrLLX

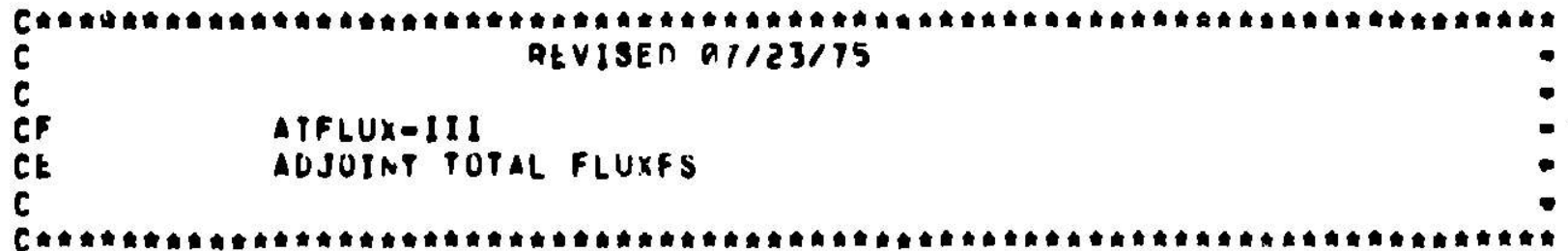

$\begin{array}{ll}\text { CO } & \text { DRDER OH GROUPS IS ACCORDING IO INCHFASING } \\ \text { CO } & \text { FNEKGY. NOTE IMAT DOUGLE PALCISION FLUXES AHE } \\ \text { CD } & \text { GIVEN WHEN MULP FO }\end{array}$

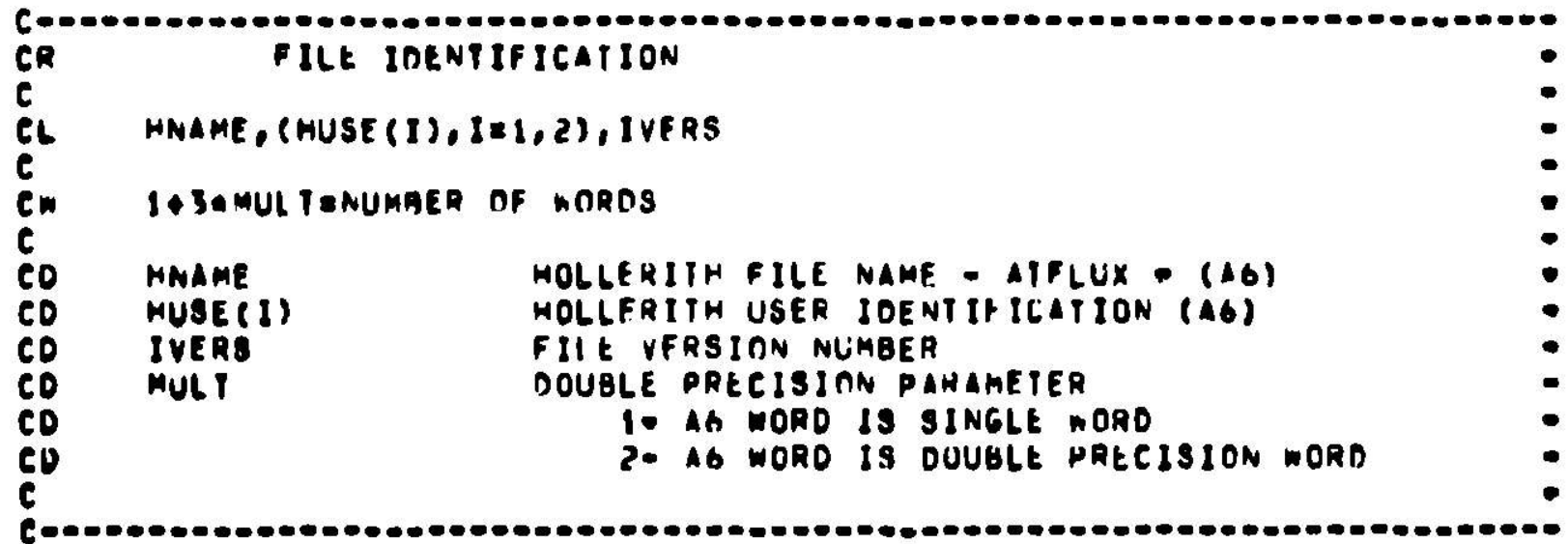

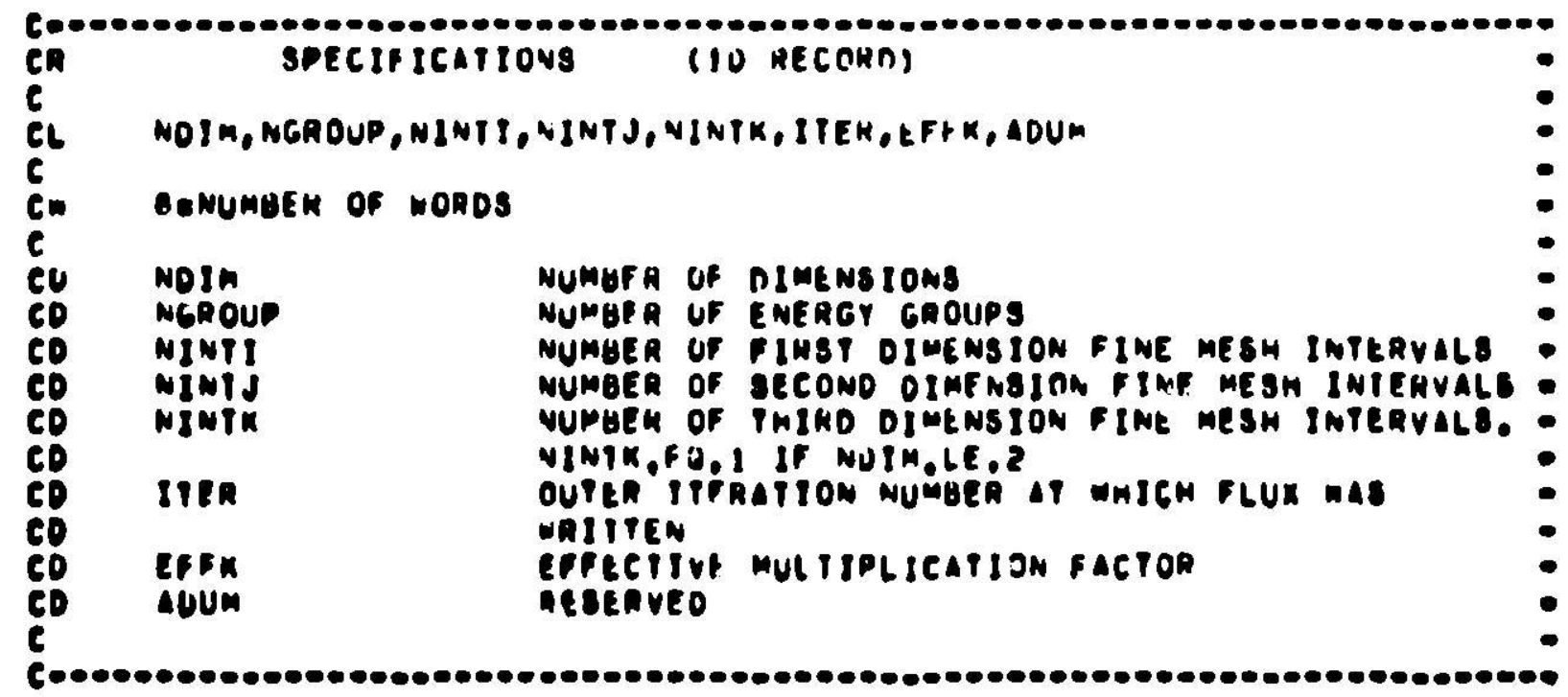

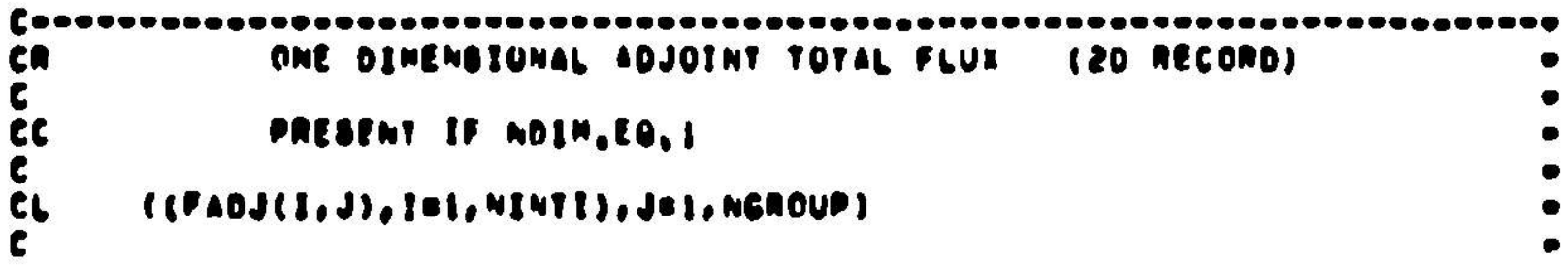


APPENDIX 1. CCCC Version III Standard Interface Files. ATFLUX (Contd.)
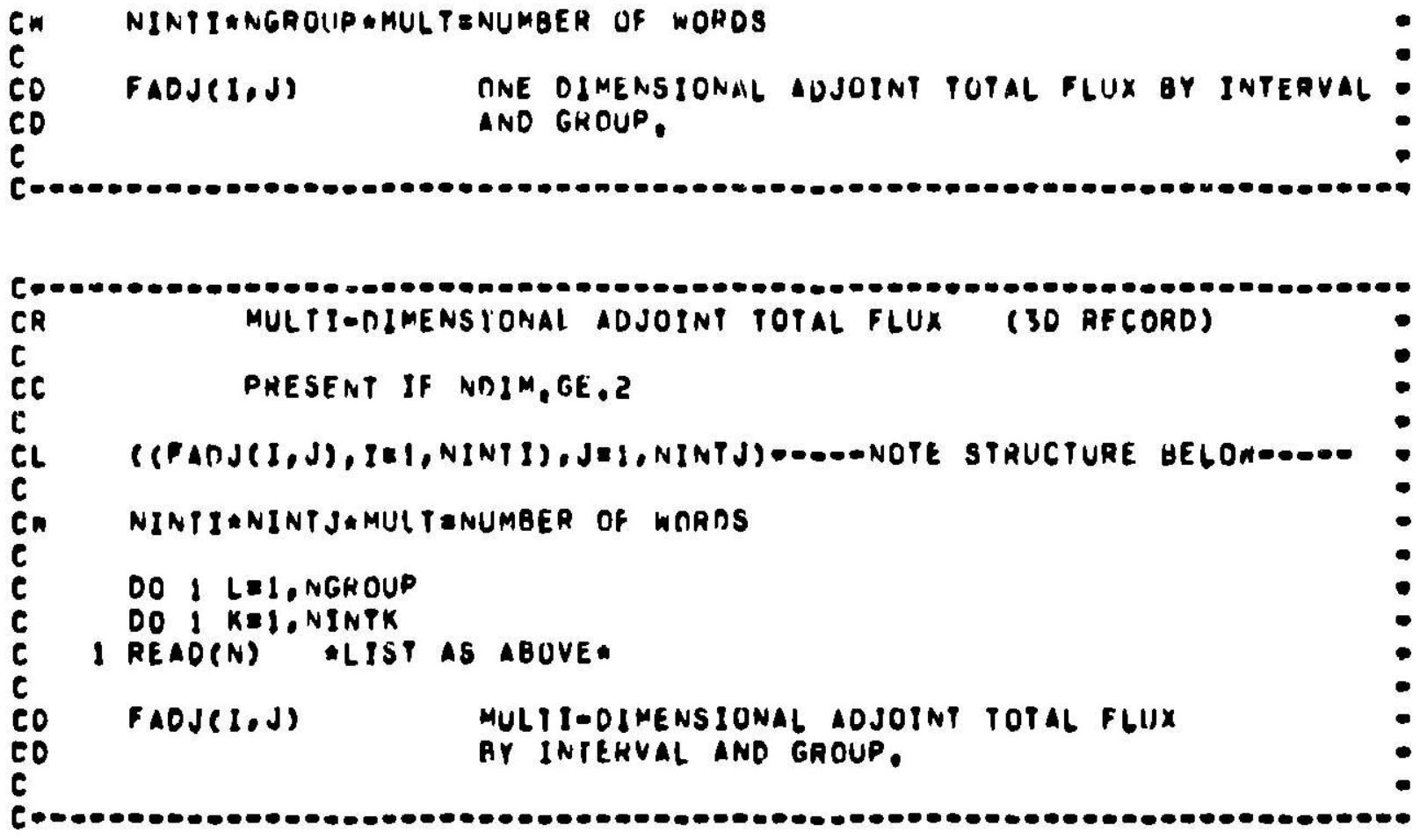
APPENDIX I. CCCC Version III Standard Interface Files. PWDINT

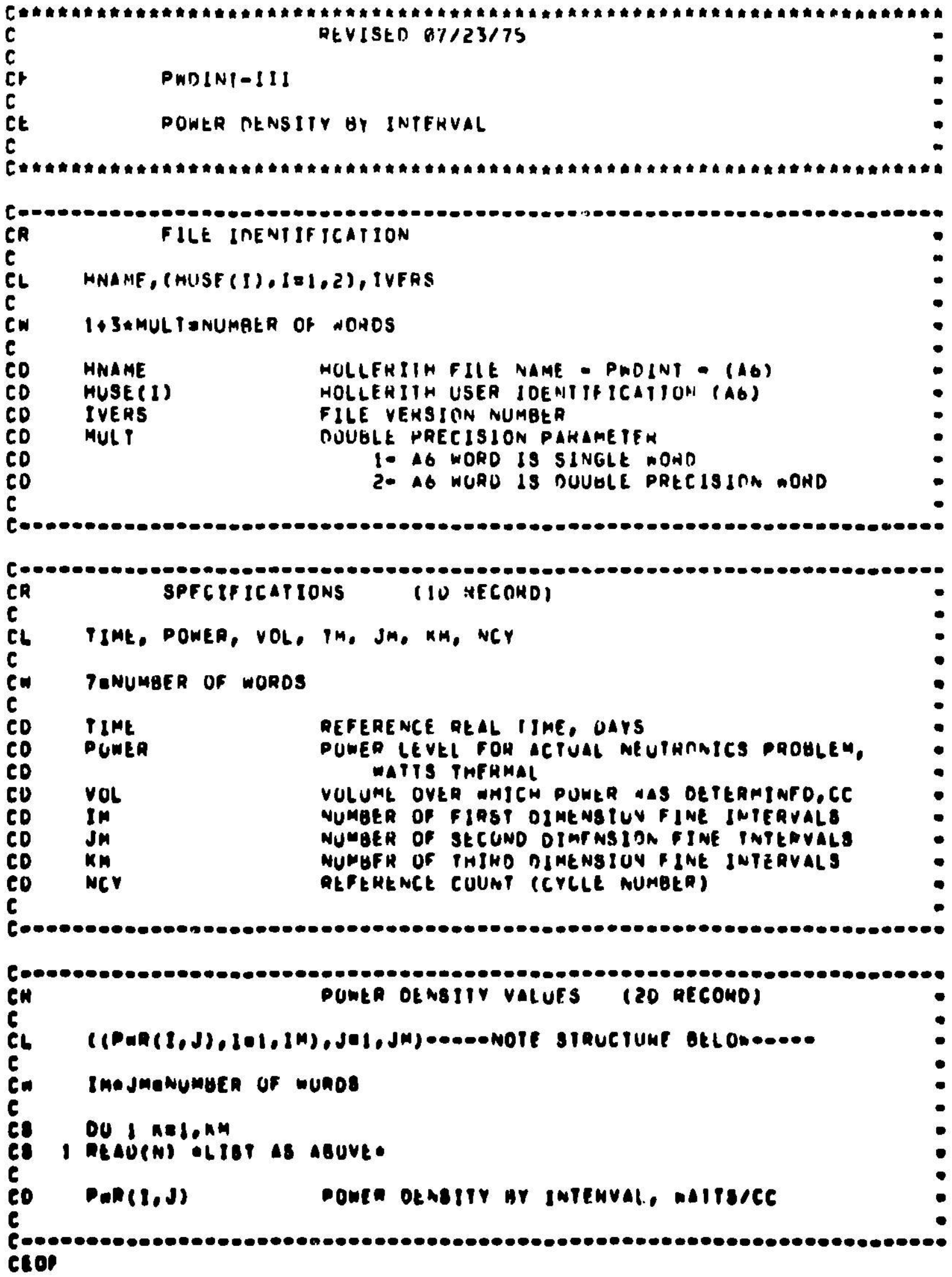


APPENDIX I. CCCC Version III Standard Interface Files. RZFLUX

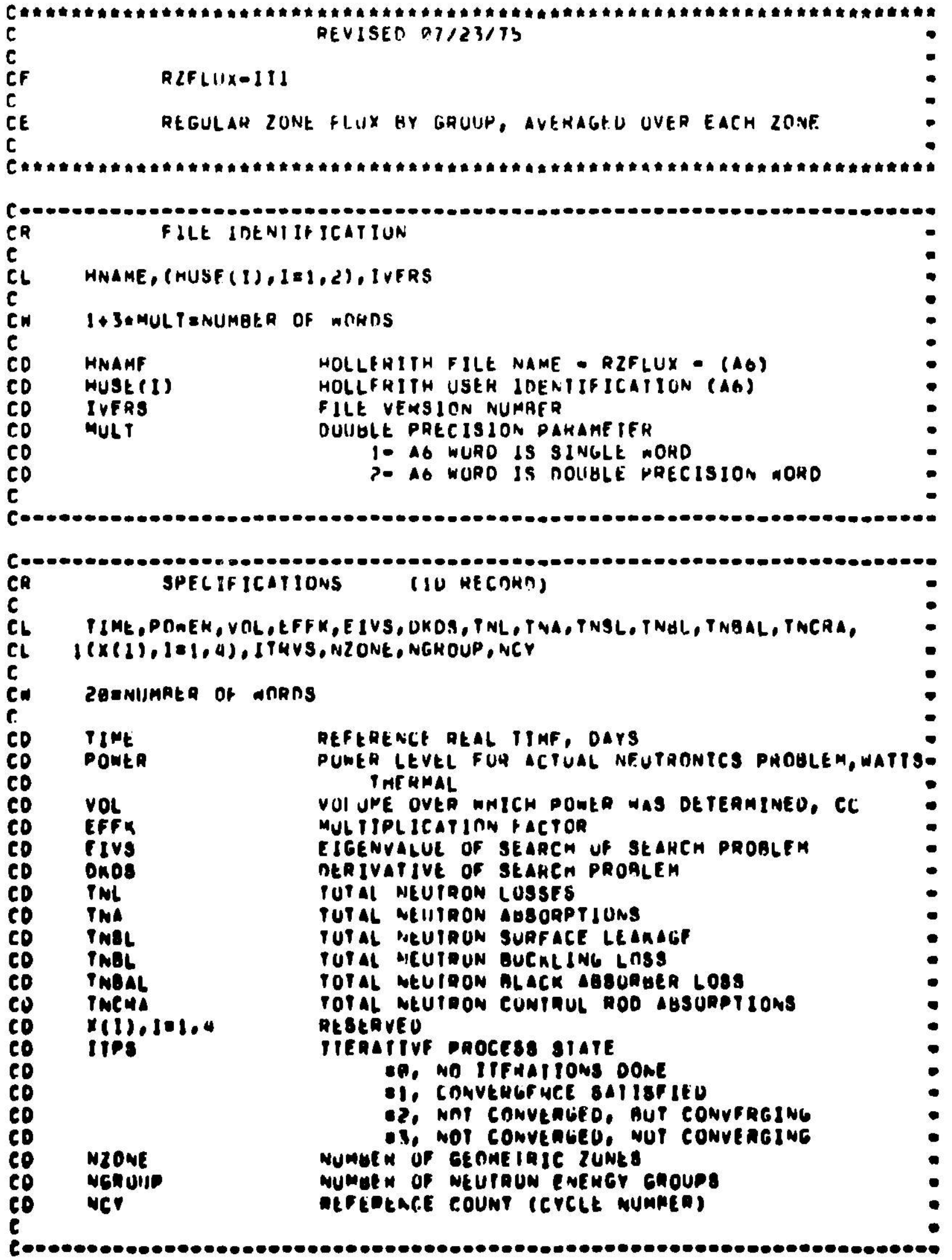


APPENDIX I. CCCC Version III Standard Interface Files. RZFLUX (Contd.)

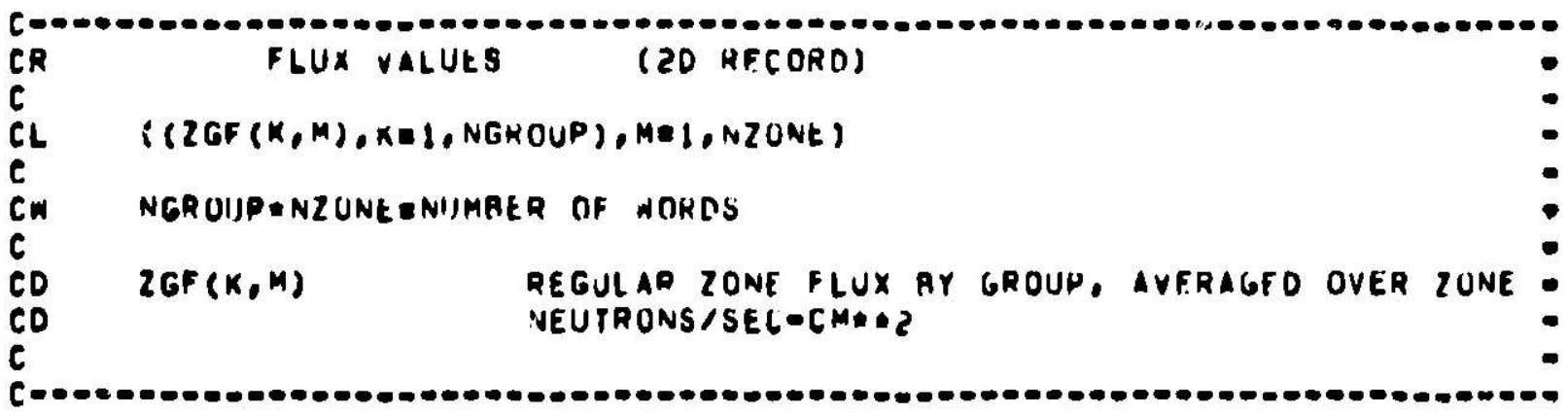


APPENIIX 1. ARCSPO16 - TIE ARC SYSTEM CATALOGUED PROCRDTRE POR GENERAT ING A PTYED SOJRCE POR AN TNHOHOGEN EOUS CALCJLATION OP A LOJ-REACTIVITY-PLANF SYNTHESIS EXPAKSION PUNCTINN.

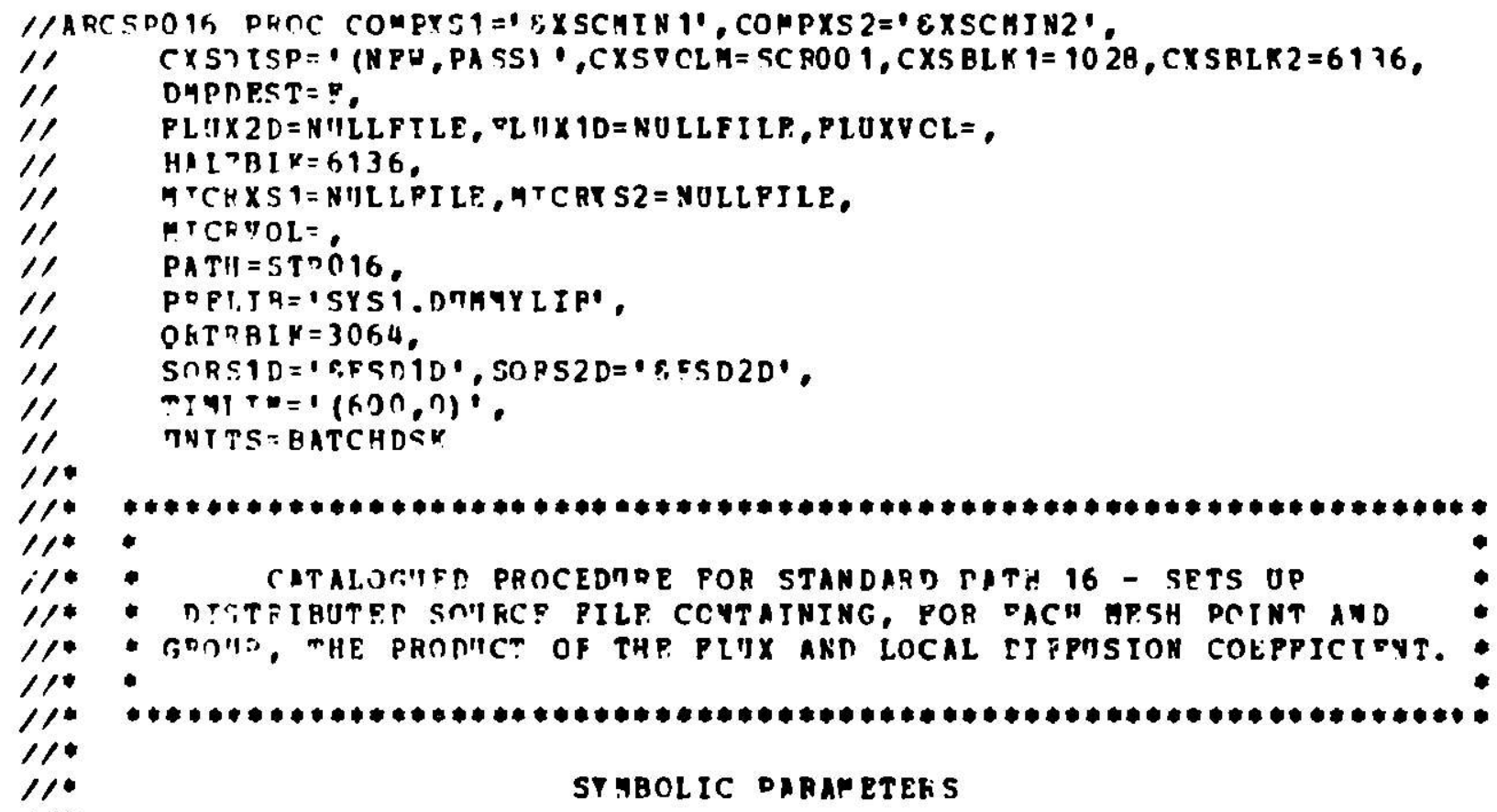


ATPENIX J. ARCSPO16. RONTINTED.

/ $/$ Oก EXEC DRY=SPATH,TI4E=6TTHLTH

$/ / S T P$ PLIB D") DSN= GPRPLIB, DISPESHP

/ D DD DSH=C116.B21006. AODLIB,DISP=SHP.

$1 /$ DD DSW $=$ C 116 . A RC . HODLIB, DISP=SHP

//PTO5POOI DD DDNAHP=SYSIN

/ PTOGPONI DC STSOOT=A

//SYSIDOAP DD SYSOUT= ENMPDEST

//FT09F001 Jn UNIT=SASCR, SPACE= (CYL, $(1,1))$.

$\begin{array}{ll}1 / & D C B=\text { (RECPM }=\text { VBS, LRECLXX, BLKST } \\ 1 / & \text { ARC SYSTEM BCD TNPUT STPEAR }\end{array}$

I/FT11:001 DD OSH=F.COAPXS1, UNIT=8IINITS, VOL=SFR= \&CXSVOLY,

$/ / \quad$ DISP $=E C T S D T S P, S P A C P=(T R P,(1,1))$,

/ DCR= (? BCPM= VBS, LRECL=X, BLKSIZ E=ECXSALKI)

I/ BILP I OP JATA SPT XS.C.MIN

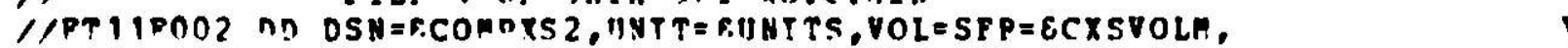

11 DTSO $=$ ECXSDTSP, SPAC $=(C Y L,(1,1))$.

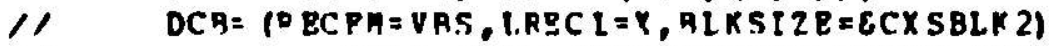

$1 /$ PTLE 2 nP CCHDOSTTTON CPOSS SECTTON SET RS. C. MTN

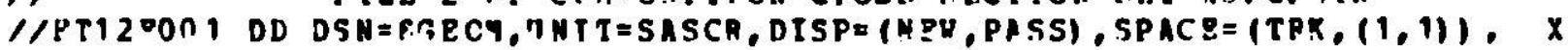

, $D C B=$ (AECPH $=\nabla A S, L R E C L=X$, BLKSTZR= GORT KBLY)

$1 /$ GEOMPTAY SDECTETCATTONS DATA SET

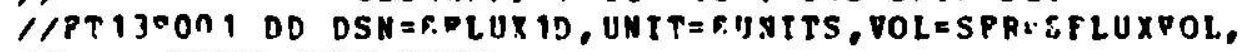

$1 /$ DTSP= (OLD, KEEP)

/ 1 in REAL PLIIX DATA SET

I/FT 14:031 DD NSH=5.PLUV2R, UNTT=EUNTTS, VOL =SER=EPLOXVOL,

1/ DISA= (OLO, KEPP)

II 20 PDAL PI $1 X$ DATA S:T

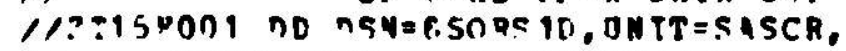

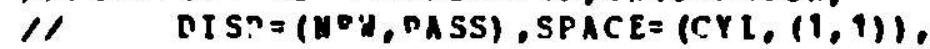

$1 / D C A=(R E C P M=V A S, L R F C L=X$, BLKSIZ $D=E H A L F A L X)$

11 10 DTSTRTAJTED SCNRCE TATA SET

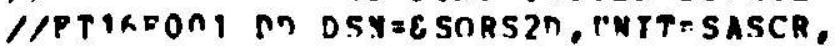

$1 / \quad D I B D=($ SEY, PASS), SRACE $=(C Y L,(1,1))$.

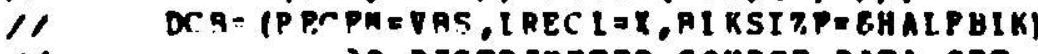

20 DISTP:NITEO SNIRCE DATA SET

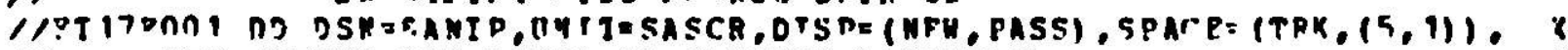

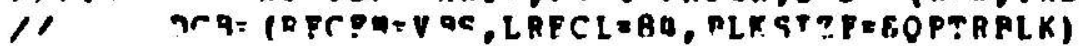

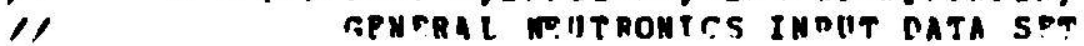

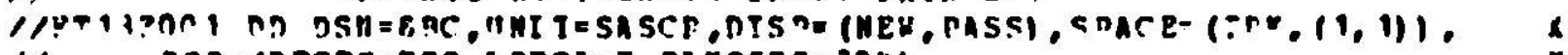

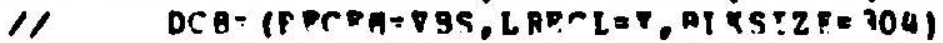

$1 /$ BMIMARY COMCTTICY SPECIPICATIUHS

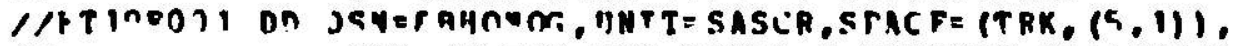

/1 DCBE (PECPH=VBS,LRECT. X, ALKSIZPE EKALPBLY)

$1 /$ ATPRTAL AVC COAFOSITION SPECIFTCATIOAS

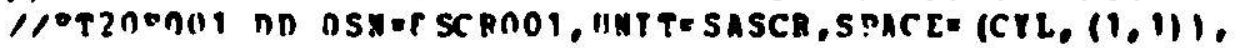

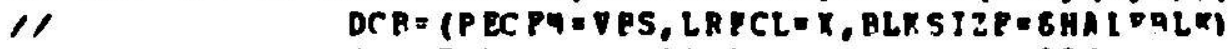

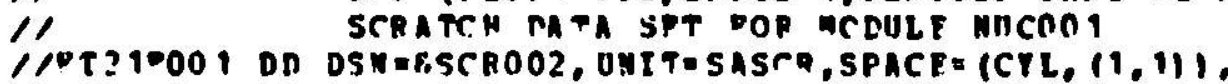

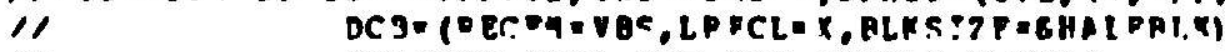

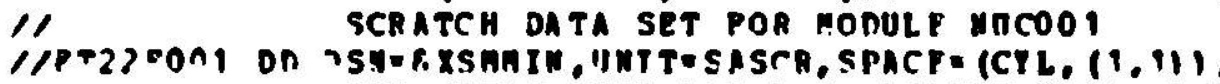

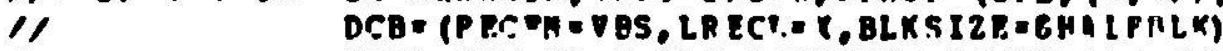

11

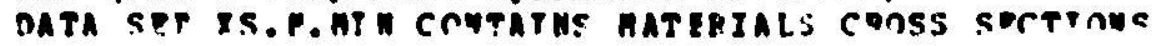

$Y$

X

$x$

$x$

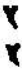

$r$

$x$

$r$

$x$

$x$

$\gamma$

$x$

$x$

$r$

$x$

$x$

$x$

8

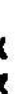

$x$

$\gamma$

$x$

$x$

$x$

$P$ 
APRPNDIX.T. ARCSP016. CONTINOFD.

//FT23POO1 DN DSN=EHTCPXS1, $X$

$1 / \quad T N I T=E O N I T S, D I S P=S H R, V O L=S E R=E H I C R V O L \quad X$

$1 /$ THIS TS FILF, OF THF DATA SET XS. ISO DEPINING $x$

// TSOTOPE CROSS SECTIONS

//FT235002 DD DSY T, ATCPXS 2 ,

$1 / \quad U N I T=8, U N I T S, D I S P=S H^{D}, \nabla O L=S F R=E H I C R \nabla O L$.

$1 /$ THIS IS PTLE 2 OP THE DATA SET XS.TSO DEPTVIYS

$1 / \quad$ ISOTOPE CROSS SPCTIONS

//FT24POO OD NSN=ETSTSC2A, UNTT= SASCD, SPACP $=(T R K,(1,1))$,

$1 / \quad D C B=(R E C P H=V B S, L O E C L=X$, BLKST2F=644) $X$

$1 /$ PILE 1 DF DATA SET XS. ISO2 CONTAINS A SHODTRNFD PORM OF $x$

$1 /$ THE DITA SET XS.ISO

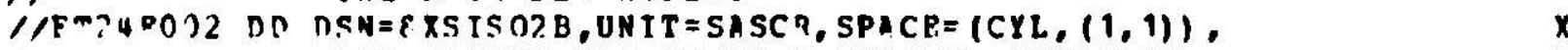

$1 / \quad D C B=(F E C P M=$ VBS, LRECL=X, BLKSIZF=EHALFBLF) $\quad X$

$1 /$ PILE 2 O? DATA 5ET XS. ISO2

//FT2GDON1 DT DSN= S, XSCAN 1 , IINT T = SASCF, SPACF = (TRK, $(1,1))$

$1 / \quad$ CCB $=($ FECFY $=V B S, L R F C L=X$, PLY SIZP $=E H A L P B L K)$

// PILE 1 NF DATA SET YS.C.ANI

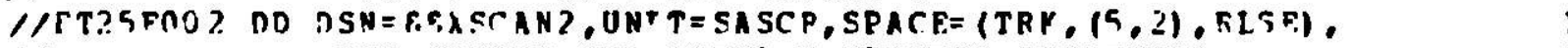

$1 / \quad D C S=(P E C P H=V B S$, LRECL $=X$, RLKSIZE $=E H A I F B L K) \quad X$

// PTLF 2 JP DPTA SET XS.C.ANT

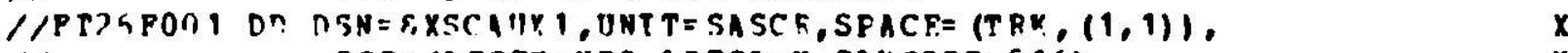

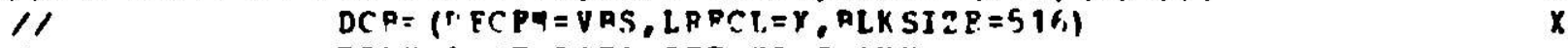

I/ DILF, I MATA SFT XS.C.AUX

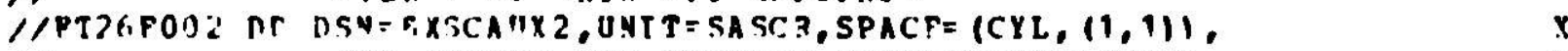

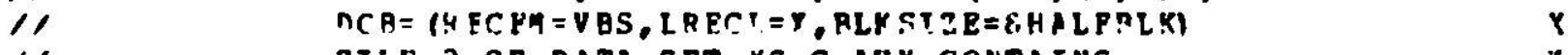

// PTIE, OP DATA SDT XS.C.ANX CCNTAINS

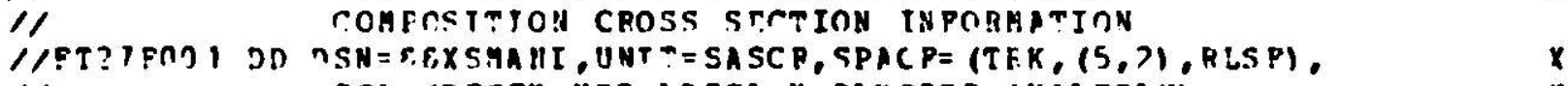

$11 \quad$ CCH $=$ (PDCPW = VPC, LEFCI = Y, PL.KSITE=LHAL.PPL.KI $\quad X$

$1 /$ DATA SFT XS.M.ANT COMTATS MATELTAL CROSS SECTEOHS

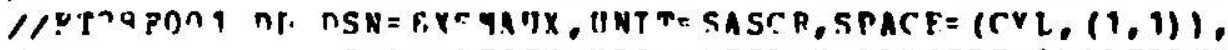

$1 / \quad n C \eta=($ P $P C P M=V B S, L F \Gamma r L=X, F L K S T Z E=F . H A L \nabla B L K)$

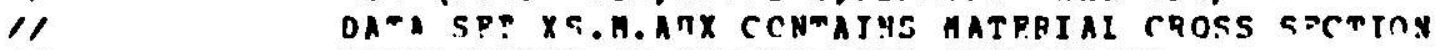

$1 /$ TNEORYATTOY CV CAOTIPD AKT SCATTERJMC:

//PT29P0OI NO D.SV= LSCPANI, JNIT=SASCR,SPACF= (CYL, $(1,1))$,

$1 / \quad$ DC $3=(P E C F M=V A S, I D \circ C I=Y, R L K S T 2 F=E H A I F H I K)$

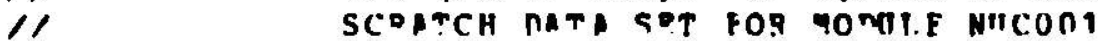

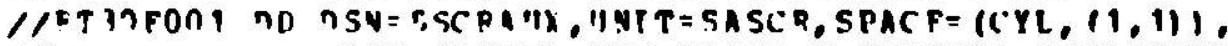

$1 / \quad D C 3=(9 R C E M=V G S, L P E C L=X, P L K S: Z L=E H A L P P(X)$

// SCEITCH TATA SFT FOP TCRULE NICOCI

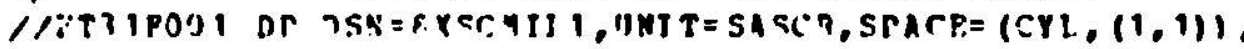

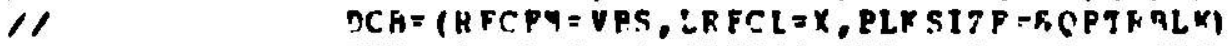

$1 !$ DIP 1 CP COMPOSJ TION CPOSS SFCTION SET Xj.r."

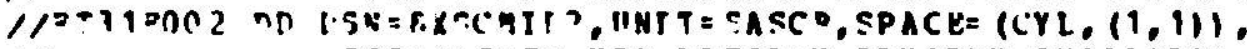

$1 / \quad D C B=(K E C E Y=Y P S, I R P C I=X$, ALKSI Z F =FHALPRLK)

/1 PII.E? CO CCMPOSTTINN CPOSS SFCTIOH SOT XS.C. YII

/,*

H.

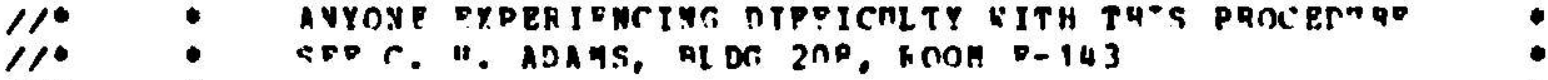

110

-

110

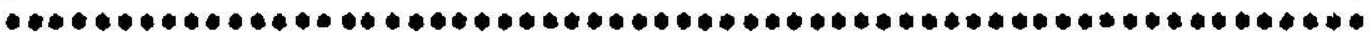

110

/ PNNn

r $x$

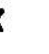
x 


\begin{abstract}
AFPENDIY Y. STPO16 - THE ARC SYSTFM STANDARD PATH FOP GENEFATING - FIXFT SOITRE POR AN INHOMOGENEUUS CALCULATIUN OF A LO"O-OEACTIVTTY-RLANE SYNTHFSTS EXPANSION P'INCMION.
\end{abstract}

$c$
$c$
$c$
$c$
$c$
$c$
$c$
$c$
$c$
$c$
$c$
$c$
$c$
$c$
$c$
$c$
$c$
$c$
$c$
$c$
$c$
$c$
$c$
$c$
$c$

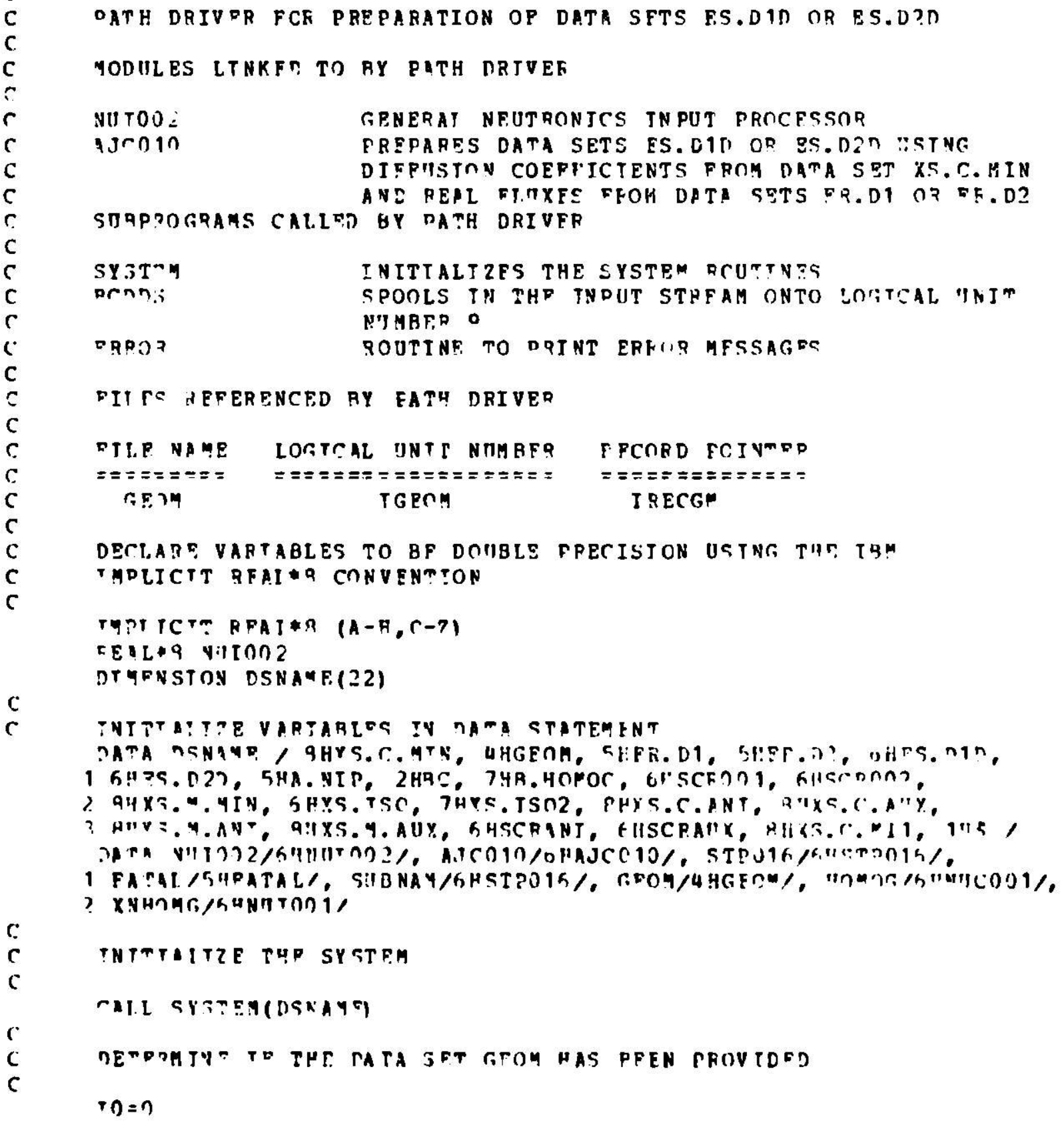


209

APPENDIX K. STP016. CONTINIED.

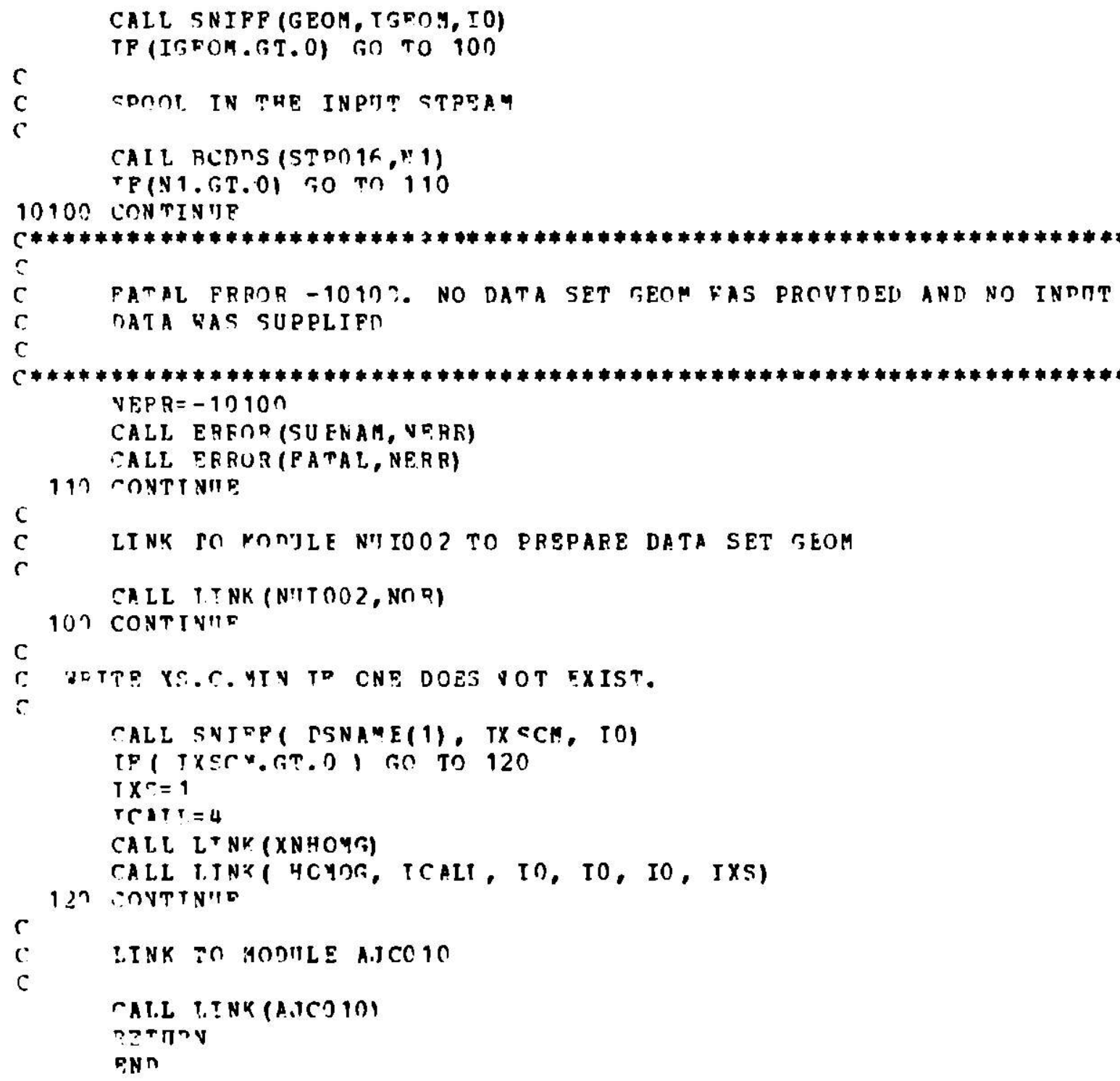




\section{ACKNOWLEDGMENTS}

A number of people made significant contributions to the programing of SYN3D and to th1s report. R. P. Hosteny coded the HMG4C overlay; W. F. Miller was responsible for the planar leakage integral calculations in the overlay INTEG. Contributions to this report were made by R. P. Hosteny and H. Henryson, II. Users whose feedback uncovered bugs and helped shape the code Include C. L. Beck, E. K. Fufite, G. L. Grasesech1, K. R. Krack, M. J. Lineberry, and D. C. Wade. A. R. HInds made several programming suggest lons which resulted in significant improvements in running times. 
REFERECES

I. H. R. Cadvell, "PDQ-7 Raterence Manual", WAPD-TH-678 (1967).

2. E. L. Hachaprose, "Iterative Solution of Eillpte Syaceme", (Prentice-Hall, 1966), P. 31.

3. H. H. l.letle, Jr., and R. H. Herdle, "2DB Viser'e Manuel", aML-831 (1968).

4. T. A. Daly, C. K. Leat and A. S. Kinnedy, "The AlC Syeten TwoDienelonal Diffueton Theory Capablidty, DARC2D", NNL-7716 (1972).

S. T. B. Fouler, D. R, Vondy, C. W. Cunnlnghea, "Muclear Reactor Core Anolysis Code: Cltation", Ounl-TK-2696 (Rev. 2) (1971).

6. D. R. Vondy, T. B. Fauler and G. M. Cunninghes, "vemruns: A Code Block for Solving Muleteroup Meutronics Problem Applying the Findte-Difference Dlflution-Theory Approxlation to Meutron Tramport". OAvL- 5062 (1975).

7. S. Keplan, "Sone Men Machode of Flux Synthesls", Mucl. Sc1. Eas.. 13. 22 (1962).

8. S. Keplan, O. J. Karlawe and H. R. Cackell, "Equations and Progran for Solution of the Neutron Group Diffueton Equetion by Synchesie Approxdeac Ions", WAPD-TH-377 (1963).

9. J. B. Yelnaky and S. Kaplen, "Synchesds of Three-Dimanelonal Flux Shepes Uelng Dleconelnuoue Sete of Trlel Tunctlone", Mucl. Sel. Ens.. 28. $426(1967)$.

10. J. 1. Yesinaky, "Combined Space-TIme Synthesis with Axially Disconcinuous Trial Punctions", MAPD-TH-736 (2967).

11. H. M. Stecey, Jr., "A Varleclonel Multelchanael space-Tien Syncheals Method for Honeparable Reactor Traneleace", Mucl. Scl. Ens.. M, is (1968).

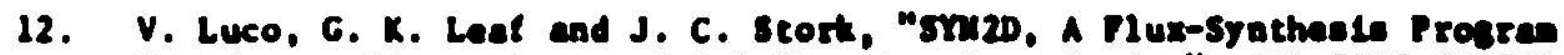

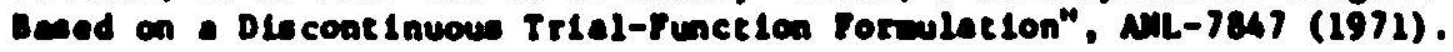

13. G. Buckel, "Approxiention der stacloaltren, Dreldimenelonalen Mehrgruppen-Neutronen-Diffuloneglel chung Durch eIn synthasevertehren at den Karletuher Syachese-Prostem Kary". Krx-1349 (1971).

16. H. Schaffler, P. Schnur and R. AThle, "ELn Rechenprogrem sur Löauns

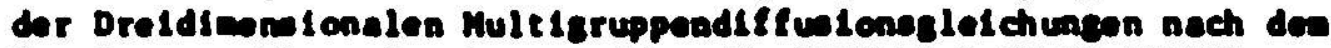
Enelterten Pluse-5ynthosevertchren", Enith K 72-06 (1972). 
15. E. L. Wachepress and M. Becker, "Variational Multichannel Synthesis with Discontinuous Trial Functions", KAPL-3095 (1965); also see "Varlational Synthesis with Discontinuous Trial Functions", in Proc. Conference on the Applications of Computing Methods to Reactor Problems, Argonne National Laboratory, ANL-7050 (1965).

16. W. L. Woudruff, "Some Improvements In Varfational Flux Synthesis Methodg", ANL-7696 (1970).

17. W. B. Terney, "Interface Conditions for Discontinuous Flux Synthesis Methodg", Nucl. Sc1. Eng., 41, 303 (1970).

18. E. L. Wachspress, "On the Use of Different Radial Trial Functions In Different Ax!al Zones of a Neutron Flux Synthesis Computation", Nucl. Sc1. Eng., 34, 342 (1968).

19. J. E. Meyer, "Synthesis of Three-D1mensional Power Shapes - A FluxYelght Ing Synthes 18 Technique", Proc. 2nd Intern. Conf. Peareful Uses of Atomlc Energy, Geneva, 1958, P/636, 11, 519 (1958).

20. J. B. Yasinsky, "On the Use of Space-Synthesis w1th Energy Group Collape1ng", WAPD-TM-959 (1970).

21. C. H. Adamy and W. M. Stacey, Jr., "An Anomaly Arising in the Collapsed-Group Flux Synthesis Approximation", Nucl. Sc1. Eng., 36. 444 (1969).

22. E. L. Wachepress, "Iterative Solution of Elliptic Systems", (PrenticeHall, 1966), P. 83.

23. E. L. Wachspress, 1bid, p. 26.

24. B. M. Carmichael, "Standard Interface F1les and Procedures for Reactor Phyelcs Codes, Version III", Los Alamos Scientific Laboratory Report LA-5486-MS (February 1974).

25. L. C. Just, et.al., "The System Aspects and Interface Data Sets of the Argonne Reactor Computation (ARC) System", Argonne National Laboratory Report ANL-7711 (Apr11 1971).

26. E. A. Kovaloky and D. E. Neel, "The ARC System Neutronics Input Procesers", Argonne National Laboratory Report ANL-7713 (Jan. 1971).

27. C. H. Adan and W. M. Stacey, Jr., "Flux Synthesis Calculations for Fast Reactors", Nucl. Sc1. Eng., 54, 201 (1974).

28. C. H. Adam and M. J. LIneberry, "Experlence with SIngle-Channel Flux Synchesia Calculations for Three-Dimensional, Fast Reactor Models". Proc. Meeting on Computational Methods In Nuclear Engineering, Charleaton, South Carolina, Apr11 15-17 (1975). 
29. C. H. Adams and M. J. Lineberry, Private communication (1975).

30. S. Pilate et al., "A Three-Dimensional Synthesis Method Tested and Applied In Fast Breeders," KFK-1345, Kernforschungszentrum, Karlsruhe (1971). 
